Universidad de Lima

Facultad de Ingeniería Industrial

Carrera de Ingeniería Industrial

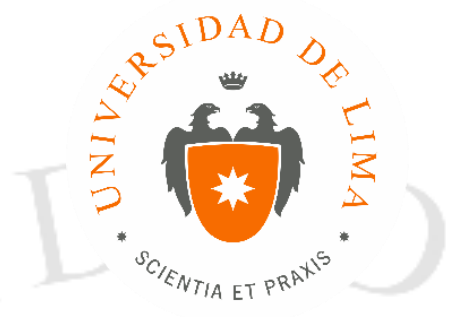

\title{
ESTUDIO DE PRE-FACTIBILIDAD PARA LA INSTALACIÓN DE UNA PLANTA PRODUCTORA DE COMPOTAS PARA BEBÉS A PARTIR DE DURAZNO (Prunus persica) ENRIQUECIDO CON MACA (Lepidium meyenii walpers), QUINUA (Chenopodium quinoa willdenow), KIWICHA (Amaranthus caudatus linnaeus) Y CAÑIHUA (Chenopodium pallidicaule)
}

Trabajo de investigación para optar el título profesional de Ingeniero industrial

Horacio Alfredo Aldana Minaya

Código 20090027

Ricardo André Rivas Romero

Código 20090970

Asesor

Pedro Antonio Arroyo Gordillo

Lima - Perú

Octubre del 2016 


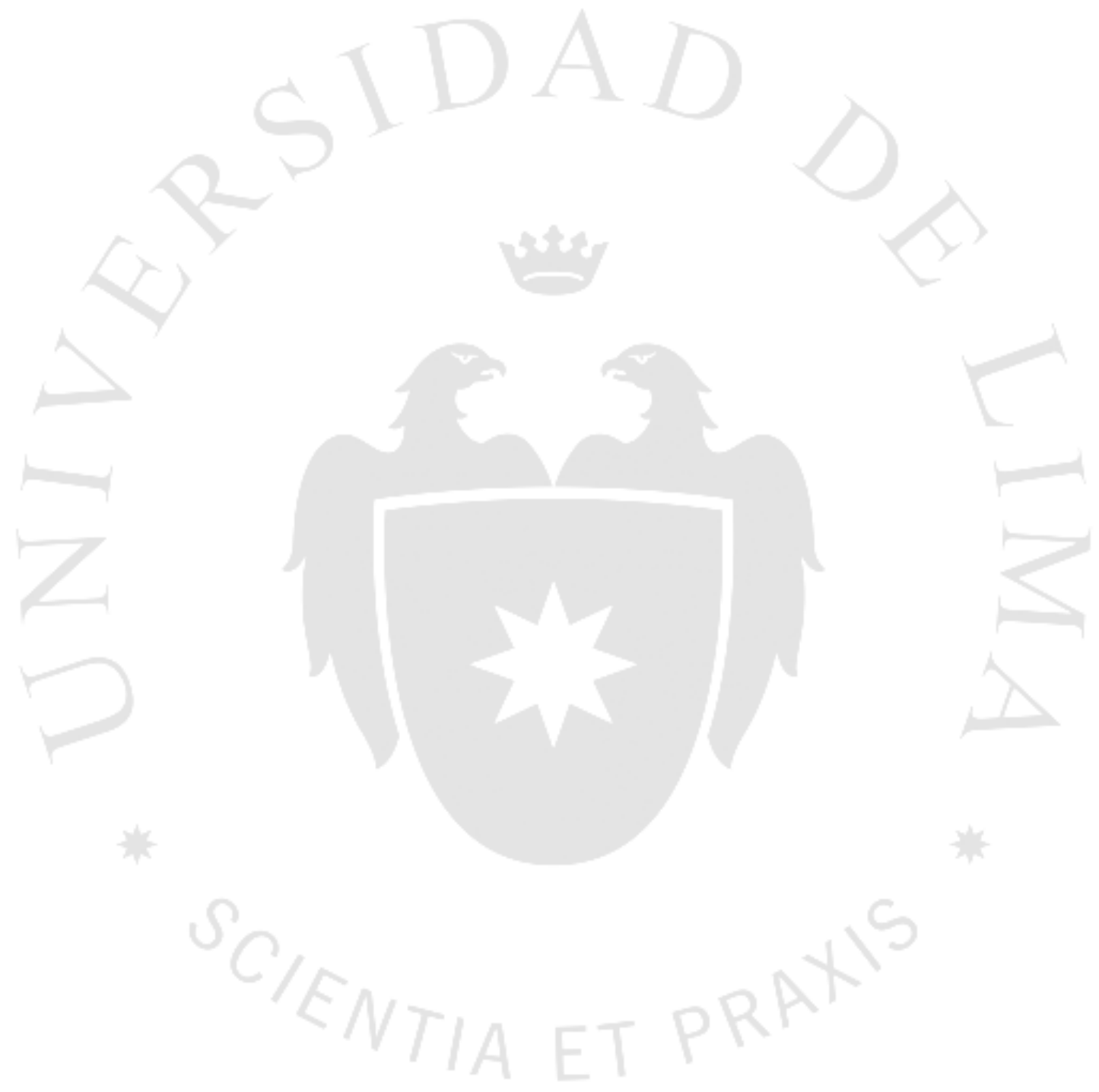




\section{ESTUDIO DE PRE-FACTIBILIDAD PARA LA}

INSTALACIÓN DE UNA PLANTA PRODUCTORA DE COMPOTAS PARA BEBÉS A PARTIR DE DURAZNO (Prunus persica) ENRIQUECIDO CON MACA (Lepidium meyenii walpers), QUINUA (Chenopodium quinoa willdenow), KIWICHA (Amaranthus caudatus linnaeus) Y CAÑIHUA (Chenopodium pallidicaule) 


\section{TABLA DE CONTENIDO}

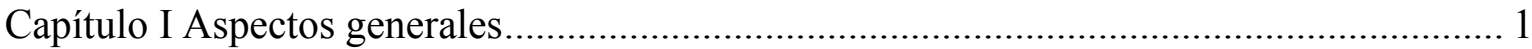

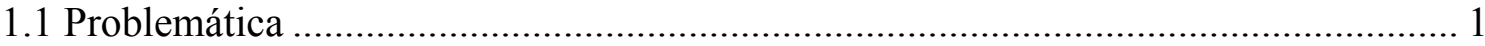

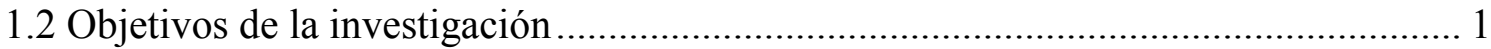

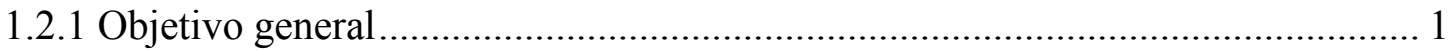

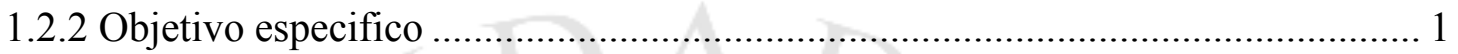

1.3 Alcance y limitaciones de la investigación ........................................................... 2

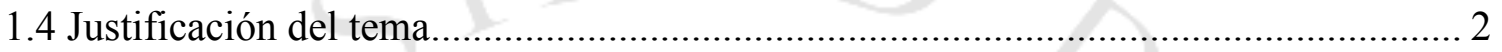

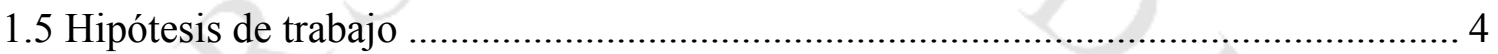

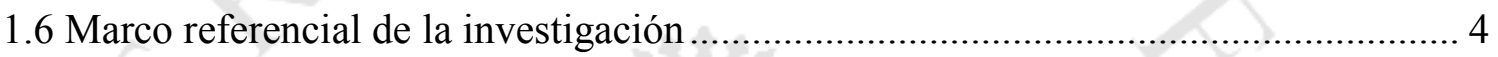

1.7 Marco Conceptual ................................................................................................. 5

Capítulo II Estudio de mercado .............................................................................. 7

2.1 Aspectos generales del estudio de mercado .................................................... 7

2.1.1 Definición comercial del producto ............................................................. 7

2.1.2 Principales características del producto ........................................................ 8

2.1.3 Determinación del área geográfica que abarcará el estudio .............................. 8

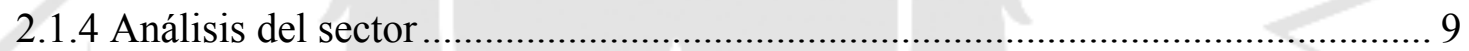

2.1.5 Determinación de la metodología que se empleará en la investigación de

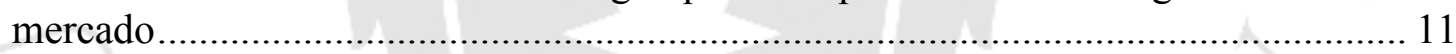

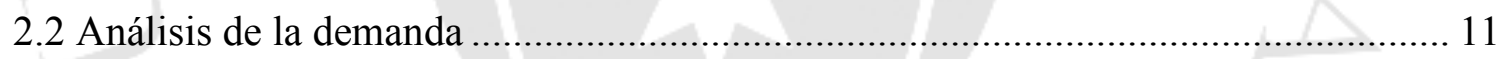

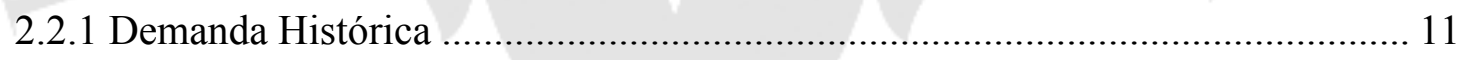

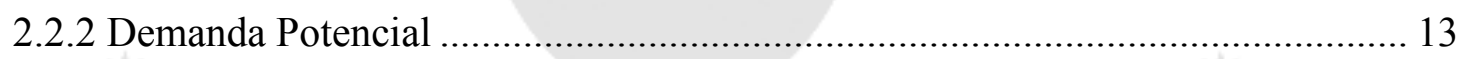

2.2.3 Proyección de la demanda y metodología de análisis..................................... 18

2.2.4 Consideraciones sobre la vida útil del proyecto .......................................... 19

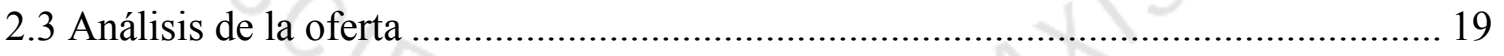

2.3.1 Empresas productoras, importadoras y comercializadoras .............................. 19

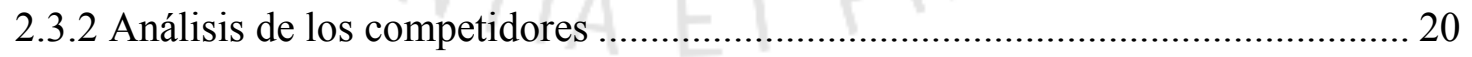

2.4 Determinación de la Demanda para el proyecto ................................................ 21

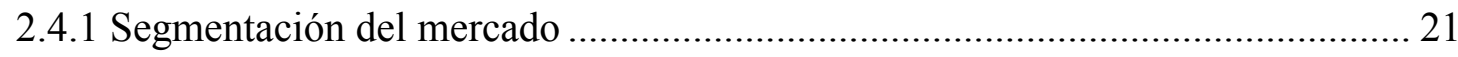

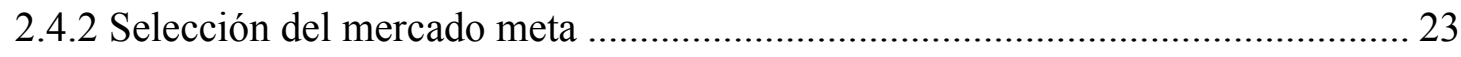

2.4.3 Demanda específica para el proyecto ........................................................... 25

2.5 Definición de la Estrategia de Comercialización.................................................... 27

2.5.1 Políticas de comercialización y distribución ................................................. 27 


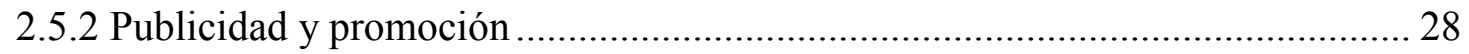

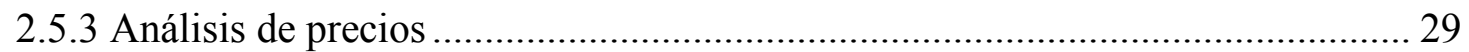

2.6 Análisis de Disponibilidad de los insumos principales ............................................ 30

2.6.1 Características principales de la materia prima ………………......................... 30

2.6.2 Potencialidad del recurso en la zona de influencia del proyecto .......................... 31

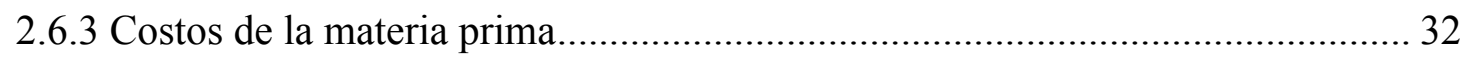

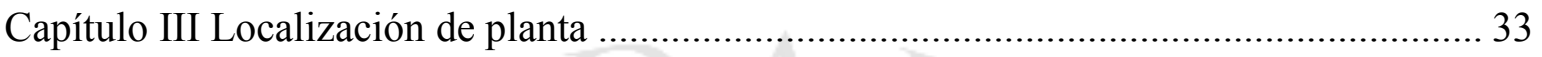

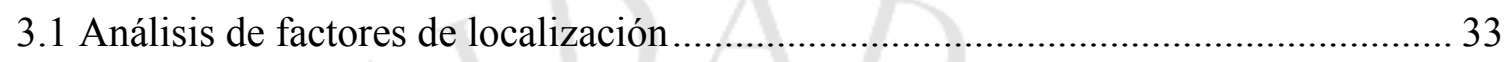

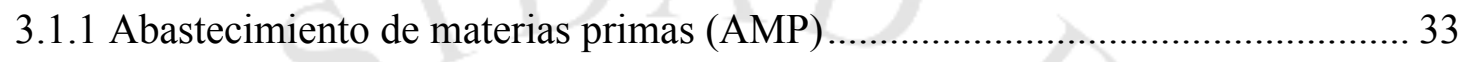

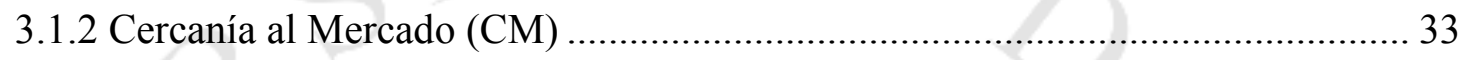

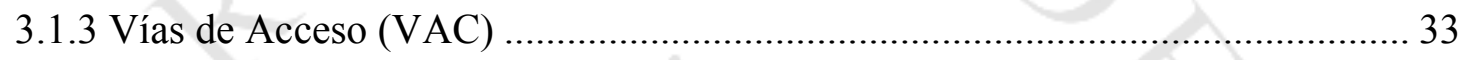

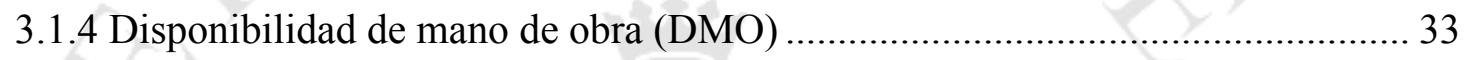

3.1.5 Abastecimiento de energía eléctrica (AEE) ..................................................... 34

3.1.6 Disponibilidad de agua potable y sistemas de alcantarillado (DASA) .............. 34

3.1.7 Disponibilidad de parques industriales (DPI) …….......................................... 34

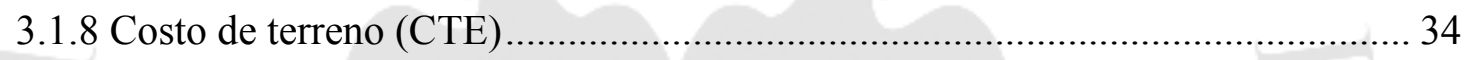

3.2 Identificación y descripción de las alternativas de localización .................................. 34

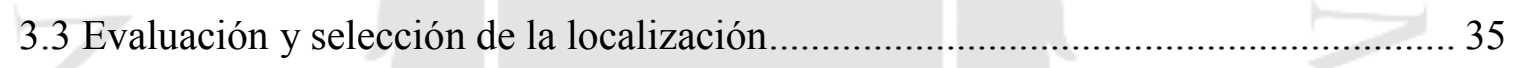

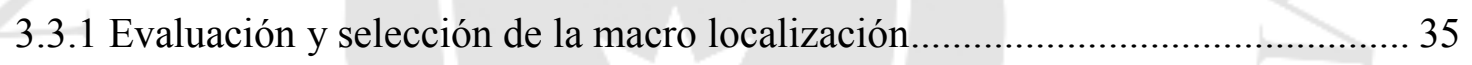

3.3.2 Evaluación y selección de la micro localización ................................................. 42

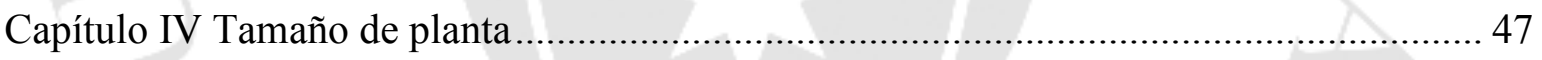

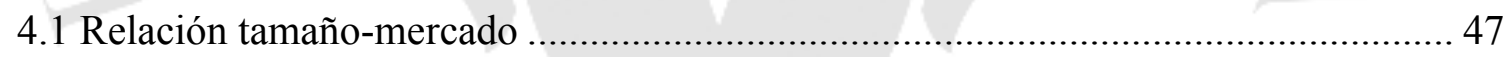

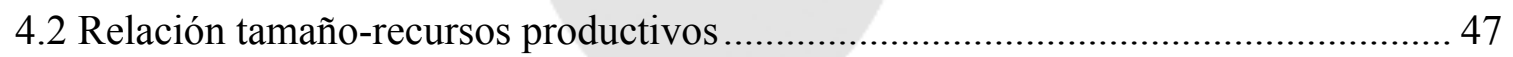

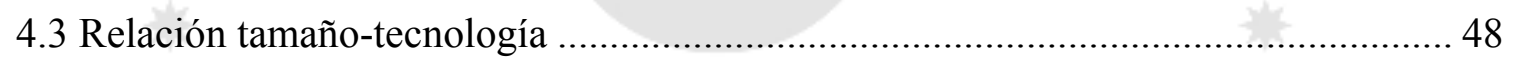

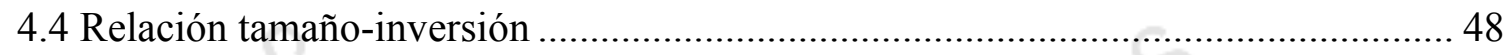

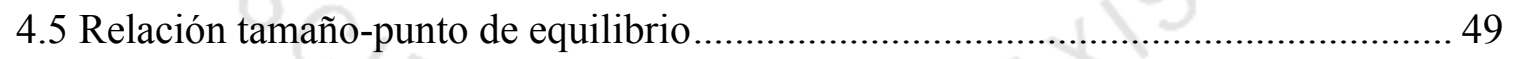

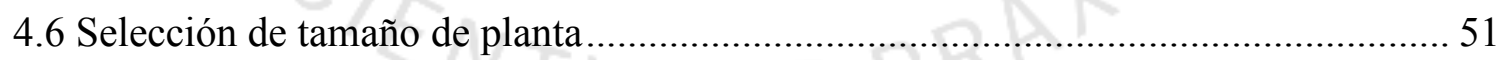

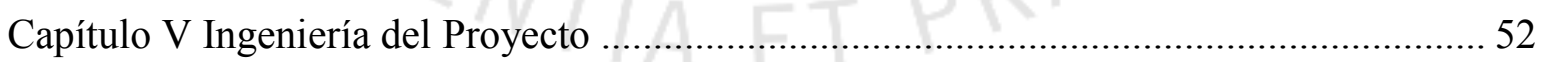

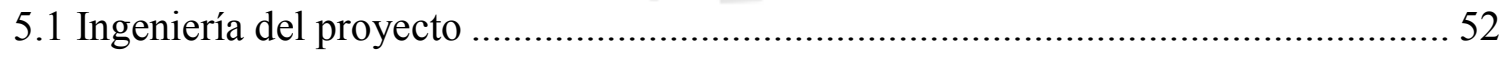

5.1.1 Especificaciones técnicas del producto …………......................................... 52

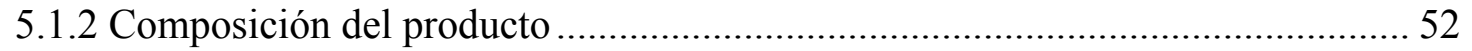

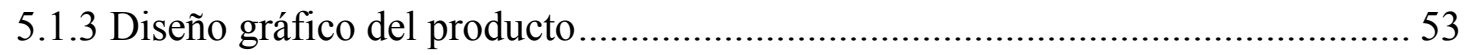

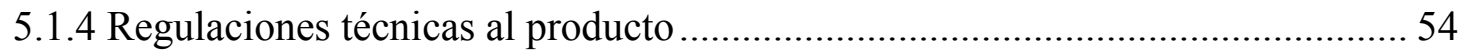

5.2 Tecnologías existentes y procesos de producción ..................................................... 54 


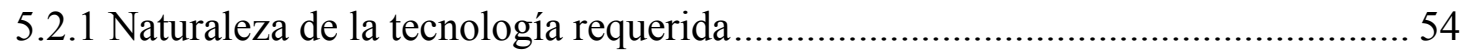

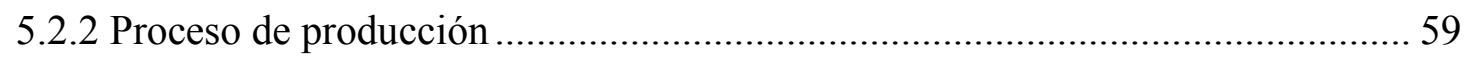

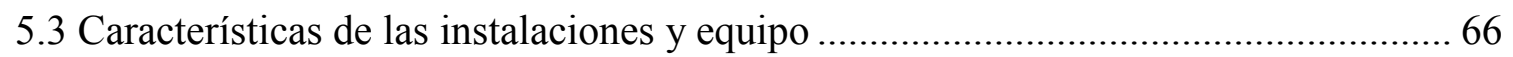

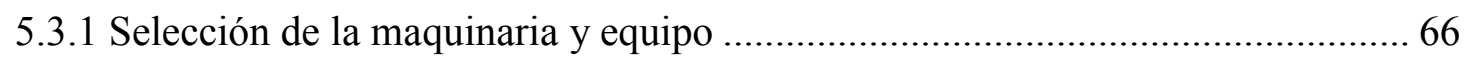

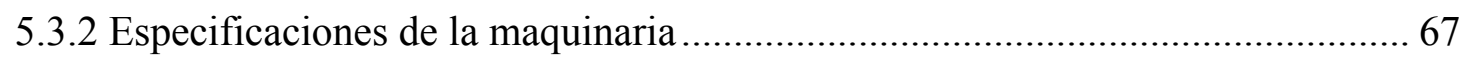

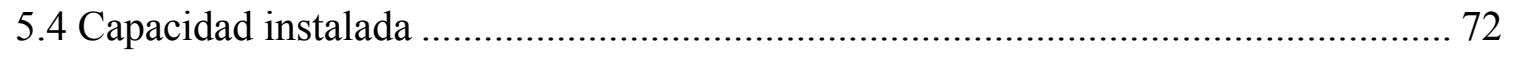

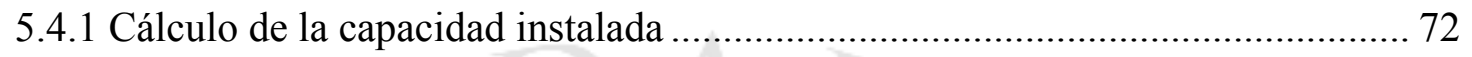

5.4.2 Calculo detallado del número de máquinas requeridas ..................................... 74

5.5 Resguardo de calidad y/o inocuidad del producto ................................................... 74

5.5.1 Calidad de la materia prima, de los insumos, del proceso y del producto ........... 74

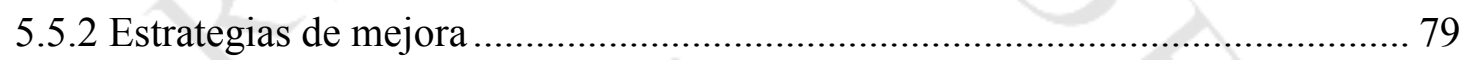

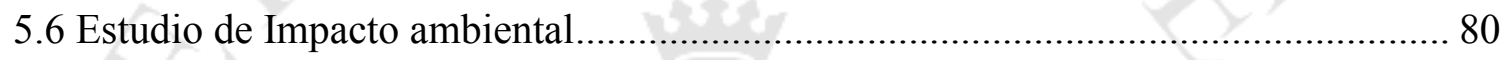

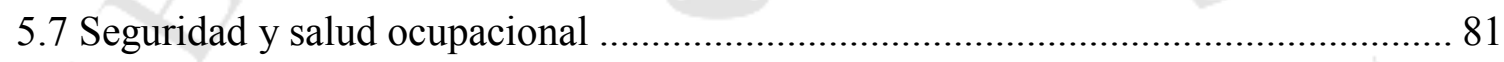

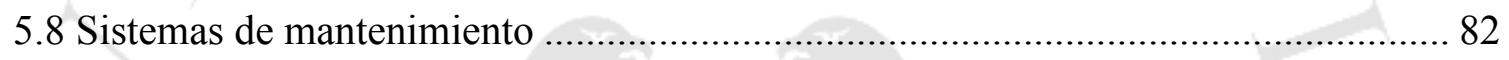

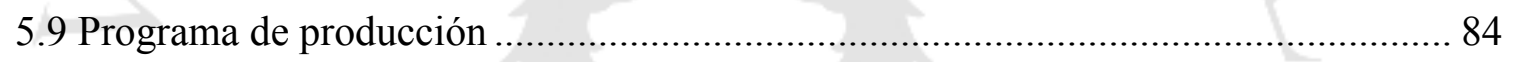

5.9.1 Factores para la programación de la producción ................................................. 84

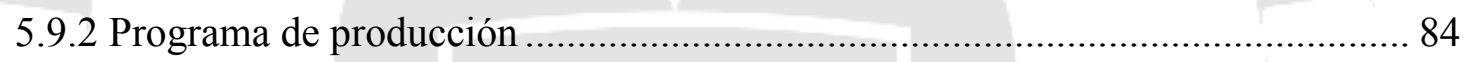

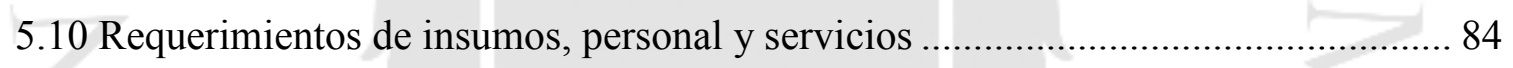

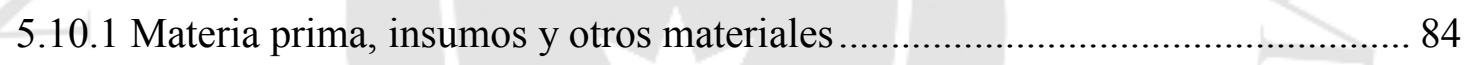

5.10.2 Servicios: Energía eléctrica, agua, vapor combustible, etc................................ 85

5.10.3 Determinación del número de operarios y trabajadores indirectos................... 87

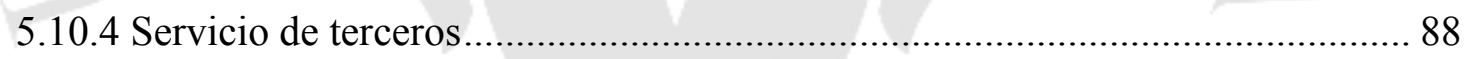

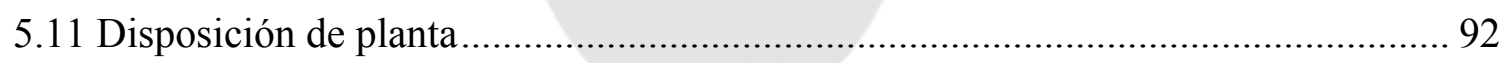

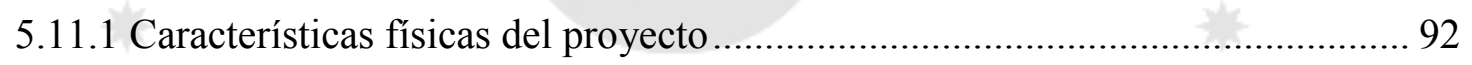

5.11.2 Determinación de las zonas físicas requeridas ............................................. 93

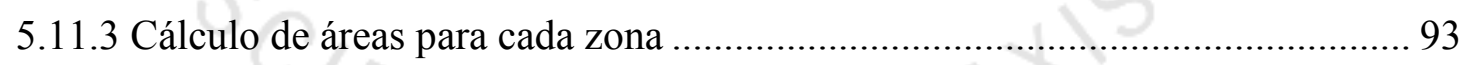

5.11.4 Dispositivos de seguridad industrial y señalización ..................................... 100

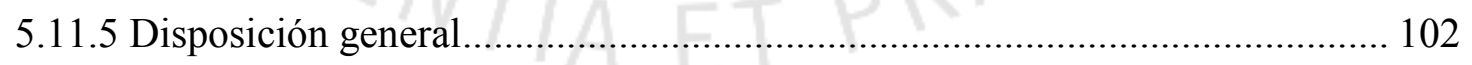

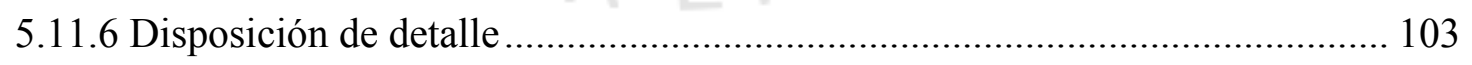

5.12 Cronograma de implementación del proyecto …………….................................... 105

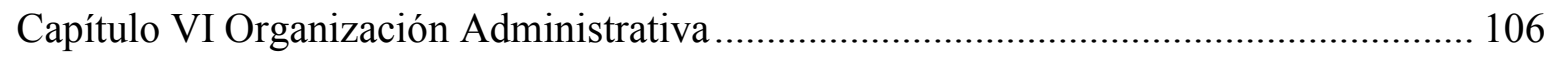

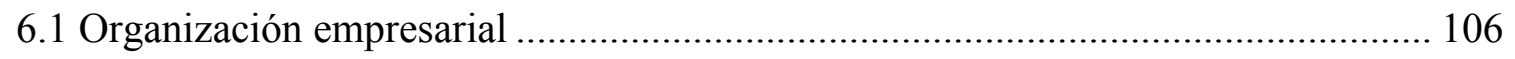

6.2 Requerimientos de personal directivo, administrativo y de servicios ..................... 108

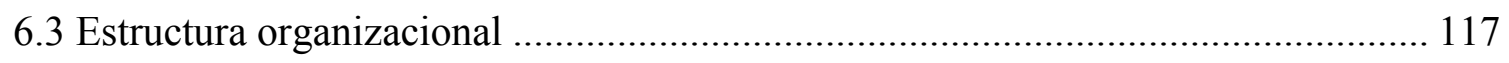


Capítulo VII Aspectos Económicos y Financieros ……………………………….......... 118

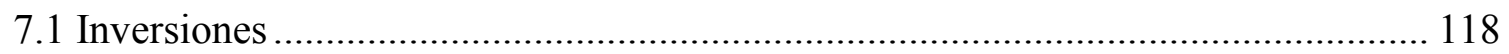

7.1.1 Estimación de las inversiones de largo plazo (tangibles e intangibles) ............ 118

7.1.2 Estimación de inversiones de corto plazo - Capital de trabajo ........................... 119

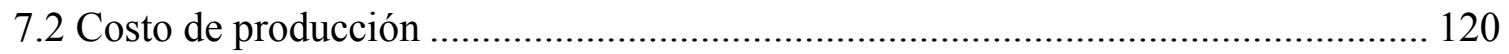

7.2.1 Costo de materia prima, insumos y otros materiales ........................................ 120

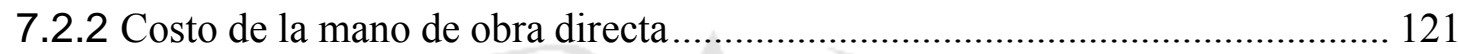

7.2.3 Costo indirecto de fabricación (materiales indirectos, mano de obra indirecta y

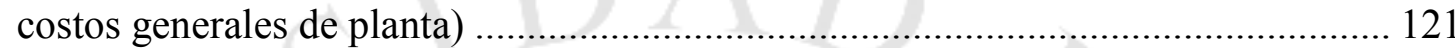

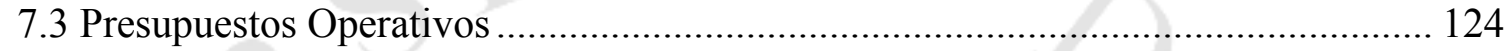

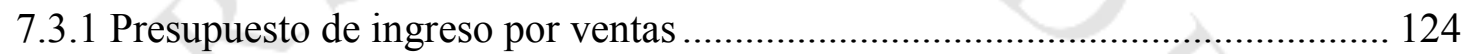

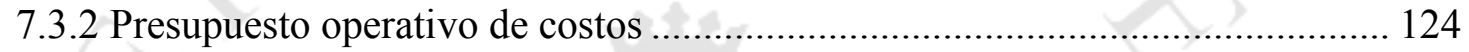

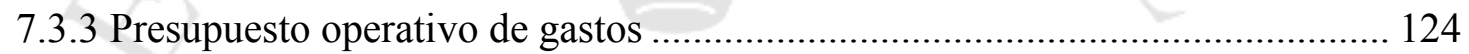

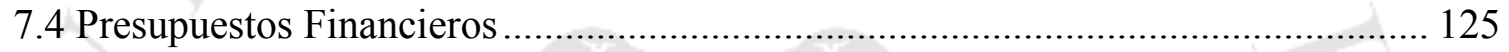

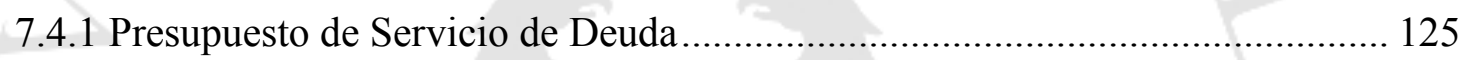

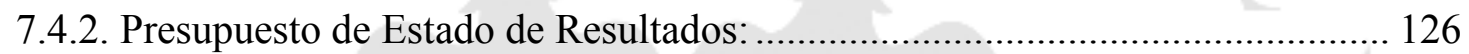

7.4.3. Presupuesto de Estado de Situación Financiera................................................ 126

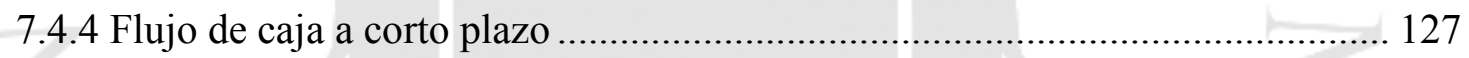

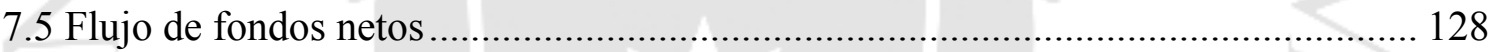

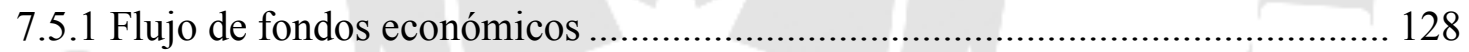

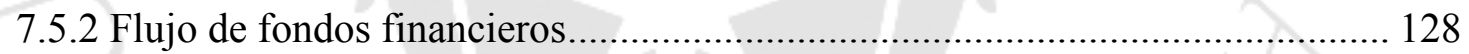

Capítulo VIII Evaluación Económica y Financiera del Proyecto .......................................... 129

8.1 Evaluación económica: VAN, TIR, B/C, PR ………………………………..... 129

8.2 Evaluación financiera: VAN, TIR, B/C, PR ................................................... 129

8.3 Análisis de ratios (liquidez, solvencia, rentabilidad) e indicadores económicos y

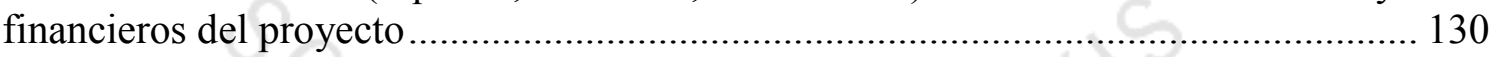

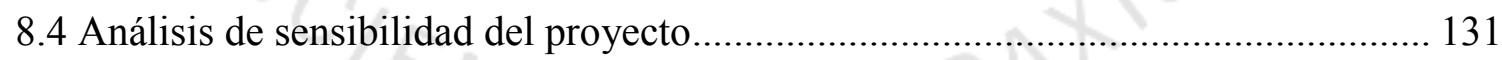

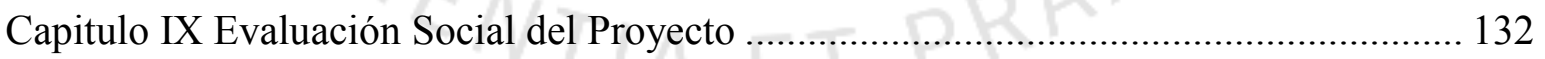

9.1 Identificación de las zonas y comunidades de influencia del proyecto .................... 132

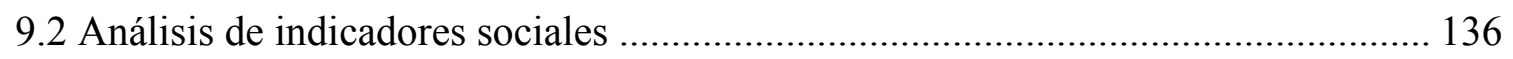

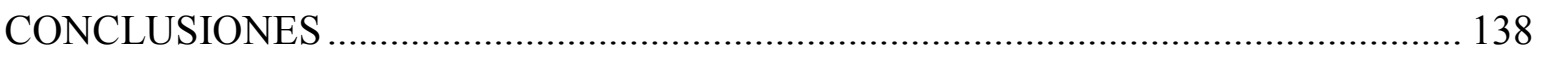

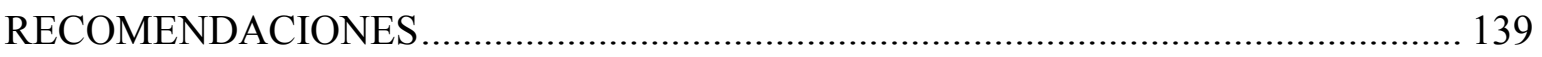

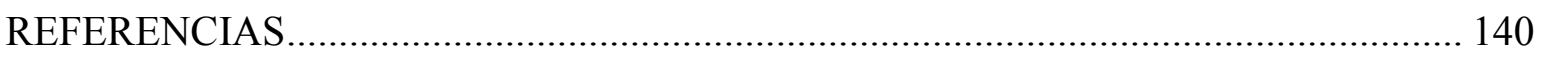

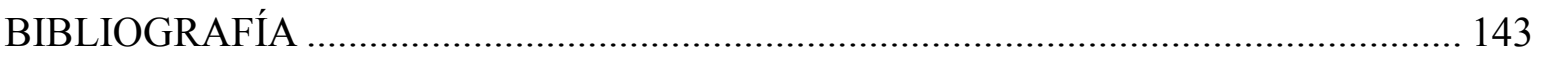

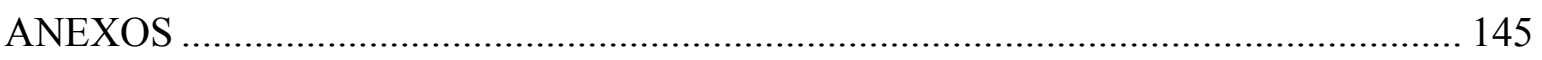




\section{ÍNDICE DE TABLAS}

Tabla 2.1 Ventas de alimento preparado para bebés en Perú en toneladas 11

Tabla 2.2 Importaciones históricas de Prepared Baby Food (compotas para bebés) 12

Tabla 2.3 Demanda anual de compotas para bebés en Perú en kilogramos 12

Tabla 2.4 Ventas de alimento preparado en Perú en toneladas 13

Tabla 2.5 Cálculo del consumo per cápita en Perú 13

Tabla 2.6 Ventas de alimento preparado para bebés en Chile en toneladas 14

Tabla 2.7 Cálculo del consumo per cápita en Chile 14

Tabla 2.8 Ventas de alimento preparado para bebés en Brasil en miles de toneladas 15

Tabla 2.9 Cálculo del consumo per cápita en Brasil 15

Tabla 2.10 Población de Colombia del 2007 al 2015

Tabla 2.11 Venta de alimento preparado para bebés en Colombia en toneladas 16

Tabla 2.12 Cálculo del consumo per cápita en Colombia 16

Tabla 2.13 Población de Ecuador del 2007 al 2015

Tabla 2.14 Venta de alimento preparado para bebés en Ecuador en toneladas

Tabla 2.15 Cálculo del consumo per cápita en Ecuador $\quad 17$

Tabla 2.16 Cálculo de la demanda potencial de Perú en compotas 18

Tabla 2.17 Demanda potencial de Perú del 2016 al 2021 en compotas 18

Tabla 2.18 Demanda histórica de compotas para bebés en Perú 18

Tabla 2.19 Demanda proyectada de compotas para bebés en Perú 19

Tabla 2.20 Segmentación geográfica mercado meta 23

Tabla 2.21 Clasificación psicográfica $/[T T / 725$

Tabla 2.22 Resultados de encuesta respecto a la intensidad de compra 26

Tabla 2.23 Demanda para el proyecto 26

Tabla 2.24 Demanda del proyecto en kg, TM y envases de compota 27

Tabla 2.25 Presupuesto anual de publicidad y promoción en soles 29

Tabla 2.26 Tendencia histórica de los precios de las compotas para bebés en Perú en la presentación de 113 gramos del año 2011 al 2015 
Tabla 2.27 Precios actuales de las compotas para bebés

Tabla 2.28 Costo de la materia prima $\quad 32$

Tabla 3.1 Producción a nivel regional de durazno en el año 2015

Tabla 3.2 Producción a nivel regional de maca en el año 2015

Tabla 3.3 Producción a nivel regional de quinua en el año 2015

Tabla 3.4 Producción a nivel regional de kiwicha en el año 2015

Tabla 3.5 Producción a nivel regional de cañihua en el año 2015

Tabla 3.6 Rutas de viaje terrestre y distancias al mercado objetivo, por región 38

Tabla 3.7 Red vial nacional según región del año 2015

Tabla 3.8 Situación de la PEA a nivel regional 39

Tabla 3.9 Cobertura de electrificación por región en porcentaje (\%) del año $2015 \quad 40$

Tabla 3.10 Potencia instalada y producción de energía eléctrica a nivel regional del año 2015

Tabla 3.11 Cobertura de agua potable en el área urbana por región (Porcentaje) del año 2012

Tabla 3.12 Cobertura de alcantarillado u otra forma de disposición de excretas en el área urbana (Porcentaje) del año 2015

Tabla 3.13 Parques industriales (P.I.) por región 41

Tabla 3.14 Calificación de factores de macro localización $\quad 42$

Tabla 3.15 Ranking de factores de macro localización 42

Tabla 3.16 Análisis de macro localización 42

Tabla 3.17 Población Económicamente Activa total y ocupada de los distritos de Lima y

Callao, según Censo Nacional 2007

Tabla 3.18 Tarifas por energía eléctrica, según empresas de distribución eléctrica en Lima 43

Tabla 3.19 Tarifas por agua potable u alcantarillado, según Sedapal en Lima 44

Tabla 3.20 Distribución de plantas de tratamiento de aguas residuales en Lima y Callao $\quad 44$

Tabla 3.21 Precios de terrenos por distritos 44

Tabla 3.22 Calificación de factores de micro localización 45

Tabla 3.23 Ranking de factores de micro localización $\quad 45$

Tabla 3.24 Análisis de micro localización 45

Tabla 3.25 Análisis costo a costo 46 
Tabla 4.1 Relación tamaño-mercado

Tabla 4.2 Relación tamaño-recursos productivos

Tabla 4.3 Relación tamaño-tecnología

Tabla 4.4 Relación tamaño-inversión

Tabla 4.5 Recursos financieros

Tabla 4.6 Relación tamaño-punto de equilibrio

Tabla 4.7 Selección de tamaño de planta

Tabla 5.1 Composición de la compota

Tabla 5.2 Valor nutricional de la compota de 113 gramos

Tabla 5.3 Selección de la tecnología

Tabla 5.4 Báscula de piso portátil

Tabla 5.5 Lavadora de frutas

Tabla 5.6 Faja transportadora de banda

Tabla 5.7 Máquina descarozadora

Tabla 5.8 Orientadora de mitades

Tabla 5.9 Peladora química

Tabla 5.10 Escaldadora tipo inmersión

Tabla 5.11 Despulpadora de frutas

Tabla 5.12 Mezcladora de paletas

Tabla 5.13 Marmita a vapor eléctrica

Tabla 5.14 Máquina de llenado de líquidos y tapado de frascos

Tabla 5.15 Etiquetadora automática

Tabla 5.16 Máquina formadora de cajas y encajadora de envases

Tabla 5.17 Tanque de almacenamiento de acero inoxidable

Tabla 5.18 Bomba de doble husillo

Tabla 5.19 Esterilizadora de envases y tapas

Tabla 5.20 Tanque de almacenamiento de hidróxido de sodio

Tabla 5.21 Bomba peristáltica SPX32

Tabla 5.22 Montacargas

Tabla 5.23 Capacidad instalada 
Tabla 5.25 Características de las materias primas

Tabla 5.26 Características de los insumos

Tabla 5.27 Análisis de riesgos

Tabla 5.28 Puntos críticos de control

Tabla 5.29 Impactos ambientales

Tabla 5.30 IPER

Tabla 5.31 Mantenimiento de equipos

Tabla 5.32 Programa de producción de vida útil del proyecto

Tabla 5.33 Requerimiento de materia prima

Tabla 5.34 Requerimiento de materiales

Tabla 5.35 Requerimiento de insumos

Tabla 5.36 Implementos de seguridad alimentaria

Tabla 5.37 Cálculo de consumo de energía eléctrica anual en KW

Tabla 5.38 Requerimiento de agua para procesos

Tabla 5.39 Consumo de agua del personal y requerida para la limpieza de la instalación

Tabla 5.40 Número de operarios en la planta

Tabla 5.41 Mano de obra indirecta en oficinas

Tabla 5.42 Presupuesto anual de mantenimiento en soles

Tabla 5.43 Presupuesto anual de limpieza en soles

Tabla 5.44 Cálculo del costo por envío

Tabla 5.45 Cantidad de envíos anual

Tabla 5.46 Presupuesto anual de distribución en soles

Tabla 5.47 Composición del sistema de vigilancia

Tabla 5.48 Presupuesto anual de vigilancia en soles

Tabla 5.49 Determinación del área de producción

Tabla 5.50 Cálculo del almacén temporal de mezcla pasteurizada

Tabla 5.51 Cálculo del almacén temporal de cajas de durazno antes del pesado

Tabla 5.52 Cálculo del almacén temporal de cajas de las harinas antes del pesado

Tabla 5.53 Cálculo del almacén temporal antes del esterilizado de envases

Tabla 5.54 Cálculo del almacén temporal antes del esterilizado de tapas 
Tabla 5.56 Cálculo del almacén temporal de producto terminado en el área de encajonado

Tabla 5.57 Análisis del 30\% de los almacenes temporales

Tabla 5.58 Calculo del área de producción

Tabla 5.59 Calculo del área del almacén de materias primas

Tabla 5.60 Cálculo del área del almacén de insumos parte 1

Tabla 5.61 Cálculo del área del almacén de insumos parte 2

Tabla 5.62 Cálculo del área del almacén de productos terminados

Tabla 5.63 Cálculo del área del almacén de los barriles de gasolina

Tabla 5.64 Presupuesto de dispositivos de seguridad industrial

Tabla 5.65 Lista de motivos

Tabla 5.66 Tabla relacional

Tabla 7.1 Inversión fija tangible del proyecto

Tabla 7.2 Inversión fija intangible del proyecto

Tabla 7.3 Capital de trabajo para los 4 primeros meses de operación

Tabla 7.4 Inversión total del proyecto

Tabla 7.5 Relación deuda/capital propio

Tabla 7.6 Costo de materias primas para el periodo del proyecto

Tabla 7.7 Costo de los insumos para el periodo del proyecto

Tabla 7.8 Costo de mano de obra directa

Tabla 7.9 Costos Implementos de seguridad

Tabla 7.10 Costo de mano de obra indirecta

Tabla 7.11 Costo de energía eléctrica

Tabla 7.12 Costo de agua potable

Tabla 7.13 Costo de telefonía e internet

Tabla 7.14 Costo de anexos - teléfonos fijos

Tabla 7.15 Costo de combustible para el período del proyecto

Tabla 7.16 Costo de mantenimiento

Tabla 7.17 Presupuesto de ingreso por ventas

Tabla 7.18 Presupuesto de costo de producción

Tabla 7.19 Presupuesto operativo de gastos administrativos 
Tabla 7.21 Estado de resultados

Tabla 7.22 Estado de situación financiera Año 1

Tabla 7.23 Cálculo de flujo de caja

Tabla 7.24 Flujo de fondos económicos

Tabla 7.25 Flujo de fondos financieros

Tabla 8.1 Evaluación económica

Tabla 8.2 Cálculo del VAN económico por años y del periodo de recupero

Tabla 8.3 Evaluación financiera

Tabla 8.4 Cálculo del VAN financiero por años y del periodo de recupero

Tabla 9.1 Disminución de la tasa de desempleo en Lima y Ventanilla

Tabla 9.2 Revalorización del terreno de la planta

Tabla 9.3 Generación de residuos sólidos para el periodo del proyecto

Tabla 9.4 Cálculo del valor agregado

Tabla 9.5 Cálculo de la densidad de capital

Tabla 9.6 Cálculo de intensidad de capital

Tabla 9.7 Cálculo de productividad de la mano de obra

Tabla 9.8 Cálculo de relación producto - capital 


\section{ÍNDICE DE FIGURAS}

Figura 1.1 Evolución del consumo per cápita en Perú en compotas por persona 3

Figura 1.2 Evolución del ingreso real promedio per cápita mensual. 2009 - 2014

Figura 2.1 Población por departamento del Perú $\quad 8$

Figura 2.2 Distribución de personas según nivel socioeconómico en Lima Metropolitana 9

Figura 2.3 Distribución de niveles por zona Apeim en Lima Metropolitana 9

Figura 2.4 Población de Perú 13

Figura 2.5 Datos de Chile 14

Figura 2.6 Datos de Brasil 15

Figura 2.7 Evolución del consumo per cápita Perú, Chile y Brasil en compotas por persona 17

Figura 2.8 Participación de mercado de las marcas de alimento para bebés $\quad 21$

Figura 2.9 Participación(\%) de las marcas de alimentos para bebés en el año 2015

Figura 2.10 Lealtad en la compra de producto 22

Figura 2.11 Penetración de productos de consumo familiar $\quad 22$

Figura 2.12 Distribución de personas según nivel socioeconómico en Lima Metropolitana 24

Figura 2.13 Intención de compra obtenida de encuesta 25

Figura 2.14 Porcentaje de ventas de los lugares de distribución de alimentos para bebés del año 2009 al 2015

Figura 3.1 Red vial nacional al año 2015

Figura 5.1 Compota Wawa

Figura 5.2 Seleccionado mediante rodillos o candilones $\quad 55$

Figura 5.3 Descarozado a torsión $1 / H+$ I

Figura 5.4 Descarozado por cuchareo $\quad 56$

Figura 5.5 Diagrama de operaciones del proceso para la elaboración de compotas para 63

bebés a partir de durazno enriquecido con maca, quinua, kiwicha y cañihua

Figura 5.6 Balance de materia $\quad 66$

Figura 5.7 Criterios de evaluación IPER $\quad 82$ 
Figura 5.8 Nivel de riesgo

Figura 5.9 Ruta de distribución en KM para la cadena de farmacias Inkafarma en la ciudad de Lima

Figura 5.10 Distribución de niveles socioeconómicos por zona Apeim en Lima Metropolitana

Figura 5.11 Ubicación de dispositivos de seguridad industrial y señalización

Figura 5.12 Diagrama relacional

Figura 5.13 Análisis de relaciones

Figura 5.14 Disposición de la planta de producción de compotas para bebés

Figura 5.15 Cronograma de implementación del proyecto

Figura 6.1 Organigrama de la empresa

Figura 8.1 Análisis de sensibilidad financiera

Figura 9.1 Ubicación de la Planta

132

Figura 9.2 Población avenida Chillón 


\section{ÍNDICE DE ANEXOS}

Anexo 1 Encuesta sobre alimentos para bebé

Anexo 2 Depreciación de activos tangibles

Anexo 3 Depreciación fabril y no fabril

Anexo 4 Amortización de intangibles

117

Anexo 5 Imágenes del terreno

130 


\section{RESUMEN EJECUTIVO}

En el capítulo I se concluye que el proyecto es técnicamente viable debido a que es posible producir la compota y hay disponibilidad de materia prima, además es económicamente viable debido a que el consumo per cápita de compotas para bebé en Perú sigue la tendencia a aumentar debido a un aumento progresivo del ingreso el cual les da mayor capacidad adquisitiva a las personas e incrementa su consumo. Finalmente es socialmente viable debido a que dinamiza la economía de los agricultores ya que las materias primas que ellos producen que son el durazno, maca, quinua, kiwicha y cañihua se les está dando un valor agregado al convertirlo en una compota para bebés e incorporarlo al mercado Limeño. Asimismo conforme la planta de producción opere se presentará un aumento de la demanda de las materias primas lo cual representará un aumento en los ingresos de los agricultores y por lo tanto una mejora en su calidad de vida además de crear puestos de trabajo en la planta de producción.

En el capítulo II se establece que el país al cual está destinado la compota para bebés es Perú específicamente la ciudad de Lima, para bebés menores a los 2 años de edad cuyos padres pertenecen a los niveles socioeconómicos $\mathrm{A}, \mathrm{B}$ y $\mathrm{C}$ y cuyo estilo de vida es catalogado como los sofisticados y las modernas.

En el capítulo III se determina que la planta estará ubicada en la ciudad de Lima específicamente en el distrito de Ventanilla.

En el capítulo IV se establece que el tamaño de la planta es de 1849 toneladas/año el cual es determinado por el tamaño de mercado.

En el capítulo V se establecen las especificaciones técnicas de la compota y se determina la fórmula a utilizar la cual es aprobada por un nutricionista. Luego se establecen las tecnologías existentes, se selecciona la tecnología a utilizar y se determina el proceso de producción. Posteriormente se muestra la maquinaria a utilizar y se determina la capacidad instalada la cual es de $2.460 .326 \mathrm{~kg}$ de compota/año. 
En el capítulo VI se establece la organización administrativa de la empresa es decir los puestos que se requieren, las funciones que debe realizar y las competencias y formación profesional que debe tener.

En el capítulo VII se determina que la inversión total es de 4.748 .698 soles siendo el $40 \%$ financiamiento y el $60 \%$ capital propio.

En el capítulo VIII se observa que tanto el VAN económico que es 4.252.919 soles y el VAN financiero que es 4.639 .674 soles son mayores a 0 , por lo tanto la inversión del proyecto es aceptable pues genera más ganancias después de recuperar lo invertido. Esta afirmación se ve fortalecida debido a que la TIR económica la cual es $42 \%$ y la TIR financiera la cual es $52 \%$ son mayores que el costo de capital (Cok) el cual es $23 \%$. Además la evaluación económica muestra que el periodo de recupero sería de 4 años y 6 meses mientras la evaluación financiera muestra que sería en 4 años y 1 mes, siendo esta última la más importante para los inversionistas, pues se concentra más en los ingresos y egresos que tendría el proyecto. Luego la relación beneficio/costo financiera es de 2,63 es decir por cada sol invertido se genera 2,63 soles de ingreso. En conclusión el proyecto es viable debido a que genera más dinero de lo invertido en él y presenta unos flujos tentadores para la inversión.

En el capítulo IX se realiza la evaluación social del proyecto, estableciéndose la ubicación de la planta en el distrito de Ventanilla específicamente al costado de la planta térmica de ciclo combinado de Ventanilla. Luego se determina que los impactos que genera la empresa en la comunidad donde está ubicada son: aumento de la congestión vehicular, disminución de la tasa de desempleo, revalorización de los terrenos, aumento de la contaminación por generación de residuos sólidos, emisión de gases contaminantes y generación de efluentes. Después se procede a cuantificar estos impactos y por último se realiza la medición del impacto social mediante indicadores macroeconómicos. 


\section{EXECUTIVE SUMMARY}

On chapter I we conclude that the project is technically feasible because is possible to produce the compote and we have availability of raw material, what's more is economically viable because the per capita consumption of compotes for babies in Peru follow the trends to increase because there is a progressive increase in incomes that give people more purchasing power and increase the consumption. Finally is socially viable because boost the farmers economy as the raw materials that they produce that are peach, maca, quinoa, amaranth and cañihua are being given added value by turning it into a compote for babies and incorporate into Lima market. Also as the production plant operates is going to be an increase of the demand of raw materials that is going to represent an increase of farmers incomes and improve their quality life, else the production plant is going to create new jobs.

On chapter II we establish that the country that we are going to attend is Peru specifically the city of Lima, for babies with less than 2 years and which fathers are part of the socioeconomic level A, B and C and their style of life are the sophisticated and modern.

On chapter III we determinate that the production plant is going to be on the city of Lima specifically on the district of Ventanilla.

On chapter IV we establish that the size of the production plant is 1849 tonnes/year which is determinate by the market size.

On chapter $\mathrm{V}$ we establish the technical specifications of the compote and we determinate the formula which was approved by a nutritionist. After that we establish the existing technologies, we select the technology to use and we determinate the production process. Then the machines that are going to be use are show and the capacity install is $2.460 .326 \mathrm{~kg}$ of compotes/year.

On chapter VI we establish the administrative organization of the company specifically the job positions, functions, skills and professional studies that are necessary. 
On chapter VII we establish that the total investment is 4.748 .698 soles, $40 \%$ of the amount will be financed and $60 \%$ by own capital.

Chapter VIII shows that economic NPV which is 4.252 .919 soles and financial NPV which is 4.639 .674 soles are greater than 0 so the project investment is acceptable because it generates more profits after return of investment. This statement is strengthened because the economic IRR is $42 \%$ and financial IRR is $52 \%$ and both are higher than the cost of capital (Cok) which is $23 \%$. Besides the economic evaluation shows that the recovery period is 4 years and 6 months and the financial evaluation shows that the recovery period is 4 years and 1 month. The last one is the most important for investors because is focus on incomes and expenses of the project. Then the financial ratio benefit/cost is 2,63 so for each sol that is invested we generated 2,63 soles for incomes. As a conclusion the project is viable because it generates more money than the invested on it and presents a tempting flow for investment.

On chapter IX we make the social evaluation of the project, we establish the location of the production plant on Ventanilla district specifically next to the thermal plant of combined cycle of Ventanilla. Then we determinate that the company impacts on the community where is located are: increased traffic congestion, decreased unemployment rate, revaluation of the land, increased pollution by solid waste generation, greenhouse gas emissions and effluent generation. After that we proceed to quantify these impacts and finally we make the measurement of the social impact by macroeconomic indicators. 


\section{CAPÍTULO I: ASPECTOS GENERALES}

\subsection{Problemática}

Para buscar el desarrollo del Perú no basta con tener recursos naturales, sino que es necesario tener un capital humano preparado tanto físicamente como intelectualmente para enfrentar los retos futuros. Es por ello que el siguiente trabajo se concentrará en una etapa esencial de la vida como la nutrición en la infancia pues ahí se da el crecimiento y maduración cerebral además de la multiplicación neuronal. La exposición a procesos prolongados de desnutrición en la infancia puede ocasionar deficiencias permanentes en el desarrollo además de rezago intelectual. Es ahí que en la búsqueda de soluciones a este problema de desnutrición nace el proyecto siguiente "Estudio de pre-factibilidad para la instalación de una planta productora de compotas para bebés a partir de durazno enriquecido con maca, quinua, kiwicha y cañihua" en el cual se busca rescatar los conocimientos ancestrales de los incas sobre granos andinos y combinarlo con tecnología de punta para ofrecer un alimento rico en vitaminas y proteínas para los infantes.

\subsection{Objetivos de la investigación}

\subsubsection{Objetivo general}

Determinar la viabilidad técnica, económica, financiera y social para la instalación de una planta productora de compotas para bebés a partir de durazno enriquecido con maca, quinua, kiwicha y cañihua.

\subsubsection{Objetivo especifico}

- Determinar el mercado objetivo y sus preferencias con respecto a este tipo de producto.

- Obtener un producto de alta calidad que sea competitivo en el mercado nacional e internacional.

- Determinar la ubicación de la planta, el tamaño y su distribución interna. 


\subsection{Alcance y limitaciones de la investigación}

El siguiente estudio de pre-factibilidad se limita a la elaboración de una compota para bebés a partir de durazno enriquecido con maca, quinua, kiwicha y cañihua. No considera el uso de otras frutas u granos andinos para obtener distintos sabores. Su mercado es el departamento de Lima.

\subsection{Justificación del tema}

A. Técnica

El proyecto es viable técnicamente debido a que es factible producir la compota y hay disponibilidad de materia prima e insumos.

Se procederá a demostrar la factibilidad de la producción de la compota mediante los siguientes procesos:

- Obtención de la pulpa de durazno

Se busca obtener una pasta de durazno homogénea en donde se ha desactivado las enzimas pécticas y las enzimas responsables del pardeamiento enzimático las cuales producen cambios desagradables en el color y sabor de las frutas.

- Elaboración de la compota

Se busca obtener una compota de apariencia y textura suave. Esto se logra mediante la mezcla de acuerdo a fórmula de la pasta de durazno, harina de maca, quinua, kiwicha y cañihua. Además de someterlo al proceso de pasteurización donde se eliminaran los microorganismos y agentes patógenos para garantizar la inocuidad del alimento.

Se procederá a demostrar la disponibilidad de materia prima e insumos:

- El durazno se produce en los departamentos de Lima, Cajamarca, Ayacucho, Cusco, Puno, Ucayali, San Martín, Loreto, Piura, Ancash, Ica, Huánuco, Apurímac, Moquegua y Tacna (Ministerio de Agricultura, s.f.)

- La producción nacional de quinua se realiza en Puno, Cusco, Junín, Arequipa, Huancavelica, Ayacucho, Apurímac, La libertad, Lambayeque, Huánuco, Tacna, Áncash, Cajamarca, Lima, Ica, Moquegua y Amazonas ; mientras que la de kiwicha se desarrolla principalmente en los departamentos de Arequipa, Huancavelica, Cusco, Áncash, Ayacucho, Apurímac y La libertad. La quinua se cosecha entre abril y junio, 
mientras que la kiwicha entre febrero y octubre con una mayor concentración entre abril y agosto. (Ministerio de agricultura, s.f.)

- Los mayores centros de producción de maca se encuentran en los departamentos de Junín (La meseta de Bombón), Pasco (Las partes altas del Valle de Mantaro) y Huancavelica. Pero últimamente por la importancia que ha adquirido el cultivo se siembran en las alturas de todos los Departamentos del Perú (Universidad Nacional Agraria La Molina, s.f.).

- La cañihua se cultiva en las regiones altiplánicas de Perú y Bolivia, encontrándose a los $3.800 \mathrm{msnm}$. La zona de mayor producción está concentrada en Puno al norte del Lago Titicaca, luego está Cuzco y Arequipa. (Ministerio de agricultura, s.f.).

B. Económica

El proyecto se considera económicamente viable por lo siguiente:

El consumo per cápita de compotas para bebé en Perú sigue la tendencia a aumentar debido a un aumento progresivo del ingreso el cual les da mayor capacidad adquisitiva a las personas e incrementa su consumo.

Figura 1.1

Evolución del consumo per cápita en Perú en compotas por persona

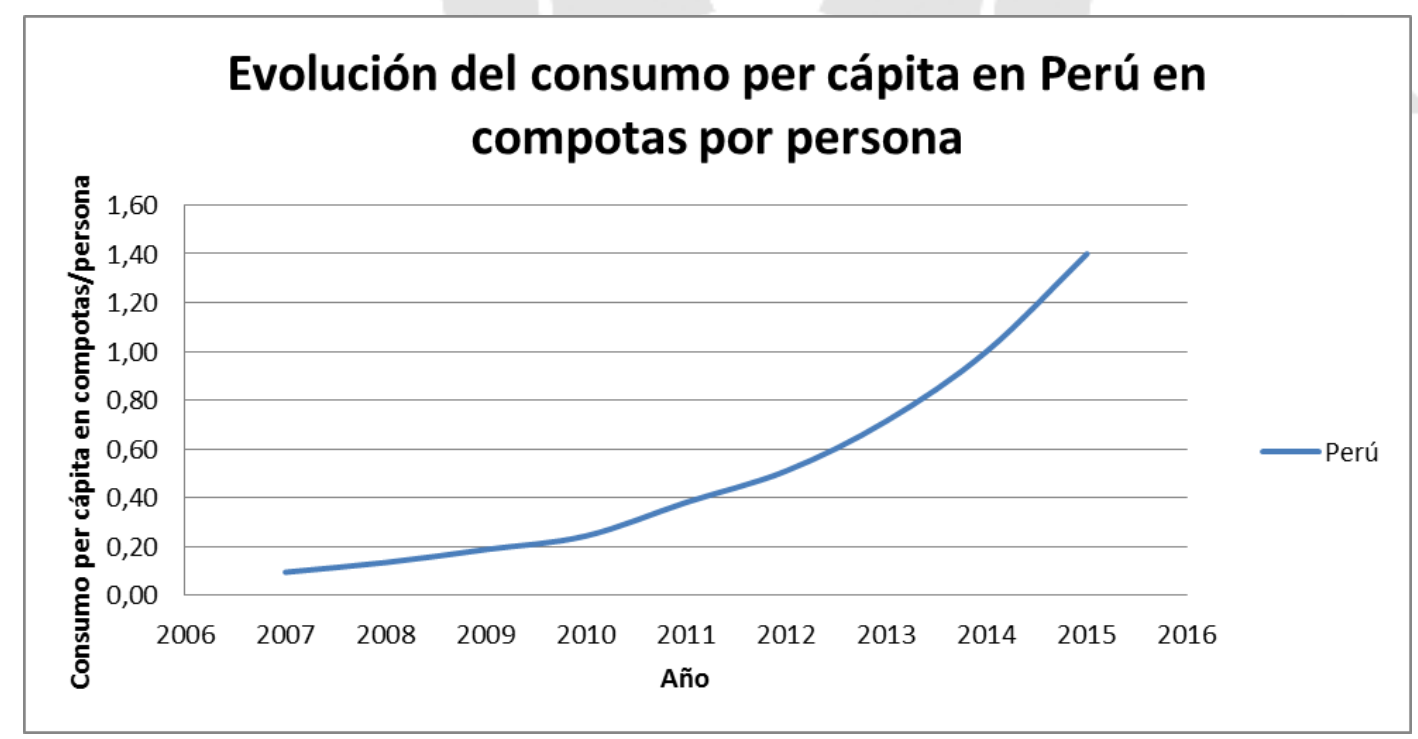

Elaboración propia 
Figura 1.2

Evolución del ingreso real promedio per cápita mensual. 2009 - 2014

PERÚ: EVOLUCIÓN DEL INGRESO REAL PROMEDIO PER CÁPITA MENSUAL, 2009-2014

(Nuevos soles constantes base $=2014$ a precios de Lima Metropolitana)

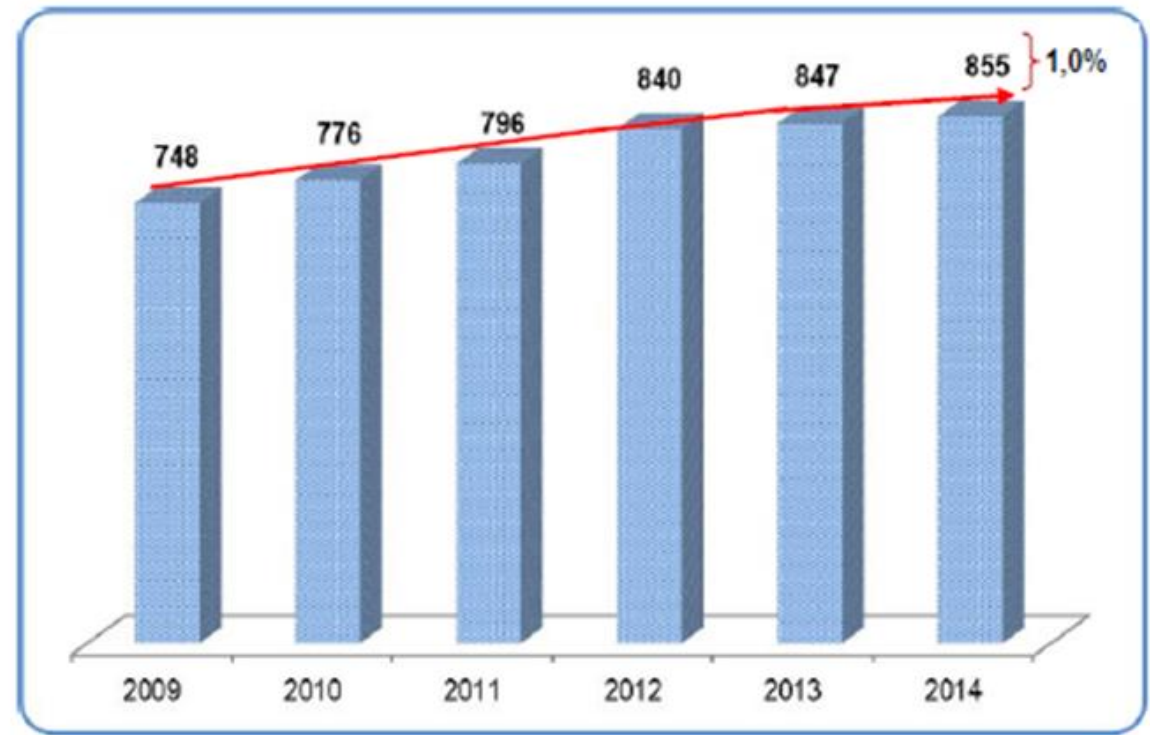

Fuente: INEI, (2015)

C. Social

El proyecto permitirá dinamizar la economía de los agricultores ya que las materias primas que ellos producen que son el durazno, maca, quinua, kiwicha y cañihua se les está dando un valor agregado al convertirlo en una compota para bebés e incorporarlo al mercado Limeño. Asimismo conforme la planta de producción opere se presentará un aumento de la demanda de las materias primas lo cual representará un aumento en los ingresos de los agricultores y por lo tanto una mejora en su calidad de vida además de crear puestos de trabajo en la planta de producción.

\subsection{Hipótesis de trabajo}

La instalación de una planta productora de compotas para bebés a partir de durazno enriquecido con maca, quinua, kiwicha y cañihua es factible, pues existe un mercado que va a aceptar el producto y además es tecnológica, económica y financieramente viable.

\subsection{Marco referencial de la investigación}

El marco referencial está conformado por las siguientes investigaciones: 
A. Estudio de pre factibilidad para la instalación de una planta procesadora de alimentos para bebés a base de quinua (Chenopodium quinoa willdenow), kiwicha (Caudatus linnaeus), cañihua (Chenopodium pallidicaule), manzana, plátano y leche.

\section{Similitud:}

- Utiliza harina de Quinua, Kiwicha y Cañihua en el proceso de producción.

- Busca obtener un producto rico en vitaminas y proteínas para los bebés.

\section{Diferencia:}

- La compota que producen no puede ser consumida por el bebé ya que a este no se le debe dar leche de vaca hasta el primer año de edad pues reciben cantidades inadecuadas de hierro, ácidos grasos esenciales y algunas vitaminas. Igualmente reciben demasiada proteína, sodio y potasio cuyos niveles pueden ser demasiado altos para que su organismo lo maneje.

\section{Objetivo:}

- Determinar la factibilidad de instalar una planta procesadora de alimentos para bebés, empleando frutas, cultivos andinos y leche en el proceso de elaboración de compotas.

B. Estudio de factibilidad para instalar una planta de extracción de pulpa de durazno (prunus pérsica) en la provincia de Huaral.

Similitud:

- Utiliza el durazno como materia prima.

\section{Diferencia:}

- El producto a comercializar es pulpa de durazno envasado en bolsas asépticas.

\section{Objetivo:}

- Determinar la factibilidad de instalar una planta de extracción de pulpa de durazno en la provincia de Huaral.

\subsection{Marco Conceptual}

En la actualidad hay una preocupación importante por la alimentación de los bebés pues un comienzo sano es un futuro saludable.

Esta alimentación es atendida, durante los primeros meses, por la leche materna la cual tiene los requerimientos necesarios de vitaminas, minerales y ácidos grasos para que el bebé pueda desarrollar su sistema inmunológico y habilidad cognitiva pero a partir de los 6 
meses comienza a tomar importancia los alimentos complementarios como las compotas por el aporte nutricional que tienen. Es por ello que para suplir esta necesidad aparecen grandes industrias como Alpina, Gerber, Heinz y el Grupo Irex los cuales se disputan el mercado con diferentes sabores de compotas.

\section{Glosario de términos}

- Maca: Tubérculo andino muy alimenticio y de propiedades medicinales.

- Quinua: Planta anual de la familia de las Quenopodiáceas, de la que hay varias especies, de hojas rómbicas y flores pequeñas dispuestas en racimos. Las hojas tiernas y las semillas, muy abundantes y menudas, son comestibles.

- Cañihua: Especie de mijo que sirve de alimento a los indios y con el cual, fermentado, se hace chicha.

- Kiwicha: Planta herbácea de hasta un metro de altura, con nervios en el envés de las hojas y pequeñísimas semillas de gran valor nutritivo de color amarillo, que al tostarse aumentan de tamaño.

- Durazno: Nombre genérico de varias especies de árboles, como el melocotonero, el pérsico y el duraznero.

- Compota: Dulce de fruta cocida con agua y azúcar.

- Vacío: Dicho de una forma de envasar sin aire.

- Inocuo: Que no hace daño.

- Rodamiento: Cojinete formado por dos cilindros concéntricos entre los que se intercala una corona de bolas o rodillos que ruedan sobre ambas superficies.

- Chumacera: Pieza de metal o madera, con una muesca en que descansa y gira cualquier eje de maquinaria.

- Acoplamiento: Dispositivo que sirve para unir los extremos de dos ejes u otros elementos mecánicos. 


\section{CAPÍTULO II: ESTUDIO DE MERCADO}

\subsection{Aspectos generales del estudio de mercado}

\subsubsection{Definición comercial del producto}

El producto final es una compota para bebés a partir de durazno enriquecido con maca, quinua, kiwicha y cañihua. Para describirlo se utilizará la definición del libro de Kotler \& Armstrong.

Niveles de producto:

- Producto básico: Alimento rico en vitaminas, proteínas y minerales.

- Producto real: Compota para bebés a partir de durazno enriquecido con maca, quinua, kiwicha y cañihua en una presentación de 113 gramos la cual es ideal para la capacidad gástrica del bebé y en un envase plástico que garantizará la inocuidad del alimento.

- Producto aumentado: Producto con garantía y servicio post - venta (El cliente puede contactarse con la empresa en caso de dudas o consultas con respecto al consumo del producto o a su composición).

Partida arancelaria:

La partida arancelaria es la número 2007.10.00 la cual hace referencia a preparaciones homogeneizadas específicamente para confituras, jaleas y mermeladas, purés y pastas de frutas $\mathrm{u}$ otros frutos, obtenidos por cocción, incluso con adición de azúcar u otro edulcorante.

CIIU:

- Sección D de Industrias manufactureras

- División 15 de elaboración de productos alimenticios y bebidas

- Grupo 151 de producción, procesamiento y conservación de carne, pescado, frutas, legumbres, hortalizas, aceites y grasas.

- Clase 1513 de elaboración y conservación de frutas, legumbres y hortalizas. En la cual se incluye la elaboración de compotas, mermeladas y jaleas. 


\subsubsection{Principales características del producto}

\subsubsection{Usos y propiedades}

La compota es un alimento complementario para el bebé a partir de los 6 meses debido a la cantidad de vitaminas, minerales y proteínas que contiene ya que sus componentes son el durazno, maca, quinua, kiwicha y cañihua.

\subsubsection{Bienes sustitutos y complementarios}

Como bien sustituto tenemos a las compotas caseras, los cereales Nestum y Cerelac los cuales limitan el precio de la compota a ofrecer y por lo tanto afectan la rentabilidad de la empresa. Y no hay bienes complementarios

\subsubsection{Determinación del área geográfica que abarcará el estudio}

El área geográfica a estudiar es la ciudad de Lima debido a que tiene la mayor cantidad de población en Perú y manteniendo como objetivo satisfacer los niveles socioeconómicos A, B y $\mathrm{C}$.

Figura 2.1

Población por departamento del Perú

\begin{tabular}{|c|c|c|c|c|c|c|}
\hline & 2010 & 2011 & 2012 & 2013 & 2014 & 2015 \\
\hline PERU & $29,461,933$ & $29,797,694$ & $30,135,875$ & $30,475,144$ & $30,814,175$ & $31,151,643$ \\
\hline AMAZONAS & 413,314 & 415,466 & 417,508 & 419,404 & 421,122 & 422,629 \\
\hline ÁNCASH & $1,116,265$ & $1,122,792$ & $1,129,391$ & $1,135,962$ & $1,142,409$ & $1,148,634$ \\
\hline APURIMAC & 446,813 & 449,365 & 451,881 & 454,324 & 456,652 & 458,830 \\
\hline AREQUIPA & $1,218,168$ & $1,231,553$ & $1,245,251$ & $1,259,162$ & $1,273,180$ & $1,287,205$ \\
\hline AYACUCHO & 650,718 & 658,400 & 666,029 & 673,609 & 681,149 & 688,657 \\
\hline CAJAMARCA & $1,500,584$ & $1,507,486$ & $1,513,892$ & $1,519,764$ & $1,525,064$ & $1,529,755$ \\
\hline PROV. CONST. DEL CALLAO & 941,268 & 955,385 & 969,170 & 982,800 & 996,455 & $1,010,315$ \\
\hline cusco & $1,274,742$ & $1,283,540$ & $1,292,175$ & $1,300,609$ & $1,308,806$ & $1,316,729$ \\
\hline HUANCAVELICA & 475,693 & 479,641 & 483,580 & 487,472 & 491,278 & 494,963 \\
\hline HUÁNUCO & 826,932 & 834,054 & 840,984 & 847,714 & 854,234 & 860,537 \\
\hline ICA & 747,338 & 755,508 & 763,558 & 771,507 & 779,372 & 787,170 \\
\hline JUNIN & $1,301,844$ & $1,311,584$ & $1,321,407$ & $1,331,253$ & $1,341,064$ & $1,350,783$ \\
\hline LA LIBERTAD & $1,746,913$ & $1,769,181$ & $1,791,659$ & $1,814,276$ & $1,836,960$ & $1,859,640$ \\
\hline LAMBAYEQUE & $1,207,589$ & $1,218,492$ & $1,229,260$ & $1,239,882$ & $1,250,349$ & $1,260,650$ \\
\hline LIMA & $9,113,684$ & $9,252,401$ & $9,395,149$ & $9,540,996$ & $9,689,011$ & $9,838,251$ \\
\hline LORETO & 983,371 & 995,355 & $1,006,953$ & $1,018,160$ & $1,028,968$ & $1,039,372$ \\
\hline MADRE DE DIOS & 121,183 & 124,404 & 127,639 & 130,876 & 134,105 & 137,316 \\
\hline MOQUEGUA & 171,155 & 172,995 & 174,859 & 176,736 & 178,612 & 180,477 \\
\hline PASCO & 292,955 & 295,315 & 297,591 & 299,807 & 301,988 & 304,158 \\
\hline PIURA & $1,769,555$ & $1,784,551$ & $1,799,607$ & $1,814,622$ & $1,829,496$ & $1,844,129$ \\
\hline PUNO & $1,352,523$ & $1,364,752$ & $1,377,122$ & $1,389,684$ & $1,402,496$ & $1,415,608$ \\
\hline SAN MARTIN & 782,932 & 794,730 & 806,452 & 818,061 & 829,520 & 840,790 \\
\hline TACNA & 320,021 & 324,498 & 328,915 & 333,276 & 337,583 & 341,838 \\
\hline TUMBES & 221,498 & 224,895 & 228,227 & 231,480 & 234,638 & 237,685 \\
\hline UCAYALI & 464,875 & 471,351 & 477,616 & 483,708 & 489,664 & 495,522 \\
\hline
\end{tabular}

Fuente: INEI, (2015) 
Figura 2.2

Distribución de personas según nivel socioeconómico en Lima Metropolitana Apeim

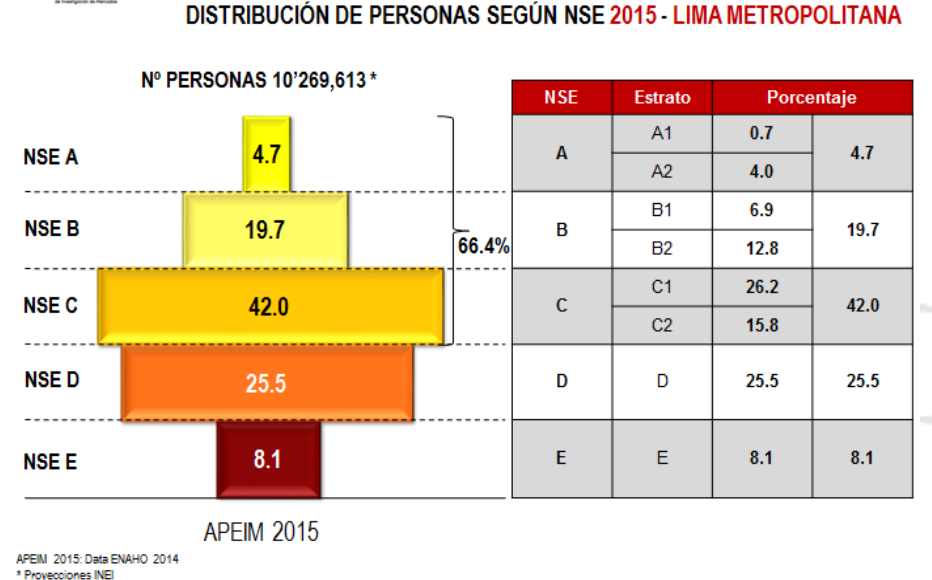

Fuente: Apeim, (2015)

Figura 2.3

Distribución de niveles socioeconómicos por zona Apeim en Lima Metropolitana

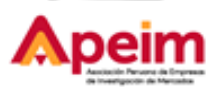

DISTRIBUCIÓN DE NIVELES POR ZONAAPEIM 2015 - LIMA METROPOLITANA PERSONAS - (\%) HORIZONTALES

\begin{tabular}{|l|c|c|c|c|c|c|}
\hline \multirow{2}{*}{ Zona } & \multicolumn{5}{c|}{ Niveles Socioeconómicos } \\
\cline { 2 - 8 } & TOTAL & NSEA & NSE B & NSEC & NSED & NSEE \\
\hline Total & 100 & 4.7 & 19.7 & 42.0 & 25.5 & 8.1 \\
\hline Zona 1 (Puente Piedra, Comas, Carabayllo) & 100 & 0.5 & 13.7 & 46.6 & 26.4 & 12.8 \\
\hline Zona 2 (Independencia, Los Olivos, San Martin de Porras) & 100 & 1.9 & 22.8 & 52.2 & 18.6 & 4.5 \\
\hline Zona 3 (San Juan de Lurigancho) & 100 & 1.1 & 9.6 & 43.4 & 36.6 & 9.3 \\
\hline Zona 4 (Cercado, Rimac, Brena, La Victoria) & 100 & 2.0 & 21.8 & 45.4 & 25.7 & 5.1 \\
\hline $\begin{array}{l}\text { Zona 5 (Ate, Chaclacayo, Lurigancho, Santa Anita, San Luis, El } \\
\text { Agustino) }\end{array}$ & 100 & 2.2 & 13.0 & 41.7 & 33.6 & 9.5 \\
\hline Zona 6 (Jesús Maria, Lince, Pueblo Libre, Magdalena, San Miguel) & 100 & 22.5 & 46.7 & 23.9 & 5.4 & 1.5 \\
\hline Zona 7 (Miraflores, San Isidro, San Borja, Surco, La Molina) & 100 & 29.4 & 45.1 & 17.6 & 5.6 & 2.3 \\
\hline Zona 8 (Surquillo, Barranco, Chorrilos, San Juan de Mirafores) & 100 & 4.5 & 20.9 & 40.4 & 25.3 & 8.9 \\
\hline Zona 9 (Villa El Salvador, Villa Maria del Triunfo, Lurin, Pachacamác) & 100 & 0.0 & 9.8 & 45.5 & 35.5 & 9.2 \\
\hline Zona 10 (Callao, Bellavista, La Perla, La Punta, Carmen de la Legua, & 100 & 1.6 & 17.3 & 42.8 & 25.9 & 12.4 \\
\hline Ventanilla) & 100 & 0.0 & 10.1 & 48.5 & 26.3 & 15.1 \\
\hline Otros
\end{tabular}

APENI 2015: Data ENAHO 2014

Fuente: Apeim, (2015)

\subsubsection{Análisis del sector}

Para el análisis del sector se utilizará como referencia las 5 fuerzas competitivas del libro

Estrategia Competitiva de Michael Porter: 
- Intensidad de la rivalidad entre los competidores existentes:

En la actualidad las empresas que se disputan el mercado son Compañía Nestlé Costa Rica la cual produce Gerber, Delimex de México la cual fabrica Heinz, Alpina Productos Alimenticios la cual fabrica Alpina y el Grupo Irex el cual fabrica Agú. El producto que se ofrece al ser poco diferenciado en contenido genera que las empresas compitan en precio y mejor ubicación en el punto de venta (hipermercados, supermercados y farmacias) por lo tanto se concluye que la intensidad de la rivalidad entre los competidores existentes es alta.

- Competidores potenciales:

En la actualidad no hay la amenaza de ingreso de nuevos competidores debido a las barreras de entrada como economías de escala que obligan al nuevo competidor producir en grandes volúmenes para distribuir los costos fijos en más productos y así poder obtener una mayor utilidad. Además del capital necesario para poder invertir en infraestructura, compra de materia prima, insumos, maquinaria y personal calificado.

- Productos sustitutos:

Como productos sustitutos se tiene a las compotas caseras, los cereales Nestum y Cerelac los cuales limitan el precio de las compotas a ofrecer y afectan la rentabilidad de las empresas.

- Poder de negociación de los proveedores:

En la actualidad hay muchos proveedores no agrupados de durazno, maca, quinua, kiwicha y cañihua por lo tanto su poder de negociación es bajo. Asimismo no hay la amenaza de una integración hacia adelante lo que ocasionaría se conviertan en futuros competidores.

- Poder de negociación de los consumidores:

Los compradores los cuales son padres del nivel socioeconómico A, B y C cuyo estilo de vida está catalogado como los sofisticados y las modernas y son de la ciudad de Lima no están agrupados por lo tanto tienen poco poder de negociación y no hay la amenaza de una integración hacia atrás lo que ocasionaría se conviertan en futuros competidores. 


\subsubsection{Determinación de la metodología que se empleará en la investigación de mercado}

La metodología a utilizar en la investigación de mercado es un modelo mixto es decir que combina factores cuantitativos y cualitativos. Para poder obtener la demanda del proyecto se realizarán los siguientes pasos:

a) Calcular la demanda histórica proyectada de Perú en Kg del año 2016 al 2021.

b) Determinar qué porcentaje representa la población de la ciudad de Lima con respecto al total del Perú del año 2016 al 2021 y qué porcentaje de la población de la ciudad de Lima pertenece al nivel socioeconómico A, B y C.

c) Determinar qué porcentaje de la población de la ciudad de Lima pertenece a los estilos de vida de los sofisticados y las modernas.

d) Realizar una encuesta a padres y madres de bebés para obtener la intención e intensidad de compra.

e) La multiplicación de todos estos factores permitirá obtener la demanda proyectada para el estudio en $\mathrm{Kg}$ del año 2016 al 2021.

\subsection{Análisis de la demanda}

\subsubsection{Demanda Histórica}

\subsubsection{Importaciones / exportaciones}

El mercado peruano solamente es atendido por las importaciones pues no hay producción nacional de compotas y por lo tanto tampoco exportaciones. Es por ello que basándonos en la ecuación:

$$
\text { Demanda }=\text { Producción }+ \text { importaciones }- \text { exportaciones }
$$

Se deduce que:

$$
\text { Demanda }=\text { Importaciones }
$$

Para ello el dato de la demanda la obtenemos de la siguiente tabla:

Tabla 2.1

Ventas de alimento preparado para bebés en Perú en toneladas

\begin{tabular}{|c|c|c|c|c|c|c|c|c|c|}
\hline \multicolumn{1}{|c|}{} & \multicolumn{8}{|c|}{ Sales of Baby Food by Cate gory: Volume 2007 - 2015 in tonnes } \\
\hline Category & $\mathbf{2 0 0 7}$ & $\mathbf{2 0 0 8}$ & $\mathbf{2 0 0 9}$ & $\mathbf{2 0 1 0}$ & $\mathbf{2 0 1 1}$ & $\mathbf{2 0 1 2}$ & $\mathbf{2 0 1 3}$ & $\mathbf{2 0 1 4}$ & $\mathbf{2 0 1 5}$ \\
\hline Prepared Baby Food & 308,00 & 441,20 & 620,60 & 814,10 & $1.285,80$ & $1.740,00$ & $2.463,47$ & $3.484,66$ & $4.929,17$ \\
\hline
\end{tabular}

Fuente: Euromonitor, (2015) 
La categoría Prepared Baby food (alimento preparado para bebés) son las compotas por lo tanto las ventas es la cantidad demandada la cual es igual a las importaciones. Entonces con ello se determina las importaciones históricas:

Tabla 2.2

Importaciones históricas de Prepared Baby Food (compotas para bebés) en Perú en Kg

\begin{tabular}{|c|c|}
\hline Año & $\begin{array}{c}\text { Importaciones en kg de } \\
\text { compotas para bebés }\end{array}$ \\
\hline 2007 & 308.000 \\
\hline 2008 & 441.200 \\
\hline 2009 & 620.600 \\
\hline 2010 & 814.100 \\
\hline 2011 & 1.285 .800 \\
\hline 2012 & 1.740 .000 \\
\hline 2013 & 2.463 .468 \\
\hline 2014 & 3.484 .661 \\
\hline 2015 & 4.929 .172 \\
\hline
\end{tabular}

Elaboración propia

\subsubsection{Producción Nacional}

No hay producción nacional de compotas por lo tanto se considera 0 para todos los años.

\subsubsection{Demanda interna aparente (DIA)}

La demanda interna aparente es la siguiente:

Tabla 2.3

Demanda anual de compotas para bebés en Perú en kilogramos

\begin{tabular}{|c|c|c|c|c|}
\hline Año & $\begin{array}{c}\text { Producción } \\
(\mathbf{k g})\end{array}$ & $\begin{array}{c}\text { Importación } \\
(\mathbf{k g})\end{array}$ & $\begin{array}{c}\text { Exportación } \\
(\mathbf{k g})\end{array}$ & $\begin{array}{c}\text { Demanda } \\
(\mathbf{k g})\end{array}$ \\
\hline 2007 & 0 & 308.000 & 0 & 308.000 \\
\hline 2008 & 0 & 441.200 & 0 & 441.200 \\
\hline 2009 & 0 & 620.600 & 0 & 620.600 \\
\hline 2010 & 0 & 814.100 & 0 & 814.100 \\
\hline 2011 & 0 & 1.285 .800 & 0 & 1.285 .800 \\
\hline 2012 & 0 & 1.740 .000 & 0 & 1.740 .000 \\
\hline 2013 & 0 & 2.463 .468 & 0 & 2.463 .468 \\
\hline 2014 & 0 & 3.484 .661 & 0 & 3.484 .661 \\
\hline 2015 & 0 & 4.929 .172 & 0 & 4.929 .172 \\
\hline
\end{tabular}

Elaboración propia 


\subsubsection{Demanda Potencial}

\subsubsection{Patrones de consumo}

Las compotas se utilizan como alimento complementario para los bebés a partir de los 6 meses y puede consumirse en el desayuno, almuerzo, cena y entre comidas.

\subsubsection{Determinación de la demanda potencial}

Para el cálculo de la demanda potencial se comparará el consumo per cápita de 5 realidades similares las cuales son Perú, Chile, Brasil, Colombia y Ecuador eligiéndose el mayor consumo per cápita para el cálculo de la demanda potencial.

- Perú:

Para hallar el cálculo de consumo per cápita en Perú se considerará que el peso de las compotas es 113 gramos y adicionalmente se utilizará las siguientes tablas:

Figura 2.4

Población de Perú

$\begin{array}{lcccccc} & 2010 & 2011 & 2012 & 2013 & 2014 & 2015 \\ \text { PERU } & 29,461,933 & 29,797,694 & 30,135,875 & 30,475,144 & 30,814,175 & 31,151,643\end{array}$

Fuente: INEI, (2015)

Tabla 2.4

Ventas de alimento preparado para bebés en Perú en toneladas

\begin{tabular}{|c|r|r|r|r|r|c|c|c|c|}
\cline { 2 - 10 } \multicolumn{1}{c|}{} & \multicolumn{8}{c|}{ Sales of Baby Food by Category: Volume 2007 - 2015 in tonnes } \\
\hline Category & $\mathbf{2 0 0 7}$ & $\mathbf{2 0 0 8}$ & $\mathbf{2 0 0 9}$ & $\mathbf{2 0 1 0}$ & $\mathbf{2 0 1 1}$ & $\mathbf{2 0 1 2}$ & $\mathbf{2 0 1 3}$ & $\mathbf{2 0 1 4}$ & $\mathbf{2 0 1 5}$ \\
\hline Prepared Baby Food & 308,00 & 441,20 & 620,60 & 814,10 & $1.285,80$ & $1.740,00$ & $2.463,47$ & $3.484,66$ & $4.929,17$ \\
\hline
\end{tabular}

Fuente: Euromonitor, (2015)

Tabla 2.5

Cálculo del consumo per cápita en Perú

\begin{tabular}{|c|c|c|c|c|c|c|c|c|c|}
\hline & \multicolumn{9}{|c|}{ Año } \\
\hline & 2007 & 2008 & 2009 & 2010 & 2011 & 2012 & 2013 & 2014 & 2015 \\
\hline $\begin{array}{l}\text { Ventas de alimento preparado } \\
\text { para bebés en toneladas }\end{array}$ & 308 & 441 & 621 & 814 & 1.286 & 1.740 & 2.463 & 3.485 & 4.929 \\
\hline $\begin{array}{l}\text { Ventas de alimento preparado } \\
\text { para bebés en kg }\end{array}$ & 308.000 & 441.200 & 620.600 & 814.100 & 1.285 .800 & 1.740 .000 & 2.463 .468 & 3.484 .661 & 4.929.172 \\
\hline Ventas en cantidad de & 2.725 .664 & 3.904 .425 & 5.492 .035 & 7.204 .425 & 11.378 .761 & 15.398 .230 & 21.800 .604 & 30.837 .704 & 43.620 .991 \\
\hline Población & 28.481 .901 & 28.807 .034 & 29.132 .013 & 29.461 .933 & 29.797 .694 & 30.135 .875 & 30.475 .144 & 30.814 .175 & 31.151 .643 \\
\hline $\begin{array}{l}\text { Consumo per cápita en Perú en } \\
\text { Compotas/persona }\end{array}$ & 0,10 & 0,14 & 0,19 & 0,24 & 0,38 & 0,51 & 0,72 & 1,00 & 1,40 \\
\hline
\end{tabular}

Elaboración propia 
- Chile:

Para hallar el cálculo de consumo per cápita en Chile se considerará que el peso de las compotas es 113 gramos y adicionalmente se utilizará las siguientes tablas:

Figura 2.5

Datos de Chile

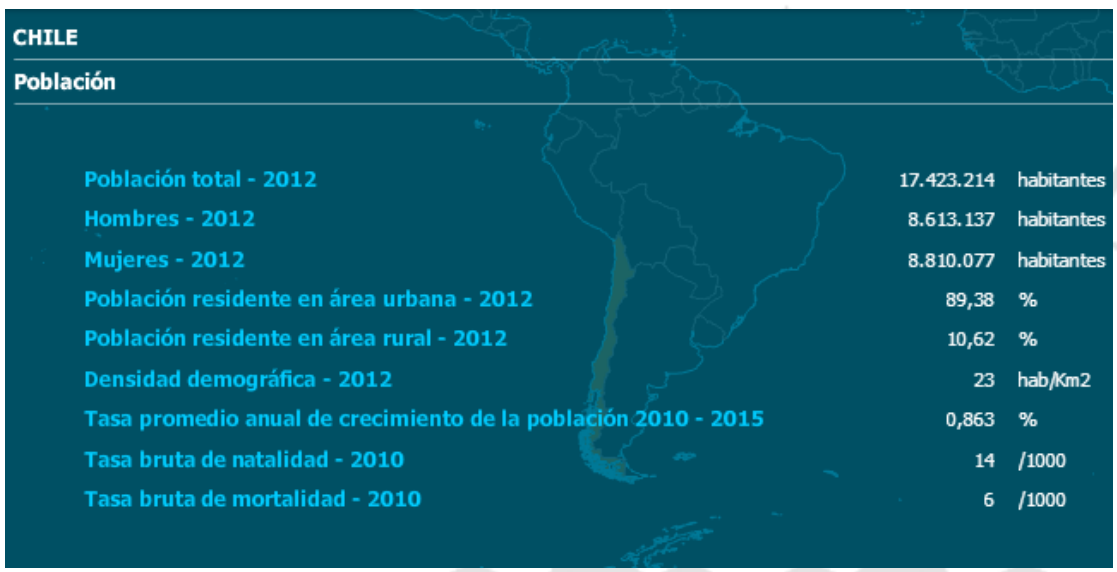

Fuente: United Nations Statistics Division, (2013)

Tabla 2.6

Ventas de alimento preparado para bebés en Chile en toneladas

\begin{tabular}{|c|c|c|c|c|c|c|c|c|c|}
\cline { 2 - 10 } \multicolumn{1}{c|}{} & \multicolumn{8}{c|}{ Sales of Baby Food by Category: Volume 2007 - 2015 in tonnes } \\
\hline Category & $\mathbf{2 0 0 7}$ & $\mathbf{2 0 0 8}$ & $\mathbf{2 0 0 9}$ & $\mathbf{2 0 1 0}$ & $\mathbf{2 0 1 1}$ & $\mathbf{2 0 1 2}$ & $\mathbf{2 0 1 3}$ & $\mathbf{2 0 1 4}$ & $\mathbf{2 0 1 5}$ \\
\hline Prepared Baby Food & $1.461,00$ & $1.506,30$ & $1.528,90$ & $1.573,30$ & $1.626,80$ & $1.660,00$ & $1.696,70$ & $1.735,70$ & $1.779,50$ \\
\hline
\end{tabular}

Fuente: Euromonitor, (2015)

Tabla 2.7

Cálculo del consumo per cápita en Chile

\begin{tabular}{|l|c|c|c|c|c|c|c|c|c|}
\hline & \multicolumn{9}{|c|}{ Año } \\
\cline { 2 - 10 } & $\mathbf{2 0 0 7}$ & $\mathbf{2 0 0 8}$ & $\mathbf{2 0 0 9}$ & $\mathbf{2 0 1 0}$ & $\mathbf{2 0 1 1}$ & $\mathbf{2 0 1 2}$ & $\mathbf{2 0 1 3}$ & $\mathbf{2 0 1 4}$ & $\mathbf{2 0 1 5}$ \\
\hline $\begin{array}{l}\text { Ventas de alimento preparado } \\
\text { para bebés en toneladas }\end{array}$ & 1.461 & 1.506 & 1.529 & 1.573 & 1.627 & 1.660 & 1.697 & 1.736 & 1.780 \\
\hline $\begin{array}{l}\text { Ventas de alimento preparado } \\
\text { para bebés en kg }\end{array}$ & 1.461 .000 & 1.506 .300 & 1.528 .900 & 1.573 .300 & 1.626 .800 & 1.660 .000 & 1.696 .700 & 1.735 .700 & 1.779 .500 \\
\hline Ventas en cantidad de & 12.929 .204 & 13.330 .088 & 13.530 .088 & 13.923 .009 & 14.396 .460 & 14.690 .265 & 15.015 .044 & 15.360 .177 & 15.747 .788 \\
\hline Población & 16.690 .481 & 16.834 .520 & 16.979 .802 & 17.126 .338 & 17.274 .138 & 17.423 .214 & 17.573 .576 & 17.725 .236 & 17.878 .205 \\
\hline $\begin{array}{l}\text { Consumo per cápita en Chile } \\
\text { en Compotas/persona }\end{array}$ & 0,77 & 0,79 & 0,80 & 0,81 & 0,83 & 0,84 & 0,85 & 0,87 & 0,88 \\
\hline
\end{tabular}

Elaboración propia

- Brasil 
Para hallar el cálculo de consumo per cápita en Brasil se considerará que el peso de las compotas es 113 gramos y adicionalmente se utilizará las siguientes tablas:

Figura 2.6

Datos de Brasil

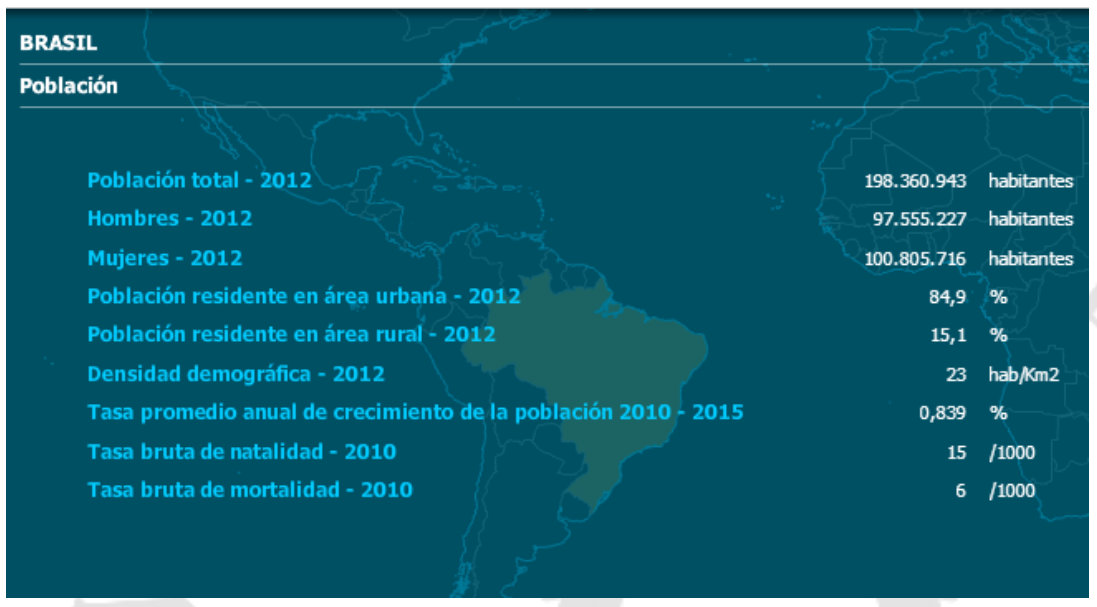

Fuente: United Nations Statistics Division, (2013)

Tabla 2.8

Ventas de alimento preparado para bebés en Brasil en miles de toneladas

\begin{tabular}{|c|c|c|c|c|c|c|c|c|c|}
\cline { 2 - 10 } \multicolumn{1}{c|}{} & \multicolumn{1}{c|}{ Sales of Baby Food by Category: Volume 2007 - 2015 in thousands of tonnes } \\
\hline Category & 2007 & $\mathbf{2 0 0 8}$ & $\mathbf{2 0 0 9}$ & $\mathbf{2 0 1 0}$ & $\mathbf{2 0 1 1}$ & $\mathbf{2 0 1 2}$ & $\mathbf{2 0 1 3}$ & $\mathbf{2 0 1 4}$ & $\mathbf{2 0 1 5}$ \\
\hline Prepared Baby Food & 8,00 & 8,20 & 8,70 & 9,40 & 9,90 & 10,40 & 10,90 & 11,40 & 11,91 \\
\hline
\end{tabular}

Fuente: Euromonitor, (2015)

Tabla 2.9

Cálculo del consumo per cápita en Brasil

\begin{tabular}{|c|c|c|c|c|c|c|c|c|c|}
\hline & \multicolumn{9}{|c|}{ Año } \\
\hline & 2007 & 2008 & 2009 & 2010 & 2011 & 2012 & 2013 & 2014 & 2015 \\
\hline $\begin{array}{l}\text { Ventas de alimento preparado } \\
\text { para bebés en toneladas }\end{array}$ & 8.000 & 8.200 & 8.700 & 9.400 & 9.900 & 10.400 & 10.900 & 11.400 & 11.911 \\
\hline $\begin{array}{l}\text { Ventas de alimento preparado } \\
\text { para bebés en } \mathrm{kg}\end{array}$ & 8.000 .000 & 8.200 .000 & 8.700 .000 & 9.400 .000 & 9.900 .000 & 10.400 .000 & 10.900 .000 & 11.400 .000 & 11.910 .714 \\
\hline Ventas en cantidad de & 70.796 .460 & 72.566 .372 & 76.991 .150 & 83.185 .841 & 87.610 .619 & 92.035 .398 & 96.460 .177 & 100.884 .956 & 105.404 .551 \\
\hline Población & 190.245 .115 & 191.841.271 & 193.450 .819 & 195.073 .872 & 196.710 .542 & 198.360 .943 & 200.025 .191 & 201.703 .403 & 203.395 .694 \\
\hline $\begin{array}{l}\text { Consumo per cápita en Brasil } \\
\text { en Compotas/persona }\end{array}$ & 0,37 & 0,38 & 0,40 & 0,43 & 0,45 & 0,46 & 0,48 & 0,50 & 0,52 \\
\hline
\end{tabular}

Elaboración propia

- Colombia 
Para hallar el cálculo de consumo per cápita en Colombia se considerará que el peso de las compotas es 113 gramos y adicionalmente se utilizará las siguientes tablas:

Tabla 2.10

Población de Colombia del 2007 al 2015

\begin{tabular}{|l|c|c|c|c|c|c|c|c|c|}
\hline & \multicolumn{10}{|c|}{ Año } \\
\cline { 2 - 10 } & 2007 & 2008 & 2009 & 2010 & $\mathbf{2 0 1 1}$ & $\mathbf{2 0 1 2}$ & $\mathbf{2 0 1 3}$ & $\mathbf{2 0 1 4}$ & $\mathbf{2 0 1 5}$ \\
\hline Población & 43.926 .929 & 44.451 .147 & 44.978 .832 & 45.509 .584 & 46.044 .601 & 46.581 .823 & 47.121 .089 & 47.661 .787 & 48.203 .405 \\
\hline
\end{tabular}

Fuente: Departamento administrativo nacional de estadística de Colombia, (2015)

Tabla 2.11

Ventas de alimento preparado para bebés en Colombia en toneladas

\begin{tabular}{|l|c|c|c|c|c|c|c|c|c|}
\hline & \multicolumn{9}{|c|}{ Año } \\
\cline { 2 - 9 } & $\mathbf{2 0 0 7}$ & $\mathbf{2 0 0 8}$ & $\mathbf{2 0 0 9}$ & $\mathbf{2 0 1 0}$ & $\mathbf{2 0 1 1}$ & $\mathbf{2 0 1 2}$ & $\mathbf{2 0 1 3}$ & $\mathbf{2 0 1 4}$ & $\mathbf{2 0 1 5}$ \\
\hline $\begin{array}{l}\text { Ventas de alimento preparado } \\
\text { para bebés en toneladas }\end{array}$ & $4.547,71$ & $4.704,46$ & $4.861,13$ & $4.862,40$ & $5.169,30$ & $5.509,90$ & $5.620,10$ & $5.636,50$ & $5.654,40$ \\
\hline
\end{tabular}

Fuente: Euromonitor, (2015)

Tabla 2.12

Cálculo del consumo per cápita en Colombia

\begin{tabular}{|l|c|c|c|c|c|c|c|c|c|}
\hline \multicolumn{1}{|c|}{} & \multicolumn{7}{|c|}{ Año } \\
\cline { 2 - 10 } & $\mathbf{2 0 0 7}$ & $\mathbf{2 0 0 8}$ & $\mathbf{2 0 0 9}$ & $\mathbf{2 0 1 0}$ & $\mathbf{2 0 1 1}$ & $\mathbf{2 0 1 2}$ & $\mathbf{2 0 1 3}$ & $\mathbf{2 0 1 4}$ & $\mathbf{2 0 1 5}$ \\
\hline $\begin{array}{l}\text { Ventas de alimento preparado } \\
\text { para bebés en toneladas }\end{array}$ & 4.548 & 4.704 & 4.861 & 4.862 & 5.169 & 5.510 & 5.620 & 5.637 & 5.654 \\
\hline $\begin{array}{l}\text { Ventas de alimento preparado } \\
\text { para bebés en kg }\end{array}$ & 4.547 .706 & 4.704 .459 & 4.861 .133 & 4.862 .400 & 5.169 .300 & 5.509 .900 & 5.620 .100 & 5.636 .500 & 5.654 .400 \\
\hline $\begin{array}{l}\text { Ventas en cantidad de } \\
\text { compotas }\end{array}$ & 40.245 .187 & 41.632 .377 & 43.018 .876 & 43.030 .088 & 45.746 .018 & 48.760 .177 & 49.735 .398 & 49.880 .531 & 50.038 .938 \\
\hline Población & 43.926 .929 & 44.451 .147 & 44.978 .832 & 45.509 .584 & 46.044 .601 & 46.581 .823 & 47.121 .089 & 47.661 .787 & 48.203 .405 \\
\hline $\begin{array}{l}\text { Consumo per cápita en } \\
\text { Colombia en } \\
\text { Compotas/persona }\end{array}$ & 0,92 & 0,94 & 0,96 & 0,95 & 0,99 & 1,05 & 1,06 & 1,05 & 1,04 \\
\hline
\end{tabular}

Elaboración propia

- Ecuador

Para hallar el cálculo de consumo per cápita en Ecuador se considerará que el peso de las compotas es 113 gramos y adicionalmente se utilizará las siguientes tablas:

Tabla 2.13

Población de Ecuador del 2007 al 2015

\begin{tabular}{|l|c|c|c|c|c|c|c|c|c|}
\hline & \multicolumn{2}{|c|}{ Año } \\
\cline { 2 - 10 } & $\mathbf{2 0 0 7}$ & $\mathbf{2 0 0 8}$ & $\mathbf{2 0 0 9}$ & $\mathbf{2 0 1 0}$ & $\mathbf{2 0 1 1}$ & $\mathbf{2 0 1 2}$ & $\mathbf{2 0 1 3}$ & $\mathbf{2 0 1 4}$ & $\mathbf{2 0 1 5}$ \\
\hline Población & 14.215 .000 & 14.473 .000 & 14.738 .000 & 15.012 .228 & 15.266 .431 & 15.520 .973 & 15.774 .749 & 16.027 .466 & 16.278 .844 \\
\hline
\end{tabular}

Fuente: Instituto nacional de estadística y censos de Ecuador, (2015) 
Tabla 2.14

Ventas de alimento preparado para bebés en Ecuador en toneladas

\begin{tabular}{|l|c|c|c|c|c|c|c|c|c|}
\hline & \multicolumn{9}{|c|}{ Año } \\
\cline { 2 - 9 } & $\mathbf{2 0 0 7}$ & $\mathbf{2 0 0 8}$ & $\mathbf{2 0 0 9}$ & $\mathbf{2 0 1 0}$ & $\mathbf{2 0 1 1}$ & $\mathbf{2 0 1 2}$ & $\mathbf{2 0 1 3}$ & $\mathbf{2 0 1 4}$ & $\mathbf{2 0 1 5}$ \\
\hline $\begin{array}{l}\text { Ventas de alimento preparado } \\
\text { para bebés en toneladas }\end{array}$ & 418,98 & 584,02 & 748,98 & 859,90 & $1.093,10$ & $1.291,30$ & $1.454,70$ & $1.547,40$ & $1.707,00$ \\
\hline
\end{tabular}

Fuente: Euromonitor, (2015)

Tabla 2.15

Cálculo del consumo per cápita en Ecuador

\begin{tabular}{|l|c|c|c|c|c|c|c|c|c|}
\hline & \multicolumn{7}{|c|}{ Año } \\
\cline { 2 - 10 } & $\mathbf{2 0 0 7}$ & $\mathbf{2 0 0 8}$ & $\mathbf{2 0 0 9}$ & $\mathbf{2 0 1 0}$ & $\mathbf{2 0 1 1}$ & $\mathbf{2 0 1 2}$ & $\mathbf{2 0 1 3}$ & $\mathbf{2 0 1 4}$ & $\mathbf{2 0 1 5}$ \\
\hline $\begin{array}{l}\text { Ventas de alimento preparado } \\
\text { para bebés en toneladas }\end{array}$ & 419 & 584 & 749 & 860 & 1.093 & 1.291 & 1.455 & 1.547 & 1.707 \\
\hline $\begin{array}{l}\text { Ventas de alimento preparado } \\
\text { para bebés en kg }\end{array}$ & 418.980 & 584.020 & 748.978 & 859.900 & 1.093 .100 & 1.291 .300 & 1.454 .700 & 1.547 .400 & 1.707 .000 \\
\hline Ventas en cantidad de & 3.707 .788 & 5.168 .322 & 6.628 .128 & 7.609 .735 & 9.673 .451 & 11.427 .434 & 12.873 .451 & 13.693 .805 & 15.106 .195 \\
\hline Población & 14.215 .000 & 14.473 .000 & 14.738 .000 & 15.012 .228 & 15.266 .431 & 15.520 .973 & 15.774 .749 & 16.027 .466 & 16.278 .844 \\
\hline $\begin{array}{l}\text { Consumo per cápita en } \\
\text { Ecuador en Compotas/persona }\end{array}$ & 0,26 & 0,36 & 0,45 & 0,51 & 0,63 & 0,74 & 0,82 & 0,85 & 0,93 \\
\hline
\end{tabular}

Elaboración propia

Por lo tanto la evolución del consumo per cápita es de la siguiente forma:

Figura 2.7

Evolución del consumo per cápita de Perú, Chile, Brasil, Colombia y Ecuador en compotas por persona

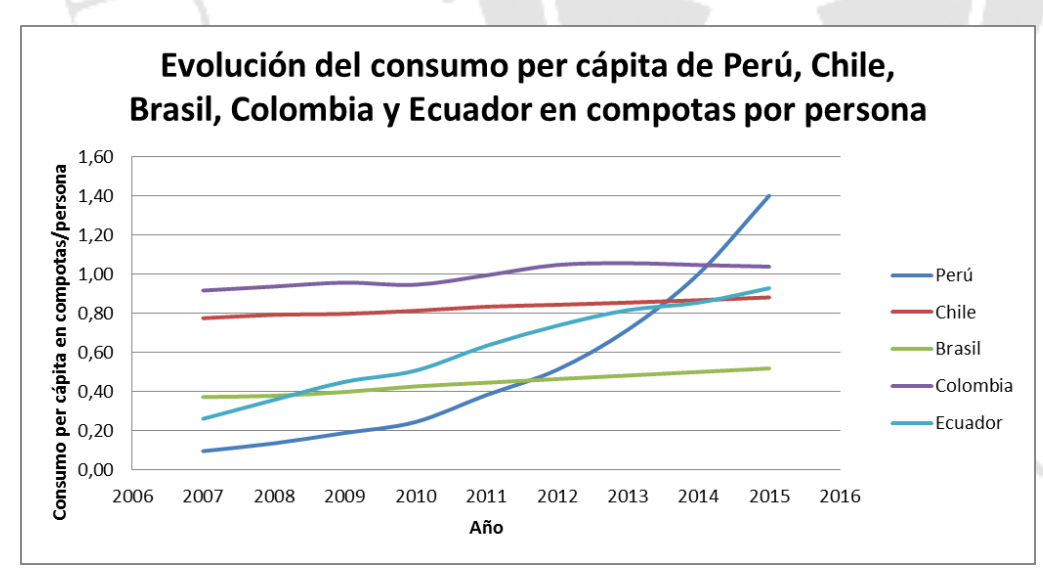

Elaboración propia

Del gráfico se concluye que el consumo per cápita de Perú sigue la tendencia a crecer además que de las cinco realidades similares comparadas, Perú es el país con mayor consumo per cápita y por lo tanto esto determina su demanda potencial la cual se obtiene de la siguiente forma: 
Tabla 2.16

Cálculo de la demanda potencial de Perú en compotas

\begin{tabular}{|c|c|c|c|}
\hline Año & $\begin{array}{c}\text { Consumo per cápita } \\
\text { en Perú en } \\
\text { Compotas/persona }\end{array}$ & $\begin{array}{c}\text { Población } \\
\text { de Perú }\end{array}$ & $\begin{array}{c}\text { Demanda } \\
\text { potencial de } \\
\text { Perú en } \\
\text { compotas }\end{array}$ \\
\hline 2007 & 0,10 & 28.481 .901 & 2.725 .664 \\
\hline 2008 & 0,14 & 28.807 .034 & 3.904 .425 \\
\hline 2009 & 0,19 & 29.132 .013 & 5.492 .035 \\
\hline 2010 & 0,24 & 29.461 .933 & 7.204 .425 \\
\hline 2011 & 0,38 & 29.797 .694 & 11.378 .761 \\
\hline 2012 & 0,51 & 30.135 .875 & 15.398 .230 \\
\hline 2013 & 0,72 & 30.475 .144 & 21.800 .604 \\
\hline 2014 & 1,00 & 30.814 .175 & 30.837 .704 \\
\hline 2015 & 1,40 & 31.151 .643 & 43.620 .991 \\
\hline
\end{tabular}

Elaboración propia

Luego proyectamos la demanda potencial de Perú en compotas

$$
\begin{gathered}
\mathrm{Y}=1.14470364739 \mathrm{E}-181 . \mathrm{X}^{57.0120367564} \\
\quad \text { Correlation: } 0.996779897237 \\
\text { Covariance: } 4.94150226994 \mathrm{E}-5
\end{gathered}
$$

Tabla 2.17

Demanda potencial de Perú del 2016 al 2021 en compotas

\begin{tabular}{|c|c|}
\hline Año & $\begin{array}{c}\text { Demanda potencial de } \\
\text { Perú en compotas }\end{array}$ \\
\hline 2016 & 61.703 .390 \\
\hline 2017 & 87.281 .564 \\
\hline 2018 & 123.462 .770 \\
\hline 2019 & 174.642 .329 \\
\hline 2020 & 247.037 .572 \\
\hline 2021 & 349.443 .131 \\
\hline
\end{tabular}

Elaboración propia

\subsubsection{Proyección de la demanda y metodología de análisis}

Para la proyección de la demanda se utilizará una regresión del tipo exponencial.

Tabla 2.18

Demanda histórica de compotas para bebés en Perú

\begin{tabular}{|c|c|}
\hline Año & $\begin{array}{c}\text { Cantidad de compotas a } \\
\text { vender en } \mathbf{~ k g}\end{array}$ \\
\hline 2007 & 308.000 \\
\hline 2008 & 441.200 \\
\hline 2009 & 620.600 \\
\hline 2010 & 814.100 \\
\hline 2011 & 1.285 .800 \\
\hline 2012 & 1.740 .000 \\
\hline
\end{tabular}

Elaboración propia 


$$
Y=1,60907946652 \mathrm{E}-297 \cdot \mathrm{e}^{0,346800393021 . \mathrm{x}}
$$

Correlation: 0,998428732854

Covariance: 1,21380137557

Con los cálculos anteriores proyectamos la demanda:

Tabla 2.19

Demanda proyectada de compotas para bebés en Perú

\begin{tabular}{|c|c|}
\hline Año & $\begin{array}{c}\text { Cantidad de compotas } \\
\text { a vender en } \mathbf{~} \mathbf{g}\end{array}$ \\
\hline 2016 & $6.972 .483,04$ \\
\hline 2017 & $9.862 .816,74$ \\
\hline 2018 & $13.951 .293,03$ \\
\hline 2019 & $19.734 .583,17$ \\
\hline 2020 & $27.915 .245,70$ \\
\hline 2021 & $39.487 .073,82$ \\
\hline
\end{tabular}

Elaboración propia

\subsubsection{Consideraciones sobre la vida útil del proyecto}

De acuerdo a los organismos internacionales como el Banco Mundial y el Fondo Monetario Internacional se recomienda que el horizonte de vida de un proyecto sea máximo 7 años debido a la volatilidad en los mercados locales y mundiales. Es por ello que para el estudio de pre -factibilidad para la instalación de una planta productora de compotas para bebés a partir de durazno enriquecido con maca, quinua, kiwicha y cañihua se consideró un horizonte de vida de 6 años. Asimismo la compota para bebés dentro de su ciclo de vida se encuentra en una etapa de crecimiento.

\subsection{Análisis de la oferta}

\subsubsection{Empresas productoras, importadoras y comercializadoras}

Las empresas que producen las compotas para bebés que se importan al país son: Compañía Nestlé Costa Rica S.A. la cual fabrica Gerber, Delimex de México la cual fabrica Heinz, Alpina Productos Alimenticios S.A. la cual fabrica Alpina y el Grupo Irex el cual fabrica Agú.

Adicionalmente Gerber es importado por Nestlé Marcas Perú SAC, Heinz por G.W.Yichang \& CIA SA, Alpina por Alpina Perú S.A.C y Agú por Química Suiza SA. 


\subsubsection{Análisis de los competidores}

Actualmente la participación de cada marca de alimento para bebés es la siguiente:

Figura 2.8

Participación de mercado de las marcas de alimento para bebés

\begin{tabular}{|c|c|c|c|c|c|}
\hline $\begin{array}{l}\text { S retal value isp } \\
\text { Brand }\end{array}$ & Company & 2012 & 2013 & 2014 & 2015 \\
\hline Enfagrow & $\begin{array}{l}\text { Mead Johnson Nutrition } \\
\text { Peru SRL. }\end{array}$ & 26.6 & 25.7 & 25.4 & 25.8 \\
\hline Enfamat & $\begin{array}{l}\text { Mead Johnson Nutrition } \\
\text { Peru SRL. }\end{array}$ & 13.4 & 13.6 & 13.8 & 13.9 \\
\hline Pediasure & Abbott Laboratonos SA & 6.8 & 7.6 & 8.0 & 8.7 \\
\hline Babylac & Eckerd Perù SA & 6.5 & 79 & 83 & 84 \\
\hline Nan & Nestle Perù SA & 7.8 & 7.3 & 72 & 7.3 \\
\hline Nido & Nestle Perú SA & 62 & 6.2 & 6.5 & 70 \\
\hline Heinz & Molitalisa SA & 21 & 23 & 22 & 22 \\
\hline Gain & Abbott Laboratorios SA & 1.2 & 1.8 & 19 & 1.9 \\
\hline Simtac & Abbott Laboratorios SA & 2.8 & 1.8 & 1.8 & 1.8 \\
\hline s. 26 & Ptaer Perú SA & 13 & 1.5 & 1.6 & 1.6 \\
\hline Blema & $\begin{array}{l}\text { Distnbuidora } \\
\text { Continental } 6 \text { SA }\end{array}$ & 1.4 & 1.2 & 12 & 12 \\
\hline Formulac & Albis SA & 09 & 1.0 & 1.0 & 1.1 \\
\hline Lactokods & $\begin{array}{l}\text { Botica Tomes de } \\
\text { Limatambo SAC }\end{array}$ & 0.9 & 0.6 & 0.6 & 0.7 \\
\hline Promil & Pezer Perú SA & 1.0 & 0.8 & 0.8 & 0.7 \\
\hline Nestum & Nestle Penù SA & 0.7 & 0.6 & 0.6 & 0.6 \\
\hline Compota Ago & Quimica suka SA & 0.4 & 0.4 & 0.4 & 0.4 \\
\hline isomit & Laboratonos Wyeth SA & 0.5 & 0.4 & 0.4 & 0.4 \\
\hline Nutramigen & $\begin{array}{l}\text { Mead Johnson Nutrition } \\
\text { Peru SRL. }\end{array}$ & 0.3 & 0.3 & 0.3 & 0.4 \\
\hline Nidina & Nestlé Penù SA & 0.3 & 0.3 & 0.3 & 0.3 \\
\hline Ceretac & Nestle Perú sA & 0.3 & 0.3 & 0.3 & 0.3 \\
\hline Nutribon & int Peru SAC & 0.0 & 0.2 & 0.2 & 0.2 \\
\hline Gertser Paso 2 & Nestle Pera SA & 0.5 & 0.4 & 0.3 & 0.0 \\
\hline Compoca Apina Baty & Perufarma SA & 0.2 & 0.0 & 0.0 & 0.0 \\
\hline Belacta & Orogueria La Victoria SA & 0.3 & 0.2 & 0.2 & . \\
\hline Formance & Abbott Laboratorios SA & - & - & . & . \\
\hline Enfagrow & $\begin{array}{l}\text { Bristol-Myers Squitib } \\
\text { Perú SA }\end{array}$ & $=$ & - & * & - \\
\hline Entarnat & $\begin{array}{l}\text { Bristol-Myers Squitb } \\
\text { Peru SA }\end{array}$ & - & - & - & - \\
\hline Nutramigen & $\begin{array}{l}\text { Bristol-Myers Squibb } \\
\text { Perú SA }\end{array}$ & - & * & - & = \\
\hline Bebelac & Ints Peru SAC & $=$ & . & . & $=$ \\
\hline Progress Gold & Laboratorios Wyeth SA & . & . & . & . \\
\hline Others & & 17.8 & 17.6 & 16.9 & 14.9 \\
\hline Total & & 1000 & 100.0 & 1000 & 100.0 \\
\hline
\end{tabular}

Fuente: Euromonitor, (2015)

Como se puede apreciar las marcas Heinz, Gerber Paso 2, Compota Agú y Compota Alpina Baby son compotas para bebés las cuales tienen en total el 2,67\% del mercado de alimentos para bebés en el año 2015. El otro 97,33\% es atendido por otros alimentos complementarios para el bebé. 
Figura 2.9

Participación (\%) de las marcas de alimentos para bebés en el año 2015

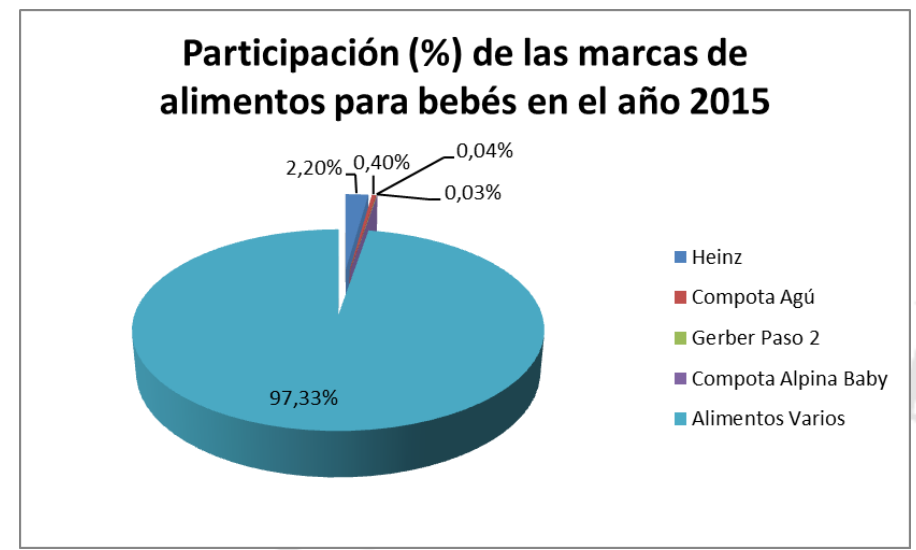

Fuente: Euromonitor, (2015)

Se puede ver que en compotas para bebés Heinz es el de mayor participación de mercado con $2.20 \%$.

\subsection{Determinación de la Demanda para el proyecto}

\subsubsection{Segmentación del mercado}

El mercado de compotas para bebés es atendido por Heinz, Gerber, Alpina y Agú los cuales apuntan al nivel socioeconómico A, B y C ya que el Estado Peruano se encarga de brindar alimentos de forma gratuita a los sectores de menor ingreso como D y E. El ingreso familiar mensual que recibe el NSE A es más de 6000 soles por mes, el NSE B recibe de 2000 a 6000 soles por mes, el NSE C recibe de 840 soles a 2000 soles por mes, el NSE D recibe de 420 a 1200 soles y el NSE E recibe hasta 840 soles por mes. Los consumidores de compotas tienen un nivel medio de lealtad de marca del $46 \%$ por lo tanto las amas de casa están dispuestas a comprar otra marca cuando no encuentran la marca que desean en el punto de venta o hay alguna oferta en otra marca y los niveles socioeconómicos que más consumen son A y B. 
Figura 2.10

Lealtad en la compra de producto

\section{Hogares}

EI nivel de lealtad a la marca para las amas de casa no supera el $56 \%$

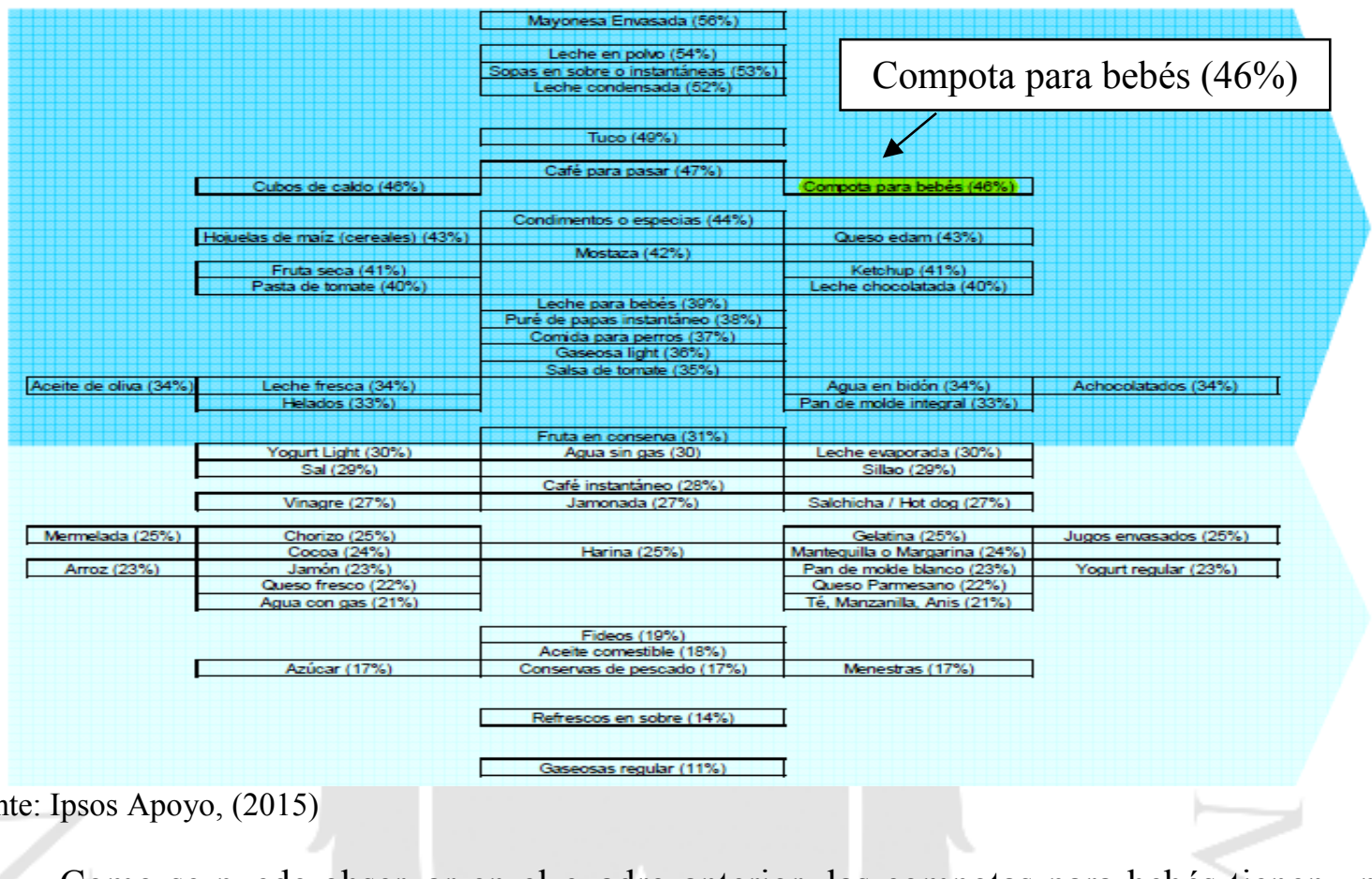

Como se puede observar en el cuadro anterior, las compotas para bebés tienen un nivel de lealtad de marca del $46 \%$.

Figura 2.11

Penetración de productos de consumo familiar PENETRACIÓN DE PRODUCTOS DE CONSUMO FAMILIAR

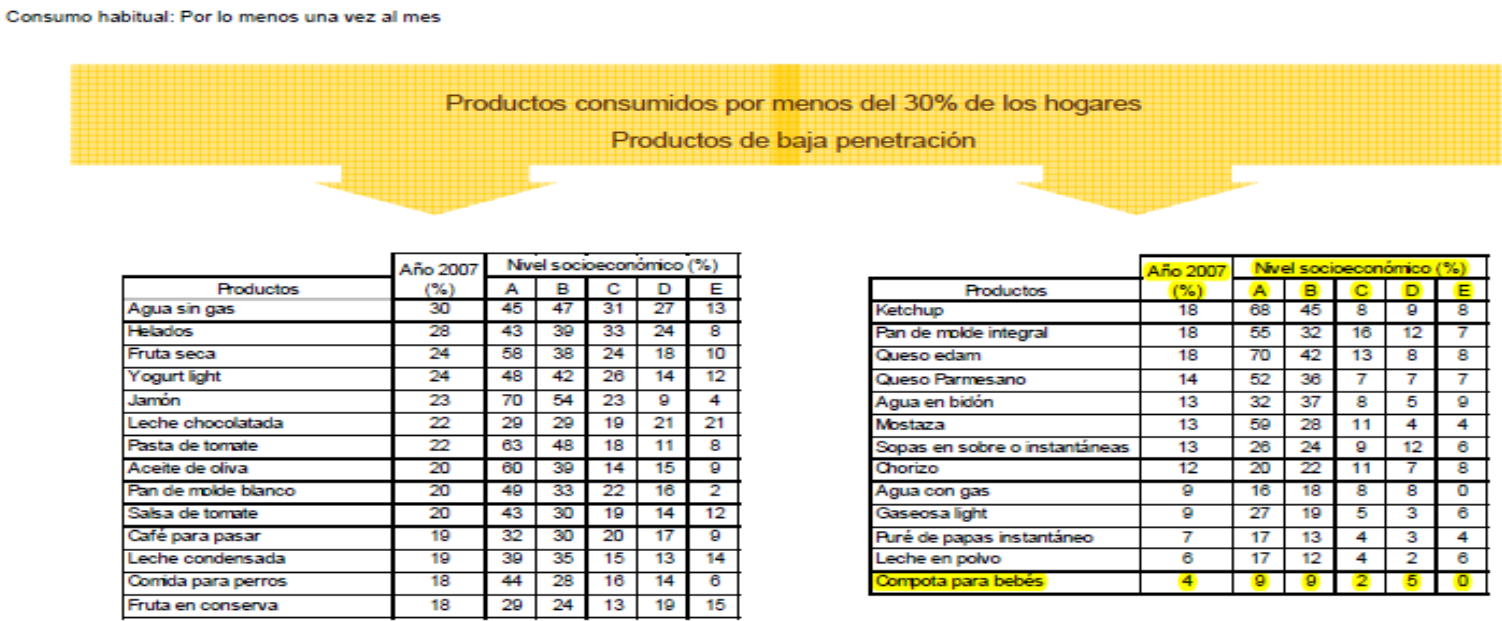

Fuente: Ipsos Apoyo, (2015) 
Del cuadro anterior se observa que en el año 2007 el $4 \%$ de los hogares en el Perú consumió compotas para bebés. Si se clasifica por nivel socioeconómico a la población del Perú su consumo sería el siguiente: el 9\% del NSE A consume compotas para bebés, el 9\% del NSE B consume compotas para bebés, el 2\% del NSE C consume compotas para bebés y el 5\% del NSE D consume compotas para bebés.

\subsubsection{Selección del mercado meta}

Para la selección del mercado meta se utilizará la clasificación del libro de Kotler \& Armstrong la cual consiste en lo siguiente:

\section{a) Segmentación geográfica}

El país al cual está destinado la compota para bebés es Perú, específicamente la ciudad de Lima la cual tiene 9838251 habitantes al año 2015 y cuya densidad es urbana. En el siguiente cuadro se muestra el porcentaje de la población de la ciudad de Lima con respecto a la población del Perú para los años 2016 al 2021.

Tabla 2.20

Segmentación geográfica mercado meta

\begin{tabular}{|c|c|c|c|}
\hline \multicolumn{4}{|c|}{ Segmentación Geográfica } \\
\hline Año & $\begin{array}{c}\text { Población de Perú } \\
\text { (personas) }\end{array}$ & $\begin{array}{c}\text { Población de Lima } \\
\text { (personas) }\end{array}$ & $\begin{array}{c}\text { Población } \\
\text { de Lima (\%) }\end{array}$ \\
\hline 2016 & $31.507 .909,04$ & $9.947 .867,65$ & $31,57 \%$ \\
\hline 2017 & $31.846 .999,63$ & $10.083 .258,24$ & $31,66 \%$ \\
\hline 2018 & $32.185 .922,16$ & $10.218 .648,83$ & $31,75 \%$ \\
\hline 2019 & $32.524 .676,77$ & $10.354 .039,42$ & $31,83 \%$ \\
\hline 2020 & $32.863 .263,65$ & $10.489 .430,01$ & $31,92 \%$ \\
\hline 2021 & $33.201 .682,94$ & $10.624 .820,61$ & $32,00 \%$ \\
\hline
\end{tabular}

Fuente: INEI, (2015)

Para realizar el cálculo se utilizaron dos regresiones. Una para estimar la población del Perú hasta el año 2021 y otra para estimar la población de la región de Lima hasta el año 2021, teniendo como base los datos poblacionales proporcionados por el INEI desde el año 2000 hasta el 2015.

Para la población del Perú se utilizó la siguiente regresión:

$$
\begin{gathered}
\mathrm{Y}=-5171256560,62+683776176,94 * \mathrm{LN}(\mathrm{X}) \\
\text { Correlation }=0,999810824137
\end{gathered}
$$




$$
\text { Covarianza }=3845,86204891
$$

Para la población de Lima se utilizó la siguiente regresión:

$$
\begin{gathered}
\mathrm{Y}=-262999564,162+135390,591176 * \mathrm{X} \\
\text { Correlation }=0,999747143655 \\
\text { Covariance }=3068853.4
\end{gathered}
$$

\section{b) Segmentación demográfica}

La compota a ofrecer está destinada a bebés, menores a los 2 años de edad, de género tanto masculino como femenino cuyos padres perciben un ingreso medio.

\section{c) Segmentación socioeconómica}

Las compotas para bebés están destinadas a los niveles socioeconómicos A, B y C de Lima Metropolitana.

Figura 2.12

Distribución de personas según nivel socioeconómico en Lima Metropolitana

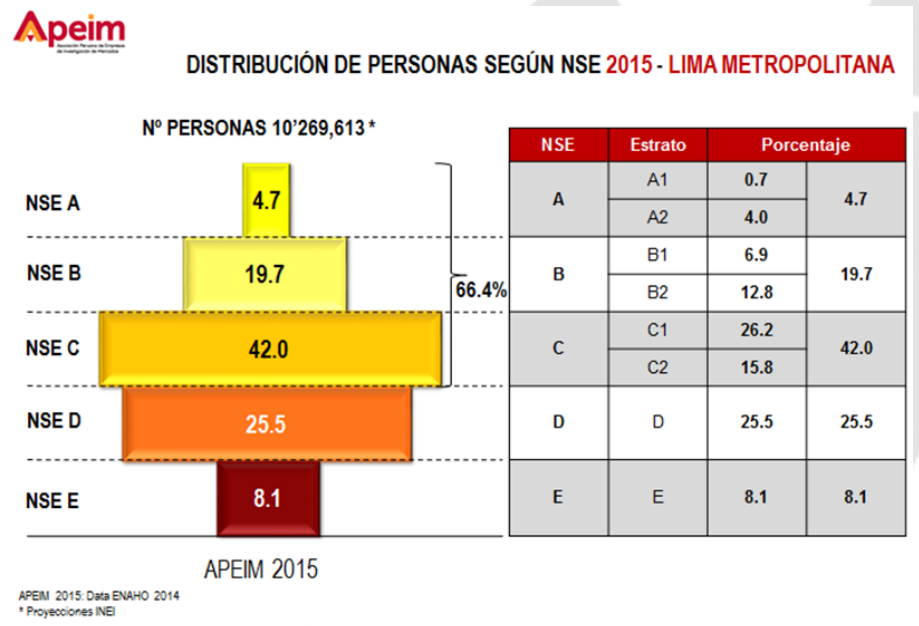

Fuente: Apeim, (2015)

Como se puede apreciar del cuadro anterior, los niveles socioeconómicos A, B y C representan el $66,4 \%$ de la población de Lima metropolitana y los niveles socioeconómicos D y E representan el 33,6\% (los cuales reciben alimento gratuito por parte del estado ya que sus ingresos no alcanzan para la canasta básica de alimentos).

\section{d) Segmentación psicográfica}

Las compotas para bebés están destinadas a padres cuyo estilo de vida sea comprar productos naturales que puedan aportar al desarrollo de sus bebés. De acuerdo a la clasificación de los estilos de vida realizada por la empresa consultora Arellano Marketing, 
se determinó que los padres deben pertenecer al grupo de los sofisticados y las modernas. Los primeros se caracterizan por consumir productos light y las segundas por comprar productos de marca y que les faciliten las tareas del hogar.

Tabla 2.21

Clasificación psicográfica

\begin{tabular}{|l|r|}
\hline $\begin{array}{c}\text { Clasificación psicográfica } \\
\text { de Lima 2015 }\end{array}$ & \multicolumn{1}{|c|}{$\%$} \\
\hline Sofisticados & $8 \%$ \\
\hline Modernas & $27 \%$ \\
\hline Total & $35 \%$ \\
\hline
\end{tabular}

Fuente: Arellano Marketing, (2015)

\subsubsection{Demanda específica para el proyecto}

Para determinar la demanda del proyecto se debe conocer los factores de intensión y de intensidad de compra para los que se realizó una encuesta:

\section{Encuesta:}

Se realizaron 37 encuestas a fin de analizar la posible aceptación de las compotas para bebé a base de durazno enriquecidas con maca, quinua, kiwicha y cañihua, a padres y madres de bebés que pertenecen a los niveles socioeconómicos A, B y C. (Ver anexo 1)

Factor de Intención de Compra: La preguntada realizada en la encuesta fue la siguiente: ¿Compraría una compota para bebé a base de durazno enriquecido con maca, quinua, kiwicha y cañihua? Se obtuvieron los siguientes resultados:

Figura 2.13

Intención de compra obtenida de encuesta

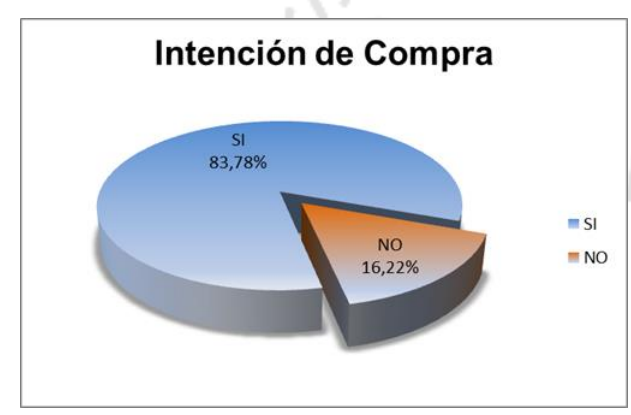

Elaboración propia

Factor Intensidad de compra: La pregunta realizada en la encuesta fue la siguiente: "En una escala del 1 al 10, diga usted, teniendo en cuenta: 1=Muy poco probable que lo 
compre; y $10=$ De todas maneras lo compro, ¿con qué seguridad compraría las compotas para bebés a base de durazno enriquecidas con maca, quinua, kiwicha y cañihua?". Se obtuvo los siguientes resultados:

Tabla 2.22

Resultados de encuesta respecto a la intensidad de compra

\begin{tabular}{|r|r|r|}
\hline Intensidad de compra (i) & $\mathbf{N}^{\circ}$ Veces $(\mathbf{n})$ & $\mathbf{n} \times \mathbf{~}$ \\
\hline 1 & 0 & 0 \\
\hline 2 & 0 & 0 \\
\hline 3 & 0 & 0 \\
\hline 4 & 0 & 0 \\
\hline 5 & 1 & 5 \\
\hline 6 & 3 & 18 \\
\hline 7 & 11 & 77 \\
\hline 8 & 11 & 88 \\
\hline 9 & 5 & 45 \\
\hline 10 & 0 & 0 \\
\hline Total & 31 & 233 \\
\hline
\end{tabular}

Elaboración propia

$$
\text { Porcentaje de intensidad de compra: } \frac{\sum(n * i)}{\sum n} \div 10=\mathbf{7 5}, \mathbf{1 6} \%
$$

Para determinar la demanda del proyecto se tomará la proyección de la demanda del punto 2.2.3 y los datos ya calculados en la selección del mercado meta, que son los siguientes: Población de Lima (\%) del 2016 al 2021, NSE A, B y C: 66,4\%, clasificación psicográfica: $35 \%$, intensión de compra: $83,78 \%$, intensidad de compra: $75,16 \%$.

Tabla 2.23

Demanda para el proyecto

\begin{tabular}{|c|c|c|c|c|c|c|c|}
\hline Año & $\begin{array}{c}\text { Demanda } \\
\text { histórica } \\
\text { proyectada } \\
\text { de Perú (Kg) }\end{array}$ & $\begin{array}{c}\text { Población } \\
\text { de Lima } \\
(\%)\end{array}$ & $\begin{array}{c}\text { NSE } \\
(\mathbf{A} / \mathbf{C} \text { ) }\end{array}$ & $\begin{array}{c}\text { Clasificación } \\
\text { psicográfica } \\
(\%)\end{array}$ & $\begin{array}{c}\text { Intención } \\
\text { de Compra } \\
(\%)\end{array}$ & $\begin{array}{c}\text { Intensidad } \\
\text { de Compra } \\
(\%)\end{array}$ & $\begin{array}{c}\text { Demanda } \\
\text { proyectada } \\
\text { para el } \\
\text { estudio (kg) }\end{array}$ \\
\hline 2016 & 6.972 .483 & $31,60 \%$ & $66,40 \%$ & $35,00 \%$ & $83,78 \%$ & $75,16 \%$ & 322.172 \\
\hline 2017 & 9.862 .817 & $31,70 \%$ & $66,40 \%$ & $35,00 \%$ & $83,78 \%$ & $75,16 \%$ & 457.008 \\
\hline 2018 & 13.951 .293 & $31,70 \%$ & $66,40 \%$ & $35,00 \%$ & $83,78 \%$ & $75,16 \%$ & 648.235 \\
\hline 2019 & 19.734 .583 & $31,80 \%$ & $66,40 \%$ & $35,00 \%$ & $83,78 \%$ & $75,16 \%$ & 919.422 \\
\hline 2020 & 27.915 .246 & $31,90 \%$ & $66,40 \%$ & $35,00 \%$ & $83,78 \%$ & $75,16 \%$ & 1.303 .986 \\
\hline 2021 & 39.487 .074 & $32,00 \%$ & $66,40 \%$ & $35,00 \%$ & $83,78 \%$ & $75,16 \%$ & 1.849 .297 \\
\hline
\end{tabular}

Elaboración propia 
Tabla 2.24

Demanda del proyecto en $\mathrm{kg}$, TM y envases de compota

\begin{tabular}{|c|c|c|c|}
\hline Año & $\begin{array}{c}\text { Demanda } \\
\text { proyectada para } \\
\text { el estudio (kg) }\end{array}$ & $\begin{array}{c}\text { Demanda } \\
\text { proyectada para } \\
\text { el estudio (TM) }\end{array}$ & $\begin{array}{c}\text { Demanda proyectada } \\
\text { para el estudio } \\
\text { (envases de compota) }\end{array}$ \\
\hline 2016 & 322.172 & 322 & 2.851 .082 \\
\hline 2017 & 457.008 & 457 & 4.044 .317 \\
\hline 2018 & 648.235 & 648 & 5.736 .591 \\
\hline 2019 & 919.422 & 919 & 8.136 .482 \\
\hline 2020 & 1.303 .986 & 1.304 & 11.539 .700 \\
\hline 2021 & 1.849 .297 & 1.849 & 16.365 .465 \\
\hline
\end{tabular}

Elaboración propia

\subsection{Definición de la Estrategia de Comercialización}

\subsubsection{Políticas de comercialización y distribución}

a) Política de comercialización

Los clientes tendrán dos modalidades de pago los cuales son:

- Pago al contado: El cliente envía su orden de compra donde se indica la cantidad a demandar, el precio de la compota y el monto total a pagar. Asimismo realiza el abono a la cuenta de la empresa por el monto total, se le da la conformidad y se le envía el producto.

- 50\% al contado y 50\% al crédito con pago a 30 días: Para ingresar a esta modalidad de pago el cliente pasa por una evaluación crediticia donde se mide su capacidad de pago y si tiene bienes por un valor mayor a sus deudas, de ser positiva esta evaluación el cliente ingresa a una base de datos de la empresa y se trabaja de la siguiente forma. El cliente envía su orden de compra donde se indica la cantidad a demandar, el precio de la compota y el monto total a pagar. Asimismo realiza el abono a la cuenta de la empresa por el 50\% del monto total, se le da la conformidad, se le indica la fecha en la cual tiene que realizar el abono del otro $50 \%$ y luego se procede a enviar el producto. Solo se atenderá a clientes que no tengan deudas con la empresa.

b) Política de distribución

Se establecerán alianzas estratégicas con empresas distribuidoras, negociando precios y fijándolos de forma anual. Estas se encargarán de recoger la mercadería en la fábrica y llevarla a los puntos de venta como hipermercados que representan el 14,20\% de las ventas 
de alimentos para bebés, supermercados que representan el 9,80\% de las ventas de alimentos para bebés, bodegas (Independent small grocers) los cuales representan el 1,40\% de las ventas de alimentos para bebés, tiendas de alimentos, quioscos y mercados (Other grocery retailers) que representan el $12,20 \%$ de las ventas de alimentos para bebés y farmacias (Health and Beauty Retailers) que representan el 62,40\% de las ventas de alimentos para bebés.

Figura 2.14

Porcentaje de ventas de los lugares de distribución de alimentos para bebés del año 2009 al 2015

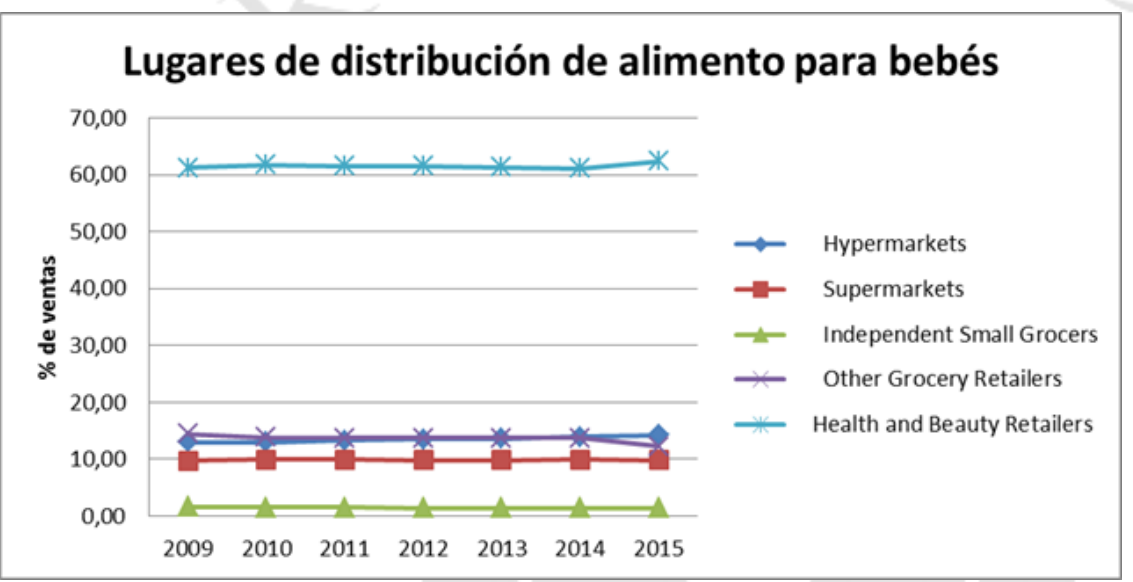

Fuente: Euromonitor, (2015)

\subsubsection{Publicidad y promoción}

Para su explicación se utilizará la mezcla de promoción del libro de Kotler \& Armstrong la cual lo divide en:

- Publicidad: Se pagará transmisiones por radio y televisión, medios impresos como la revista Somos, internet, anuncios en exteriores, publicidad interna dentro de hipermercados, supermercados y farmacias para exhibir correctamente el producto.

- Promoción de ventas: Cupones de descuento que vienen en periódicos y revistas para la compra en hipermercados, supermercados y farmacias.

- Relaciones públicas: Se desarrollarán boletines de prensa, patrocinios y eventos especiales para padres. 
Para el cálculo del presupuesto de publicidad y promoción se utilizará como referencia el libro de Marketing de productos de Douglas Gray y Donald Cyr donde se establece que el presupuesto de publicidad y promoción en la industria en general es el 3\% de las ventas.

Tabla 2.25

Presupuesto anual de publicidad y promoción en soles

\begin{tabular}{|c|c|c|c|c|c|c|}
\hline \multirow{2}{*}{ Presupuesto } & \multicolumn{7}{|c|}{ Año } \\
\cline { 2 - 7 } & $\mathbf{2 0 1 6}$ & $\mathbf{2 0 1 7}$ & $\mathbf{2 0 1 8}$ & $\mathbf{2 0 1 9}$ & $\mathbf{2 0 2 0}$ & $\mathbf{2 0 2 1}$ \\
\hline Publicidad y promoción & 153.958 & 218.393 & 309.776 & 439.370 & 623.144 & 883.735 \\
\hline
\end{tabular}

Elaboración propia

\subsubsection{Análisis de precios}

\subsubsection{Tendencia histórica de los precios}

El precio de la compota Gerber se mantuvo constante del año 2011 al 2014 y disminuyó para el año 2015, el precio de la compota Alpina tuvo un crecimiento del año 2011 al 2013 y disminuyó para el año 2014 y 2015, el precio de la compota Agú creció del año 2011 al 2013 y se mantuvo constante hasta el año 2015 y el precio de la compota Heinz creció significativamente del año 2011 al 2012, se mantuvo constante hasta el año 2013 y creció para el año 2014 manteniéndose constante hasta el año 2015.

Tabla 2.26

Tendencia histórica de los precios de las compotas para bebés en Perú en la presentación de 113 gramos del año 2011 al 2015

\begin{tabular}{|c|c|c|c|c|c|}
\hline \multirow{2}{*}{ Marca de compota } & \multicolumn{5}{|c|}{ Año } \\
\cline { 2 - 6 } & $\mathbf{2 0 1 1}$ & $\mathbf{2 0 1 2}$ & $\mathbf{2 0 1 3}$ & $\mathbf{2 0 1 4}$ & $\mathbf{2 0 1 5}$ \\
\hline Alpina & $\mathrm{S} / .2,40$ & $\mathrm{~S} / .2,53$ & $\mathrm{~S} / .2,65$ & $\mathrm{~S} / .2,57$ & $\mathrm{~S} / .2,39$ \\
\hline Heinz & $\mathrm{S} / .2,00$ & $\mathrm{~S} / .2,55$ & $\mathrm{~S} / .2,55$ & $\mathrm{~S} / .2,70$ & $\mathrm{~S} / .2,70$ \\
\hline Gerber & $\mathrm{S} / .2,50$ & $\mathrm{~S} / .2,50$ & $\mathrm{~S} / .2,50$ & $\mathrm{~S} / .2,50$ & $\mathrm{~S} / .2,20$ \\
\hline Agú & $\mathrm{S} / .2,40$ & $\mathrm{~S} / .2,45$ & $\mathrm{~S} / .2,50$ & $\mathrm{~S} / .2,50$ & $\mathrm{~S} / .2,50$ \\
\hline
\end{tabular}

Fuente: Euromonitor, (2015)

\subsubsection{Precios actuales}

Tabla 2.27

Precios actuales de las compotas para bebés

\begin{tabular}{|c|c|}
\hline Marca de compota & Año 2015 \\
\hline Alpina & S/.2,39 \\
\hline Heinz & S/.2,70 \\
\hline Gerber & S/.2,20 \\
\hline Agú & S/.2,50 \\
\hline
\end{tabular}

Fuente: Euromonitor, (2015) 


\subsection{Análisis de Disponibilidad de los insumos principales}

\subsubsection{Características principales de la materia prima}

a) Cañihua: Las semillas de cañihua ofrecen un alto contenido proteico para las dietas escasas en carnes. Además poseen un balance de aminoácidos de primera línea siendo particularmente rica en lisina, isoleucina y triptofan. Esta calidad proteica en combinación con un contenido de carbohidratos del orden del $60 \%$ y aceites vegetales del orden del 8\%, la hacen altamente nutritiva. (Ministerio de Agricultura, s.f.)

b) Kiwicha: Contiene de 15 a $18 \%$ de proteínas, mientras que el maíz, alcanza únicamente el 10\%. Por otra parte, las semillas contienen un alto valor de aminoácidos como la lisina. El grano de kiwicha tiene un contenido de calcio, fósforo, hierro, potasio, zinc, vitamina E y complejo de vitamina B. Su fibra, comparada con la del trigo y otros cereales es muy fina y suave. No es necesario separarla de la harina, es más juntas constituyen una gran fuente de energía. Los granos de almidón varían en diámetro de 1 a 3.5 micrones, al igual que los de la quinua, y mucho más pequeños que los del trigo y el maíz. Su estructura diminuta los hace útiles en la industria. (Ministerio de Agricultura, s.f.)

c) Maca: Recompone el equilibrio mental y físico, reduce el estrés, aumenta la fertilidad de ambos sexos, alivia dolores pre menstruales y regula el ciclo menstrual, alivia las molestias de la menopausia, apoya el desarrollo de los adolescentes, no tiene efectos laterales dañinos. (Ministerio de Agricultura, s.f.)

d) Quinua: Tiene un excepcional balance de proteínas, grasa, aceite y almidón. El contenido de proteínas es alto ya que el embrión constituye una gran parte de la semilla. El promedio de proteínas en el grano es de 16\%, pero puede contener hasta $23 \%$, más del doble que cualquier otro cereal. Además las proteínas contenidas están cerca del porcentaje que dicta la FAO para la nutrición humana. Las proteínas de la quinua tienen un alto grado de aminoácidos, lisina, metionina y cistina. Las semillas contiene entre 58 y $68 \%$ de almidón y 5\% de azúcares, a pesar que los granos de almidón son bastante pequeños, éstos contienen cerca de $20 \%$ de amilosa, y forman gelatinas entre los 55 a $65^{\circ} \mathrm{C}$. La grasa contenida es de 4 a 9\%, de los cuales la mitad contiene ácido linoleico, esencial para la dieta humana. Contiene un alto nivel de 
calcio y fósforo. Los nutrientes concentrados de las hojas tienen un bajo índice de nitrato y oxalato, los cuales son considerados elementos perjudiciales en la nutrición. (Ministerio de Agricultura, s.f.)

e) Durazno: Entre sus beneficios se tiene lo siguiente:

- Ayuda a estimular la secreción de jugos digestivos.

- Auxilia en la limpieza de los riñones y vesícula biliar.

- Protegen la salud visual

- Al ser una fuente de antioxidantes, previene el crecimiento de tumores y por consiguiente, de ciertos tipos de cáncer y arrugas.

- Es rico en minerales como el potasio, que regula la tensión arterial; el fósforo, fundamental para el sistema nervioso y el cerebro; y el magnesio que contribuye a prevenir los estados de cansancio, ansiedad y estrés.

- Contiene calcio, recomendado para prevenir el deterioro del sistema óseo en las mujeres.

- Es bajo en calorías.

- Activa la función renal y favorece a la disolución de las piedras en el riñón.

- Contiene hierro recomendado en personas con anemia y falta de apetito.

- Beneficia la actividad intestinal. Con gran contenido de fibra para combatir el estreñimiento.

- Depura el organismo y elimina toxinas.

\subsubsection{Potencialidad del recurso en la zona de influencia del proyecto}

La materia prima se puede obtener de los siguientes lugares:

- El durazno se produce en las regiones de Lima, Ancash, Ayacucho, Cusco, Apurímac, Moquegua y Tacna.

- La producción nacional de quinua se realiza en Puno, Arequipa, Ayacucho, Junín, Cusco, Apurímac, La Libertad, Huancavelica, Lambayeque, Huánuco, Tacna, Ancash, Cajamarca, Lima, Ica, Moquegua y Amazonas.

- La producción nacional de kiwicha se desarrolla principalmente en las regiones de Cusco, Apurímac, Arequipa, Ancash, Ayacucho, La Libertad, Huancavelica. 
- Los mayores centros de producción de maca se encuentran en las regiones de Junín, Huancavelica y Cerro de Pasco específicamente en la meseta de Bombón y las partes altas del valle de Mantaro. La importancia que ha adquirido este cultivo ha hecho que se comience a sembrar en las alturas de todas las regiones del Perú.

- La cañihua se cultiva en las regiones altiplánicas de Perú y Bolivia, entre Puno, Cusco y Arequipa. La zona de mayor producción está concentrada al norte del Lago Titicaca.

De lo narrado se concluye que hay disponibilidad de materia prima pero para elegir un lugar específico de donde abastecer es necesario determinar la localización de planta cuyo análisis será desarrollado posteriormente.

\subsubsection{Costos de la materia prima}

El costo de la materia prima es el siguiente:

Tabla 2.28

Costo de la materia prima

\begin{tabular}{|l|c|c|}
\hline \multicolumn{1}{|c|}{ Materia prima } & Unidad & $\begin{array}{c}\text { Precio } \\
\text { (soles/unidad) }\end{array}$ \\
\hline Durazno & $\mathrm{kg}$ & 1,4 \\
\hline Harina de maca & $\mathrm{kg}$ & 35 \\
\hline Harina de quinua & $\mathrm{kg}$ & 18 \\
\hline Harina de kiwicha & $\mathrm{kg}$ & 10 \\
\hline Harina de cañihua & $\mathrm{kg}$ & 20 \\
\hline
\end{tabular}

Elaboración propia 


\section{CAPÍTULO III: LOCALIZACIÓN DE PLANTA}

\subsection{Análisis de factores de localización}

\subsubsection{Abastecimiento de materias primas (AMP)}

En este factor se analizará la disponibilidad del durazno, la maca, la quinua, la kiwicha y la cañihua por región y estación para mantener un volumen de producción estable. Además se relaciona directamente a los costos de transporte y al costo total de producción, es por ello que se analizará la producción de las materias primas por región. Se encontró que Lima es la mayor región productora de durazno, Junín tiene la mayor producción de maca, Cusco es el mayor productor de kiwicha y Puno es el mayor productor de quinua y cañihua.

\subsubsection{Cercanía al Mercado (CM)}

En este factor se analizará el abastecimiento de la materia prima a la planta de producción. Por lo tanto se realizará un análisis de las distancias desde las posibles ubicaciones hasta el mercado objetivo que se encuentra en Lima por sus características poblacionales. La distancia más corta sería si se ubicase la planta de producción en Lima o Junín, desde Cusco o Puno se deben recorrer más de $1.000 \mathrm{~km}$.

\subsubsection{Vías de Acceso (VAC)}

En este factor se analizará la longitud y el estado de las vías, de las posibles regiones para la ubicación de la planta, además influye en los costos logísticos y los tiempos de transporte. Depende de este criterio la factibilidad del transporte de las materias primas o la distribución del producto terminado.

\subsubsection{Disponibilidad de mano de obra (DMO)}

En este factor se busca conocer la capacidad de la población económicamente activa de la región para asumir los puestos de trabajo de la planta. Esta se ve afectada por el desarrollo de la región, las condiciones socioeconómicas y la infraestructura. Lima posee la mayor PEA así como la población con mayor grado de estudios superando ampliamente a otras regiones en cuanto a capacidad laboral. 


\subsubsection{Abastecimiento de energía eléctrica (AEE)}

La energía eléctrica es necesaria para el funcionamiento de toda la planta es por ello que para el análisis se considerará la capacidad disponible por región y las tarifas eléctricas. Lima posee la mayor cobertura eléctrica del país seguida por Junín y además tiene una mayor tasa de producción de energía eléctrica.

\subsubsection{Disponibilidad de agua potable y sistemas de alcantarillado (DASA)}

La disponibilidad de agua potable y sistema de alcantarillado se analizará pues el agua es requerida para el proceso de producción y el funcionamiento de la planta, además de ser necesario un sistema de alcantarillado.

\subsubsection{Disponibilidad de parques industriales (DPI)}

Los parques industriales son zonas reservadas para actividades productivas del sector industrial cuya área posee infraestructura, equipamiento, servicios comunes y servicios públicos necesarios, por lo tanto es un factor importante a conocer para la instalación de una planta de producción. Lima posee la mayor cantidad de parques industriales del país

por lo tanto ofrece mayor disponibilidad en comparación con las otras regiones candidatas que solo poseen un parque industrial.

\subsubsection{Costo de terreno (CTE)}

Este factor determinará las posibles ubicaciones de la planta en función del precio por m2 de la zona que varía según la ciudad, región o zona industrial.

\subsection{Identificación y descripción de las alternativas de localización}

Lima: Cuenta con una población de 8730820 personas, según el censo nacional del 2007, y concentra la mayor población del país de los sectores socioeconómicos A y B. Bordeando su litoral le cruza la carretera Panamericana y desde la ciudad de Lima nace la Carretera central en dirección este hacia Junín. Se abastece de agua mediante los ríos Rímac, Chillón y Lurín que desembocan en el océano Pacifico. Es la sede de los tres poderes del estado peruano.

Junín: La región de Junín cuenta con una población de 1225474 personas, según el censo nacional del 2007. Su capital es la ciudad de Huancayo. Es una región ubicada entre las cordilleras que se extiende hasta la selva. Se abastece de agua mediante el rio Mantaro, 
Ene, Tambo principalmente. La economía se desarrolla en los valles a base de la agricultura y la ganadería.

Cusco: La región de Cusco cuenta con una población de 1171403 personas, según el censo nacional del 2007. Su capital es la ciudad de Cuzco. De Abril a Octubre tiene una estación seca y una temporada de lluvias de Noviembre a Marzo. Sus principales actividades económicas son el turismo, la extracción de minerales y la agricultura de tubérculos nativos. Además mantiene unos de los más altos porcentajes de PEA ocupada del país.

Puno: La región de Puno cuenta con una población de 1268441 personas, según el censo nacional del 2007. Su capital es la ciudad de Puno, que se ubica entre los 3800 a 4100 msnm. Tiene un clima frio y seco, con temporadas de lluvias entre Diciembre y Abril. En este ambiente se desarrolla la agricultura de productos aborígenes, así como la ganadería de forma artesanal y de autoconsumo.

\subsection{Evaluación y selección de la localización}

\subsubsection{Evaluación y selección de la macro localización}

\subsubsection{Abastecimiento de materias primas (AMP)}

Se procederá al análisis de la producción de las materias primas por región.

Durazno: El durazno, que compone el $93 \%$ del producto final es la materia prima principal. Es una fruta que se puede producir desde el nivel del mar hasta los $3000 \mathrm{msnm}$., pero la mejor altitud para su cultivo es la de 200-500 msnm. Su siembra, la cual es poco exigente, es mejor en los suelos cálidos, secos, ligeros y profundos. La producción de esta fruta ha tenido un rápido incremento en los últimos años, aumentando su participación en el mercado nacional que depende cada vez menos de las importaciones.

Tabla 3.1

Producción a nivel regional de durazno en el año 2015

\begin{tabular}{|c|c|}
\hline \multicolumn{2}{|c|}{ PRODUCCION A NIVEL REGIONAL DE DURAZNO EN EL AÑO 2015} \\
\hline Región & Producción(Ton) \\
\hline Lima & 32.825 \\
\hline $\begin{array}{l}\text { Resto(Ancash, Ayacucho, Cusco, Apurímac, Moquegua } \\
\text { y Tacna) }\end{array}$ & 17.675 \\
\hline TOTAL & 50.500 \\
\hline
\end{tabular}

Fuente: Euromonitor, (2015) 
Maca: La siembra de la maca se realiza entre los meses de Agosto a Noviembre con las primeras lluvias de la estación, su crecimiento dura de 8 a 9 meses. Es una planta propia de los Andes estando su zona ecológica situada entre los 3800 y 4450 msnm., crece en terrenos ácidos de $\mathrm{ph}<5$ y sin salinidad que deben tener abundante materia orgánica.

Tabla 3.2

Producción a nivel regional de maca en el año 2015

\begin{tabular}{|c|c|}
\hline \multicolumn{2}{|c|}{ PRODUCCION ANIVEL REGIONAL DE MACA EN EL AÑO 2015} \\
\hline Región & Producción(Ton) \\
\hline Junín & 51.447 \\
\hline Pasco & 4.609 \\
\hline Huancavelica & 1.711 \\
\hline 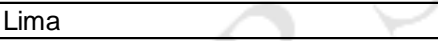 & 120 \\
\hline$x_{2}^{2}$ & 82 \\
\hline TOTAL & 57.969 \\
\hline
\end{tabular}

Fuente: INEI, (2015)

Quinua: La quinua es una planta que se cultiva comúnmente a los $2500 \mathrm{msnm}$, pero puede crecer desde los 0 a los $4000 \mathrm{msnm}$. Es un cultivo natural de los Andes, sin embargo en el año 2013, se realizó satisfactoriamente la primera cosecha de quinua en la costa central que obtuvo más de $4000 \mathrm{~kg} /$ hectárea siendo mayor a la producción promedio de la Sierra que llega a los $1000 \mathrm{~kg} /$ hectárea aproximadamente. La mayor eficiencia y menor periodo vegetativo presenta una clara ventaja para seguir explorando el cultivo de la quinua en la costa que podría facilitar más el abastecimiento de esta materia prima.

\section{Tabla 3.3}

Producción a nivel regional de quinua en el año 2015

\begin{tabular}{|l|r|}
\hline \multicolumn{2}{|c|}{ Producción a nivel regional de quinua en el año 2015 } \\
\hline \multicolumn{1}{|c|}{ Región } & Producción(Ton) \\
\hline Puno & 38221 \\
\hline Arequipa & 22356 \\
\hline Ayacucho & 14630 \\
\hline Junín & 8518 \\
\hline Apurímac & 5785 \\
\hline Cusco & 4337 \\
\hline La Libertad & 3172 \\
\hline Áncash & 1674 \\
\hline Huánuco & 1428 \\
\hline Huancavelica & 1034 \\
\hline Lima & 984 \\
\hline Ica & 958 \\
\hline Tacna & 891 \\
\hline Lambayeque & 778 \\
\hline Cajamarca & 572 \\
\hline Piura & 123 \\
\hline Moquegua & 106 \\
\hline Pasco & 28 \\
\hline Amazonas & 26 \\
\hline & $\mathbf{1 0 5 . 6 2 1}$ \\
\hline
\end{tabular}

Fuente: INEI, (2015) 
Kiwicha: La kiwicha tiene un alto valor nutricional y su cosecha suele producir $2000 \mathrm{~kg} /$ hectárea en promedio y se puede cultivar desde 0 hasta los $3400 \mathrm{msnm}$, es una planta propia de los Andes y Perú es su mayor productor a nivel mundial.

Tabla 3.4

Producción a nivel regional de kiwicha en el año 2015

\begin{tabular}{|l|r|}
\hline \multicolumn{1}{|c|}{ Producción a nivel regional de kiwicha en el año 2015 } \\
\hline \multicolumn{1}{|c|}{ Región } & Producción(ton) \\
\hline AREQUIPA & 1.447 \\
\hline APURIMAC & 1.280 \\
\hline ANCASH & 1.003 \\
\hline CUZCO & 811 \\
\hline LA LIBERTAD & 130 \\
\hline AYACUCHO & 116 \\
\hline HUANCAVELICA & 49 \\
\hline LAMBAYEQUE & 1 \\
\hline \multicolumn{2}{|c|}{ TOTAL } \\
\hline
\end{tabular}

Fuente: INEI, (2015)

Cañihua: El origen de la cañihua está en las zonas del altiplano peruano, actualmente se siembra aproximadamente 5000 hectáreas a una altura de entre los 3500 a $4200 \mathrm{msnm}$, su cosecha alcanza entre los 750 a $800 \mathrm{~kg}$ /hectárea y esta se realiza entre los meses de Marzo a Junio. Es un cultivo resistente a las heladas, sequías y bajas temperaturas. Su producción se realiza principalmente en la región de Puno al norte del lago Titicaca.

Tabla 3.5

Producción a nivel regional de cañihua en el año 2015

\begin{tabular}{|c|c|}
\hline PRODUCCION A NIVEL REC & EN EL AÑO 2015 \\
\hline Región & Producción(Ton) \\
\hline PUNO & 4.462 \\
\hline CUZCO & 265 \\
\hline AREQUIPA & 7 \\
\hline TOTAL & 4.734 \\
\hline
\end{tabular}

Fuente: INEI, (2015)

De lo analizado se observa que de las 24 regiones las 4 más favorables son: Lima, Junín, Cuzco y Puno; debido a su proximidad a las materias primas.

\subsubsection{Cercanía al Mercado (CM)}

Para su análisis se examinarán los medios de transporte y las distancias desde las posibles ubicaciones hasta el mercado objetivo que se encuentra en Lima por sus características poblacionales. 
Tabla 3.6

Rutas de viaje terrestre y distancias al mercado objetivo, por región

\begin{tabular}{|l|l|r|}
\hline Mercado-Región & Ruta terrestre(Recomendable) & Distancia(Km) \\
\hline LIMA & LIMA & 0 \\
\hline JUNIN-LIMA & JUNIN-LIMA & 310 \\
\hline PUNO-LIMA & PUNO-AREQUIPA-ICA-LIMA & 1.334 \\
\hline CUZCO-LIMA & CUZCO-APURIMAC-AYACUCHO-ICA-LIMA & 1.085 \\
\hline
\end{tabular}

Fuente: MINAG, (2015)

Se realizará el análisis de la vía terrestre. Como Lima es el mercado objetivo, si la planta de producción se instala en esta región la distancia sería de $0 \mathrm{~km}$. Para ir de Puno a Lima, se debe ir desde la ciudad de Juliaca a la ciudad de Arequipa a $281 \mathrm{~km}$, y seguir la Panamericana Sur desde Arequipa, pasando por Ica y llegando a la ciudad de Lima a 1009 $\mathrm{km}$ de distancia. Mediante esta ruta el tiempo de viaje puede ser de 19 a 22 horas. Para ir de Junín a Lima desde Huancayo se debe tomar la carretera central margen derecho hacia al norte en dirección a la Oroya y seguir hasta llegar a Lima, con un tiempo de viaje de 5 horas y 30 minutos. Desde Cuzco a Lima, se debe tomar primero la ruta hacia la ciudad de Abancay a $190 \mathrm{~km}$, luego ir a la ciudad de Puquio a $287 \mathrm{~km}$ tomando la carretera sur oeste que sigue al Rio Pachachaca por un tramo. Entre Puquio y la ciudad de Nazca hay $157 \mathrm{~km}$, una vez ahí se debe tomar la carretera Panamericana sur hacia Lima cubriendo unos 450 $\mathrm{km}$. El tiempo de viaje es de 21 horas aproximadamente.

Figura 3.1

Red vial nacional al año 2015

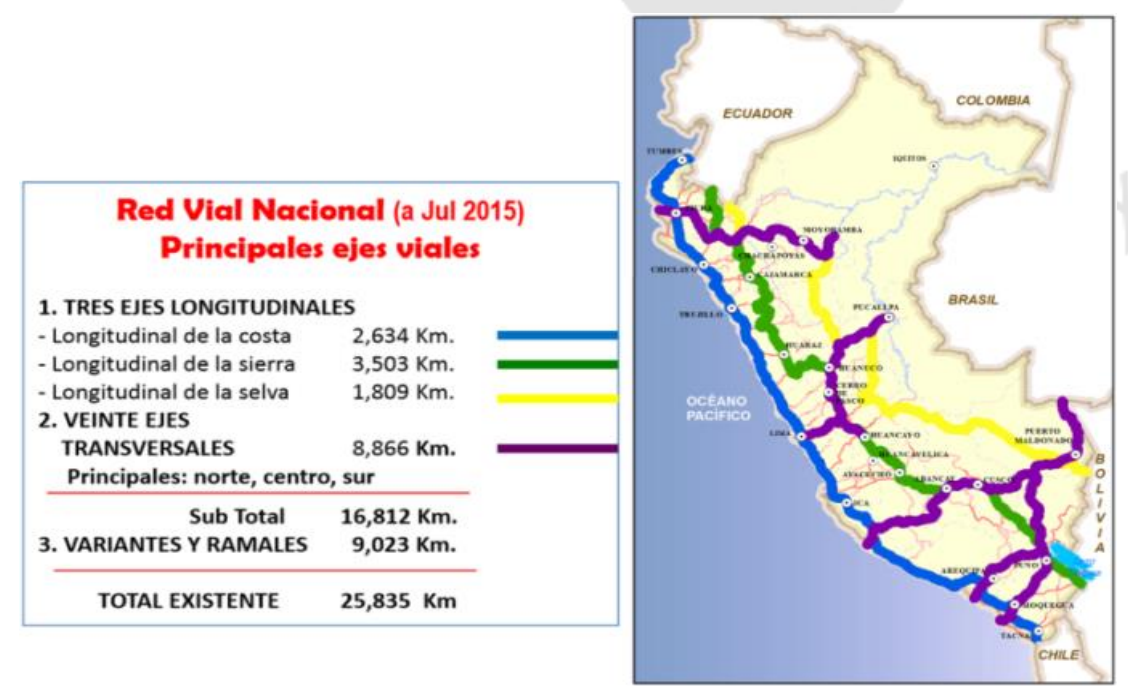

Fuente: MINAG y Provias, (2015) 


\subsubsection{Vías de Acceso (VAC)}

De este criterio depende la factibilidad del transporte de las materias primas y la distribución del producto terminado. Del siguiente cuadro, se puede apreciar que Puno es la región con mayor red vial nacional pavimentada seguido por Cuzco. Cabe mencionar que solo se analiza el estado de las carreteras de la red vial nacional en las regiones involucradas en el transporte de las materias primas y el producto terminado.

Tabla 3.7

Red vial nacional según región del año 2015

\begin{tabular}{|l|r|r|r|}
\hline \multirow{2}{*}{ REGION } & \multicolumn{3}{|c|}{ NACIONAL EXISTENTE POR LONGITUD } \\
\cline { 2 - 4 } & PAVIMENTADA & NO PAVIMENTADA & SUBTOTAL \\
\hline PUNO & 1.396 & 621 & 2.017 \\
\hline CUSCO & 1.190 & 628 & 1.818 \\
\hline AYACUCHO & 1.384 & 338 & 1.722 \\
\hline LIMA & 1.132 & 581 & 1.713 \\
\hline JUNIN & 934 & 603 & 1.537 \\
\hline AREQUIPA & 1.080 & 353 & 1.433 \\
\hline APURIMAC & 680 & 477 & 1.157 \\
\hline ICA & 629 & 69 & 698 \\
\hline
\end{tabular}

Fuente: MTC, (2015)

\subsubsection{Disponibilidad de mano de obra (DMO)}

Como se aprecia en el siguiente cuadro, Lima posee la mayor PEA así como la población con mayor grado de estudios superando a otras regiones en cuanto a capacidad laboral.

Tabla 3.8

Situación de la PEA a nivel regional

\begin{tabular}{|l|r|r|r|r|r|}
\hline \multicolumn{1}{|c|}{ Región } & PEA total & \multicolumn{1}{|c|}{$\begin{array}{c}\text { PEA } \\
\text { ocupada }\end{array}$} & $\begin{array}{c}\text { PEA con } \\
\text { educación } \\
\text { secundaria } \\
\text { completa }\end{array}$ & $\begin{array}{c}\text { PEAcon } \\
\text { educación } \\
\text { superior } \\
\text { completa }\end{array}$ & $\begin{array}{c}\text { Porcentaje } \\
\text { de PEA } \\
\text { Ocupada } \\
\text { (\%) }\end{array}$ \\
\hline Lima & 5.106 .983 & 4.866 .262 & 2.308 .403 & 2.048 .081 & $95,29 \%$ \\
\hline La Libertad & 947.811 & 911.126 & 371.729 & 225.792 & $96,13 \%$ \\
\hline Piura & 898.269 & 867.858 & 358.185 & 215.943 & $96,61 \%$ \\
\hline Puno & 783.615 & 765.245 & 320.892 & 171.001 & $97,66 \%$ \\
\hline Cajamarca & 778.378 & 768.061 & 211.809 & 147.926 & $98,67 \%$ \\
\hline Cusco & 749.155 & 734.676 & 291.550 & 188.285 & $98,07 \%$ \\
\hline Junín & 694.964 & 677.942 & 278.214 & 222.536 & $97,55 \%$ \\
\hline Arequipa & 660.706 & 628.875 & 284.474 & 257.189 & $95,18 \%$ \\
\hline Lambayeque & 636.171 & 616.348 & 287.280 & 141.304 & $96,88 \%$ \\
\hline Áncash & 607.702 & 584.379 & 231.328 & 155.593 & $96,16 \%$ \\
\hline Loreto & 500.687 & 485.418 & 212.049 & 93.611 & $96,95 \%$ \\
\hline Huánuco & 444.883 & 431.172 & 139.598 & 84.558 & $96,92 \%$ \\
\hline San Martín & 425.377 & 415.880 & 156.872 & 89.162 & $97,77 \%$ \\
\hline Ica & 415.533 & 394.190 & 183.792 & 156.361 & $94,86 \%$ \\
\hline Ayacucho & 333.703 & 320.914 & 128.418 & 67.157 & $96,17 \%$ \\
\hline Ucayali & 265.200 & 258.190 & 123.311 & 61.169 & $97,36 \%$ \\
\hline Huancavelica & 254.383 & 249.523 & 92.251 & 33.922 & $98,09 \%$ \\
\hline Apurímac & 246.245 & 240.702 & 87.692 & 42.902 & $97,75 \%$ \\
\hline Amazonas & 225.480 & 221.647 & 78.205 & 31.770 & $98,30 \%$ \\
\hline Tacna & 179.173 & 169.581 & 79.248 & 60.541 & $94,65 \%$ \\
\hline Pasco & 158.754 & 152.120 & 63.300 & 40.996 & $95,82 \%$ \\
\hline Tumbes & 129.325 & 123.224 & 57.940 & 37.196 & $95,28 \%$ \\
\hline Moquegua & 103.914 & 98.312 & 40.972 & 36.501 & $94,61 \%$ \\
\hline Madre de Dios & 74.283 & 72.339 & 33.631 & 19.819 & $97,38 \%$ \\
\hline Fuente: & & & & \\
\hline
\end{tabular}

Fuente: INEI, (2015) 


\subsubsection{Abastecimiento de energía eléctrica (AEE)}

En este factor se analizará si la región es capaz de satisfacer las necesidades energéticas de la planta de producción. Como se puede ver en los siguientes cuadros, Lima posee la mayor cobertura eléctrica del país y además una mayor tasa de producción de energía eléctrica.

Tabla 3.9

Cobertura de electrificación por región en porcentaje (\%) del año 2015

\begin{tabular}{|l|r|l|r|l|r|}
\hline Región & $\%$ Cobertura & Región & \% Cobertura & Región & $\%$ Cobertura \\
\hline Lima & 94,2 & La Libertad & 84,9 & Ucayali & 75 \\
\hline Arequipa & 93,3 & Junín & 84,1 & Apurímac & 74,4 \\
\hline Tacna & 93,1 & Piura & 82,6 & Ayacucho & 72,4 \\
\hline Moquegua & 91,5 & Madre de dios & 80,3 & Puno & 71,3 \\
\hline lca & 89,3 & Huancavelica & 78,3 & Loreto & 69,5 \\
\hline Lambayeque & 88,3 & Cusco & 77,7 & Amazonas & 68,9 \\
\hline Tumbes & 86,6 & Pasco & 77,4 & Cajamarca & 62,5 \\
\hline Áncash & 85,5 & San Martín & 75,5 & Huánuco & 62,3 \\
\hline
\end{tabular}

Fuente: INEI, (2015)

Tabla 3.10

Potencia instalada y producción de energía eléctrica a nivel regional del año 2015

\begin{tabular}{|l|r|r|}
\hline Región & $\begin{array}{c}\text { Potencia total instalada de } \\
\text { energía eléctrica, servicio } \\
\text { privado (Mega watt) }\end{array}$ & $\begin{array}{c}\text { Total de producción de energía } \\
\text { eléctrica destinada a servicio } \\
\text { privado (Giga watt/hora) }\end{array}$ \\
\hline LIMA & 330,9 & 525,3 \\
\hline JUNIN & 42,3 & 153,8 \\
\hline CUSCO & 48,7 & 88,8 \\
\hline PUNO & 15,2 & 11,0 \\
\hline
\end{tabular}

Fuente: INEI, (2015)

\subsubsection{Disponibilidad de agua potable y sistemas de alcantarillado (DASA)}

En este factor se analizará la facilidad de abastecimiento de agua y la disponibilidad de un sistema de alcantarillado para la salida de las aguas residuales.

Tabla 3.11

Cobertura de agua potable en el área urbana por región (Porcentaje) del año 2015

\begin{tabular}{|l|r|l|r|l|r|}
\hline Región & Cobertura & Región & Cobertura & Región & Cobertura \\
\hline Tacna & 98,7 & Lima & 92,6 & Tumbes & 87,9 \\
\hline Moquegua & 97,9 & Madre de dios & 92,4 & Ucayali & 87,4 \\
\hline Cusco & 97,5 & Lambayeque & 91,4 & Piura & 86,9 \\
\hline Junín & 95,8 & Apurímac & 90,9 & Pasco & 80,5 \\
\hline Huancavelica & 95,3 & La Libertad & 89,8 & Puno & 80,3 \\
\hline Arequipa & 95,2 & Ica & 89,2 & San Martín & 74,8 \\
\hline Áncash & 94,4 & Huánuco & 88,6 & Amazonas & 73 \\
\hline Cajamarca & 93,1 & Ayacucho & 88 & Loreto & 72,9 \\
\hline
\end{tabular}

Fuente: INEI, (2015) 
Tabla 3.12

Cobertura de alcantarillado u otra forma de disposición de excretas en el área urbana

(Porcentaje) del año 2015.

\begin{tabular}{|l|r|l|l|l|r|}
\hline Región & Cobertura & Región & Cobertura & Región & Cobertura \\
\hline Moquegua & 92,8 & Ayacucho & 82,4 & Piura & 70,3 \\
\hline Lima & 90,3 & lca & 82,2 & Amazonas & 70,3 \\
\hline Cusco & 90,3 & Arequipa & 81,3 & Tumbes & 69,6 \\
\hline Tacna & 90 & Junín & 80,2 & Pasco & 67,3 \\
\hline Cajamarca & 89,6 & Huancavelica & 80 & San Martín & 55,7 \\
\hline Apurímac & 87,9 & La libertad & 79,3 & Madre de dios & 51,1 \\
\hline Áncash & 87,7 & Huánuco & 79,1 & Loreto & 46,9 \\
\hline Lambayeque & 86,6 & Puno & 75,8 & Ucayali & 38,7 \\
\hline
\end{tabular}

Fuente: INEI, (2015)

Como se puede apreciar, Cusco posee la mayor cobertura de agua potable y Lima tiene la mayor cobertura de alcantarillado además de la mayor red de alcantarillado del país.

\subsubsection{Disponibilidad de parques industriales (DPI)}

Ubicar la planta de producción en estas áreas asegura el pleno funcionamiento de la misma. Lima posee la mayor cantidad de parques industriales del país por lo tanto ofrece mayor disponibilidad en comparación con las otras regiones candidatas que solo poseen un parque industrial como se puede ver en el siguiente cuadro.

Tabla 3.13

Parques industriales (P.I.) por región

\begin{tabular}{|l|l|l|l|}
\hline Región & Parques industriales & Región & Parques industriales \\
\hline Tumbes & P.I. de Tumbes & Lima & P.I. Lomas de Carabayllo \\
\hline Piura & P.I. de Sullana & & P.I. El Asesor-ATE \\
\hline Lambayeque & P.I. Pimentel-Chiclayo & & P.I. Huaycan-ATE \\
\hline La libertad & P.I. Aminor & & P.I. Villa María del Triunfo \\
\hline & P.I. El Porvenir & & P.I. Villa el Salvador \\
\hline Ica & P.I. Ica & & P.I. Infantas-Los Olivos \\
\hline Arequipa & P.I. Arequipa & & P.I. Pachacutec-Ventanilla \\
\hline & P.I. Apima & & P.I. Ventanilla-Callao \\
\hline & P.I. Rio Seco & Amazonas & P.I. Amazonas \\
\hline & P.I. El Palomar & Ucayali & P.I. Ucayali \\
\hline Puno & P.I. Taparachi & Junín & P.I. Huancayo \\
\hline Tacna & P.I. Tacna & Cusco & P.I. Cusco \\
\hline
\end{tabular}

Fuente: Produce, (2015)

\section{- Evaluación de los factores de macro localización}

De acuerdo a lo analizado se determinaron las cuatro regiones más favorables: Lima, Junín, Cusco y Puno. 
Tabla 3.14

Calificación de factores de macro localización

\begin{tabular}{|l|r|}
\hline CALIFICACION & PUNTAJE \\
\hline Excelente & 10 \\
\hline Muy bueno & 8 \\
\hline Bueno & 6 \\
\hline Regular & 4 \\
\hline Malo & 2 \\
\hline Pésimo & 0 \\
\hline
\end{tabular}

Elaboración propia

Tabla 3.15

Ranking de factores de macro localización

\begin{tabular}{|l|r|r|r|r|r|r|r|r|r|}
\hline FACTOR & AMP & CM & VAC & DMO & AEE & DASA & DPI & PUNTOS & $\%$ PONDERADO \\
\hline AMP & & 1 & 1 & 1 & 1 & 1 & 1 & 6 & $\mathbf{2 8 , 5 7 \%}$ \\
\hline CM & 0 & & 1 & 1 & 1 & 1 & 1 & 5 & $\mathbf{2 3 , 8 1 \%}$ \\
\hline VAC & 0 & 0 & & 0 & 0 & 0 & 1 & 1 & $\mathbf{4 , 7 6 \%}$ \\
\hline DMO & 0 & 0 & 1 & & 0 & 0 & 1 & 2 & $\mathbf{9 , 5 2 \%}$ \\
\hline AEE & 0 & 0 & 1 & 1 & & 0 & 0 & 2 & $\mathbf{9 , 5 2} \%$ \\
\hline DASA & 0 & 0 & 1 & 1 & 1 & & 0 & 3 & $\mathbf{1 4 , 2 9 \%}$ \\
\hline DPI & 0 & 0 & 0 & 0 & 1 & 1 & & 2 & $\mathbf{9 , 5 2 \%}$ \\
\hline \multicolumn{19}{|c|}{} \\
\hline
\end{tabular}

Elaboración propia

Tabla 3.16

Análisis de macro localización

\begin{tabular}{|l|r|r|r|r|r|r|r|r|r|}
\hline LOCALIDAD/ & \multirow{2}{*}{$\begin{array}{l}\text { PACTORES } \\
\text { FAnderado }\end{array}$} & \multicolumn{2}{|c|}{ LIMA } & \multicolumn{2}{c|}{ JUNIN } & \multicolumn{2}{c|}{ CUSCO } & \multicolumn{2}{c|}{ PUNO } \\
\cline { 2 - 11 } & & Calif. & Puntaje & Calif. & Puntaje & Calif. & Puntaje & Calif. & Puntaje \\
\hline AMP & $28,57 \%$ & 8 & 2,29 & 6 & 1,71 & 6 & 1,71 & 6 & 1,71 \\
\hline CM & $23,81 \%$ & 10 & 2,38 & 6 & 1,43 & 4 & 0,95 & 2 & 0,48 \\
\hline VAC & $4,76 \%$ & 8 & 0,38 & 8 & 0,38 & 8 & 0,38 & 8 & 0,38 \\
\hline DMO & $9,52 \%$ & 10 & 0,95 & 8 & 0,76 & 6 & 0,57 & 6 & 0,57 \\
\hline AEE & $9,52 \%$ & 10 & 0,95 & 8 & 0,76 & 6 & 0,57 & 2 & 0,19 \\
\hline DASA & $14,29 \%$ & 8 & 1,14 & 8 & 1,14 & 8 & 1,14 & 6 & 0,86 \\
\hline DPI & $9,52 \%$ & 10 & 0,95 & 8 & 0,76 & 8 & 0,76 & 8 & 0,76 \\
\hline & & & $\mathbf{9 , 0 5}$ & & $\mathbf{6 , 9 5}$ & & $\mathbf{6 , 0 9}$ & & $\mathbf{4 , 9 5}$ \\
\hline
\end{tabular}

Elaboración propia

Del análisis realizado se determina que de las cuatro regiones seleccionadas para la macro localización, Lima es el mejor lugar para la instalación de la planta de producción.

\subsubsection{Evaluación y selección de la micro localización}

\subsubsection{Disponibilidad de mano de obra (DMO)}

En este factor se busca conocer la capacidad de la población económicamente activa para asumir los puestos de trabajo de la planta. Como se puede ver en el siguiente cuadro, Villa el Salvador posee una buena PEA seguido de Ventanilla y Puente Piedra. 
Tabla 3.17

Población Económicamente Activa total y ocupada de los distritos de Lima y Callao, según Censo Nacional 2007

\begin{tabular}{|c|c|c|c|c|c|c|c|}
\hline Zona & Distrito & PEA & PEA ocupada & Zona & Distrito & PEA & PEA ocupada \\
\hline LIMA ESTE & SAN JUAN DE LURIGANCHO & 398.567 & 384.582 & LIMA CENTRO & SURQUILLO & 43.073 & 41.678 \\
\hline LIMA NORTE & SAN MARTIN DE PORRES & 254.203 & 243.329 & LIMA CENTRO & BREÑA & 38.161 & 36.496 \\
\hline LIMA ESTE & ATE VITARTE & 211.577 & 204.753 & LIMA CENTRO & MAGDALENA VIEJA & 35.375 & 33.970 \\
\hline LIMA NORTE & COMAS & 207.279 & 199.664 & CALLAO & BELLAVISTA & 31.700 & 30.345 \\
\hline CALLAO & CALLAO & 177.152 & 169.190 & LIMA CENTRO & JESUS MARIA & 31.306 & 30.193 \\
\hline LIMA SUR & VILLA EL SALVADOR & 172.953 & 165.489 & LIMA SUR & PACHACAMAC & 30.083 & 28.911 \\
\hline LIMA SUR & VILLA MARIA DEL TRIUNFO & 168.448 & 162.371 & LIMA CENTRO & SAN ISIDRO & 29.469 & 28.865 \\
\hline LIMA SUR & SAN JUAN DE MIRAFLORES & 164.542 & 158.435 & LIMA CENTRO & LINCE & 27.470 & 26.548 \\
\hline LIMA NORTE & LOS OLIVOS & 144.292 & 138.936 & LIMA SUR & LURIN & 27.301 & 26.417 \\
\hline LIMA CENTRO & SANTIAGO DE SURCO & 136.846 & 132.812 & CALLAO & LA PERLA & 26.867 & 25.591 \\
\hline LIMA CENTRO & LIMA & 132.672 & 128.007 & LIMA ESTE & SAN LUIS & 26.313 & 25.508 \\
\hline LIMA SUR & CHORRILLOS & 130.406 & 126.216 & LIMA CENTRO & MAGDALENA DEL MAR & 24.245 & 23.455 \\
\hline CALLAO & VENTANILLA & 112.390 & 107.468 & CALLAO & CARMEN DE LA LEGUA REYNOSO & 18.072 & 17.387 \\
\hline LIMA NORTE & PUENTE PIEDRA & 95.661 & 92.123 & LIMA ESTE & CHACLACAYO & 17.788 & 17.137 \\
\hline LIMA CENTRO & LA VICTORIA & 91.371 & 88.525 & LIMA CENTRO & BARRANCO & 16.163 & 15.563 \\
\hline LIMA NORTE & CARABAYLLO & 89.288 & 85.905 & LIMA NORTE & ANCON & 13.096 & 12.598 \\
\hline LIMA NORTE & INDEPENDENCIA & 89.022 & 85.404 & LIMA ESTE & CIENEGUILLA & 9.153 & 8.740 \\
\hline LIMA ESTE & SANTA ANITA & 86.390 & 83.203 & LIMA SUR & PUCUSANA & 4.409 & 4.213 \\
\hline LIMA ESTE & EL AGUSTINO & 81.241 & 78.624 & LIMA NORTE & SANTA ROSA & 4.387 & 4.192 \\
\hline LIMA CENTRO & RIMAC & 76.443 & 73.610 & LIMA SUR & PUNTA HERMOSA & 2.677 & 2.536 \\
\hline LIMA ESTE & LURIGANCHO & 72.853 & 70.307 & LIMA SUR & SAN BARTOLO & 2.376 & 2.282 \\
\hline LIMA ESTE & LA MOLINA & 63.691 & 62.018 & LIMA SUR & PUNTA NEGRA & 2.181 & 2.083 \\
\hline LIMA CENTRO & SAN MIGUEL & 61.223 & 58.969 & CALLAO & LA PUNTA & 1.945 & 1.876 \\
\hline LIMA CENTRO & SAN BORJA & 50.898 & 49.416 & LIMA SUR & SANTA MARIA DEL MAR & 358 & 343 \\
\hline LIMA CENTRO & MIRAFLORES & 43.628 & 42.344 & & & & \\
\hline
\end{tabular}

Fuente: INEI, (2016)

\subsubsection{Abastecimiento de energía eléctrica (AEE)}

Para este factor se considerará las tarifas eléctricas. Como se puede observar en el siguiente cuadro hay mayor cargo por energía activa en Lima Norte que incluye Ventanilla y Puente Piedra que en Lima sur que incluye a Villa el Salvador.

Tabla 3.18

Tarifas por energía eléctrica, según empresas de distribución eléctrica en Lima

\begin{tabular}{|l|l|l|}
\hline Zona & Empresa & Tarifa (BT5B No residencial) \\
\hline \multirow{2}{*}{ Lima Norte } & \multirow{2}{*}{ Edelnor } & Cargo Fijo Mensual: 0.36 S/./Mes \\
\cline { 3 - 3 } & & Cargo por Energía Activa: $39.43 \mathrm{ctm}$. S/./Kw.h \\
\hline \multirow{2}{*}{ Lima Sur } & \multirow{2}{*}{ Luz del sur } & Cargo Fijo Mensual: 0.36 S/./Mes \\
\cline { 3 - 3 } & & Cargo por Energía Activa: $38.61 \mathrm{ctm}$. S/./Kw.h \\
\hline
\end{tabular}

Fuente: Osinergmin, (2016)

\subsubsection{Disponibilidad de agua potable y sistemas de alcantarillado (DASA)}

En este factor se analizarán los precios del agua potable y el alcantarillado y luego la disposición de las aguas residuales por distrito en el que se observa que la planta de tratamiento de Puente Piedra y Ventanilla tienen una buena disposición. 
Tabla 3.19

Tarifas por agua potable u alcantarillado, según Sedapal en Lima

\begin{tabular}{|c|c|c|c|}
\hline Cargo fijo (soles/mes) & \multicolumn{3}{|c|}{4,886} \\
\hline \multirow{2}{*}{ Categoría } & Rangos de consumo & \multicolumn{2}{|c|}{ Tarifas (soles/m3) } \\
\hline & $\mathrm{m} 3 / \mathrm{mes}$ & Agua potable & Alcantarillado \\
\hline \multicolumn{4}{|l|}{ No residencial } \\
\hline \multirow{2}{*}{ Industrial } & 0 a 1000 & 4,49 & 1,96 \\
\hline & 1000 a mas & 4,82 & 2,1 \\
\hline
\end{tabular}

Fuente: Sedapal, (2016)

Tabla 3.20

Distribución de plantas de tratamiento de aguas residuales en Lima y Callao

\begin{tabular}{|l|l|l|r|l|l|l|l|l|}
\hline ZONA & \multicolumn{1}{|c|}{ PLANTA } & \multicolumn{1}{|c|}{ UBICACIÓN } & CAUDAL & $\begin{array}{r}\text { SISTEMADE } \\
\text { TRATAMIENTO }\end{array}$ & ZONA & \multicolumn{1}{|c|}{ PLANTA } & \multicolumn{1}{c|}{ UBICACIÓN } & CAUDAL \\
TRATAMIENTO
\end{tabular}

Fuente: Sedapal, (2016)

\subsubsection{Costo de terreno (CTE)}

En este factor se determinaran las posibles ubicaciones de la planta en función del $\mathrm{precio} / \mathrm{m} 2$.

Tabla 3.21

Precios de terrenos por distritos

\begin{tabular}{|l|r|}
\hline Distrito & Precios de terreno \\
\hline Ventanilla-Pachacutec & $140 \$ / \mathrm{m} 2$ \\
\hline Puente Piedra & $250 \$ / \mathrm{m} 2$ \\
\hline Villa Salvador & $375 \$ / \mathrm{m} 2$ \\
\hline San Martin de Porres & $960 \$ / \mathrm{m} 2$ \\
\hline ATE Vitarte & $628 \$ / \mathrm{m} 2$ \\
\hline
\end{tabular}

Elaboración propia

\section{- Evaluación de los factores de micro localización}

De la información analizada se determinó que los distritos más favorables son: Ventanilla, Puente piedra, Villa el Salvador, San Martin de Porres y ATE Vitarte. 
Tabla 3.22

Calificación de factores de micro localización

\begin{tabular}{|l|r|}
\hline CALIFICACION & PUNTAJE \\
\hline Excelente & 10 \\
\hline Muy bueno & 8 \\
\hline Bueno & 6 \\
\hline Regular & 4 \\
\hline Malo & 2 \\
\hline Pésimo & 0 \\
\hline
\end{tabular}

Elaboración propia

Tabla 3.23

Ranking de factores de micro localización

\begin{tabular}{|l|r|r|r|r|r|r|}
\hline FACTORES & DMO & AEE & DASA & CTE & PUNTOS & \% PONDERADO \\
\hline DMO & & 0 & 0 & 1 & 1 & $\mathbf{1 6 , 6 7 \%}$ \\
\hline AEE & 1 & & 0 & 0 & 1 & $\mathbf{1 6 , 6 7 \%}$ \\
\hline DASA & 1 & 1 & & 0 & 2 & $\mathbf{3 3 , 3 3 \%}$ \\
\hline CTE & 0 & 1 & 1 & & 2 & $\mathbf{3 3 , 3 3 \%}$ \\
\hline \multicolumn{7}{|c|}{} \\
\hline
\end{tabular}

Elaboración propia

Tabla 3.24

Análisis de micro localización

\begin{tabular}{|c|c|c|c|c|c|c|c|c|c|c|c|}
\hline \multirow{2}{*}{$\begin{array}{l}\text { LOCALIDAD/ } \\
\text { FACTORES }\end{array}$} & \multirow{2}{*}{ Ponderado } & \multicolumn{2}{|c|}{ VENTANILLA } & \multicolumn{4}{|c|}{ PUENTE PIEDRA VILLA SALVADOR } & \multicolumn{2}{|c|}{ SAN MARTIN } & \multicolumn{2}{|c|}{ ATE VITARTE } \\
\hline & & Calif. & Puntaje & Calif. & Puntaje & Calif. & Puntaje & Calif. & Puntaje & Calif. & Puntaje \\
\hline DMO & $16,67 \%$ & 6 & 1,00 & 6 & 1,00 & 6 & 1,00 & 8 & 1,33 & 8 & 1,33 \\
\hline AEE & $16,67 \%$ & 6 & 1,00 & 6 & 1,00 & 8 & 1,33 & 6 & 1,00 & 8 & 1,33 \\
\hline DASA & $33,33 \%$ & 8 & 2,67 & 8 & 2,67 & 6 & 2,00 & 8 & 2,67 & 8 & 2,67 \\
\hline CTE & $33,33 \%$ & 10 & 3,33 & 8 & 2,67 & 6 & 2,00 & 4 & 1,33 & 4 & 1,33 \\
\hline 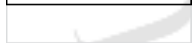 & & & 8,00 & & 7,33 & & 6,33 & & 6,33 & & 6,67 \\
\hline
\end{tabular}

Elaboración propia

Del análisis realizado se determina que Ventanilla es el mejor lugar para la instalación de la planta, sin embargo debido a que los puntajes están próximos entre sí, se hará un análisis costo a costo, para determinar con más detalle la localización de la planta.

\section{Análisis Costo a Costo}

Para realizar el análisis se considera el consumo de energía eléctrica y el costo del terreno pues son los dos factores que presentan costos variables de acuerdo a la ubicación de la planta. 
Tabla 3.25

Análisis costo a costo

\begin{tabular}{|c|c|c|c|c|c|c|c|}
\hline \multirow[b]{2}{*}{ DISTRITOS } & \multicolumn{3}{|c|}{ ENERGIA ELECTRICA (AEE) } & \multicolumn{3}{|c|}{ COSTO DE TERRENO (CTE) } & \multirow{2}{*}{$\begin{array}{l}\text { ANÁLISIS } \\
\text { Costo total } \\
\text { (soles) }\end{array}$} \\
\hline & $K W$ / año & \begin{tabular}{|c|}
$\begin{array}{c}\text { Costo } \\
\text { (soles/KW) }\end{array}$ \\
\end{tabular} & $\begin{array}{c}\begin{array}{c}\text { Costo Energia } \\
\text { (soles/año) }\end{array} \\
\end{array}$ & $\begin{array}{l}\text { Costo } \\
(\$ / \mathrm{m} 2) \\
\end{array}$ & $\begin{array}{c}\text { Espacio } \\
\text { Requerido (m2) }\end{array}$ & $\begin{array}{c}\text { Costo Terreno } \\
\text { (soles) }\end{array}$ & \\
\hline Ventanilla - Pachacutec & 222.135 & 0,394 & \begin{tabular}{|r|}
87.588 \\
\end{tabular} & 140 & 2376 & 1.123 .658 & 1.211 .246 \\
\hline Puente Piedra & 222.135 & 0,394 & 87.588 & 250 & 2376 & 2.006 .532 & 2.094 .120 \\
\hline Villa Salvador & 222.135 & 0,386 & 85.766 & 375 & 2376 & 3.009 .798 & 3.095 .564 \\
\hline San Martin de Porres & 222.135 & 0,394 & 87.588 & 960 & 2376 & 7.705 .083 & 7.792 .671 \\
\hline ATE Vitarte & 222.135 & 0,386 & 85.766 & 628 & 2376 & 5.040 .408 & 5.126 .175 \\
\hline
\end{tabular}

Elaboración propia

Del análisis realizado se determina que Ventanilla es el mejor lugar para la instalación de la planta.

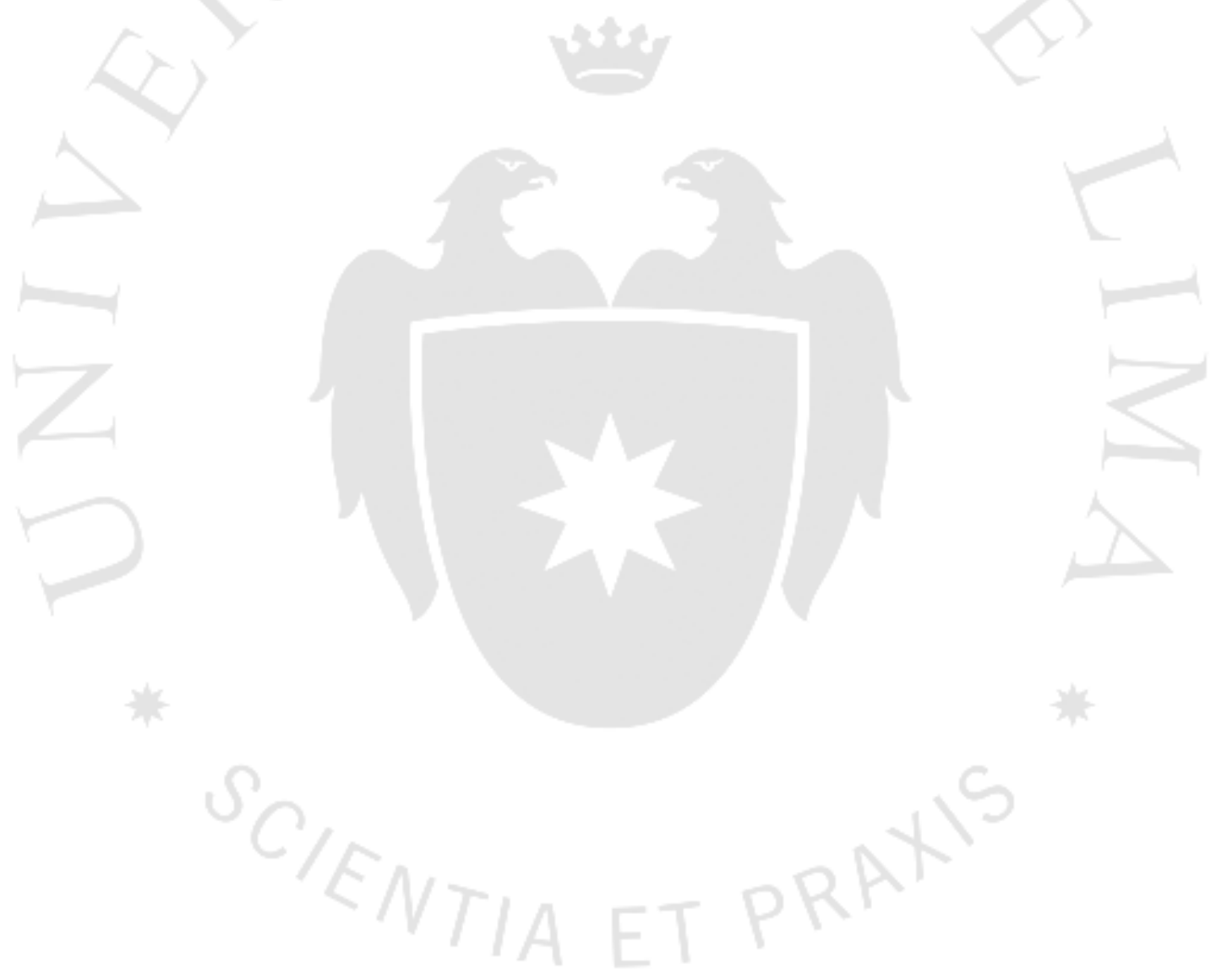




\section{CAPÍTULO IV: TAMAÑO DE PLANTA}

\subsection{Relación tamaño-mercado}

Según el estudio de mercado realizado, la demanda para el proyecto en el año 2021 (al sexto año del proyecto) será 1.849 toneladas o 16.365 .465 compotas para bebés.

Tabla 4.1

Relación tamaño-mercado

\begin{tabular}{|r|r|r|}
\hline Año & $\begin{array}{c}\text { Demanda } \\
\text { proyectada para } \\
\text { el estudio (TM) }\end{array}$ & $\begin{array}{c}\text { Demanda proyectada } \\
\text { para el estudio } \\
\text { (envases de compota) }\end{array}$ \\
\hline 2016 & 322 & 2.851 .082 \\
\hline 2017 & 457 & 4.044 .317 \\
\hline 2018 & 648 & 5.736 .591 \\
\hline 2019 & 919 & 8.136 .482 \\
\hline 2020 & 1.304 & 11.539 .700 \\
\hline 2021 & 1.849 & 16.365 .465 \\
\hline
\end{tabular}

Elaboración propia

\subsection{Relación tamaño-recursos productivos}

Los principales recursos productivos del proyecto son el durazno, la maca, la quinua, la kiwicha y la cañihua. Como se puede ver en el siguiente cuadro, los requerimientos de materia prima con respecto a la producción nacional fueron:

Tabla 4.2

Relación tamaño-recursos productivos

\begin{tabular}{|l|r|r|r|}
\hline \multicolumn{1}{|c|}{ Materia prima } & $\begin{array}{r}\text { Produccion } \\
\text { nacional (TM ) }\end{array}$ & $\begin{array}{c}\text { Requerimiento de } \\
\text { materia prima (TM ) }\end{array}$ & $\begin{array}{c}\text { Tipo de } \\
\text { recurso }\end{array}$ \\
\hline Durazno & 50500 & 2.311 & llimitado \\
\hline Harina de maca & 57969 & 35 & llimitado \\
\hline Harina de quinua & 105621 & 35 & llimitado \\
\hline Harina de kiwicha & 4837 & 35 & llimitado \\
\hline Harina de cañihua & 4734 & 35 & llimitado \\
\hline
\end{tabular}

Elaboración propia

Por lo tanto, se concluye que para el proyecto la disponibilidad de materia prima es ilimitada. 


\subsection{Relación tamaño-tecnología}

Según el análisis de capacidad de planta, los principales procesos tienen las siguientes capacidades expresadas en compotas por año:

Tabla 4.3

Relación tamaño-tecnología

\begin{tabular}{|c|c|c|c|}
\hline $\begin{array}{l}\text { Proceso de } \\
\text { producción }\end{array}$ & $\begin{array}{c}\text { Producción: } \\
\text { kg/hora }\end{array}$ & $\begin{array}{c}\text { Conversión } \\
\text { a anual }\end{array}$ & $\begin{array}{c}\text { Capacidad de } \\
\text { producción (kg/año) }\end{array}$ \\
\hline \multicolumn{4}{|c|}{ 1ra Etapa Obtención de la pulpa de durazno } \\
\hline Pesado & 9.000 & 3.146 & 28.314 .053 \\
\hline Lavado & 3.000 & 3.146 & 9.438 .018 \\
\hline Seleccionado & 1.597 & 6.342 & 10.126 .189 \\
\hline Descarozado & 2.237 & 3.203 & 7.165 .835 \\
\hline Orientado & 10.487 & 3.417 & 35.829 .521 \\
\hline Separado de cáscara & 3.000 & 3.417 & 10.249 .892 \\
\hline Lavado con agua & 3.000 & 3.417 & 10.249 .892 \\
\hline Escaldado & 4.000 & 3.901 & 15.605 .827 \\
\hline Despulpado & 1.000 & 3.901 & 3.901 .457 \\
\hline Tamizado & 1.000 & 3.901 & 3.901 .457 \\
\hline
\end{tabular}

2da Etapa Preparación de la compota

\begin{tabular}{|l|r|r|r|}
\hline Mezclado & 3.917 & 3.629 & 14.213 .641 \\
\hline Pasteurizado & 1.679 & 3.629 & 6.091 .560 \\
\hline Llenado & 407 & 7.258 & 2.952 .392 \\
\hline Tapado & 407 & 7.258 & 2.952 .392 \\
\hline Etiquetado & 339 & 7.258 & $\mathbf{2 . 4 6 0 . 3 2 6}$ \\
\hline Encajado & 13.560 & 3.629 & 49.206 .528 \\
\hline
\end{tabular}

Elaboración propia

Para el cálculo de la capacidad de planta, se debe multiplicar la tasa de producción en $\mathrm{kg}$ por hora de cada proceso por el número de máquinas u operarios de éste, por las horas disponibles al año, por el factor de utilización, por el factor de eficiencia y por el factor de conversión, para poder obtener la capacidad de producción de producto terminado en kg por año. Como se observa, la operación cuello de botella es el proceso de etiquetado, por consiguiente la relación tamaño-tecnología o capacidad de planta asciende a 2.460 .326 $\mathrm{kg}$ de compota/año o de 21.772.800 envases/año. La conversión de kilogramos a envases de compota, se realiza teniendo en cuenta que cada envase alberga 113 gramos de compota procesada.

\subsection{Relación tamaño-inversión}

Esta dada por la disponibilidad de recursos financieros para costear todo el proyecto. 
Tabla 4.4

Relación tamaño-inversión

\begin{tabular}{|l|r|r|}
\hline INVERSIONES & COSTO (S/.) & PORCENTAJE \\
\hline Inversión Tangible & 3.317 .501 & $70 \%$ \\
\hline Inversión Intangible & 81.336 & $2 \%$ \\
\hline Capital de Trabajo & 1.349 .861 & $28 \%$ \\
\hline Inversión Total & $\mathbf{4 . 7 4 8 . 6 9 8}$ & $100 \%$ \\
\hline
\end{tabular}

Elaboración propia

Tabla 4.5

Recursos financieros

\begin{tabular}{|l|r|r|}
\hline & Porcentaje & Monto (S/.) \\
\hline Financiamiento & $40 \%$ & 1.899 .479 \\
\hline Capital propio & $60 \%$ & 2.849 .219 \\
\hline Inversión Total & & 4.748 .698 \\
\hline
\end{tabular}

Elaboración propia

\subsection{Relación tamaño-punto de equilibrio}

Para el punto de equilibrio, se estimaron los costos fijos totales, el precio de venta unitario y el costo variable unitario. Los costos fijos incluyen todos los costos que permanecerán constantes en todo el año. Incluye el costo de mano de obra, energía eléctrica, depreciación fabril y no fabril, amortización de intangibles, costo de telefonía e internet, combustible, equipo de seguridad. Los costos variables incluyen el costo de materia prima e insumos, costo de agua y alcantarillado y el costo variable unitario se obtiene dividiendo el costo variable total entre la producción total en compotas del año 2021. 
Tabla 4.6

Relación tamaño-punto de equilibrio

\begin{tabular}{|c|c|c|}
\hline & 2021 & Unidad \\
\hline \multicolumn{3}{|l|}{ Costos y Gastos fijos } \\
\hline Mano de obra directa & 606.667 & soles/año \\
\hline Mano de obra indirecta & 970.667 & soles/año \\
\hline Energia eléctrica & 87.617 & soles/año \\
\hline Agua y alcantarillado (Fijo) & 2.701 & soles/año \\
\hline Combustible & 76.951 & soles/año \\
\hline Equipos de seguridad alimentaria & 44.059 & soles/año \\
\hline Telefonía e internet & 24.264 & soles/año \\
\hline Seguridad y Señalización & 261 & soles/año \\
\hline Mantenimiento Tercerizado & 17.827 & soles/año \\
\hline Vigilancia & 90.228 & soles/año \\
\hline Limpieza & 72.863 & soles/año \\
\hline Depreciacion fabril & 142.152 & soles/año \\
\hline Depreciacion no fabril & 2.084 & soles/año \\
\hline Amortización intangibles & 8.134 & soles/año \\
\hline Gastos financieros (Interés) & 134.293 & soles/año \\
\hline \multirow{2}{*}{ Costo y Gasto Fijo Total } & 2.280 .767 & soles/año \\
\hline & 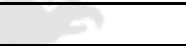 & 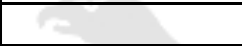 \\
\hline \multirow[t]{2}{*}{ Producción Total } & 17.729 .253 & envases/año \\
\hline & 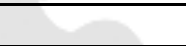 & +2 \\
\hline \multicolumn{3}{|l|}{ Costos y Gastos variables } \\
\hline Materia prima & 6.178 .251 & soles/año \\
\hline Insumos & 4.759 .871 & soles/año \\
\hline Agua y alcantarillado (Variable) & 46.694 & soles/año \\
\hline Publicidad y promoción & 770.813 & soles/año \\
\hline \multirow[t]{2}{*}{\begin{tabular}{|l} 
Distribución \\
\end{tabular}} & 18.906 & soles/año \\
\hline & & \\
\hline \multirow[t]{2}{*}{ Cvu } & 0,66 & soles/envase \\
\hline & & 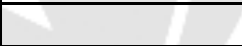 \\
\hline Precio Unitario & 1,57 & soles/envase \\
\hline \multirow[t]{2}{*}{ Punto de Equilibrio } & 2.517 .765 & compotas/año \\
\hline & 285 & TM/año \\
\hline
\end{tabular}

Elaboración propia

Para obtener el punto de equilibrio se utiliza la fórmula:

$$
\text { Punto de equilibrio }=\frac{\mathrm{CF} /}{\mathrm{PVu}-\mathrm{CVu}}=\frac{2.277 .553}{(1.57-0.66)}=2.517 .765 \frac{\text { compotas }}{\text { año }}
$$

Por tanto el tamaño mínimo de planta deberá ser de 2.517 .765 compotas/año o 285 toneladas/año. 


\subsection{Selección de tamaño de planta}

Según las consideraciones anteriores el tamaño de planta del proyecto estaría determinado por el mercado, ascendiendo a un total de 1.849 Toneladas/año o 16.365 .465 envases de compotas/año, tal y como se muestra en el siguiente cuadro.

Tabla 4.7

Selección de tamaño de planta

\begin{tabular}{|l|r|r|}
\hline Relacion & Compotas/año & Toneladas/año \\
\hline Relación tamaño - tecnologia & 21.772 .800 & 2.460 \\
\hline Relación tamaño - mercado & 16.365 .465 & 1.849 \\
\hline Relacion tamaño - recursos productivos & llimitado & llimitado \\
\hline Relación tamaño - inversión & - & - \\
\hline Relacion tamaño - punto de equilibrio & 2.517 .765 & 285 \\
\hline
\end{tabular}

Elaboración propia 


\section{CAPÍTULO V: INGENIERÍA DEL PROYECTO}

\subsection{Ingeniería del proyecto}

\subsubsection{Especificaciones técnicas del producto}

El producto final es una compota para bebés a partir de durazno enriquecido con maca, quinua, kiwicha y cañihua. Para describirlo utilizaremos la definición del libro de Kotler \& Armstrong.

Niveles de producto:

- Producto básico: Alimento rico en vitaminas, proteínas y minerales

- Producto real: Compota para bebés a partir de durazno enriquecido con maca, quinua, kiwicha y cañihua en una presentación de 113 gramos la cual es ideal para la capacidad gástrica del bebé y en un envase plástico que garantizará la inocuidad del alimento.

- Producto aumentado: Producto con garantía y servicio post - venta (El cliente puede contactarse con la empresa en caso de dudas o consultas con respecto al consumo del producto o a su composición).

\subsubsection{Composición del producto}

Los valores nutricionales del producto son los siguientes:

Tabla 5.1

Composición de la compota

\begin{tabular}{|l|r|}
\hline \multicolumn{1}{|c|}{ Insumos } & Gramos \\
\hline Pulpa de Durazno & 105 \\
\hline Harina de Maca & 2 \\
\hline Harina de Quinua & 2 \\
\hline Harina de Kiwicha & 2 \\
\hline Harina de Cañihua & 2 \\
\hline Total & $\mathbf{1 1 3}$ \\
\hline
\end{tabular}

Elaboración propia 
Tabla 5.2

Valor nutricional de la compota de 113 gramos

\begin{tabular}{|l|r|r|r|r|r|}
\hline \multicolumn{1}{|c|}{ Insumos } & $\begin{array}{r}\text { Energía } \\
\text { (Kcal) }\end{array}$ & \multicolumn{1}{c|}{$\begin{array}{c}\text { Energía } \\
\text { (KJ) }\end{array}$} & \multicolumn{1}{c|}{$\begin{array}{c}\text { Proteínas } \\
\text { (grs.) }\end{array}$} & $\begin{array}{c}\text { Grasa total } \\
\text { (grs.) }\end{array}$ & $\begin{array}{c}\text { Carbohidratos } \\
\text { totales (grs.) }\end{array}$ \\
\hline Pulpa de Durazno & 67,2 & 281,4 & 0,63 & 0,105 & 17,955 \\
\hline Harina de Maca & 6,28 & 26,28 & 0,236 & 0,032 & 1,326 \\
\hline Harina de Quinua & 6,86 & 28,68 & 0,272 & 0,116 & 1,332 \\
\hline Harina de Kiwicha & 6,86 & 28,68 & 0,256 & 0,132 & 1,382 \\
\hline Harina de Cañihua & 6,88 & 28,78 & 0,286 & 0,1 & 1,256 \\
\hline Total & 94,08 & 393,82 & 1,68 & 0,485 & 23,251 \\
\hline
\end{tabular}

Elaboración propia

\subsubsection{Diseño gráfico del producto}

Para el diseño gráfico del producto se definió que el nombre de la marca es Wawa pues significa bebé en quechua y refuerza el diferencial de la compota que son los cereales andinos. Asimismo el diseño de la etiqueta resalta las materia primas las cuales son el durazno, la maca, la quinua, la kiwicha y la cañihua, adicionalmente cumple con la normativa de establecer el peso de la compota la cual es 113 gramos, además que es recomendable consumir a partir de los 6 meses de edad y por último mantiene como mensaje que la leche materna es el mejor alimento para el lactante.

Figura 5.1

Compota Wawa
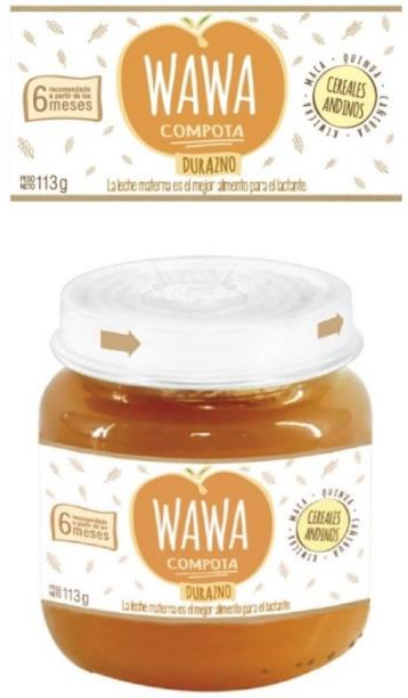

Elaboración propia 


\subsubsection{Regulaciones técnicas al producto}

CODEX STAN 73-1981. Actualmente no existe una norma técnica peruana de compotas de durazno, solo se encuentra normada la compota a base de manzana cuyo código es NTP 203.106:1985.

\subsection{Tecnologías existentes y procesos de producción}

\subsubsection{Naturaleza de la tecnología requerida}

\subsubsection{Descripción de la tecnología existente}

En la actualidad existen diversas tecnologías para los procesos a realizar:

a) Pesado

Para el pesado hay 2 tipos de balanzas:

- Las balanzas fijas: Las cuales son colocadas en un área determinada y no se pueden movilizar.

- Las balanzas portátiles: Las cuales te permiten movilizarlas de acuerdo a los requerimientos del proceso productivo.

b) Lavado

El lavado se puede realizar de 2 formas:

- Lavado por inmersión: El producto es sumergido en agua con solución de TEGO al $0.1 \%$ para su desinfección.

- Lavado por aspersión: El producto es lavado mediante aspersores con solución de TEGO al $0.1 \%$ para su desinfección.

c) Seleccionado

El seleccionado se puede realizar de 2 formas:

- Rodillos o candilones: Este método se utiliza cuando tienes diferentes líneas de producción de acuerdo al tamaño de los duraznos. Los duraznos caen a través de las aberturas de diferentes longitudes entre rodillos a una faja transportadora y al costado de estas hay operarios los cuales retiran los duraznos verdes, podridos y dañados y luego las fajas transportadoras alimentan a las máquinas descarozadoras las cuales trabajan con un tamaño determinado de durazno. 


\section{Figura 5.2}

Seleccionado mediante rodillos o candilones

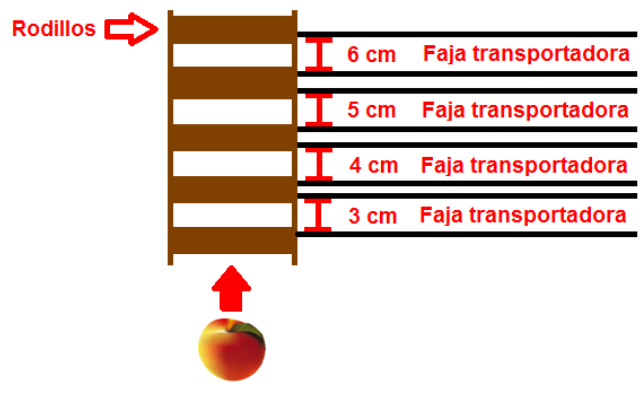

Elaboración propia

- Faja transportadora: Para utilizar este método previamente debes coordinar con el proveedor de los duraznos y especificar el tamaño que desees. Luego al costado de la faja transportadora debe haber operarios para retirar los duraznos verdes, podridos, dañados y los que no cumplan con el tamaño deseado.

d) Descarozado

El descarozado se puede realizar de 2 formas:

- Descarozado a torsión: Un brazo mecánico posiciona el durazno entre las copas de torsión quedando el carozo fijo por una maniobra de pinzamiento que es efectuada por una herramienta dentada que mantiene el carozo mientras actúan las copas que torsionan la fruta en sentido inverso, luego el conjunto de la fruta cae y pasa por una bandeja vibrante con perforaciones la cual separa el carozo de las mitades de durazno.

Figura 5.3

Descarozado a torsión

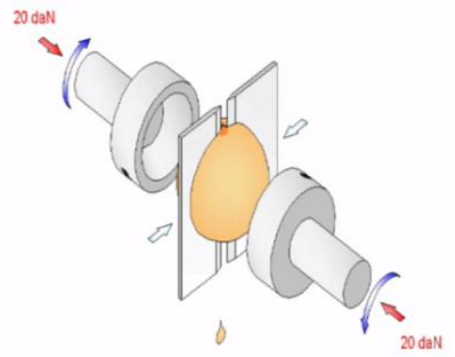

Fuente: OMIP, (2016) 
- Descarozado por cuchareo: Una guillotina metálica fraccionada cae sobre el durazno y en el hueco de cada fracción posee un cucharin giratorio que separa el carozo de la pulpa girando alrededor del mismo, luego el conjunto de la fruta cae y pasa por una bandeja vibrante con perforaciones la cual separa el carozo de las mitades de durazno.

Figura 5.4

Descarozado por cuchareo
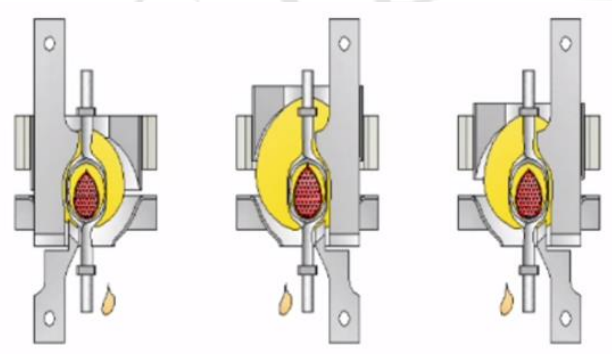

Fuente: OMIP, (2016)

e) Orientado

Para el orientado hay 2 tipos:

- Manual: Los operarios colocan los duraznos copa hacia abajo.

- Automático: Una maquina orientadora coloca los duraznos copa hacia abajo mediante vibración.

f) Pelado químico

Para el pelado químico hay 2 tipos:

- Pelado químico por inmersión: Los duraznos en mitades son sumergidos en hidróxido de sodio al 1.5 - 2\% de concentración para separar la cáscara del durazno y luego son sometidos a un lavado con agua para retirar los restos de hidróxido de sodio y cáscaras.

- Pelado químico por aspersión: Los duraznos en mitades con la copa hacia abajo son sometidos a una ducha con hidróxido de sodio al 1.5 - 2\% mediante aspersores para separar la cáscara del durazno y luego a una ducha con agua para retirar las cáscaras y el hidróxido de sodio.

g) Escaldado

Hay 2 formas para realizar el escaldado de los duraznos: 
- El primer proceso consiste en triturar los duraznos en mitades y mediante una electrobomba pasarlo por un intercambiador de calor de haz de tubos para desactivar las enzimas pécticas, el problema es que la pasta se puede quedar atorada en el intercambiador.

- El segundo proceso es el escaldado por inmersión donde se sumergen los duraznos a $90^{\circ} \mathrm{C}$ por medio de un transportador con arreadores logrando desactivar las enzimas pécticas

h) Despulpado y tamizado

Existe un único método para este proceso pero la variación está en el insumo:

- El despulpado tamizado se realiza en una máquina despulpadora en la cual se va a obtener pulpa de durazno sin cáscaras y sin restos de carozo. En caso se alimente el durazno entero lavado esta despulpadora va a destruir la cáscara y presionar la pulpa contra el tamiz lo cual genera que pase la pulpa y los restos de carozo y cáscara salgan por la parte posterior del equipo, pero si se alimenta los duraznos en mitades sin cáscara y sin carozo (pueden quedar ciertas trazas) aumenta la eficiencia de la máquina y se obtiene un producto de mayor calidad.

i) Mezclado

En la industria de alimentos para el mezclado de productos pastosos y de alta viscosidad se utiliza la mezcladora de paletas la cual permite obtener una mezcla homogénea y uniforme.

j) Pasteurizado

Hay 2 formas para realizar el pasteurizado de la mezcla:

- Pasteurización mediante una marmita a vapor la cual requiere una caldera que le suministre el mismo. Este vapor transfiere su calor a la mezcla mediante una chaqueta de vapor que rodea a la marmita. El pasteurizado se realiza a $90^{\circ} \mathrm{C}$ por 5 minutos.

- Pasteurización mediante una mamita a vapor eléctrica la cual utiliza una resistencia eléctrica para evaporar el agua en la cual está sumergida y a su vez este vapor transfiere su calor a la mezcla mediante la chaqueta de vapor que rodea a la marmita. El pasteurizado se realiza a $90^{\circ} \mathrm{C}$ por 5 minutos. 
k) Esterilizado

El esterilizado se realiza en una máquina esterilizadora de tipo giratorio pero la diferencia es en la forma en que se realiza:

- La primera forma es inyectar aire caliente a una temperatura de $80^{\circ} \mathrm{C}$ para un calentamiento previo de los envases y tapas, luego inyectar agua oxigenada nebulizada a una concentración del $30 \%$ y por último inyectar aire caliente a una temperatura de $80^{\circ} \mathrm{C}$ el cual permite eliminar posibles residuos de agua oxigenada.

- La segunda forma se diferencia de la primera en que en lugar de aire caliente se utiliza vapor saturado a $100-110^{\circ} \mathrm{C}$ como fluido para activar el agua oxigenada y hacerla evaporar.

1) Llenado y tapado

Para el llenado y tapado este debe realizarse al vacío ya que el producto no utiliza preservantes y la ausencia de oxígeno evita que el producto se degrade.

m) Etiquetado

Hay 2 formas para realizar el etiquetado:

- Manual: Un operario coloca las etiquetas autoadhesivas en el envase.

- Automático: Una máquina con sensor detecta la presencia del envase y coloca la etiqueta autoadhesiva

n) Encajado

Hay 2 formas para realizar el encajado:

- Manual: Un operario coloca las compotas en las cajas

- Automático: Una máquina encajadora forma las cajas de cartón y coloca las compotas en ella.

\subsubsection{Selección de la tecnología}




\section{Tabla 5.3}

\section{Selección de la tecnología}

\begin{tabular}{|c|c|c|}
\hline OPERACIÓN & TECNOLOGÍA & DESCRIPCIÓN \\
\hline Pesado & Balanza portátil & $\begin{array}{l}\text { Para el pesado se seleccionó la balanza portátil ya que te permite } \\
\text { movilizarla de acuerdo a los requerimientos del proceso productivo. }\end{array}$ \\
\hline Lavado & Lavado por inmersión & $\begin{array}{l}\text { Para el lavado se seleccionó el lavado por inmersión debido a que } \\
\text { cumple con los requerimientos de limpieza del durazno. }\end{array}$ \\
\hline Seleccionado & Faja transportadora & $\begin{array}{l}\text { Para el seleccionado se utilizará la faja transportadora ya que se } \\
\text { tendrá una sola línea de producción. }\end{array}$ \\
\hline Descarozado & Máquina descarozadora por cuchareo & $\begin{array}{l}\text { Para el descarozado se utilizará la máquina descarozadora por } \\
\text { cuchareo la cual tiene un sistema de orientado automático en las } \\
\text { cavidades de la cadena porta frutos (Posiciona la zona de unión al } \\
\text { pedúnculo hacia abajo y la sutura natural paralela hacia la cuchilla } \\
\text { para que el corte siga la misma), luego los duraznos son cortados } \\
\text { mediante cuchillas planas y descarozado con cuchillas curvas. } \\
\text { Finalmente el conjunto de la fruta cae sobre una bandeja vibrante con } \\
\text { perforaciones la cual separa los carozos de las mitades del durazno. }\end{array}$ \\
\hline Orientado & Máquina orientadora & $\begin{array}{l}\text { Para colocar los duraznos copa hacia abajo se utilizará la máquina } \\
\text { orientadora ya que realiza la función con más rapidez y evita el error } \\
\text { humano. }\end{array}$ \\
\hline Pelado químico & Método por aspersión & $\begin{array}{l}\text { Para el pelado químico se utilizará el método por aspersión ya que } \\
\text { tiene un uso más eficiente del agua. }\end{array}$ \\
\hline Escaldado & Por inmersión & $\begin{array}{l}\text { Para el escaldado se utilizará el escaldado por inmersión ya que se } \\
\text { adecua más a la configuración de la línea de producción. }\end{array}$ \\
\hline Despulpado y tamizado & Máquina despulpadora & $\begin{array}{l}\text { Para el despulpado y tamizado se utilizará una máquina despulpadora } \\
\text { a la cual se alimentarán duraznos en mitades lo que genera una } \\
\text { mayor eficiencia en el proceso. }\end{array}$ \\
\hline Mezclado & Mezcladora de paletas & $\begin{array}{l}\text { Se utilizará una mezcladora de paletas ya que es la adecuada para la } \\
\text { mezcla de productos pastosos en la industria de alimentos. }\end{array}$ \\
\hline Pasteurizado & Marmita a vapor eléctrica & $\begin{array}{l}\text { Se utilizará el pasteurizado mediante una marmita a vapor eléctrica } \\
\text { debido a que no depende de otra máquina para trabajar. }\end{array}$ \\
\hline Esterilizado & Esterilizadora de tipo giratorio & $\begin{array}{l}\text { Se utilizará una esterilizadora de tipo giratorio la cual realiza el } \\
\text { proceso de esterilizado mediante aire caliente y agua oxigenada. }\end{array}$ \\
\hline Llenado y tapado & Llenado y tapado al vacío & $\begin{array}{l}\text { Se utilizará una máquina llenadora tapadora al vacío debido a que el } \\
\text { producto no tiene preservantes y la ausencia de oxígeno le permite } \\
\text { una duración de } 6 \text { meses. }\end{array}$ \\
\hline Etiquetado & Etiquetadora con sensor & $\begin{array}{l}\text { Se utilizará una máquina etiquetadora con sensor ya que realiza el } \\
\text { proceso más rápido y con menor porcentaje de error. }\end{array}$ \\
\hline Encajado & Máquina encajadora & $\begin{array}{l}\text { Se utilizará una máquina encajadora ya que realiza el proceso más } \\
\text { rápido y con menor porcentaje de error. }\end{array}$ \\
\hline
\end{tabular}

Elaboración propia

\subsubsection{Proceso de producción}

\subsubsection{Descripción del proceso}


- Recepción de la materia prima e insumos: Llegan los duraznos en cajas, las harinas de maca, quinua, kiwicha y cañihua en sacos, los frascos y tapas en cajas, la solución desinfectante de tego en envases de plástico de 20 litros, las planchas de cartón amarradas, las etiquetas en bobinas embolsadas y los camiones cisterna con soda cáustica líquida al 50\% de concentración.

- Pesado: Luego de la recepción se realiza el pesado de los duraznos y las harinas de maca, quinua, kiwicha y cañihua en las básculas.

- Control de calidad: Las harinas de maca, quinua, kiwicha y cañihua pasan por un control de calidad donde se evalúa si existe algún riesgo biológico (desarrollo de organismos patógenos y mico toxinas) mediante un análisis microbiológico, riesgo físico (incorporación de algún material que no sea harina) mediante un análisis físico organoléptico en el cual el técnico de calidad mira, palpa y verifica el color de las harinas.

- Lavado: Los duraznos son lavados con una solución de TEGO al $0.1 \%$ en una máquina lavadora de frutas donde estos son empujados por la corriente de agua en combinación con un sistema compartimental de paletas de velocidad variable. Esta lavadora contiene una cinta transportadora modular montada sobre el fondo del tanque que permite un transporte controlado de los productos con flotabilidad negativa a través de la lavadora hasta el elevador de descarga. Para reforzar la acción de lavado convencional, hay un sistema especial de agitación por aire que intensifica el resultado de lavado/limpieza.

- Seleccionado: Después del lavado se realiza la selección donde se eliminan todos los duraznos no aptos para el procesamiento (verdes, podridos o dañados) y los que no cumplen con el tamaño adecuado, esto se realizará a través de una cinta transportadora, mediante inspección visual siendo separados manualmente.

- Descarozado: Los duraznos ingresan a la máquina descarozadora y son ubicados en las cavidades de la cadena porta frutos la cual tiene un sistema de orientado automático (Posiciona la zona de unión al pedúnculo hacia abajo y la sutura natural paralela hacia la cuchilla para que el corte siga la misma), luego los duraznos son cortados mediante cuchillas planas y descarozado con cuchillas curvas. Finalmente 
el conjunto de la fruta cae sobre una bandeja vibrante con perforaciones la cual separa los carozos de las mitades del durazno.

- Orientar: Los duraznos en mitades son colocados con la copa hacia abajo mediante vibración, la velocidad de la máquina es de hasta 3000 mitades por minuto.

- Dilución: La soda cáustica líquida que ingresó en camiones cisterna a una concentración del 50\% es almacenada en tanques de polietileno de alta densidad que disponen de muros de contención en caso de derrame. Luego para llevar a cabo la dilución de la soda cáustica se transporta mediante tuberías de acero al carbono a un tanque intermedio de polietileno de alta densidad el cual se llena de agua y posteriormente se permite el paso de la soda cáustica concentrada al $50 \%$ hasta obtener una solución del 1.5 al 2\%. De este tanque intermedio, la soda cáustica diluida se transporta mediante tuberías a la peladora química.

- Pelado químico: Los duraznos con la copa hacia abajo pasan un por sistema de ducha con hidróxido de sodio del $1.5-2 \%$ a una temperatura de $92-95^{\circ} \mathrm{C}$, luego pasan por un envejecimiento por cámara de vapor vivo que concentra la soda cáustica sobre la piel haciéndolo más efectivo y finalmente por una ducha de agua que elimina la soda cáustica y la piel.

- Escaldado: Los duraznos en mitades pasan a un proceso de escaldado en el cual se desactivan las enzimas pécticas responsables del pardeamiento enzimático (que producen cambios desagradables en el color y sabor de las frutas) y para reblandecer su tejido para la posterior operación de despulpado.

- Despulpado y tamizado: Los duraznos en mitades pasan por la máquina despulpadora la cual a su vez es tamizadora y obtenemos una pasta fina (En caso los duraznos en mitades tengan residuos de cáscaras y carozos estos se eliminan durante el proceso). Una vez obtenida la pulpa esta es llevada al mezclado.

- Mezclado: La pulpa de durazno y la harina de maca, quinua, kiwicha y cañihua son mezcladas de acuerdo a fórmula en la mezcladora de paletas. Posteriormente la mezcla es trasladada a la marmita de vapor.

- Pasteurizado: Esta se realiza en una marmita a vapor eléctrica en la cual se busca eliminar los microorganismos que podrían alterar el producto así como los patógenos mediante tratamiento térmico que se realiza a $90^{\circ} \mathrm{C}$ por 5 minutos. En la 
parte izquierda de la marmita hay una bomba la cual envía la pasta a un tanque de acero inoxidable para almacenar el producto y alimentar a la llenadora tapadora.

- Esterilizado: Los envases de plástico y tapas son esterilizados en una máquina esterilizadora de tipo giratorio. El proceso de esterilizado se realiza en 3 fases: en la primera se inyecta aire caliente a una temperatura de $80^{\circ} \mathrm{C}$ para un calentamiento previo de los envases y tapas, en la segunda se inyecta agua oxigenada nebulizada a una concentración del $30 \%$ y en la tercera fase se inyecta aire caliente a una temperatura de $80^{\circ} \mathrm{C}$ el cual permite eliminar posibles residuos de agua oxigenada. Luego estos envases de plástico y tapas pasan a la máquina llenadora tapadora.

- Llenado y tapado: La mezcla pasteurizada y los envases y tapas esterilizados ingresan a la máquina llenadora- tapadora al vacío la cual garantiza tener una compota inocua y de duración de 6 meses.

- Etiquetado: Las compotas pasan por una máquina etiquetadora automática con sensor la cual detecta el envase y realiza el proceso de etiquetado.

- Encajado: Las compotas son almacenadas en cajas de cartón mediante una máquina encajadora (en cada caja hay 200 compotas).

\subsubsection{Diagrama de proceso: DOP}




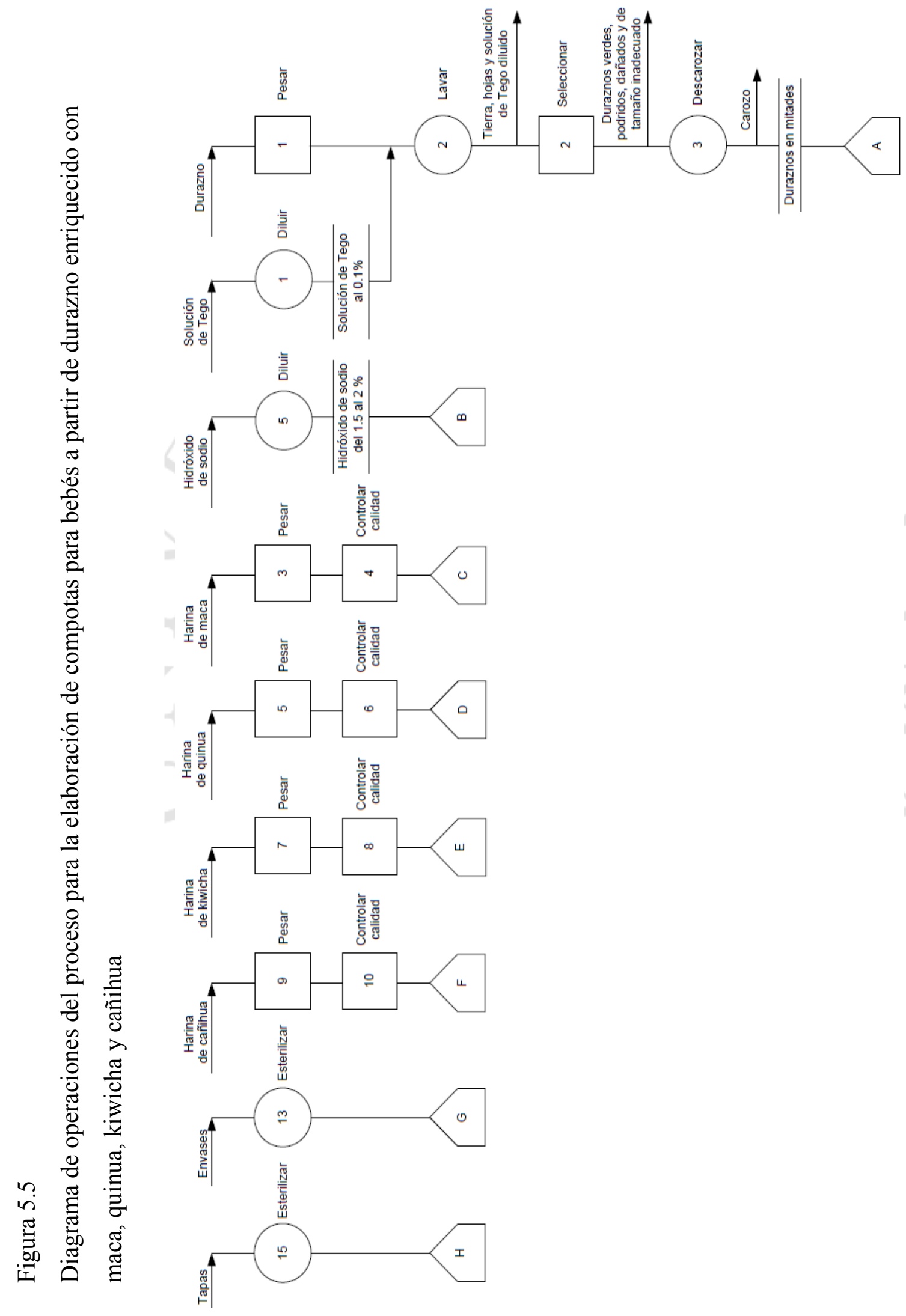




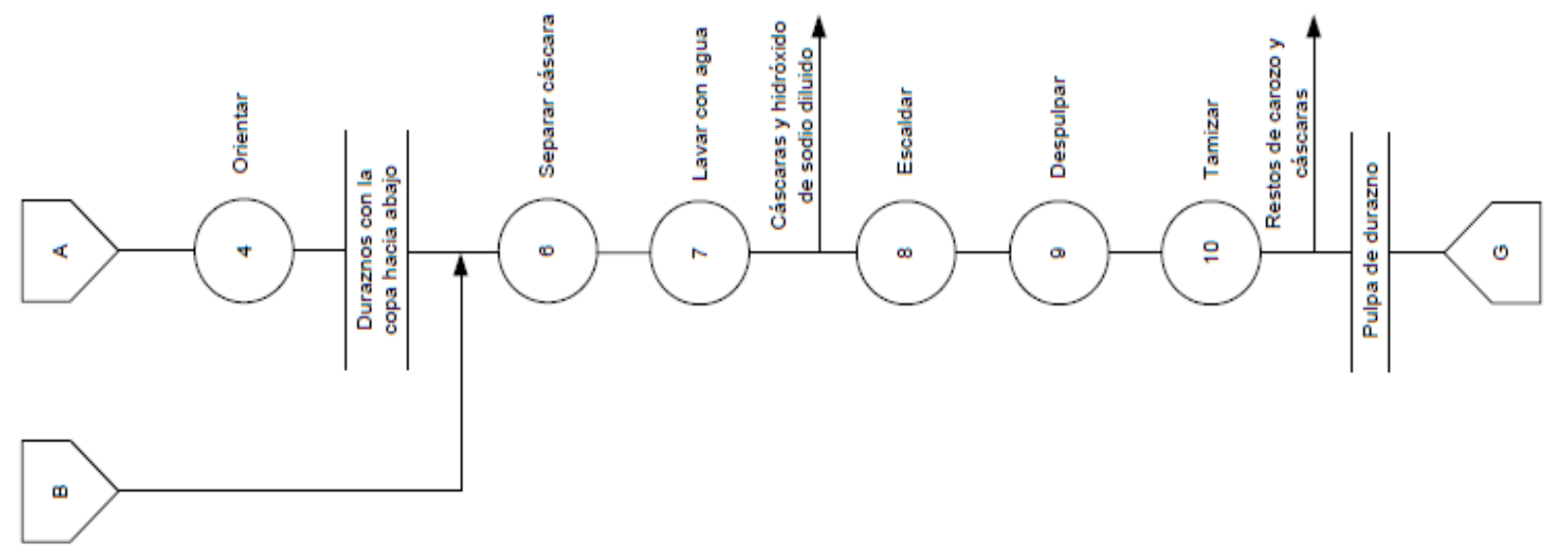



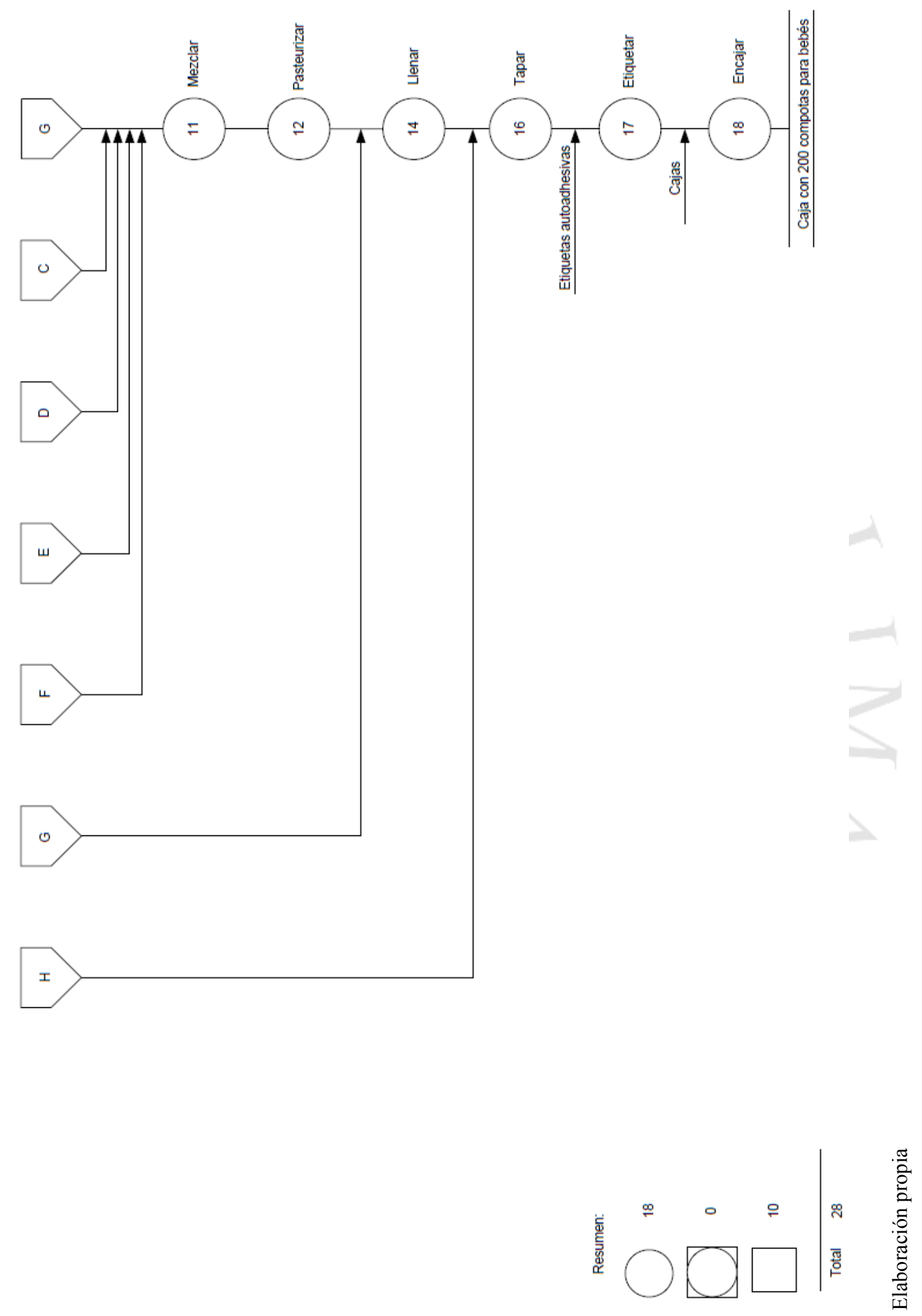


\subsubsection{Balance de materia y energía}

Figura 5.6

Balance de materia

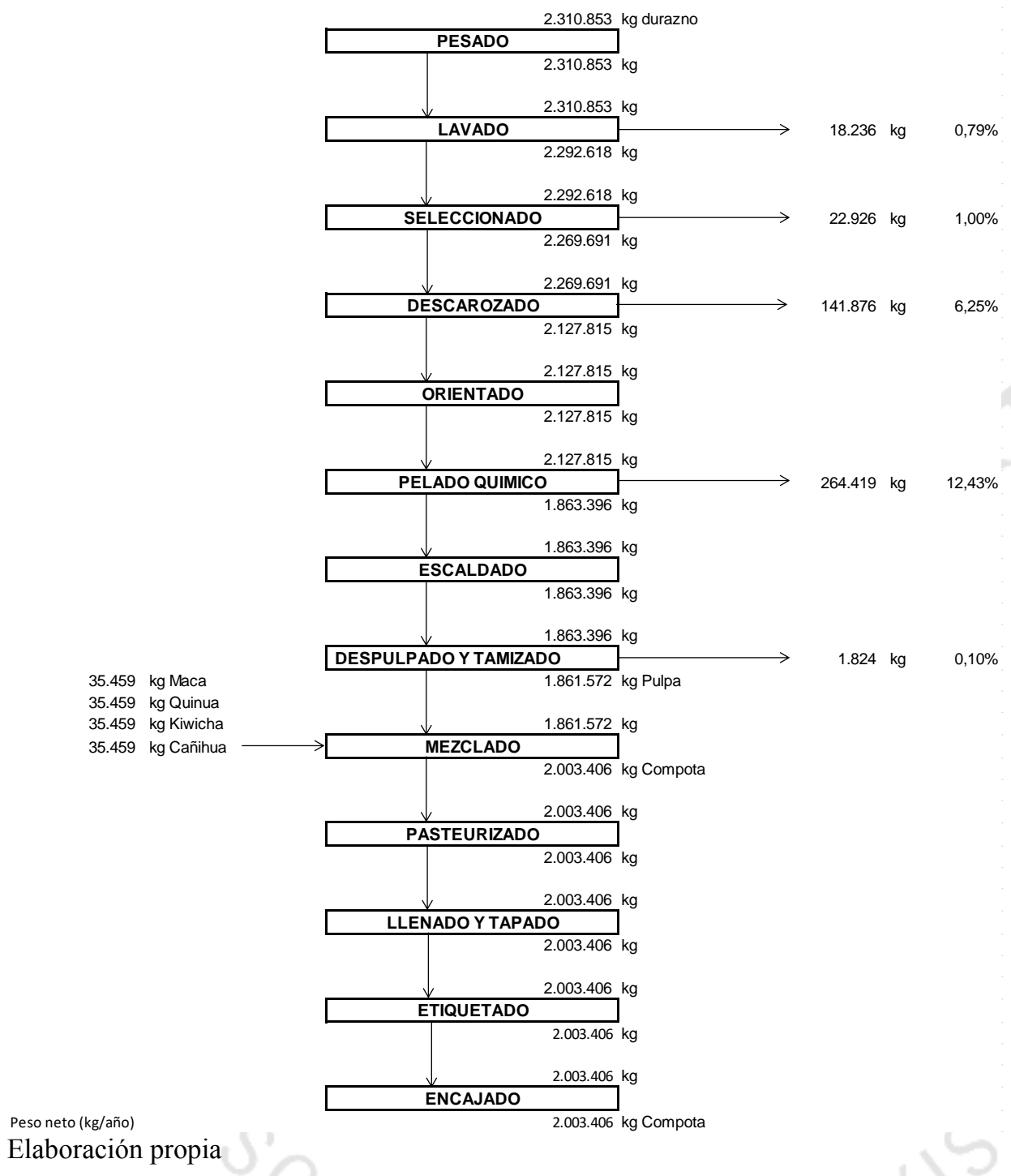

\subsection{Características de las instalaciones y equipo}

\subsubsection{Selección de la maquinaria y equipo}

En base a los requerimientos de producción y los datos obtenidos en el análisis de la tecnología existente, se determinó las máquinas y equipos necesarios los cuales se detallarán a continuación:

- 2 Básculas de piso portátiles

- Lavadora de frutas 
- Faja transportadora de banda

- Máquina descarozadora

- Máquina orientadora de mitades

- Peladora química

- Escaldadora tipo inmersión

- Despulpadora de frutas

- Mezcladora de paletas

- Marmita a vapor eléctrica

- Máquina de llenado y tapado de frascos al vacío

- Etiquetadora automática

- Máquina formadora de cajas y encajadora de envases

- Esterilizadora de envases

- Esterilizadora de tapas

- 2 Tanques de almacenamiento de hidróxido de sodio

- Tanque de acero inoxidable

- Bomba de doble husillo

- Bomba peristáltica SPX32

- 2 Montacargas CAD

\subsubsection{Especificaciones de la maquinaria}

Las especificaciones de las máquinas y equipos seleccionados para el proceso serán presentadas a continuación:

\section{Tabla 5.4}

Báscula de piso portátil

\begin{tabular}{|c|c|c|}
\hline \multicolumn{3}{|c|}{ Bascula de piso portatil } \\
\hline Marca: Mettler-Toledo & Modelo: 2888 DECKMATE & c \\
\hline Capacidad: $300 \mathrm{~kg} / \mathrm{min}$ & 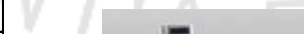 & \\
\hline $\begin{array}{l}\text { Dimensiones: Largo } 610 \mathrm{~mm} \text {, Ancho } 610 \\
\mathrm{~mm} \text {, Altura } 63 \mathrm{~mm}\end{array}$ & & \\
\hline Potencia: No consume energia electrica & & \\
\hline $\begin{array}{l}\text { Requerimientos: Cuatro celdas de carga } \\
\text { de } 350 \text { ohmios - acero inoxidable } \\
\text { hermeticamente selladas }\end{array}$ & & \\
\hline
\end{tabular}

Fuente: Mettler-Toledo, (2016) 


\section{Tabla 5.5}

Lavadora de frutas

\begin{tabular}{|l|l|}
\hline \multicolumn{2}{|c|}{ Lavadora de frutas } \\
\hline Marca: Sormac & Modelo: FW-100 \\
\hline Capacidad: 3 TMhora & $\begin{array}{l}\text { Dimensiones: Largo 5,000 mm, Ancho } \\
700 \mathrm{~mm} \text {, Altura 1,000 mm }\end{array}$ \\
\hline Potencia: $5,74 \mathrm{kw}$ \\
\hline $\begin{array}{l}\text { Requerimientos: Tension electrica } \\
\text { 230/400 V, trifasica, 50/60 } \mathrm{Hz}, \text { Frutas de } \\
\text { hasta un diametro maximo de } 250 \mathrm{~mm}, \\
\text { suministro de agua, tego diluido }\end{array}$ \\
\hline
\end{tabular}

Fuente: Sormac, (2016)

\section{Tabla 5.6}

Faja transportadora de banda

\begin{tabular}{|l|l|}
\hline \multicolumn{2}{|c|}{ Faja transportadora de banda } \\
\hline Marca: Camprodon & Tipo: L3060-64R \\
\hline Velocidad: 0,12 mts/seg & Modelo: TIC1004 \\
\hline $\begin{array}{l}\text { Dimensiones: Largo 3,000 mm, Ancho 1,100 } \\
\text { mm, Altura 1,600 mm }\end{array}$ \\
\hline Potencia: 0,18 kw \\
\hline $\begin{array}{l}\text { Requerimientos: 220/380 V, especificaciones } \\
\text { de arranques hora, inclinación, acumulación de } \\
\text { producto. }\end{array}$
\end{tabular}

Fuente: Camprodon, (2016)

Tabla 5.7

\section{Máquina descarozadora}

\begin{tabular}{|l|l|}
\hline \multicolumn{3}{|c|}{ Máquina descarozadora } \\
\hline Marca: O.M.I.P. & Modelo: CP2 \\
\hline Capacidad: 320 duraznos/min \\
\hline $\begin{array}{l}\text { Dimensiones: Largo } 1,788 \mathrm{~mm} \text {, Ancho } \\
1,105 \mathrm{~mm} \text {, Altura 1,321 } \mathrm{mm}\end{array}$ \\
\hline Potencia: 2.2 kw \\
\hline $\begin{array}{l}\text { Requerimientos: Tensión eléctrica } 380 \\
\text { V, Diámetro de fruta entre } 44 \mathrm{~mm} \text { y } \\
102 \mathrm{~mm} \text {, ducto de salida de carosos }\end{array}$
\end{tabular}

Fuente: Omip, (2016) 
Tabla 5.8

Orientadora de mitades

\begin{tabular}{|c|c|}
\hline \multicolumn{2}{|c|}{ Orientadora de mitades } \\
\hline Marca: O.M.I.P & Modelo: ORIENTATORE DI COPPE \\
\hline Capacidad: 3000 mitades durazno/minuto & \\
\hline $\begin{array}{l}\text { Dimensiones: Largo 2,000 mm, Ancho } 950 \\
\text { mm, Altura 1,000 mm }\end{array}$ & \\
\hline Potencia: $0,75 \mathrm{kw}$ & \\
\hline $\begin{array}{l}\text { Requerimientos: Frutas de hasta un } \\
\text { diámetro máximo de } 130 \mathrm{~mm}\end{array}$ & \\
\hline
\end{tabular}

Fuente: Omip, (2016)

Tabla 5.9

Peladora química

\begin{tabular}{|l|l|}
\hline \multicolumn{2}{|c|}{ Peladora química } \\
\hline Marca: O.M.I.P & Modelo: FW-100 \\
\hline Capacidad: 3 TMhora & $\begin{array}{l}\text { Dimensiones: Largo } 5,000 \mathrm{~mm} \text {, Ancho } \\
\text { 1,500 mm, Altura 1,700 } \mathrm{mm}\end{array}$ \\
\hline Potencia: 3 kw & $\begin{array}{l}\text { Requerimientos: Solución de hidróxido } \\
\text { de sodio diluido a } 92 / 95{ }^{\circ} \mathrm{C} \text {, suministro } \\
\text { de agua, ducto para expulsión de } \\
\text { agua, hidróxido de sodio y cáscaras. }\end{array}$ \\
\hline
\end{tabular}

Fuente: Omip, (2016)

Tabla 5.10

Escaldadora tipo inmersión

\begin{tabular}{|l|l|}
\hline \multicolumn{2}{|c|}{ Escaldadora tipo inmersión } \\
\hline Marca: Jersa & Modelo: Modelo I \\
\hline Capacidad: 4 TMhora & \\
\hline Dimensiones: Largo total 4.980mm, \\
Ancho total 1.350mm, Altura de carga \\
1.450mm, Altura de descarga 1.415mm \\
\hline Potencia: 1,5 HP \\
\hline $\begin{array}{l}\text { Requerimientos: Tensión eléctrica 220 o } \\
\text { 440 V, Tolva de descarga, suministro de } \\
\text { agua }\end{array}$ \\
\hline
\end{tabular}

Fuente: Jersa, (2016)

Tabla 5.11

Despulpadora de frutas

\begin{tabular}{|l|l|}
\hline \multicolumn{2}{|c|}{ Despulpadora de frutas } \\
\hline Marca: Cl Talsa & Modelo: D1000 \\
\hline Capacidad: 1 TMhora & $\begin{array}{l}\text { Dimensiones: Largo 868 mm, Ancho 600 } \\
\text { mm, Altura 1,510 mm }\end{array}$ \\
\hline Potencia: 4 HP/1,750 RPM \\
\hline $\begin{array}{l}\text { Requerimientos: Energía trifásica 220V } \\
\text { tamices } \\
\text { tamicespecificar las medidas para los 2 }\end{array}$ \\
\hline
\end{tabular}

Fuente: CI Talsa, (2016) 


\section{Tabla 5.12}

Mezcladora de paletas

\begin{tabular}{|l|l|}
\hline \multicolumn{2}{|c|}{ Mezcladora de paletas } \\
\hline Marca: Cabinplant & Modelo: Paddle mixer \\
\hline Capacidad: 350 lts & \\
\hline Dimensiones: Largo $1,750 \mathrm{~mm}$, Ancho \\
1,100 mm, Altura 1,000 $\mathrm{mm}$ \\
\hline Potencia: $1 \mathrm{kw}$ \\
\hline $\begin{array}{l}\text { Requerimientos: Especificar tipo de } \\
\text { mezcla }\end{array}$ \\
\hline
\end{tabular}

Fuente: Cabinplant, (2016)

Tabla 5.13

Marmita a vapor eléctrica

\begin{tabular}{|l|l|}
\hline \multicolumn{2}{|c|}{ Marmita a vapor eléctrica fija } \\
\hline Marca: Cleveland & Modelo: KEL 40 \\
\hline Capacidad: 150 lts / $5 \mathrm{~min}$ \\
\hline Dimensiones: $686 \times 929 \times 1016 \mathrm{~mm}$ \\
\hline Potencia: $21 \mathrm{kw}$ \\
\hline $\begin{array}{l}\text { Requerimientos: Energía eléctrica } \\
\text { trifásica a 220 V, suministro de vapor } \\
\text { a 20psi }\end{array}$ \\
\hline
\end{tabular}

Fuente: Cleveland, (2016)

Tabla 5.14

Máquina de llenado de líquidos y tapado de frascos

\begin{tabular}{|l|l|}
\hline \multicolumn{2}{|c|}{ Máquina de llenado de líquidos y tapado de frascos } \\
\hline Marca: Pharmachine & Modelo: FGF300 \\
\hline Capacidad: 60 envases/minuto & \\
\hline Dimensiones: Largo $3,500 \mathrm{~mm}$, Ancho \\
1,730 mm, Altura $1,680 \mathrm{~mm}$ \\
\hline Potencia: 3 kw \\
\hline $\begin{array}{l}\text { Requerimientos: Tensión eléctrica 380V } \\
\text { 50Hz, suministro de frascos, suministro } \\
\text { de tapas }\end{array}$
\end{tabular}

Fuente: Pharmachine, (2016)

\section{Tabla 5.15}

Etiquetadora automática

\begin{tabular}{|l|l|}
\hline \multicolumn{2}{|c|}{ Etiquetadora automática } \\
\hline Marca: Fast Line & Serie: ECOLINE \\
\hline Capacidad: 50 etiquetados/minuto & Modelo: ETTA-50 \\
\hline $\begin{array}{l}\text { Dimensiones: Largo } 2,500 \mathrm{~mm} \text {, Ancho } \\
100 \mathrm{~mm} \text {, Altura 1,500 } \mathrm{mm}\end{array}$ & \\
\hline Potencia: 0,96 kw & \\
\hline $\begin{array}{l}\text { Requerimientos: Suministro de } \\
\text { etiquetas }\end{array}$ & \\
\hline
\end{tabular}

Fuente: Fast Line, (2016) 
Tabla 5.16

Máquina formadora de cajas y encajadora de envases

\begin{tabular}{|l|l|}
\hline \multicolumn{2}{|c|}{ Máquina formadora de cajas y encajadora de envases } \\
\hline Marca: DOSIMUR S.L. & Modelo: FCEN-A \\
\hline Capacidad: 600 cajas/hora \\
\hline $\begin{array}{l}\text { Dimensiones: Largo } 3,434 \mathrm{~mm} \text {, Ancho } \\
1,000 \mathrm{~mm} \text {, Altura } 2,331 \mathrm{~mm}\end{array}$ \\
\hline Potencia: $3 \mathrm{kw}$ \\
\hline $\begin{array}{l}\text { Requerimientos: Consumo de aire } 50 \mathrm{NL}, \\
\text { tensión eléctrica } 380 \mathrm{~V} 5 \mathrm{~Hz}, \text { presión } \\
\text { neumática } 6 \text { bar, suministros de cajas } \\
\text { para armar }\end{array}$ \\
\hline
\end{tabular}

Fuente: Dosimur S.L, (2016)

Tabla.5.17

Tanque de almacenamiento de acero inoxidable

\begin{tabular}{|l|c|}
\hline \multicolumn{2}{|c|}{ Tanque de almacenamiento de acero inoxidable } \\
\hline Marca: Jersa & \\
\hline Capacidad: $1000 \mathrm{Lts}$ & \\
\hline $\begin{array}{l}\text { Dimensiones: Largo } 1,000 \mathrm{~mm} \text {, Ancho } \\
1,000 \mathrm{~mm} \text {, Altura } 2,000 \mathrm{~mm}\end{array}$ \\
\cline { 1 - 1 } $\begin{array}{l}\text { Requerimientos: especificar materiales a } \\
\text { almacenar, ducto de salida de } 25,4 \mathrm{~mm}\end{array}$ & \\
\hline
\end{tabular}

Fuente: Jersa, (2016)

Tabla 5.18

Bomba de doble husillo

\begin{tabular}{|l|l|}
\hline \multicolumn{2}{|c|}{ Bomba de doble husillo } \\
\hline Marca: Bornemann Pumps & Modelo: SLH 180 \\
\hline Capacidad: Mínimo $230 \mathrm{~m} 3 / \mathrm{hr}$ \\
\hline Potencia: $1,5 \mathrm{~kW}$ \\
\hline $\begin{array}{l}\text { Dimensiones: Largo } 400 \mathrm{~mm} \text {, Ancho } \\
175 \mathrm{~mm} \text {, Altura } 230 \mathrm{~mm}\end{array}$ \\
\hline $\begin{array}{l}\text { Requerimientos: Viscosidad máxima } \\
1.000 .000 \mathrm{~mm} 2 / \text { segundo, temperatura } \\
\text { máxima } 200^{\circ} \mathrm{C} \text {, presión } 50 \text { bar }\end{array}$ \\
\hline
\end{tabular}

Fuente: Bornemann Pumps, (2016)

Tabla 5.19

Esterilizadora de envases y tapas

\begin{tabular}{|l|l|}
\hline \multicolumn{2}{|c|}{ Esterilizadora de envases y tapas } \\
\hline Marca: Rotoax & Modelo: ECS \\
\hline Capacidad: 60 envases/minuto & \\
\hline Dimensiones: Largo $1700 \mathrm{~mm}$, Ancho \\
$1500 \mathrm{~mm}$, Altura $2000 \mathrm{~mm}$
\end{tabular}

Fuente: Rotoax, (2016) 
Tabla 5.20

Tanque de almacenamiento de hidróxido de sodio

\begin{tabular}{|l|l|}
\hline \multicolumn{2}{|c|}{ Tanque de almacenamiento de hidróxido de sodio } \\
\hline Marca: Plastynak & Modelo: Reforzador extra \\
\hline Capacidad: 1100 Lts & \\
\hline $\begin{array}{l}\text { Dimensiones: Diámetro } 1100 \mathrm{~mm}, \\
\text { Altura } 1120 \mathrm{~mm}\end{array}$ \\
\hline $\begin{array}{l}\text { Requerimientos: Especificar } \\
\text { densidad o peso específico del } \\
\text { producto a contener }\end{array}$ \\
\hline
\end{tabular}

Fuente: Plastynak, (2016)

Tabla 5.21

Bomba peristáltica SPX32

\begin{tabular}{|l|l|}
\hline \multicolumn{2}{|c|}{ Bomba peristáltica SPX32 } \\
\hline Marca: Watson-Marlow Bredel & Modelo: SPX32 \\
\hline Capacidad: Mínimo 5250 litros/hr \\
\hline Potencia: 2,5 kW \\
\hline $\begin{array}{l}\text { Dimensiones: Largo } 684 \mathrm{~mm} \text {, Ancho } \\
631 \mathrm{~mm} \text {, Altura } 538 \mathrm{~mm}\end{array}$ \\
\hline $\begin{array}{l}\text { Requerimientos: Tensión eléctrica } \\
\text { 230/400V 40Hz, especificar } \\
\text { viscosidad de material }\end{array}$ \\
\hline
\end{tabular}

Fuente: Watson-Marlow Bredel, (2016)

Tabla 5.22

Montacargas

\begin{tabular}{|l|l|}
\hline \multicolumn{2}{|c|}{ MONTACARGAS CAT PC4000 } \\
\hline Marca: CAT & Modelo: PC4000 \\
\hline Capacidad: $2000 \mathrm{~kg}$ a $18,5 \mathrm{~km} / \mathrm{h}$ \\
\hline $\begin{array}{l}\text { Dimensiones: Largo } 2947 \mathrm{~mm} \text {, Ancho } 1090 \\
\mathrm{~mm} \text {, Altura } 4130 \mathrm{~mm}\end{array}$ \\
\hline $\begin{array}{l}\text { Requerimientos: } 2,1 \text { lts Gasolina, } \\
\text { capacitación de operarios }\end{array}$ \\
\hline
\end{tabular}

Fuente: CAT, (2016)

\subsection{Capacidad instalada}

\subsubsection{Cálculo de la capacidad instalada}

Para determinar la capacidad instalada en la planta se debe determinar cuál es la operación cuello de botella. Para determinar la capacidad de producción de cada operación se utilizó la siguiente fórmula:

$$
\text { Capacidad }=\mathrm{N}^{\circ} \text { maquinas } * \frac{\mathrm{kg}}{\text { hora }} * \text { Horas disponibles } * \mathrm{U} * \mathrm{E} * \text { Factor de conversión }
$$

Las horas disponibles al año, se calculan de la siguiente manera: 


$$
\text { Horas disponibles }=\frac{8 \text { Horas }}{\text { turno }} * \frac{2 \text { turno }}{\text { dia }} * \frac{6 \text { dias }}{\text { semana }} * \frac{52 \text { semanas }}{\text { año }}=4992 \frac{\text { Horas }}{\text { Año }}
$$

El factor de efíciencia que se usará será de 0.9. Para determinar el factor de utilización de las máquinas, se debe considerar que se trabaja 8 horas por turno menos 1 hora de refrigerio:

$$
\mathrm{U}=\frac{7}{8}=0.875
$$

El factor de conversión se calcula dividiendo la cantidad de producto terminado obtenido del balance de materia sobre la cantidad de entrada de cada operación.

Tabla 5.23

\begin{tabular}{|c|c|c|c|c|c|c|c|c|c|c|c|c|c|c|}
\hline \multirow[t]{2}{*}{$\begin{array}{l}\text { Proceso de } \\
\text { producción }\end{array}$} & \multirow[t]{2}{*}{ Maquina } & \multicolumn{2}{|c|}{$\begin{array}{c}\text { Cantidad entrante } \\
\text { según balance de } \\
\text { materia }\end{array}$} & \multirow[t]{2}{*}{$\begin{array}{c}\mathrm{N}^{\circ} \text { de } \\
\text { maquinas o } \\
\text { operarios }\end{array}$} & \multirow[t]{2}{*}{$\begin{array}{l}\text { Producción: } \\
\text { kg/hora }\end{array}$} & \multirow[t]{2}{*}{$\begin{array}{l}\text { Hora/ } \\
\text { turno }\end{array}$} & \multirow[t]{2}{*}{$\begin{array}{c}\text { Turno/ } \\
\text { dia }\end{array}$} & \multirow[t]{2}{*}{$\begin{array}{c}\text { Dias } \\
\text { sem }\end{array}$} & \multirow[t]{2}{*}{$\begin{array}{c}\text { Sem/ } \\
\text { año }\end{array}$} & \multirow[t]{2}{*}{$\mathbf{U}$} & \multirow[t]{2}{*}{ E } & \multirow{2}{*}{\begin{tabular}{|c|} 
Capacidad de \\
produccion anual \\
según balance de \\
materia
\end{tabular}} & \multirow{2}{*}{$\begin{array}{c}\text { Factor de } \\
\text { conversión }\end{array}$} & \multirow{2}{*}{\begin{tabular}{|c|} 
Capacidad de \\
producción anual \\
de producto \\
terminado(kg/año)
\end{tabular}} \\
\hline & & Cantidad & Unidad & & & & & & & & & & & \\
\hline \multicolumn{15}{|c|}{ 1ra Etapa Obtención de la pulpa de durazno } \\
\hline Pesado & bascula de piso portátil & 2.310 .853 & $\mathrm{Kg}$ & 1 & 9.000 & 8 & 2 & 6 & 52 & 0,88 & 0,9 & 35.380 .800 & 0,80 & 28.314 .053 \\
\hline Lavado & lavadora de frutas & 2.310 .853 & $\mathrm{Kg}$ & 1 & 3.000 & 8 & 2 & 6 & 52 & 0,88 & 0,9 & 11.793 .600 & 0,80 & 9.438 .018 \\
\hline Seleccionado & faja transportadora & 2.292 .618 & $\mathrm{Kg}$ & 2 & 1.597 & 8 & 2 & 6 & 52 & 0,88 & 0,9 & 12.553 .674 & 0,81 & 10.126 .189 \\
\hline Descarozado & $\begin{array}{l}\text { maquina } \\
\text { descarozadora }\end{array}$ & 2.269.691 & $\mathrm{Kg}$ & 1 & 2.237 & 8 & 2 & 6 & 52 & 0,88 & 0,9 & 8.794 .818 & 0,81 & 7.165 .835 \\
\hline Orientado & orientadora de mitades & 2.127 .815 & $\mathrm{Kg}$ & 1 & 10.487 & 8 & 2 & 6 & 52 & 0,88 & 0,9 & 41.225 .708 & 0,87 & 35.829 .521 \\
\hline $\begin{array}{l}\text { Separado de } \\
\text { cascara }\end{array}$ & peladora quimica & 2.127.815 & $\mathrm{Kg}$ & 1 & 3.000 & 8 & 2 & 6 & 52 & 0,88 & 0,9 & 11.793 .600 & 0,87 & 10.249 .892 \\
\hline $\begin{array}{l}\text { Lavado con } \\
\text { agua }\end{array}$ & peladora quimica & 2.127 .815 & $\mathrm{Kg}$ & 1 & 3.000 & 8 & 2 & 6 & 52 & 0,88 & 0,9 & 11.793 .600 & 0,87 & 10.249 .892 \\
\hline Escaldado & \begin{tabular}{|l|} 
escaldadora tipo \\
inmersión
\end{tabular} & 1.863 .396 & $\mathrm{Kg}$ & 1 & 4.000 & 8 & 2 & 6 & 52 & 0,88 & 0,9 & 15.724 .800 & 0,99 & 15.605 .827 \\
\hline Despulpado & despulpadora de frutas & 1.863 .396 & $\mathrm{Kg}$ & 1 & 1.000 & 8 & 2 & 6 & 52 & 0,88 & 0,9 & 3.931 .200 & 0,99 & 3.901 .457 \\
\hline Tamizado & despulpadora de frutas & 1.863 .396 & $\mathrm{Kg}$ & 1 & 1.000 & 8 & 2 & 6 & 52 & 0,88 & 0,9 & 3.931 .200 & 0,99 & 3.901 .457 \\
\hline
\end{tabular}

\section{Capacidad instalada}

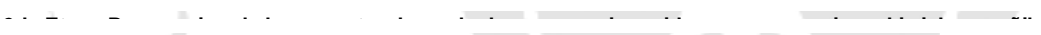

\begin{tabular}{|c|c|c|c|c|c|c|c|c|c|c|c|c|c|c|}
\hline Mezclado & mezcladora de paletas & 2.003 .406 & $\mathrm{Kg}$ & 1 & 3.917 & 8 & 2 & 6 & 52 & 0,88 & 0,9 & 15.398 .111 & 0,92 & 14.213 .641 \\
\hline Pasteurizado & $\begin{array}{l}\text { Marmita a vapor } \\
\text { eléctrica }\end{array}$ & 2.003 .406 & $\mathrm{Kg}$ & 1 & 1.679 & 8 & 2 & 6 & 52 & 0,88 & 0,9 & 6.599 .190 & 0,92 & 6.091 .560 \\
\hline Llenado & $\begin{array}{l}\text { maquina de llenado y } \\
\text { tapado }\end{array}$ & 2.003 .406 & $\mathrm{Kg}$ & 2 & 407 & 8 & 2 & 6 & 52 & 0,88 & 0,9 & 3.198 .424 & 0,92 & 2.952.392 \\
\hline Tapado & $\begin{array}{l}\text { maquina de llenado y } \\
\text { tapado }\end{array}$ & 2.003 .406 & $\mathrm{Kg}$ & 2 & 407 & 8 & 2 & 6 & 52 & 0,88 & 0,9 & 3.198 .424 & 0,92 & 2.952.392 \\
\hline Etiquetado & $\begin{array}{l}\text { etiquetadora } \\
\text { automatica }\end{array}$ & 2.003 .406 & $\mathrm{Kg}$ & 2 & 339 & 8 & 2 & 6 & 52 & 0,88 & 0,9 & 2.665 .354 & 0,92 & 2.460 .326 \\
\hline Encajado & $\begin{array}{l}\text { maquina formadora de } \\
\text { cajas }\end{array}$ & 2.003.406 & $\mathrm{Kg}$ & 1 & 13.560 & 8 & 2 & 6 & 52 & 0,88 & 0,9 & 53.307 .072 & 0,92 & 49.206 .528 \\
\hline
\end{tabular}

2da Etapa Preparacion de la compota a base de durazno, enriquecida con maca, quinua, kiwicha y cañihua

\begin{tabular}{|l|l|l|}
\hline Producto terminado & 1.849 .297 & $\mathrm{Kg} / \mathrm{hr}$ \\
\hline
\end{tabular}

Elaboración propia

Como se puede observar del cuadro anterior, la operación de etiquetado es el cuello de botella pues tiene la menor capacidad de producción anual de producto terminado. Por lo tanto la capacidad instalada es de $2.460 .326 \mathrm{~kg}$ de compota/año. 


\subsubsection{Calculo detallado del número de máquinas requeridas}

Para determinar el número de máquinas requeridas en el proceso de producción de acuerdo a la demanda proyectada del año 2021, se utilizará la siguiente fórmula:

$$
\text { Nro Máquinas }=\frac{\text { Cantidad entrada }(\text { unidad }) * \text { Testándar }\left(\frac{\mathrm{H}-\mathrm{M}}{\text { unidad }}\right)}{\mathrm{U} * \mathrm{E} * \text { Horas diponibles al año }}
$$

Utilizando estos datos se obtiene el número de máquinas que se requiere en cada proceso, como se puede observar en el siguiente cuadro:

Tabla 5.24

Número requerido de máquinas por proceso

\begin{tabular}{|c|c|c|c|c|c|c|c|c|}
\hline \multirow[t]{2}{*}{ Proceso de producción } & \multirow[t]{2}{*}{ Máquina } & \multicolumn{2}{|c|}{$\begin{array}{c}\text { Cantidad entrante según } \\
\text { balance de materia }\end{array}$} & \multicolumn{2}{|c|}{$\begin{array}{c}\text { Tiempo estándar de } \\
\text { operación }\end{array}$} & \multirow{2}{*}{$\begin{array}{c}\text { Horas } \\
\text { disponibles al } \\
\text { año * } U{ }^{*} E\end{array}$} & \multirow{2}{*}{$\begin{array}{l}\mathrm{N}^{\circ} \text { inexacto } \\
\text { de máquinas }\end{array}$} & \multirow{2}{*}{$\begin{array}{l}\quad \mathrm{N}^{\circ} \mathrm{de} \\
\text { máquinas }\end{array}$} \\
\hline & & Cantidad & Unidad & Tiempo & Unidad & & & \\
\hline Lavado & Lavadora de frutas & 2.310 .853 & $\mathrm{Kg}$ & 0,00033 & $\mathrm{H}-\mathrm{M} / \mathrm{Kg}$ & 3.931 & 0,20 & 1 \\
\hline Descarozado & Maquina descarozadora & 2.269 .691 & $\mathrm{Kg}$ & 0,00045 & $\mathrm{H}-\mathrm{M} / \mathrm{Kg}$ & 3.931 & 0,26 & 1 \\
\hline Orientado & Orientadora de mitades & 2.127 .815 & $\mathrm{Kg}$ & 0,00010 & $\mathrm{H}-\mathrm{M} / \mathrm{Kg}$ & 3.931 & 0,05 & 1 \\
\hline Separado y lavado de cascara & Peladora quimica & 2.127 .815 & $\mathrm{Kg}$ & 0,00033 & $\mathrm{H}-\mathrm{M} / \mathrm{Kg}$ & 3.931 & 0,18 & 1 \\
\hline Escaldado & Escaldadora tipo inmersion & 1.863 .396 & $\mathrm{Kg}$ & 0,00025 & $\mathrm{H}-\mathrm{M} / \mathrm{Kg}$ & 3.931 & 0,12 & 1 \\
\hline Despulpado y tamizado & Despulpadora de frutas & 1.863 .396 & $\mathrm{Kg}$ & 0,00100 & $\mathrm{H}-\mathrm{M} / \mathrm{Kg}$ & 3.931 & 0,47 & 1 \\
\hline Mezclado & Mezcladora de paletas & 2.003 .406 & $\mathrm{Kg}$ & 0,00026 & $\mathrm{H}-\mathrm{M} / \mathrm{Kg}$ & 3.931 & 0,13 & 1 \\
\hline Pasteurizado & Marmita a vapor eléctrica & 2.003 .406 & $\mathrm{Kg}$ & 0,00060 & $\mathrm{H}-\mathrm{M} / \mathrm{Kg}$ & 3.931 & 0,30 & 1 \\
\hline Llenado y tapado & Maquina de llenado y tapado & 17.729 .253 & envases & 0,00028 & H-Menvase & 3.931 & 1,25 & 2 \\
\hline Etiquetado & Etiquetadora automatica & 17.729 .253 & envases & 0,00033 & H-Menvase & 3.931 & 1,50 & 2 \\
\hline Encajado & Maquina formadora de cajas & 88.646 & cajas & 0,00167 & H-Mcaja & 3.931 & 0,04 & 1 \\
\hline Esterilizado de tapas & Maquina esterilizadora de tapas & 17.729 .253 & envases & 0,00021 & H-Menvase & 3.931 & 0,94 & 1 \\
\hline Esterilizado de envases & Maquina esterilizadora de envases & 17.729 .253 & envases & 0,00021 & H-Menvase & 3.931 & 0,94 & 1 \\
\hline
\end{tabular}

Elaboración propia

\subsection{Resguardo de calidad y/o inocuidad del producto}

\subsubsection{Calidad de la materia prima, de los insumos, del proceso y del producto}

\section{Calidad de la materia prima}

Para que el durazno (que representa el 93\% del producto final) y la harina de maca, quinua, kiwicha y cañihua (que representan el $7 \%$ del producto final) se encuentren aptos para el proceso de producción deben cumplir con las siguientes características: 
Tabla 5.25

Características de las materias primas

\begin{tabular}{|l|l|}
\hline \multicolumn{1}{|c|}{ Materia Prima } & \multicolumn{1}{c|}{ Requerimiento } \\
\hline & $\begin{array}{l}\text { - Forma: Su forma debe ser semi - esférica, con un surco } \\
\text { longitudinal bien marcado, de piel lisa o pubescente. } \\
\text { Durazno }\end{array}$ \\
& $\begin{array}{l}\text { - Polor: Amarillo o rojizo } \\
\text { - Diámetro: } 56 \mathrm{~mm}\end{array}$ \\
& $\begin{array}{l}\text { - Altura: } 54 \mathrm{~mm} \\
\text { - Sabor: Dulce } \\
\text { - Olor: Perfumado }\end{array}$ \\
\hline $\begin{array}{l}\text { Harina de maca, } \\
\text { quinua, kiwicha y } \\
\text { cañihua }\end{array}$ & $\begin{array}{l}\text { La harina debe estar libre de organismos patógenos, mico } \\
\text { toxinas y no debe tener ningún material extraño que no sea } \\
\text { harina. }\end{array}$ \\
\hline
\end{tabular}

Elaboración propia

Dichas características deberán ser especificadas al proveedor para cumplir con la calidad de la compota.

\section{Calidad de los insumos}

Al igual que la materia prima, los insumos a utilizar deben cumplir ciertos requerimientos de calidad:

Tabla 5.26

Características de los insumos

\begin{tabular}{|l|l|}
\hline Insumo & \multicolumn{1}{|c|}{ Requerimientos } \\
\hline Envase & $\begin{array}{l}\text { Debe ser de plástico y tener una superficie libre } \\
\text { de ralladuras, abolladuras o rajaduras. De un } \\
\text { diámetro de } 55 \mathrm{~mm} \text { y altura } 66 \mathrm{~mm}\end{array}$ \\
\hline Tapa & $\begin{array}{l}\text { Debe ser de plástico. De un diámetro de } 55 \mathrm{~mm} \\
\text { y altura } 10 \mathrm{~mm}\end{array}$ \\
\hline Etiqueta & $\begin{array}{l}\text { Debe tener una impresión nítida. Una altura de } \\
66 \mathrm{~mm} \text { y una longitud de } 173 \mathrm{~mm}\end{array}$ \\
\hline....
\end{tabular}

Elaboración propia

Dichas características deberán ser especificadas a los proveedores de los insumos para cumplir con la calidad de la compota.

\section{Calidad en el proceso}

Se realizará un control de calidad en las siguientes etapas:

- Al recibir las harinas de maca, quinua, kiwicha y cañihua: Se seleccionará una muestra de cada harina y se le realizará un análisis microbiológico para descartar el desarrollo de organismos patógenos y mico toxinas, asimismo se le realizará un 
análisis físico organoléptico en el cual el técnico de calidad mira, palpa y verifica el color de las harinas para descartar que incorpore algún material extraño.

- Después de esterilizar los frascos y tapas: Se seleccionará una muestra aleatoria de frascos y tapas y se le realizará una prueba de contaje de colonias. En esta prueba se pasará un hisopo en el frasco y un hisopo en la tapa y se colocará las muestras en un medio de cultivo. Luego se realizará una prueba de crecimiento de bacterias a temperatura ambiente, temperatura refrigerada y temperaturas mayores para saber si hay bacterias. El límite máximo permisible es de $10^{3}$ hasta $10^{6}$ bacterias.

- Luego del pasteurizado de la mezcla: Se tomará una muestra de la mezcla y se le realizará una prueba de contaje de colonias. En esta prueba se colocará la muestra en un medio de cultivo. Luego se realizará una prueba de crecimiento de bacterias a temperatura ambiente, temperatura refrigerada y temperaturas mayores para saber si hay bacterias. El límite máximo permisible es de $10^{3}$ hasta $10^{6}$ bacterias.

- Cuando la compota está en el almacén de producto terminado: Se seleccionará una muestra de forma aleatoria, se verificará que el envase este sellado luego se procede a abrirlo, se toma una muestra de la compota y se le realizará una prueba de contaje de colonias. En esta prueba se colocará la muestra en un medio de cultivo. Luego se realizará una prueba de crecimiento de bacterias a temperatura ambiente, temperatura refrigerada y temperaturas mayores para saber si hay bacterias. El límite máximo permisible es de $10^{3}$ hasta $10^{6}$ bacterias. Asimismo se comparará el producto contra una muestra estándar y se verificará que tenga el mismo color, olor, sabor, textura y consistencia.

Además, para garantizar la salubridad del producto se les entregará a los operarios que intervengan en el proceso de producción los siguientes elementos de protección: guantes, mascarillas, traje de cuerpo que incluye la protección a la cabeza y cubre zapatos.

\section{Calidad en el producto terminado}

Según la norma Codex el producto final debe cumplir con lo siguiente:

- El producto se envasará en recipientes que preserven las cualidades higiénicas, o de otra índole, del alimento. El contenido del envase no será inferior al $80 \%$ del volumen del envase cuando pese menos de 150 gramos. 
- En la etiqueta el nombre del alimento será el del ingrediente o ingredientes más importantes o característicos, e irá seguido de las indicaciones necesarias sobre su consistencia, o sobre el uso a que se destina. En la etiqueta figurará la lista completa de los ingredientes, por orden decreciente de proporciones, salvo que cuando se hayan añadido vitaminas o minerales se indicarán como grupos de vitaminas o de minerales, respectivamente, sin que dentro de tales grupos sea necesaria su enumeración por orden decreciente de proporciones.

- La declaración de información sobre nutrición deberá contener la cantidad de energía expresada en calorías (kcal) y/o kilojulios (kJ), y el número en gramos de proteínas, carbohidratos y grasa por cada $100 \mathrm{~g}$ de alimento vendido, así como por cada cantidad determinada de alimento cuyo consumo se sugiere.

- Se indicará la fecha de duración mínima (precedida de la expresión "Consumir preferentemente antes del") mediante el día, mes y el año en orden numérico no cifrado, con la excepción de que, para los productos que tengan una duración superior a tres meses, bastará la indicación del mes y del año. El mes podrá indicarse por letras en aquellos países en los que esta indicación no induzca a confusión al consumidor. Cuando se trate de productos en que sólo se requiera la declaración del mes y del año, y la duración del producto alcance hasta el final de un determinado año, podrá emplearse como alternativa la expresión "fin de (indicar el año)"

- Además de la fecha, se indicarán condiciones especiales para la conservación del alimento, si de su cumplimiento depende la validez de la fecha. Siempre que sea factible, las instrucciones para la conservación deberán figurar lo más cerca posible de la marca que indica la fecha. En la etiqueta, o en el folleto que acompaña al producto, se darán instrucciones sobre su preparación y uso, así como sobre su almacenamiento y conservación después de abrirse el envase.

- El producto no es substitutivo de la leche materna y no deberá presentarse como tal.

\section{Medidas de resguardo de la calidad en la producción}

Para el resguardo de la calidad en la producción se utilizará el sistema HACCP el cual permite identificar peligros específicos y medidas para su control con el fin de garantizar la inocuidad de los alimentos. Se procederá a realizar el análisis de riesgos: 
Tabla 5.27

Análisis de riesgos

\begin{tabular}{|c|c|c|c|c|c|}
\hline Etapa & Peligro & \begin{tabular}{|l|} 
EEl peligro es \\
significativo?
\end{tabular} & Justificación de la decisión & $\begin{array}{l}\text { ¿Qué medidas preventivas pueden ser } \\
\text { aplicadas? }\end{array}$ & $\begin{array}{l}\text { ¿ES esta } \\
\text { etapa un } \\
\text { PCC.? }\end{array}$ \\
\hline $\begin{array}{l}\text { Recepción de las cajas } \\
\text { de duraznos }\end{array}$ & $\begin{array}{l}\text { Deterioro de las condiciones fisicas, químicas y } \\
\text { microbiológicas del durazno }\end{array}$ & $\mathrm{Si}$ & $\begin{array}{l}\text { Mala manipulación de las cajas durante la } \\
\text { entrega que ocasionan golpes y aceleración } \\
\text { del proceso de putrefacción de los duraznos. }\end{array}$ & $\begin{array}{l}\text { Controlar y evaluar constantemente los } \\
\text { envios de los proveedores. Mejorar los } \\
\text { procedimientos de descarga y recepción }\end{array}$ & No \\
\hline $\begin{array}{l}\text { Recepción de las } \\
\text { harinas de maca, } \\
\text { quinua, kiwicha y } \\
\text { cañihua }\end{array}$ & $\begin{array}{l}\text { - Contaminación fisica por materiales extraños } \\
\text { - Aparición de insectos } \\
\text { - Contaminación química y microbiológica }\end{array}$ & $\mathrm{Si}$ & $\begin{array}{l}\text { Mal cocido de los sacos que contienen las } \\
\text { harinas. Inadecuadas condiciones de } \\
\text { transporte. Manejo de los sacos en } \\
\text { condiciones higiénicas no adecuadas }\end{array}$ & \begin{tabular}{|l|} 
Evaluación constante de los proveedores. \\
Los envios deben realizarse en sacos \\
esterilizados. Controles exhaustivos. \\
Verificar la integridad de los lotes de pedido
\end{tabular} & No \\
\hline \begin{tabular}{|l|} 
Recepción del \\
hidróxido de sodio
\end{tabular} & $\begin{array}{l}\text { Quemaduras nasales, en la boca, esófago, estómago y en } \\
\text { la piel }\end{array}$ & $\mathrm{Si}$ & Mala manipulación en la descarga & \begin{tabular}{|l|} 
Capacitación a los operarios sobre la \\
descarga del hidróxido de sodio
\end{tabular} & $\mathrm{Si}$ \\
\hline $\begin{array}{l}\text { Recepción de la } \\
\text { gasolina de } 98 \text { octanos }\end{array}$ & $\begin{array}{l}\text { Explosión, los vapores generan náuseas, dolor de cabeza, } \\
\text { alteraciones al sistema nervioso central, su ingestón } \\
\text { provoca diarrea, mareos e intoxicación y su contacto con la } \\
\text { piel y ojos produce irritación, conjuntivits y quemaduras }\end{array}$ & $\mathrm{Si}$ & Mala manipulación en la descarga & $\begin{array}{l}\text { Capacitación a los operarios sobre la } \\
\text { descarga del combustible y conectar los } \\
\text { barriles de combustible a tierra }\end{array}$ & $\mathrm{Si}$ \\
\hline $\begin{array}{l}\text { Recepción de envases } \\
\text { y tapas }\end{array}$ & $\begin{array}{l}\text { - Contaminación de envases y tapas } \\
\text { - Envases y tapas rajados }\end{array}$ & No & $\begin{array}{l}\text { Los envases y tapas pasan por un proceso } \\
\text { de esterilización }\end{array}$ & $\begin{array}{l}\text { No recepción de envases y tapas en malas } \\
\text { condiciones }\end{array}$ & No \\
\hline \begin{tabular}{|l|} 
Recepción de la \\
solución de Tego
\end{tabular} & Envases rajados & $\mathrm{Si}$ & $\begin{array}{l}\text { El liquido desinfectante podría entrar en } \\
\text { contacto con algún otro insumo. }\end{array}$ & $\begin{array}{l}\text { No recepción de envases con solución de } \\
\text { Tego en malas condiciones }\end{array}$ & No \\
\hline $\begin{array}{l}\text { Almacenamiento de los } \\
\text { duraznos }\end{array}$ & $\begin{array}{l}\text { Deterioro de las condiciones físicas, químicas y } \\
\text { microbiológicas del durazno }\end{array}$ & $\mathrm{Si}$ & $\begin{array}{l}\text { - Altera la calidad del producto final } \\
\text { - Es perjudicial para la salud de los infantes }\end{array}$ & $\begin{array}{l}\text { Evaluación de las condiciones ambientales } \\
\text { del almacén de materias primas a fin de } \\
\text { controlar la vida útl del durazno. }\end{array}$ & No \\
\hline $\begin{array}{l}\text { Almacenamiento de las } \\
\text { harinas de maca, } \\
\text { quinua, kiwicha y } \\
\text { cañihua }\end{array}$ & $\begin{array}{l}\text { - Deterioro del producto y disminución de su vida útil } \\
\text { - Enranciamiento de las harinas }\end{array}$ & $\mathrm{Si}$ & $\begin{array}{l}\text { - Rotura de las sacos } \\
\text { - Posible presencia de roedores e insectos } \\
\text { - Inadecuadas condiciones ambientales en el } \\
\text { almacén }\end{array}$ & $\begin{array}{l}\text { Realizar controles de temperatura en el } \\
\text { almacén de materia prima. Realizar un } \\
\text { programa de limpieza y fumigación en los } 3 \\
\text { almacenes }\end{array}$ & No \\
\hline $\begin{array}{l}\text { Almacenamiento de } \\
\text { envases y tapas }\end{array}$ & Ninguno & No & Los envases y tapas llegan embolsados & $\begin{array}{l}\text { Realizar un correcta disposición de las } \\
\text { bolsas de envases y tapas dentro del } \\
\text { almacén de insumos }\end{array}$ & No \\
\hline $\begin{array}{l}\text { Almacenamiento de la } \\
\text { solución de Tego }\end{array}$ & Derrame de la solución de Tego & No & $\begin{array}{l}\text { Se verifica que los envases no estén } \\
\text { dañados }\end{array}$ & $\begin{array}{l}\text { Realizar un correcta disposición de los } \\
\text { envases con solución de Tego dentro del } \\
\text { almacén de insumos }\end{array}$ & No \\
\hline Pesado & Ninguno & No & $\begin{array}{l}\text { Solo se pesan las cajas de duraznos y los } \\
\text { sacos de harina }\end{array}$ & $\begin{array}{l}\text { Limpiar y desinfectar la balanza después } \\
\text { del horario de trabajo }\end{array}$ & No \\
\hline Control de calidad & Ninguno & No & $\begin{array}{l}\text { Se verifica en el laboratorio de calidad que } \\
\text { las harinas de maca, quinua, kiwicha y } \\
\text { cañihua cumplan las condiciones fisicas, } \\
\text { químicas y biológicas }\end{array}$ & $\begin{array}{l}\text { Limpiar y desinfectar el laboratorio de } \\
\text { calidad después del horario trabajo }\end{array}$ & No \\
\hline $\begin{array}{l}\text { Lavado de los } \\
\text { duraznos }\end{array}$ & Ninguno & No & $\begin{array}{l}\text { Los duraznos son lavados con una solución } \\
\text { de Tego que es un desinfectante }\end{array}$ & $\begin{array}{l}\text { - Verificar la concentración de la solución de } \\
\text { tego con la que se lavan los duraznos } \\
\text { - Verificar si quedan residuos de tierra en } \\
\text { los duraznos después del lavado }\end{array}$ & No \\
\hline Seleccionado & Contaminación de los duraznos & No & $\begin{array}{l}\text { Los operarios que realizan el seleccionado } \\
\text { utilizan gorro, guantes y mascarilla protectora }\end{array}$ & \begin{tabular}{|l|} 
Verificar que los operarios utilicen los \\
implementos que se les entrega
\end{tabular} & No \\
\hline Descarozado & Contaminación de los duraznos & No & $\begin{array}{l}\text { La descorazadora después de cada jornada } \\
\text { de trabajo es limpiada y desinfectada }\end{array}$ & $\begin{array}{l}\text { Verificar que la máquina descarozadora } \\
\text { sea limpiada y desinfectada }\end{array}$ & No \\
\hline Orientado & Contaminación de los duraznos & No & $\begin{array}{l}\text { La orientadora después de cada jornada de } \\
\text { trabajo es limpiada y desinfectada }\end{array}$ & $\begin{array}{l}\text { Verificar que la máquina orientadora sea } \\
\text { limpiada y desinfectada }\end{array}$ & No \\
\hline Dilución & Explosión & $\mathrm{Si}$ & $\begin{array}{l}\text { Si no se realiza el procedimiento establecido } \\
\text { para la dilución del hidróxido de sodio } \\
\text { concentrado hay riesgo de explosión }\end{array}$ & $\begin{array}{l}\text { Capacitación a los operarios sobre el } \\
\text { procedimiento de dilución del hidróxido de } \\
\text { sodio concentrado }\end{array}$ & $\mathrm{Si}$ \\
\hline Pelado Químico & Ninguno & No & $\begin{array}{l}\text { No hay riesgo de contaminación porque la } \\
\text { máquina es limpiada y desinfectada después } \\
\text { de cada jornada laboral }\end{array}$ & $\begin{array}{l}\text { Verificar que la peladora química sea } \\
\text { limpiada y desinfectada }\end{array}$ & No \\
\hline Escaldado & Ninguno & No & \begin{tabular}{|l|} 
La máquina es limpiada y desinfectada \\
después de cada jornada de trabajo
\end{tabular} & $\begin{array}{l}\text { Verificar que la escaldadora sea limpiada y } \\
\text { desinfectada }\end{array}$ & No \\
\hline Despulpado y tamizado & Ninguno & No & $\begin{array}{l}\text { La máquina es limpiada y desinfectada } \\
\text { después de cada jornada de trabajo }\end{array}$ & $\begin{array}{l}\text { Verificar que la despulpadora sea limpiada } \\
\text { y desinfectada }\end{array}$ & No \\
\hline Mezclado & Contaminación de la mezcla & No & $\begin{array}{l}\text { En el mezclado se controla que solo se } \\
\text { agregue las harinas de maca, quinua, } \\
\text { kiwicha y cañihua de acuerdo a fórmula. }\end{array}$ & $\begin{array}{l}\text { Capacitar al operario de la estación sobre } \\
\text { los procedimientos del mezclado de } \\
\text { acuerdo a fórmula }\end{array}$ & No \\
\hline Pasteurizado & $\begin{array}{l}\text { Los microorganismos y organismos patógenos sobreviven } \\
\text { al pasteurizado }\end{array}$ & $\mathrm{Si}$ & $\begin{array}{l}\text { Del pasteurizado depende el tiempo de } \\
\text { duración de la compota y la calidad de ella. }\end{array}$ & $\begin{array}{l}\text { Verificar que se hace el pasteurizado de } \\
\text { acuerdo a los parámetros establecidos }\end{array}$ & $\mathrm{Si}$ \\
\hline Esterilizado & $\begin{array}{l}\text { Presencia de microorganismos en los envases y tapas } \\
\text { después del esterilizado }\end{array}$ & $\mathrm{Si}$ & $\begin{array}{l}\text { Es indispensable que los envases y tapas } \\
\text { esten esterilizados para garantizar la } \\
\text { inocuidad de la compota }\end{array}$ & $\begin{array}{l}\text { Verificar que se realiza el proceso de } \\
\text { esterilizado de acuerdo a los parámetros } \\
\text { establecidos }\end{array}$ & $\mathrm{Si}$ \\
\hline Llenado y tapado & Ninguno & No & $\begin{array}{l}\text { La máquina es limpiada y desinfectada } \\
\text { después de cada jornada de trabajo }\end{array}$ & $\begin{array}{l}\text { Verificar que la llenadora tapadora sea } \\
\text { limpiada y desinfectada }\end{array}$ & No \\
\hline Etquetado & Ninguno & No & No entra en contacto con la mezcla & $\begin{array}{l}\text { No es necesario aplicar ninguna medida } \\
\text { preventiva }\end{array}$ & No \\
\hline Encajado & Ninguno & No & No entra en contacto con la mezcla & $\begin{array}{l}\text { No es necesario aplicar ninguna medida } \\
\text { preventiva }\end{array}$ & No \\
\hline $\begin{array}{l}\text { Almacenamiento de } \\
\text { producto terminado }\end{array}$ & Ninguno & No & $\begin{array}{l}\text { El almacén de producto terminado es } \\
\text { limpiado y fumigado cada cierto tiempo }\end{array}$ & $\begin{array}{l}\text { Verificar que el almacén de producto } \\
\text { terminado se encuentre limpio }\end{array}$ & No \\
\hline
\end{tabular}

\section{Elaboración propia}


Luego se procederá a realizar el análisis de los puntos críticos de control identificados en el cuadro anterior los cuales son esenciales para prevenir o eliminar un peligro relacionado con la inocuidad de los alimentos o para reducirlo a un nivel aceptable.

Tabla 5.28

Puntos críticos de control

\begin{tabular}{|c|c|c|c|c|c|c|c|c|c|}
\hline \multirow[b]{2}{*}{ PCC } & \multirow[b]{2}{*}{ Peligro significativo } & \multirow{2}{*}{$\begin{array}{l}\text { Limites críticos } \\
\text { por medida } \\
\text { preventiva }\end{array}$} & \multicolumn{4}{|c|}{ Monitoreo } & \multirow[b]{2}{*}{$\begin{array}{l}\text { Acciones } \\
\text { correctivas }\end{array}$} & \multirow[b]{2}{*}{ Registros } & \multirow[b]{2}{*}{ Verificación } \\
\hline & & & Qué & Cómo & Frecuencia & Quién & & & \\
\hline $\begin{array}{l}\text { Recepción } \\
\text { del hidróxido } \\
\text { de sodio }\end{array}$ & $\begin{array}{l}\text { Quemaduras nasales, } \\
\text { en la boca, essófago, } \\
\text { estómago y en la piel }\end{array}$ & $\begin{array}{l}\text { Capacitaciones al } \\
\text { personal } 2 \text { veces } \\
\text { al mes }\end{array}$ & $\begin{array}{l}\text { Que se cumpla } \\
\text { el plan de } \\
\text { capacitación } \\
\text { sobre } \\
\text { prevención de } \\
\text { riesgos }\end{array}$ & $\begin{array}{l}\text { Control de asistencia } \\
\text { del personal a las } \\
\text { capacitaciones }\end{array}$ & $\begin{array}{l}2 \text { veces al } \\
\text { mes }\end{array}$ & \begin{tabular}{|l|} 
Jefe del área \\
de \\
producción \\
que cumple \\
las funciones \\
de seguridad \\
industrial
\end{tabular} & $\begin{array}{l}\text { Controlar la } \\
\text { asistencia del } \\
\text { personal } \\
\text { mensualmente e } \\
\text { incentivar } \\
\text { económicamente } \\
\text { la participación }\end{array}$ & $\begin{array}{l}\text { Documento con } \\
\text { el nombre de los } \\
\text { asistentes a las } \\
\text { charlas sobre } \\
\text { prevención de } \\
\text { riesgos }\end{array}$ & $\begin{array}{l}\text { Verificar que el } \\
\text { indicador de } \\
\text { cantidad de } \\
\text { accidentes } \\
\text { relacionados al } \\
\text { manipuleo del } \\
\text { hidróxido de sodio } \\
\text { sea menor o igual } \\
\text { a } 1 \text { mensualmente }\end{array}$ \\
\hline $\begin{array}{l}\text { Dilución del } \\
\text { hidróxido de } \\
\text { sodio }\end{array}$ & Explosión & $\begin{array}{l}\text { Capacitaciones al } \\
\text { personal } 2 \text { veces } \\
\text { al mes }\end{array}$ & $\begin{array}{l}\text { Que se cumpla } \\
\text { el plan de } \\
\text { capacitación } \\
\text { sobre } \\
\text { prevención de } \\
\text { riesgos }\end{array}$ & $\begin{array}{l}\text { Control de asistencia } \\
\text { del personal a las } \\
\text { capacitaciones }\end{array}$ & $\begin{array}{l}2 \text { veces al } \\
\text { mes }\end{array}$ & \begin{tabular}{|l|} 
Jefe del área \\
de \\
producción \\
que cumple \\
las funciones \\
de seguridad \\
industrial
\end{tabular} & $\begin{array}{l}\text { Controlar la } \\
\text { asistencia del } \\
\text { personal } \\
\text { mensualmente e } \\
\text { incentivar } \\
\text { económicamente } \\
\text { la participación }\end{array}$ & $\begin{array}{l}\text { Documento con } \\
\text { el nombre de los } \\
\text { asistentes a las } \\
\text { charlas sobre } \\
\text { prevención de } \\
\text { riesgos }\end{array}$ & $\begin{array}{l}\text { Verificar que el } \\
\text { indicador de } \\
\text { cantidad de } \\
\text { accidentes } \\
\text { relacionados al } \\
\text { manipuleo del } \\
\text { hidróxido de sodio } \\
\text { sea menor o igual } \\
\text { a } 1 \text { mensualmente }\end{array}$ \\
\hline $\begin{array}{l}\text { Recepción } \\
\text { de la } \\
\text { gasolina de } \\
98 \text { octanos }\end{array}$ & \begin{tabular}{|l|} 
Explosión, los vapores \\
generan náuseas, dolor \\
de cabeza, vómitos, \\
alteraciones al sistema \\
nervioso central, su \\
ingestión provoca \\
diarrea, mareos e \\
intoxicación y su \\
contacto con la piel y \\
ojos produce irritación, \\
conjuntivitis y \\
quemaduras
\end{tabular} & \begin{tabular}{|l|} 
\\
\\
Capacitaciones al \\
personal 2 veces \\
al mes
\end{tabular} & $\begin{array}{l}\text { Que se cumpla } \\
\text { el plan de } \\
\text { capacitación } \\
\text { sobre } \\
\text { prevención de } \\
\text { riesgos }\end{array}$ & $\begin{array}{l}\text { Control de asistencia } \\
\text { del personal a las } \\
\text { capacitaciones }\end{array}$ & $\begin{array}{l}2 \text { veces al } \\
\text { mes }\end{array}$ & \begin{tabular}{|l|} 
Jefe del área \\
de \\
producción \\
que cumple \\
las funciones \\
de seguridad \\
industrial
\end{tabular} & $\begin{array}{l}\text { Controlar la } \\
\text { asistencia del } \\
\text { personal } \\
\text { mensualmente e } \\
\text { incentivar } \\
\text { económicamente } \\
\text { la participación }\end{array}$ & $\begin{array}{l}\text { Documento con } \\
\text { el nombre de los } \\
\text { asistentes a las } \\
\text { charlas sobre } \\
\text { prevención de } \\
\text { riesgos }\end{array}$ & $\begin{array}{l}\text { Verificar que el } \\
\text { indicador de } \\
\text { cantidad de } \\
\text { accidentes } \\
\text { relacionados al } \\
\text { manipuleo de la } \\
\text { gasolina de } 98 \\
\text { octanos sea menor } \\
\text { o igual a } 1 \\
\text { mensualmente }\end{array}$ \\
\hline Pasteurizado & $\begin{array}{l}\text { Los microorganismos y } \\
\text { organismos patógenos } \\
\text { sobreviven al } \\
\text { pasteurizado }\end{array}$ & $\begin{array}{l}\text { El calentamiento } \\
\text { debe darse a } \\
90^{\circ} \mathrm{C} \text { durante } 5 \\
\text { minutos }\end{array}$ & $\begin{array}{l}\text { Temperatura a } \\
\text { la que se da el } \\
\text { pasteurizado }\end{array}$ & $\begin{array}{l}\text { Verificar el control } \\
\text { ajustable de } \\
\text { temperatura }\end{array}$ & \begin{tabular}{|l|} 
Cada vez \\
que se \\
realiza el \\
pasteurizado
\end{tabular} & $\begin{array}{l}\text { Operario de } \\
\text { la estación } \\
\text { de } \\
\text { pasteurizado }\end{array}$ & $\begin{array}{l}\text { Ajustar la } \\
\text { temperatura a lo } \\
\text { establecido en el } \\
\text { procedimiento } \\
\text { antes de realizar } \\
\text { el pasteurizado }\end{array}$ & $\begin{array}{l}\text { Documento con } \\
\text { Fecha, Hora y la } \\
\text { temperatura a la } \\
\text { que se trabajó el } \\
\text { pasteurizado }\end{array}$ & $\begin{array}{l}\text { Realizar un control } \\
\text { de calidad } \\
\text { mediante la } \\
\text { selección de una } \\
\text { muestra de la } \\
\text { mezcla } \\
\text { pasteurizada para } \\
\text { verificar que esté } \\
\text { libre de } \\
\text { microorganismos y } \\
\text { organismos } \\
\text { patógenos }\end{array}$ \\
\hline Esterilizado & $\begin{array}{l}\text { Presencia de } \\
\text { microorganismos en } \\
\text { los envases y tapas } \\
\text { después del } \\
\text { esterilizado }\end{array}$ & $\begin{array}{l}\text { El aire caliente } \\
\text { debe estar a } \\
80^{\circ} \mathrm{C} \text { y el agua } \\
\text { oxigenada } \\
\text { nebulizada a una } \\
\text { concentración del } \\
30 \%\end{array}$ & $\begin{array}{l}\text { - Temperatura } \\
\text { del aire } \\
\text { - Concentración } \\
\text { del agua } \\
\text { oxigenada } \\
\text { nebulizada }\end{array}$ & $\begin{array}{l}\text { Verificar que los } \\
\text { valores de } \\
\text { temperatura del aire y } \\
\text { concentración del } \\
\text { agua oxigenada } \\
\text { nebulizada que } \\
\text { muestra el PLC } \\
\text { coincidan con los } \\
\text { establecidos en el } \\
\text { procedimiento }\end{array}$ & $\begin{array}{l}\text { Verificar } \\
\text { cada } 30 \\
\text { minutos }\end{array}$ & $\begin{array}{l}\text { Operario de } \\
\text { la estación } \\
\text { de } \\
\text { esterilizado }\end{array}$ & $\begin{array}{l}\text { Ajustar la } \\
\text { temperatura del } \\
\text { PLC a lo } \\
\text { establecido en el } \\
\text { procedimiento } \\
\text { antes de realizar } \\
\text { el esterilizado }\end{array}$ & $\begin{array}{l}\text { Documento con } \\
\text { la Fecha, Hora, } \\
\text { la temperatura } \\
\text { del aire caliente } \\
\text { y la } \\
\text { concentración } \\
\text { del agua } \\
\text { oxigenada } \\
\text { nebulizada }\end{array}$ & $\begin{array}{l}\text { Realizar un control } \\
\text { de calidad } \\
\text { mediante una } \\
\text { selección aleatoria } \\
\text { de los envases y } \\
\text { tapas esterilizados }\end{array}$ \\
\hline
\end{tabular}

Elaboración propia

\subsubsection{Estrategias de mejora}

Las estrategias de mejora aplicadas son las siguientes:

- Economías de escala en la compra de materias primas e insumos para poder obtener costos eficientes.

- Economías de escala en la producción de la compota para bebés para poder diluir los costos fijos y así lograr ser más eficientes en la producción.

- Centrar el esfuerzo de la empresa en su actividad principal que es la producción de la compota para bebés a partir de durazno enriquecido con maca, quinua, kiwicha y 
cañihua. Esto lleva a tercerizar el mantenimiento, la limpieza, la distribución y la vigilancia que se va a desarrollar mejor por empresas especializadas. El mantenimiento de la planta y la limpieza serán realizados por la empresa $\mathrm{NCH}$ Perú, la distribución por la empresa Ransa y la vigilancia por la empresa Prosegur.

- Uso del sistema HACCP para garantizar la inocuidad de los alimentos y obtener un producto de alta calidad.

- Uso de un plan de mantenimiento definido por el Jefe de manufactura el cual deberá ejecutar la empresa NCH Perú que garantiza la disponibilidad y confiabilidad de los equipos. Asimismo disminuye el costo por mantenimiento reactivo.

\subsection{Estudio de Impacto ambiental}

Se procederá a realizar el análisis de las operaciones del proceso de producción e identificación de los posibles impactos ambientales que pudieran generar.

Tabla 5.29

Impactos ambientales

\begin{tabular}{|c|c|c|c|}
\hline Actividad & Salidas & Impacto ambiental & Medida correctiva \\
\hline $\begin{array}{l}\text { Recepción de } \\
\text { materias primas, } \\
\text { insumos y } \\
\text { combustible }\end{array}$ & $\begin{array}{l}\text { Emisión de dióxido de } \\
\text { carbono por parte de los } \\
\text { camiones }\end{array}$ & $\begin{array}{l}\text { Contaminación del aire por } \\
\text { aumento de gases de efecto } \\
\text { invernadero }\end{array}$ & $\begin{array}{l}\text { Solicitar a los proveedores que realicen } \\
\text { mantenimientos periódicos a los motores de los } \\
\text { camiones para que tengan una combustión completa }\end{array}$ \\
\hline $\begin{array}{l}\text { Almacenamiento } \\
\text { de materias } \\
\text { primas e insumos }\end{array}$ & $\begin{array}{l}\text { Emisión de dióxido de } \\
\text { carbono por parte de los } \\
\text { montacargas }\end{array}$ & $\begin{array}{l}\text { Contaminación del aire por } \\
\text { aumento de gases de efecto } \\
\text { invernadero }\end{array}$ & $\begin{array}{l}\text { Mantenimiento mensual al motor del montacargas } \\
\text { para que realice una combustión completa }\end{array}$ \\
\hline Pesado & Ninguno & Ninguno & Ninguno \\
\hline Control de calidad & Ninguno & Ninguno & Ninguno \\
\hline \multirow[b]{2}{*}{$\begin{array}{l}\text { Lavado de los } \\
\text { duraznos }\end{array}$} & $\begin{array}{l}\text { - Agua con solución de } \\
\text { Tego y restos de tierra }\end{array}$ & - Contaminación del agua & $\begin{array}{l}\text { - Tratamiento de efluentes en la planta de tratamiento } \\
\text { de aguas residuales de Ventanilla }\end{array}$ \\
\hline & $\begin{array}{l}\text { - Envases de la solución } \\
\text { de Tego }\end{array}$ & $\begin{array}{l}\text { - Contaminación por } \\
\text { generación de residuos } \\
\text { sólidos }\end{array}$ & $\begin{array}{l}\text { - Vender los envases de plástico a empresas } \\
\text { recicladoras de plástico }\end{array}$ \\
\hline Seleccionado & $\begin{array}{l}\text { Duraznos verdes, } \\
\text { podridos o dañados }\end{array}$ & $\begin{array}{l}\text { Contaminación por } \\
\text { generación de residuos } \\
\text { sólidos }\end{array}$ & $\begin{array}{l}\text { Vender los duraznos verdes, podridos o dañados a } \\
\text { empresas fabricadoras de compost }\end{array}$ \\
\hline Descarozado & Restos de carozo & $\begin{array}{l}\text { Contaminación por } \\
\text { generación de residuos } \\
\text { sólidos }\end{array}$ & $\begin{array}{l}\text { Vender los restos de carozo a empresas fabricadoras } \\
\text { de compost }\end{array}$ \\
\hline Orientado & Ninguno & Ninguno & Ninguno \\
\hline Dilución & Ninguno & Ninguno & Ninguno \\
\hline Pelado Químico & $\begin{array}{l}\text { Agua con hidróxido de } \\
\text { sodio y restos de cáscara } \\
\text { de durazno }\end{array}$ & Contaminación del agua & $\begin{array}{l}\text { Tratamiento de efluentes en la planta de tratamiento } \\
\text { de aguas residuales de Ventanilla }\end{array}$ \\
\hline Escaldado & $\begin{array}{l}\text { Agua con restos de } \\
\text { durazno }\end{array}$ & Contaminación del agua & $\begin{array}{l}\text { Tratamiento de efluentes en la planta de tratamiento } \\
\text { de aguas residuales de Ventanilla }\end{array}$ \\
\hline $\begin{array}{l}\text { Despulpado y } \\
\text { tamizado }\end{array}$ & $\begin{array}{l}\text { Restos de carozo y } \\
\text { cáscaras de durazno }\end{array}$ & $\begin{array}{l}\text { Contaminación por } \\
\text { generación de residuos } \\
\text { sólidos }\end{array}$ & $\begin{array}{l}\text { Vender los restos de carozo y cáscaras de durazno a } \\
\text { empresas fabricadoras de compost }\end{array}$ \\
\hline Mezclado & $\begin{array}{l}\text { Sacos que contenían las } \\
\text { harinas }\end{array}$ & $\begin{array}{l}\text { Contaminación por } \\
\text { generación de residuos } \\
\text { sólidos }\end{array}$ & Devolver los sacos al proveedor para su reutilización \\
\hline Pasteurizado & Ninguno & Ninguno & Ninguno \\
\hline Esterilizado & Vapor de agua oxigenada & Contaminación del aire & Ninguno pues la contaminación es mínima \\
\hline Llenado y tapado & Ninguno & Ninguno & Ninguno \\
\hline Etiquetado & $\begin{array}{l}\text { Bolsas de plástico que } \\
\text { contenían las bobinas de } \\
\text { etiquetas }\end{array}$ & $\begin{array}{l}\text { Contaminación por } \\
\text { generación de residuos } \\
\text { sólidos }\end{array}$ & $\begin{array}{l}\text { Vender las bolsas de plástico a empresas } \\
\text { recicladoras de plástico }\end{array}$ \\
\hline Encajado & Rafia & $\begin{array}{l}\text { Contaminación por } \\
\text { generación de residuos } \\
\text { sólidos }\end{array}$ & Vender la rafia a empresas recicladoras de plástico \\
\hline $\begin{array}{l}\text { Almacenamiento } \\
\text { de producto } \\
\text { terminado }\end{array}$ & $\begin{array}{l}\text { Emisión de dióxido de } \\
\text { carbono por parte de los } \\
\text { montacargas }\end{array}$ & $\begin{array}{l}\text { Contaminación del aire por } \\
\text { aumento de gases de efecto } \\
\text { invernadero }\end{array}$ & $\begin{array}{l}\text { Mantenimiento mensual al motor del montacargas } \\
\text { para que realice una combustión completa }\end{array}$ \\
\hline
\end{tabular}

Elaboración propia 


\subsection{Seguridad y salud ocupacional}

Para la planificación del sistema de gestión de la seguridad se utilizará el método IPER el cual permite priorizar los riesgos en función al nivel crítico establecido y las acciones preventivas se desarrollarán en base a los riesgos priorizados.

Tabla 5.30

IPER

\begin{tabular}{|c|c|c|c|c|c|c|c|c|c|c|c|c|}
\hline \multirow[b]{2}{*}{ Tarea } & \multirow[b]{2}{*}{ Peligro } & \multirow[b]{2}{*}{ Riesgo } & \multicolumn{5}{|c|}{ Probabilidad } & \multirow[b]{2}{*}{$\begin{array}{l}\text { Índice de } \\
\text { severidad }\end{array}$} & \multirow[b]{2}{*}{$\begin{array}{c}\text { Probabilidad } \\
\mathbf{x} \\
\text { Severidad }\end{array}$} & \multirow[b]{2}{*}{$\begin{array}{c}\text { Nivel de } \\
\text { riesgo }\end{array}$} & \multirow[b]{2}{*}{$\begin{array}{c}\text { Riesgo } \\
\text { significativo }\end{array}$} & \multirow[b]{2}{*}{ Medidas de control } \\
\hline & & & $\begin{array}{c}\text { Índice de } \\
\text { personas } \\
\text { expuestas (A) }\end{array}$ & \begin{tabular}{|c|}
\multicolumn{1}{c}{ Índice de } \\
procedimientos \\
existentes (B)
\end{tabular} & $\begin{array}{l}\text { Índice de } \\
\text { capacitación } \\
\text { (C) }\end{array}$ & $\begin{array}{l}\text { Índice de } \\
\text { exposición al } \\
\text { riesgo (D) }\end{array}$ & $\begin{array}{c}\text { Índice de } \\
\text { probabilidad } \\
(A+B+C+D)\end{array}$ & & & & & \\
\hline $\begin{array}{l}\text { Recepción y } \\
\text { almacenamiento de } \\
\text { materias primas e } \\
\text { insumos }\end{array}$ & $\begin{array}{l}\text { Hidróxido de } \\
\text { sodio }\end{array}$ & $\begin{array}{l}\text { Probabilidad de tener } \\
\text { quemaduras nasales, en la } \\
\text { boca, essófago, estómago y } \\
\text { en la piel }\end{array}$ & 1 & 1 & 1 & 2 & 5 & 3 & 15 & Moderado & $\mathrm{Si}$ & $\begin{array}{l}\text { Capacitación a los } \\
\text { operarios sobre la } \\
\text { manipulación del } \\
\text { hidróxido de sodio }\end{array}$ \\
\hline $\begin{array}{l}\text { Recepción y } \\
\text { almacenamiento del } \\
\text { combustible }\end{array}$ & $\begin{array}{l}\text { Gasolina de } 98 \\
\text { octanos }\end{array}$ & $\begin{array}{l}\text { Probabilidad de explosión, } \\
\text { náuseas, dolor de cabeza, } \\
\text { vómitos, alteraciones al } \\
\text { sistema nervioso central, } \\
\text { diarrea, mareos e } \\
\text { intoxicación, irritación de la } \\
\text { piel, conjuntivitis y } \\
\text { quemaduras }\end{array}$ & 1 & 1 & 1 & 2 & 5 & 3 & 15 & Moderado & $\mathrm{Si}$ & $\begin{array}{l}\text { Capacitación a los } \\
\text { operarios sobre la } \\
\text { manipulación de la } \\
\text { gasolina de } 98 \\
\text { octanos }\end{array}$ \\
\hline Pesado & $\begin{array}{l}\text { Astillas de las } \\
\text { cajas de madera }\end{array}$ & $\begin{array}{l}\text { Probabilidad de enterrarse } \\
\text { una astilla en la mano }\end{array}$ & 1 & 1 & 1 & 3 & 6 & 1 & 6 & Tolerable & No & $\begin{array}{l}\text { Entregar a los } \\
\text { operarios guantes } \\
\text { protectores }\end{array}$ \\
\hline Control de calidad & Ninguno & Ninguno & 1 & 1 & 1 & 1 & 4 & 1 & 4 & Trivial & No & Ninguno \\
\hline $\begin{array}{l}\text { Lavado de los } \\
\text { duraznos }\end{array}$ & Ninguno & Ninguno & 1 & 1 & 1 & 1 & 4 & 1 & 4 & Trivial & No & Ninguno \\
\hline Seleccionado & Ninguno & Ninguno & 1 & 1 & 1 & 1 & 4 & 1 & 4 & Trivial & No & Ninguno \\
\hline Descarozado & Ninguno & Ninguno & 1 & 1 & 1 & 1 & 4 & 1 & 4 & Trivial & No & Ninguno \\
\hline Orientado & Ninguno & Ninguno & 1 & 1 & 1 & 1 & 4 & 1 & 4 & Trivial & No & Ninguno \\
\hline Dilución & $\begin{array}{l}\text { Hidróxido de } \\
\text { sodio }\end{array}$ & Probabilidad de explosión & 1 & 1 & 1 & 2 & 5 & 3 & 15 & Moderado & $\mathrm{Si}$ & $\begin{array}{l}\text { Capacitación a los } \\
\text { operarios sobre el } \\
\text { procedimiento de } \\
\text { dilución del hidróxido } \\
\text { de sodio }\end{array}$ \\
\hline Pelado Químico & Ninguno & Ninguno & 1 & 1 & 1 & 1 & 4 & 1 & 4 & Trivial & No & Ninguno \\
\hline Escaldado & Ninguno & Ninguno & 1 & 1 & 1 & 1 & 4 & 1 & 4 & Trivial & No & Ninguno \\
\hline $\begin{array}{l}\text { Despulpado y } \\
\text { tamizado }\end{array}$ & Ninguno & Ninguno & 1 & 1 & 1 & 1 & 4 & 1 & 4 & Trivial & No & Ninguno \\
\hline Mezclado & Ninguno & Ninguno & 1 & 1 & 1 & 1 & 4 & 1 & 4 & Trivial & No & Ninguno \\
\hline Pasteurizado & Ninguno & Ninguno & 1 & 1 & 1 & 1 & 4 & 1 & 4 & Trivial & No & Ninguno \\
\hline Esterilizado & Ninguno & Ninguno & 1 & 1 & 1 & 1 & 4 & 1 & 4 & Trivial & No & Ninguno \\
\hline Llenado y tapado & Ninguno & Ninguno & 1 & 1 & 1 & 1 & 4 & 1 & 4 & Trivial & No & Ninguno \\
\hline Etiquetado & Ninguno & Ninguno & 1 & 1 & 1 & 1 & 4 & 1 & 4 & Trivial & No & Ninguno \\
\hline Encajado & Ninguno & Ninguno & 1 & 1 & 1 & 1 & 4 & 1 & 4 & Trivial & No & Ninguno \\
\hline $\begin{array}{l}\text { Almacenamiento de } \\
\text { producto terminado }\end{array}$ & Montacargas & $\begin{array}{l}\text { Probabilidad de atropellar a } \\
\text { un operario de planta }\end{array}$ & 1 & 1 & 1 & 3 & 6 & 2 & 12 & Moderado & $\mathrm{Si}$ & $\begin{array}{l}\text { Señalizar las áreas } \\
\text { por donde transita el } \\
\text { montacargas }\end{array}$ \\
\hline
\end{tabular}

Elaboración propia 
Figura 5.7

Criterios de evaluación IPER

\begin{tabular}{|c|c|c|c|c|c|}
\hline \multirow[b]{2}{*}{ IWoice } & \multicolumn{4}{|c|}{ PROBABILIDAD } & \multirow{2}{*}{$\begin{array}{l}\text { SEVERIDAD } \\
\text { (Consecueneia) }\end{array}$} \\
\hline & $\begin{array}{l}\text { PERSONAS } \\
\text { EXPUESTAS }\end{array}$ & $\begin{array}{l}\text { PROCEDIIIENTOS } \\
\text { EXISTENTES }\end{array}$ & CAPACITACIOH & $\begin{array}{c}\text { EXPOSICION AL } \\
\text { RESGOSO }\end{array}$ & \\
\hline 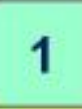 & 1 a 3 & $\begin{array}{l}\text { Existenson } \\
\text { Satisfactorios y } \\
\text { Sufifientes }\end{array}$ & $\begin{array}{l}\text { Personal } \\
\text { entrenado, conoce } \\
\text { el peligro y lo } \\
\text { previene }\end{array}$ & $\begin{array}{l}\text { Al menes una vez al } \\
\text { ano } \\
\text { ESPORADICAMENTE }\end{array}$ & $\begin{array}{l}\text { Lesionsin Ineapaeidac } \\
\text { DISCONFORT } \\
\text { ENCOMODIDAD }\end{array}$ \\
\hline 2 & 4 a12 & $\begin{array}{l}\text { Existen } \\
\text { Parcialmento y no } \\
\text { son Satisfacterios } \\
\text { o Suficientes }\end{array}$ & $\begin{array}{l}\text { Personal } \\
\text { Pareialmente } \\
\text { Entrenado, conoce } \\
\text { el Peligro pero no } \\
\text { Tama Acciones do } \\
\text { Gentrel }\end{array}$ & $\begin{array}{l}\text { Al menos una vez al } \\
\text { mes } \\
\text { EVENTUALUENTE }\end{array}$ & $\begin{array}{c}\text { Lesión cen Ineapacidad } \\
\text { Temporal } \\
\text { DARO A SALUD } \\
\text { REVERSIBLE }\end{array}$ \\
\hline 3 & 12 a mas & No Existen & $\begin{array}{l}\text { Pers onal No } \\
\text { Entrenado, No } \\
\text { canoce el Peligro, } \\
\text { No Toma Acciones } \\
\text { de Control }\end{array}$ & $\begin{array}{l}\text { Al menos una vez al } \\
\text { dia } \\
\text { PERREANENTE }\end{array}$ & $\begin{array}{l}\text { Lasión con Incapacidad } \\
\text { Permanente } \\
\text { DANNO A LA SALUD } \\
\text { IRREVERSIBLE }\end{array}$ \\
\hline
\end{tabular}

Fuente: Seguridad Integral, (2016)

Figura 5.8

Nivel de riesgo

\begin{tabular}{|c|c|}
\hline $\begin{array}{c}\text { NIVEL DE } \\
\text { RIESGO }\end{array}$ & \multicolumn{1}{c|}{ POSTURA } \\
\hline $\begin{array}{c}\text { TRIVIAL } \\
4\end{array}$ & - No requiere Acción Especifica \\
\hline $\begin{array}{c}\text { TOLERABLE } \\
5-8\end{array}$ & $\begin{array}{c}\text { - Mantener eficacia de las acciones preventivas } \\
\text { - Buscar alternativas mas económicas } \\
\text { - Comprobar e Inspeccionar Periódicamente para Mantener Nivel }\end{array}$ \\
\hline $\begin{array}{c}\text { MODERADO } \\
9-16\end{array}$ & $\begin{array}{c}\text { - Aplicar acciones para Reducir el Riesgo en un plazo determinado. } \\
\text { Si riesgo esta asociado a consecuencias Extremadamente Dañinas } \\
\text { (mortal o grave) revaluar par mejorar resultados }\end{array}$ \\
\hline $\begin{array}{c}\text { IMPORTANTE } \\
174\end{array}$ & $\begin{array}{c}\text { - No empezar el Trabajo hasta reducir el riesgo } \\
\text { - Es nosible que requiera importantes recursos para control del riesgo. } \\
\text { Si el riegos esta asociado a un trabajo que se esta realizando, } \\
\text { solucionar en corto plazo. }\end{array}$ \\
\hline $\begin{array}{c}\text { INTOLERABLE } \\
25-36\end{array}$ & $\begin{array}{l}\text { No empezar ni continuar el Proceso hasta no Reducir el Riesgo } \\
\text { Si no es posible reducir el Riesgo, prohibir el Trabajo (incluso con } \\
\text { Recursos limitados) }\end{array}$ \\
\hline
\end{tabular}

Fuente: Seguridad Integral, (2016)

\subsection{Sistemas de mantenimiento}

El mantenimiento se tercerizará y se realizaran 2 tipos de mantenimiento a las máquinas y equipos:

Mantenimiento preventivo: Es una serie de actividades planeadas previamente que se llevan a cabo para contrarrestar las causas conocidas de fallas potenciales de las funciones de los equipos. Se lleva a cabo para asegurar la disponibilidad y confiabilidad del equipo.. La principal ventaja de este mantenimiento es bajar los costos.

Mantenimiento correctivo: Consiste en reemplazar los componentes de la máquina luego de ocurrir el fallo. 


\section{Tabla 5.31}

\section{Mantenimiento de equipos}

\begin{tabular}{|c|c|c|c|c|}
\hline Máquina & Función & $\begin{array}{c}\text { Tipo de } \\
\text { mantenimiento }\end{array}$ & Frecuencia & Detalle \\
\hline \multirow{4}{*}{$\begin{array}{l}\text { Báscula de piso } \\
\text { portátil }\end{array}$} & \multirow{4}{*}{ Pesado } & \multirow{4}{*}{ Preventivo } & \multirow{4}{*}{6 meses } & - Realizar la limpieza integral interna y externa del equipo \\
\hline & & & & - Verificar el sistema electrónico \\
\hline & & & & - Verificar la calibración de cero de la báscula y si es necesario ajustarla \\
\hline & & & & - Verificar la calibración de la báscula con un peso conocido \\
\hline \multirow[b]{2}{*}{ Descarozadora } & \multirow[b]{2}{*}{ Descarozado } & Preventivo & Diario & - Realizar la limpieza general del equipo \\
\hline & & Correctivo & $\begin{array}{l}\text { Cuando se presente } \\
\text { la necesidad }\end{array}$ & $\begin{array}{l}\text { - Se aplicará mantenimiento correctivo a las partes del equipo susceptibles de falla como las cuchillas planas, las } \\
\text { cuchillas curvas y la bandeja vibrante con perforaciones }\end{array}$ \\
\hline \multirow{5}{*}{ Despulpadora } & \multirow{5}{*}{ Despulpado } & \multirow{4}{*}{ Preventivo } & Diario & - Realizar la limpieza general del equipo \\
\hline & & & Semanal & - Revisar y lubricar los rodamientos de la despulpadora \\
\hline & & & Mensual & - Revisar el sistema eléctrico \\
\hline & & & Anual & - Revisar y lubricar los rodamientos del motor eléctrico \\
\hline & & Correctivo & $\begin{array}{l}\text { Cuando se presente } \\
\text { la necesidad }\end{array}$ & $\begin{array}{l}\text { - Se aplicará mantenimiento correctivo a las partes del equipo susceptibles de falla como el tamiz, los rodamientos } \\
\text { del motor eléctrico, tornillos y pernos de ajuste. }\end{array}$ \\
\hline \multirow{3}{*}{ Encajonadora } & \multirow{3}{*}{ Encajado } & \multirow{2}{*}{ Preventivo } & Semanal & - Realizar la limpieza general del equipo \\
\hline & & & Anual & - Revisar y lubricar los rodamientos del motor eléctrico \\
\hline & & Correctivo & $\begin{array}{l}\text { Cuando se presente } \\
\text { la necesidad }\end{array}$ & $\begin{array}{l}\text { - Se aplicará mantenimiento correctivo a las partes del equipo susceptibles de falla como la cinta transportadora y el } \\
\text { sistema de sujeción de envases }\end{array}$ \\
\hline \multirow{3}{*}{ Escaldadora } & \multirow{3}{*}{ Escaldado } & \multirow{2}{*}{ Preventivo } & Diario & - Realizar la limpieza general del equipo \\
\hline & & & Anual & - Revisar y lubricar los rodamientos del motor eléctrico \\
\hline & & Correctivo & $\begin{array}{l}\text { Cuando se presente } \\
\text { la necesidad }\end{array}$ & $\begin{array}{l}\text { - Se aplicará mantenimiento correctivo a las partes del equipo susceptibles de falla como el transportador tipo } \\
\text { cadenas laterales con arreadores }\end{array}$ \\
\hline Esterilizador & & Preventivo & Semanal & - Realizar la limpieza general del equipo \\
\hline $\begin{array}{l}\text { electrónico de } \\
\text { frascos y tapas }\end{array}$ & Esterilizado & Correctivo & $\begin{array}{l}\text { Cuando se presente } \\
\text { la necesidad }\end{array}$ & $\begin{array}{l}\text { - Se aplicará mantenimiento correctivo a las partes del equipo susceptibles de falla como las boquillas atomizadoras, } \\
\text { el PLC y la electroválvula }\end{array}$ \\
\hline & & Preventivo & Semanal & - Realizar la limpieza general del equipo \\
\hline Etiquetadora & Etiquetado & Preventivo & Anual & - Revisar y lubricar los rodamientos del motor eléctrico \\
\hline & Liquetavio & Correctivo & $\begin{array}{l}\text { Cuando se presente } \\
\text { la necesidad }\end{array}$ & $\begin{array}{l}\text { - Se aplicará mantenimiento correctivo a las partes del equipo susceptibles de falla como el sensor de envases y el } \\
\text { cabezal despachador de etiquetas auto adheribles }\end{array}$ \\
\hline & & Preventivo & Diario & - Realizar la limpieza general del equipo \\
\hline Faja transportadora & Transporte & reventivo & Semanal & - Lubricar la cadena de transmisión \\
\hline 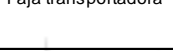 & Tianspote & Correctivo & $\begin{array}{l}\text { Cuando se presente } \\
\text { la necesidad }\end{array}$ & $\begin{array}{l}\text {-Se aplicará mantenimiento correctivo a las partes del equipo susceptibles de falla como la cadena de transmisión, } \\
\text { tornillos y pernos de ajuste }\end{array}$ \\
\hline & & Preventivo & Diario & - Realizar la limpieza general del equipo \\
\hline $\begin{array}{l}\text { Llenadora- } \\
\text { Tapadora }\end{array}$ & Llenado y tapado & Correctivo & $\begin{array}{l}\text { Cuando se presente } \\
\text { la necesidad }\end{array}$ & $\begin{array}{l}\text { - Se aplicará mantenimiento correctivo a las partes del equipo susceptibles de falla como las boquillas de llenado y } \\
\text { el PLC }\end{array}$ \\
\hline & & Preventivo & Semanal & - Realizar la limpieza general del equipo \\
\hline Lavadora de frutas & Lavado & seventivo & Anual & - Revisar y lubricar los rodamientos del motor eléctrico \\
\hline & & Correctivo & $\begin{array}{l}\text { Cuando se presente } \\
\text { la necesidad }\end{array}$ & $\begin{array}{l}\text { - Se aplicará mantenimiento correctivo a las partes del equipo susceptibles de falla como las cadenas de plástico, } \\
\text { las paletas y rodamientos del motor eléctrico }\end{array}$ \\
\hline & & Preventivo & Diario & - Realizar la limpieza general del equipo \\
\hline $\begin{array}{l}\text { Marmita a vapor } \\
\text { eléctrica }\end{array}$ & Pasteurizado & Correctivo & $\begin{array}{l}\text { Cuando se presente } \\
\text { la necesidad }\end{array}$ & $\begin{array}{l}\text { - Se aplicará mantenimiento correctivo a las partes del equipo susceptibles de falla como la válvula de alivio de } \\
\text { presión, la resistencia eléctrica, el manómetro yel mando de control de temperatura }\end{array}$ \\
\hline & & & Diario & - Realizar la limpieza general del equipo \\
\hline & & Preventivo & Semanal & - Lubricar chumaceras \\
\hline $\begin{array}{l}\text { Miezciadora de } \\
\text { paletas }\end{array}$ & Mezclado & & |Semanal & - Engrasar los acoplamientos \\
\hline & & Correctivo & $\begin{array}{l}\text { Cuando se presente } \\
\text { la necesidad }\end{array}$ & - Se aplicará mantenimiento correctivo a las partes del equipo susceptibles de falla como las paletas de mezclado \\
\hline (1 & & & & - Revisar líquido de frenos \\
\hline & & & Somanal & - Revisar el nivel de agua en el radiador \\
\hline & & & & - Revisar aceite y bandas del motor \\
\hline & & Drounntivg & & - Medir presión de llantas \\
\hline Montacargas & Transporte & reventivo & & - Realizar la limpieza y calibración del carburador \\
\hline & & & Mensurt & - Realizar un engrase y lubricación general \\
\hline & & & jivensual & - Revisar sistema de frenos, dirección, hidráulico y rodamiento \\
\hline & & & & - Revisar el sistema de combustible \\
\hline & & Correctivo & $\begin{array}{l}\text { Cuando se presente } \\
\text { la necesidad }\end{array}$ & - Se aplicará mantenimiento correctivo a las partes del equipo susceptibles de falla como las Ilantas \\
\hline Peladora auímica & Pelado & Preventivo & Diario & - Realizar la limpieza general del equipo \\
\hline & & rieventivo & Anual & - Revisar y lubricar los rodamientos del motor eléctrico \\
\hline $\begin{array}{c}\text { Tanque de acero } \\
\text { inoxidable }\end{array}$ & Almacenamiento & Preventivo & Diario & - Realizar la limpieza general del equipo \\
\hline $\begin{array}{c}\text { Tanque de } \\
\text { almacenamiento de } \\
\text { hidróxido de sodio }\end{array}$ & Almacenamiento & Preventivo & Mensual & $\begin{array}{l}\text { - Verificar que el tanque de almacenamiento de hidróxido de sodio no tenga perforaciones que puedan generar } \\
\text { derrames }\end{array}$ \\
\hline & & Proventive & Diario & - Realizar la limpieza general del equipo \\
\hline Volcadora de & Volcado & Preventivo & Anual & - Revisar y lubricar los rodamientos del motor eléctrico \\
\hline & & Correctivo & $\begin{array}{l}\text { Cuando se presente } \\
\text { la necesidad }\end{array}$ & - Se aplicará mantenimiento correctivo a las partes del equipo susceptibles de falla como los brazos oscilantes \\
\hline & & & & - Realizar la limpieza externa \\
\hline & & & Semanat & \begin{tabular}{|l} 
- Revisar si hay fugas de hidróxido de sodio \\
\end{tabular} \\
\hline $\begin{array}{l}\text { Bomba para } \\
\text { hidróxido de sodio }\end{array}$ & Transporte & Preventivo & jemanal & - Revisar si hay ruidos extraños \\
\hline & & & & - Calibrar la velocidad a la que va el hidróxido de sodio \\
\hline & & & 6 meses & - Realizar una revisión general de la bomba \\
\hline & & & & - Realizar la limpieza externa \\
\hline & & & Semanat & - Revisar si hay fugas de la mezcla de producto \\
\hline $\begin{array}{l}\text { Bomba para } \\
\text { alimentos }\end{array}$ & Transporte & Preventivo & jemantal & - Revisar si hay ruidos extraños \\
\hline & & & & - Calibrar la velocidad a la que va la mezcla de producto \\
\hline & & & 6 meses & - Realizar una revisión general de la bomba \\
\hline
\end{tabular}

Elaboración propia 


\subsection{Programa de producción}

\subsubsection{Factores para la programación de la producción}

\section{Factor Humano}

Es la actividad humana que interviene en el proceso de producción. Se cuenta con 42 trabajadores en la planta de producción.

\section{Factor Recursos naturales}

Son todos los recursos que encontramos en la naturaleza y se emplearán en la fabricación del producto final. Estos son: Durazno, Maca, Quinua, Kiwicha y Cañihua.

\section{Factor capital}

Son los bienes requeridos por la empresa para realizar el proceso de producción. Los cuales son: La construcción de la fábrica, las maquinarias, los montacargas, las parihuelas, etc.

\subsubsection{Programa de producción}

Contando con todos la disposición de los factores productivos, se determinó la producción anual requerida como la demanda proyectada de cada año más un stock de seguridad que es igual a la producción mensual del año correspondiente, el producto terminado no se mantiene mucho tiempo en los almacenes debido a que es perecedero en 6 meses.

Tabla 5.32

Programa de producción de vida útil del proyecto

\begin{tabular}{|c|r|r|r|r|r|r|}
\hline Año & \multicolumn{1}{|c|}{$\mathbf{2 0 1 6}$} & \multicolumn{1}{c|}{$\mathbf{2 0 1 7}$} & \multicolumn{1}{c|}{$\mathbf{2 0 1 8}$} & \multicolumn{1}{c|}{$\mathbf{2 0 1 9}$} & \multicolumn{1}{c|}{$\mathbf{2 0 2 0}$} & \multicolumn{1}{c|}{$\mathbf{2 0 2 1}$} \\
\hline Demanda (kg) & \multicolumn{1}{|c|}{322.172} & 457.008 & 648.235 & 919.422 & 1.303 .986 & 1.849 .297 \\
\hline SS(kg) & 26.848 & 38.084 & 54.020 & 76.619 & 108.666 & 154.108 \\
\hline Producción (kg) & 349.020 & 495.092 & 702.254 & 996.041 & 1.412 .652 & 2.003 .406 \\
\hline
\end{tabular}

Elaboración propia

\subsection{Requerimientos de insumos, personal y servicios}

\subsubsection{Materia prima, insumos y otros materiales}

Las materias primas y los insumos requeridos para cumplir con la demanda proyectada del año 2016 al 2021, se muestran en los siguientes cuadros: 
Tabla 5.33

Requerimiento de materia prima

\begin{tabular}{|l|r|r|r|r|r|r|r|}
\hline \multirow{2}{*}{ Materia Prima } & \multicolumn{2}{|c|}{$\begin{array}{c}\text { Composición } \\
\text { (gramos/compota) }\end{array}$} & \multicolumn{5}{|c|}{ Requerimiento de MP para periodo del proyecto (kg/año) } \\
\cline { 3 - 8 } & 105 & \multicolumn{1}{|c|}{$\mathbf{2 0 1 6}$} & $\mathbf{2 0 1 7}$ & $\mathbf{2 0 1 8}$ & $\mathbf{2 0 1 9}$ & $\mathbf{2 0 2 0}$ & $\mathbf{2 0 2 1}$ \\
\hline Durazno & 2 & 6.177 & 571.070 & 810.024 & 1.148 .896 & 1.629 .441 & 2.310 .853 \\
\hline Harina de maca & 2 & 6.763 & 12.429 & 17.629 & 25.003 & 35.459 \\
\hline Harina de quinua & 2 & 6.177 & 8.763 & 12.429 & 17.629 & 25.003 & 35.459 \\
\hline Harina de kiwicha & 2 & 6.177 & 8.763 & 12.429 & 17.629 & 25.003 & 35.459 \\
\hline Harina de cañihua & 2 & 6.177 & 8.763 & 12.429 & 17.629 & 25.003 & 35.459 \\
\hline
\end{tabular}

Elaboración propia

Tabla 5.34

Requerimiento de materiales

\begin{tabular}{|l|r|r|r|r|r|r|}
\hline \multirow{2}{*}{ Insumo } & \multicolumn{6}{|c|}{ Requerimiento de materiales para periodo del proyecto (unid/año) } \\
\cline { 2 - 7 } & $\mathbf{2 0 1 6}$ & \multicolumn{1}{c|}{$\mathbf{2 0 1 7}$} & \multicolumn{1}{c|}{$\mathbf{2 0 1 8}$} & \multicolumn{1}{c|}{$\mathbf{2 0 1 9}$} & \multicolumn{1}{c|}{$\mathbf{2 0 2 0}$} & \multicolumn{1}{c|}{$\mathbf{2 0 2 1}$} \\
\hline Envases & 3.088 .673 & 4.381 .344 & 6.214 .640 & 8.814 .522 & 12.501 .342 & 17.729 .253 \\
\hline Tapas & 3.088 .673 & 4.381 .344 & 6.214 .640 & 8.814 .522 & 12.501 .342 & 17.729 .253 \\
\hline Etiquetas & 3.088 .673 & 4.381 .344 & 6.214 .640 & 8.814 .522 & 12.501 .342 & 17.729 .253 \\
\hline Cajas & 15.443 & 21.907 & 31.073 & 44.073 & 62.507 & 88.646 \\
\hline Cintas de embalaje & 8 & 11 & 16 & 22 & 32 & 45 \\
\hline
\end{tabular}

Elaboración propia

Tabla 5.35

Requerimiento de insumos

\begin{tabular}{|l|r|r|r|r|r|r|}
\hline \multirow{2}{*}{ Insumo } & \multicolumn{6}{|c|}{ Requerimiento de insumos para periodo del proyecto (Its/año) } \\
\cline { 2 - 7 } & $\mathbf{2 0 1 6}$ & $\mathbf{2 0 1 7}$ & $\mathbf{2 0 1 8}$ & $\mathbf{2 0 1 9}$ & $\mathbf{2 0 2 0}$ & \multicolumn{1}{c|}{$\mathbf{2 0 2 1}$} \\
\hline Tego al 0,1\% & 604 & 857 & 1.215 & 1.723 & 2.444 & 3.466 \\
\hline Hidroxido de sodio $\%$ & 8.897 & 12.620 & 17.901 & 25.389 & 36.009 & 51.068 \\
\hline
\end{tabular}

Elaboración propia

Tabla 5.36

Implementos de seguridad alimentaria

\begin{tabular}{|l|c|c|c|c|r|r|}
\hline \multirow{2}{*}{\multicolumn{1}{|c|}{ Equipos }} & \multicolumn{6}{|c|}{ Requerimiento para el periodo del proyecto (unidades/año) } \\
\cline { 2 - 7 } & $\mathbf{2 0 1 6}$ & $\mathbf{2 0 1 7}$ & $\mathbf{2 0 1 8}$ & $\mathbf{2 0 1 9}$ & \multicolumn{1}{c|}{$\mathbf{2 0 2 0}$} & \multicolumn{1}{c|}{$\mathbf{2 0 2 1}$} \\
\hline Guantes de Protección(Par) & 12.480 & 12.480 & 12.480 & 12.480 & 12.480 & 12.480 \\
\hline Mascarillas & 12.480 & 12.480 & 12.480 & 12.480 & 12.480 & 12.480 \\
\hline Trajes de cuerpo & 12.480 & 12.480 & 12.480 & 12.480 & 12.480 & 12.480 \\
\hline Cubiertas de zapatos & 12.480 & 12.480 & 12.480 & 12.480 & 12.480 & 12.480 \\
\hline
\end{tabular}

Elaboración propia

\subsubsection{Servicios: Energía eléctrica, agua, vapor combustible, etc.}

\section{Energía eléctrica:}

Para el cálculo de la energía eléctrica se toman en cuenta las operaciones y máquinas que se muestran en el siguiente cuadro: 
Tabla 5.37

Cálculo de consumo de energía eléctrica anual en KW

\begin{tabular}{|l|r|r|r|r|r|r|r|}
\hline Proceso o máquina & $\begin{array}{c}\text { Kw/ } \\
\text { hora }\end{array}$ & $\begin{array}{l}\text { Hora/ } \\
\text { turno }\end{array}$ & $\begin{array}{l}\text { Turno/ } \\
\text { dia }\end{array}$ & \multicolumn{1}{c|}{$\begin{array}{c}\text { Dias/ } \\
\text { sem }\end{array}$} & $\begin{array}{l}\text { Sem/ } \\
\text { año }\end{array}$ & \multicolumn{1}{c|}{ U } & Kw/ año \\
\hline Lavado & 5,74 & 8 & 2 & 6 & 52 & 0,88 & 25.072 \\
\hline Seleccionado & 0,18 & 8 & 2 & 6 & 52 & 0,88 & 786 \\
\hline Descarozado & 2,20 & 8 & 2 & 6 & 52 & 0,88 & 9.610 \\
\hline Orientado & 0,75 & 8 & 2 & 6 & 52 & 0,88 & 3.276 \\
\hline Pelado quimico & 3,00 & 8 & 2 & 6 & 52 & 0,88 & 13.104 \\
\hline Escaldado & 1,13 & 8 & 2 & 6 & 52 & 0,88 & 4.914 \\
\hline Despulpado y tamizado & 3,00 & 8 & 2 & 6 & 52 & 0,88 & 13.104 \\
\hline Mezcladora & 1,00 & 8 & 2 & 6 & 52 & 0,88 & 4.368 \\
\hline Pasteurizado & 21,00 & 8 & 2 & 6 & 52 & 0,88 & 91.728 \\
\hline Llenado y tapado & 3,00 & 8 & 2 & 6 & 52 & 0,88 & 13.104 \\
\hline Etiquetado & 0,96 & 8 & 2 & 6 & 52 & 0,88 & 4.193 \\
\hline Encajado & 2,50 & 8 & 2 & 6 & 52 & 0,88 & 10.920 \\
\hline Esterilizado de tapas & 1,20 & 8 & 2 & 6 & 52 & 0,88 & 5.242 \\
\hline Esterilizado de envases & 1,20 & 8 & 2 & 6 & 52 & 0,88 & 5.242 \\
\hline Bomba de doble husillo & 1,50 & 8 & 2 & 6 & 52 & 0,88 & 6.552 \\
\hline Bomba SPX32 & 2,50 & 8 & 2 & 6 & 52 & 0,88 & 10.920 \\
\hline
\end{tabular}

Elaboración propia

\section{Agua potable:}

Se tomará en cuenta el agua consumida por los procesos de producción, el personal y la limpieza de equipos e instalaciones.

Tabla 5.38

Requerimiento de agua para procesos

\begin{tabular}{|l|r|r|r|r|r|r|}
\hline \multirow{2}{*}{ Proceso } & \multicolumn{7}{|c|}{ Requerimiento de agua (m3ño) } \\
\cline { 2 - 8 } & $\mathbf{2 0 1 6}$ & $\mathbf{2 0 1 7}$ & $\mathbf{2 0 1 8}$ & $\mathbf{2 0 1 9}$ & $\mathbf{2 0 2 0}$ & $\mathbf{2 0 2 1}$ \\
\hline Lavado & 604 & 857 & 1.215 & 1.723 & 2.444 & 3.466 \\
\hline Pelado quimico & 445 & 631 & 895 & 1.269 & 1.800 & 2.553 \\
\hline Descarozado & 212 & 301 & 427 & 605 & 858 & 1.217 \\
\hline \multicolumn{1}{|c|}{ Total } & 1.261 & 1.788 & 2.537 & 3.598 & 5.103 & 7.237 \\
\hline
\end{tabular}

Elaboración propia

Para el cálculo del consumo de agua del personal de planta se considera que consumen 20 litros/persona por turno en promedio, el personal administrativo consume la mitad. Además se debe considerar un $25 \%$ adicional del consumo total de planta y oficina que estará destinado a la limpieza de los equipos e instalaciones.

Tabla 5.39

Consumo de agua del personal y requerida para la limpieza de la instalación

\begin{tabular}{|l|r|r|r|r|r|}
\hline $\begin{array}{c}\text { Consumo de } \\
\text { agua }\end{array}$ & $\begin{array}{c}\text { Cantidad } \\
\text { (persona) }\end{array}$ & $\begin{array}{c}\text { Litros/ } \\
\text { persona }\end{array}$ & $\begin{array}{c}\text { Litros/ } \\
\text { turno }\end{array}$ & $\begin{array}{c}\text { Turno/ } \\
\text { año }\end{array}$ & m3/ año \\
\hline En planta & 42 & 20 & 840 & 260 & 218 \\
\hline En oficinas & & & 420 & 260 & 109 \\
\hline \multicolumn{7}{|r}{} & & Total & 328 \\
\cline { 4 - 5 } & & $25 \%$ adic. & 82 \\
\cline { 4 - 6 } & & Total & 410 \\
\cline { 4 - 6 }
\end{tabular}

Elaboración propia 


\subsubsection{Determinación del número de operarios y trabajadores indirectos}

Para determinar el número de operarios en la planta se ha tomado en cuenta que se asignará un operador en cada área, con dos operarios para cada proceso manual. El horario de trabajo son 8 horas por turno, 2 turnos por día y 6 días a la semana. Los procesos manuales son el pesado y el seleccionado.

Tabla 5.40

Número de operarios en la planta

\begin{tabular}{|l|c|}
\hline \multicolumn{1}{|c|}{ Áreas } & Cantidad \\
\hline Pesado & 2 \\
\hline Lavado & 2 \\
\hline Seleccionado & 4 \\
\hline Descarozado & 2 \\
\hline Orientado & 2 \\
\hline Pelado quimico & 2 \\
\hline Escaldado & 2 \\
\hline Despulpado y tamizado & 2 \\
\hline Mezclado & 2 \\
\hline Pasteurizado & 2 \\
\hline Llenado y tapado & 4 \\
\hline Etiquetado & 4 \\
\hline Encajado & 2 \\
\hline Esterilizado de tapas & 2 \\
\hline Esterilizado de envases & 2 \\
\hline Calidad & 2 \\
\hline Almacen MP e Insumos & 2 \\
\hline Almacen de PT & 2 \\
\hline TOTAL & $\mathbf{4 2}$ \\
\hline
\end{tabular}

Elaboración propia

La mano de obra indirecta se le considera al personal en oficinas, que tendrá un horario de trabajo de 8 horas por turno, 1 turno por día y 5 días a la semana. Como se puede ver en el siguiente cuadro.

\section{Tabla 5.41}

Mano de obra indirecta en oficinas

\begin{tabular}{|l|r|}
\hline \multicolumn{1}{|c|}{ Areas } & Cantidad \\
\hline Gerente General & 1 \\
\hline Sub-Gerente de Adminis tración y Finanzas & 1 \\
\hline Jefe de Manufactura & 1 \\
\hline Ejecutivos de Ventas & 2 \\
\hline Ejecutivo de Marketing & 1 \\
\hline Supervisor de Producción & 1 \\
\hline Supervisor de Almacenes & 1 \\
\hline Analista de Compras & 1 \\
\hline Analista Financiero & 1 \\
\hline Analista Contable & 1 \\
\hline Analista de RR. HH. & 1 \\
\hline Recepcionista & 1 \\
\hline TOTAL & $\mathbf{1 3}$ \\
\hline
\end{tabular}

Elaboración propia 


\subsubsection{Servicio de terceros}

A continuación se procederá a indicar los servicios a tercerizar, las razones de su tercerización y la metodología para el cálculo de su presupuesto:

- Servicio de mantenimiento: Se tercerizará el servicio de mantenimiento debido al personal calificado que se necesita, además de la habilidad y experiencia que se requiere. Adicionalmente se evita el costo de tener piezas de repuesto en el inventario y la inmovilización de capital que esto representa.

Para el cálculo del presupuesto de mantenimiento se utilizó el libro Ingeniería del mantenimiento en el cual se establece que el costo anual de mantenimiento puede estimarse en $3 \%$ del valor de los activos.

Tabla 5.42

Presupuesto anual de mantenimiento en soles

\begin{tabular}{|l|r|r|r|r|r|r|}
\hline \multicolumn{1}{|c|}{ Año } & \multicolumn{1}{|c|}{$\mathbf{2 0 1 6}$} & \multicolumn{1}{c|}{$\mathbf{2 0 1 7}$} & \multicolumn{1}{c|}{$\mathbf{2 0 1 8}$} & \multicolumn{1}{c|}{2019} & \multicolumn{1}{c|}{$\mathbf{2 0 2 0}$} & \multicolumn{1}{c|}{2021} \\
\hline Costo de Máquinas & 573.970 & 573.970 & 573.970 & 573.970 & 573.970 & 573.970 \\
\hline Mantenimiento (3\%) & $\mathbf{1 7 . 2 1 9}$ & $\mathbf{1 7 . 2 1 9}$ & $\mathbf{1 7 . 2 1 9}$ & $\mathbf{1 7 . 2 1 9}$ & $\mathbf{1 7 . 2 1 9}$ & $\mathbf{1 7 . 2 1 9}$ \\
\hline
\end{tabular}

Elaboración propia

- Servicio de limpieza: Se tercerizará el servicio de limpieza debido a la mano de obra calificada, maquinaria y producto adecuados que se necesita para el tratamiento de superficies. Adicionalmente se evita la inversión en indumentaria, materiales, como así también la gestión de compra, mantenimiento de stock y maquinaria. Asimismo existe un cronograma de trabajo para optimización de tiempos y eficiencia y cuenta con profesionales de higiene y seguridad para la supervisión. Por último se eliminan todos los gastos por administración de personal. A continuación se procederá a mostrar el cálculo del presupuesto anual de limpieza:

Tabla 5.43

Presupuesto anual de limpieza en soles

\begin{tabular}{|r|r|l|}
\hline Tarifa & 8 & Euros/hora \\
\hline No Horas a trabajar $^{\circ}$ & 8 & horas/día \\
\hline Cantidad de días por semana & 6 & días/semana \\
\hline Cantidad de semanas por año & 52 & semanas/año \\
\hline$N^{\circ}$ Horas por año & 2.496 & horas/año \\
\hline Monto total en euros & 19.968 & Euros/año \\
\hline Tipo de cambio & 3,649 & Soles/Euro \\
\hline Monto total en soles & 72.863 & Soles/año \\
\hline
\end{tabular}

Elaboración propia 
- Servicio de distribución: Se tercerizará el servicio de distribución pues esto reduce la inversión en equipamiento y tecnología para la flota de camiones. Además se reducen los costos fijos al no requerir contrataciones de personal, sistemas de control de inventario, de seguridad, manejo y administración de servidores y gastos de mantenimiento y administración. Adicionalmente permite mejorar el nivel de servicio y por último permite focalizar esfuerzos en el núcleo de negocio de la compañía.

Para el cálculo del presupuesto de distribución se tomó en consideración que las farmacias (Health and Beauty retailers) representan el $62.4 \%$ de las ventas de alimentos para bebés, es por ello que para el cálculo del presupuesto de distribución se tomó como referencia al líder del sector Inkafarma el cual tiene 662 farmacias en el Perú y se estableció una ruta de distribución que pasa por los distritos donde está el público objetivo del producto los cuales son los niveles socioeconómicos A, B y C. Se detalla la ruta de distribución a continuación:

Del punto 1 al 2 se llega al distrito de Ventanilla donde el 61.7\% de su población pertenece a los niveles socioeconómicos A, B y C, luego del punto 2 al 3 se llega al distrito de Carabayllo donde el $60.8 \%$ de su población pertenece a los niveles socioeconómicos A, B y C, del punto 3 al 4 se pasa por los distritos de Comas, Los Olivos, San Martin y San Miguel donde el $60.8 \%, 76.9 \%, 76.9 \%$ y $93.1 \%$ de su población respectivamente pertenece a los niveles socioeconómicos A, B y C, del punto 4 al 5 se pasa por los distritos del Rímac y San Juan de Lurigancho donde el $69.2 \%$ y $54.1 \%$ de su población respectivamente pertenece a los niveles socioeconómicos A, B y C, del punto 5 al 6 se llega al distrito de Ate donde el $56.9 \%$ de su población pertenece a los niveles socioeconómicos $\mathrm{A}, \mathrm{B}$ y $\mathrm{C}$, del punto 6 al 7 se llega al distrito de El Agustino donde el 56.9\% de su población pertenece a los niveles socioeconómicos A, B y C, del punto 7 al 8 se llega al distrito de Pueblo Libre donde el $93.1 \%$ de su población pertenece a los niveles socioeconómicos A, B y C, del punto 8 al 9 se llega al distrito de San Isidro donde el $92.1 \%$ de su población pertenece a los niveles socioeconómicos A, B y C, del punto 9 al 10 se pasa por los distritos de Miraflores y Barranco donde el $92.1 \%$ y $65.8 \%$ de su población respectivamente pertenece a los niveles socioeconómicos A, B y C, luego 
del punto 10 al 11 se llega al distrito de Surco donde el 92.1\% de su población pertenece a los niveles socioeconómicos $\mathrm{A}, \mathrm{B}$ y $\mathrm{C}$ y por último del punto 11 al 12 se llega al distrito de Villa el Salvador donde el 55.3\% de su población pertenece a los niveles socioeconómicos $\mathrm{A}, \mathrm{B}$ y $\mathrm{C}$.

Figura 5.9

Ruta de distribución en KM para la cadena de farmacias Inkafarma en la ciudad de Lima

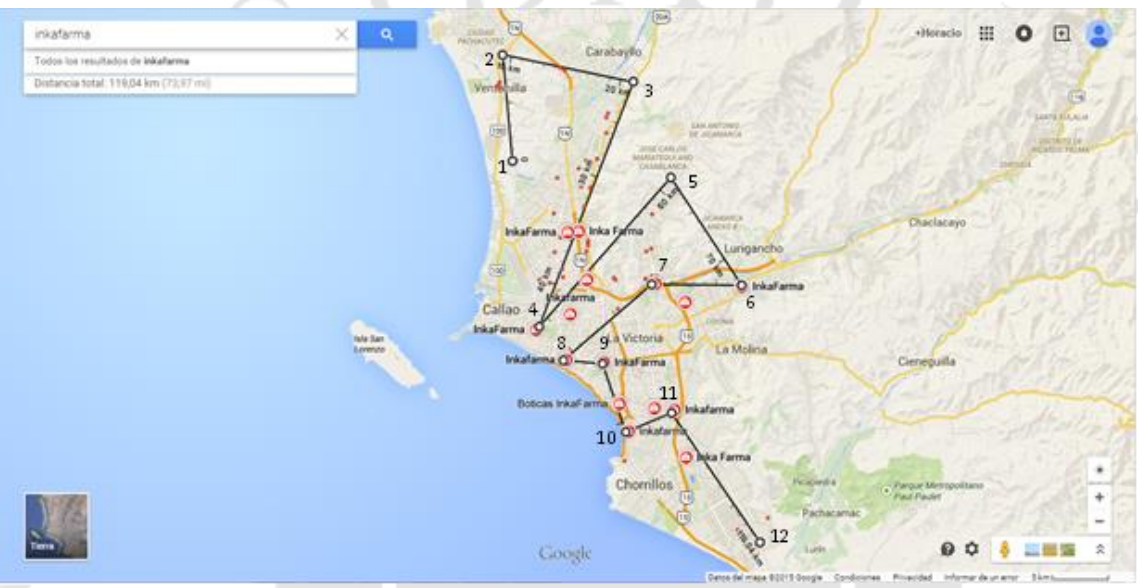

Fuente: Google Maps, (2016)

Figura 5.10

Distribución de niveles socioeconómicos por zona Apeim en Lima

\section{Apeim}

DISTRIBUCIÓN DE NIVELES POR ZONA APEIM 2015 - LIMA METROPOLITANA PERSONAS - (\%) HORIZONTALES

\begin{tabular}{|c|c|c|c|c|c|c|}
\hline \multirow{2}{*}{ Zona } & \multirow[b]{2}{*}{ TOTAL } & \multicolumn{5}{|c|}{ Niveles Socioeconómicos } \\
\hline & & NSEA & NSEB & NSEC & NSED & NSEE \\
\hline Total & 100 & 4.7 & 19.7 & 42.0 & 25.5 & 8.1 \\
\hline Zona 1 (Puente Piedra, Comas, Carabayllo) & 100 & 0.5 & 13.7 & 46.6 & 26.4 & 12.8 \\
\hline Zona 2 (Independencia, Los Olivos, San Marin de Porras) & 100 & 1.9 & 22.8 & 52.2 & 18.6 & 4.5 \\
\hline Zona 3 (San Juan de Lurigancho) & 100 & 1.1 & 9.6 & 43.4 & 36.6 & 9.3 \\
\hline Zona 4 (Cercado, Rimac, Breña, La Victoria) & 100 & 2.0 & 21.8 & 45.4 & 25.7 & 5.1 \\
\hline $\begin{array}{l}\text { Zona } 5 \text { (Ate, Chaclacayo, Lurigancho, Santa Anita, San Luis, El } \\
\text { Agusfino) }\end{array}$ & 100 & 2.2 & 13.0 & 41.7 & 33.6 & 9.5 \\
\hline Zona 6 (Jesús Maria, Lince, Pueblo Libre, Magdalena, San Miguel) & 100 & 22.5 & 46.7 & 23.9 & 5.4 & 1.5 \\
\hline Zona 7 (Mirafiores, San Isidro, San Borja, Surco, La Molina) & 100 & 29.4 & 45.1 & 17.6 & 5.6 & 2.3 \\
\hline Zona 8 (Surquillo, Barranco, Chorrillos, San Juan de Mirafiores) & 100 & 4.5 & 20.9 & 40.4 & 25.3 & 8.9 \\
\hline Zona 9 (Villa El Salvador, Villa Maria del Triunfo, Lurin, Pachacamác) & 100 & 0.0 & 9.8 & 45.5 & 35.5 & 9.2 \\
\hline $\begin{array}{l}\text { Zona } 10 \text { (Callao, Bellavista, La Perla, La Punta, Carmen de la Legua, } \\
\text { ventanilla) }\end{array}$ & 100 & 1.6 & 17.3 & 42.8 & 25.9 & 12.4 \\
\hline Otros & 100 & 0.0 & 10.1 & 48.5 & 26.3 & 15.1 \\
\hline
\end{tabular}

APEM 2015: Data ENAHO 2014

Fuente: Apeim, (2015) 
Tabla 5.44

Cálculo del costo por envío

\begin{tabular}{|l|r|l|}
\hline Costo de distribución por KM & 1,14 & dólares $/ \mathrm{km}$ \\
\hline Flete + Rentabilidad & 0,17 & dólares $/ \mathrm{km}$ \\
\hline Costo de distribución más flete & 1,31 & dólares $/ \mathrm{km}$ \\
\hline Tipo de cambio & 3,38 & soles $/$ dólar \\
\hline Costo Total de distribución & 4,41 & soles $/ \mathrm{km}$ \\
\hline Distancia a recorrer & 119,04 & $\mathrm{~km} / \mathrm{envío}$ \\
\hline \multicolumn{1}{|c|}{ Costo por envío } & $\mathbf{5 2 5 , 1 6}$ & soles/envío \\
\hline
\end{tabular}

Fuente: Ministerio de transportes y comunicaciones, (2016)

Tabla 5.45

Cantidad de envíos anual

\begin{tabular}{|r|r|}
\hline Año & $\begin{array}{c}\text { Cantidad de } \\
\text { envíos anual }\end{array}$ \\
\hline 2016 & 12 \\
\hline 2017 & 12 \\
\hline 2018 & 24 \\
\hline 2019 & 24 \\
\hline 2020 & 36 \\
\hline 2021 & 36 \\
\hline
\end{tabular}

Elaboración propia

Tabla 5.46

Presupuesto anual de distribución en soles

\begin{tabular}{|l|r|r|r|r|r|r|}
\hline \multirow{2}{*}{ Servicio } & \multicolumn{7}{|c|}{ Año } \\
\cline { 2 - 7 } & $\mathbf{2 0 1 6}$ & $\mathbf{2 0 1 7}$ & $\mathbf{2 0 1 8}$ & $\mathbf{2 0 1 9}$ & \multicolumn{1}{c|}{$\mathbf{2 0 2 0}$} & $\mathbf{2 0 2 1}$ \\
\hline Distribución & 6.302 & 6.302 & 12.604 & 12.604 & 18.906 & 18.906 \\
\hline
\end{tabular}

Elaboración propia

- Servicio de vigilancia: Se tercerizará el servicio de vigilancia pues las empresas de seguridad cuentan con personal calificado y preparado ante emergencias (robos, incendios, inundaciones, vandalismo, actos terroristas y otros actos delictivos). Adicionalmente tienen los implementos necesarios como chalecos, radios, armas, grilletes, carros rotulados y cámaras de video. Por último garantizan el nivel de servicio mediante supervisores los cuales verifican que los vigilantes cumplan con sus funciones adecuadamente. 
Tabla 5.47

Composición del sistema de vigilancia

\begin{tabular}{|l|r|l|}
\hline \multicolumn{3}{|c|}{ Composición del circuito cerrado de televisión: } \\
\hline Cuatro cámaras (un solo pago) & 600 & dólares \\
\hline $\begin{array}{l}\text { Servicio de monitoreo de las } \\
\text { cámaras( Las 24 horas) }\end{array}$ & 119 & soles/mes \\
\hline
\end{tabular}

\begin{tabular}{|l|r|l|}
\hline \multicolumn{3}{|c|}{ Personal de vigilancia: } \\
\hline $\begin{array}{l}\text { Vigilante (Las 24 horas del día y } \\
\text { los 7 días a la semana) }\end{array}$ & 3700 & soles/mes \\
\hline Cantidad de vigilantes & 2 & personas \\
\hline
\end{tabular}

Elaboración propia

Tabla 5.48

Presupuesto anual de vigilancia en soles

\begin{tabular}{|l|c|c|c|c|c|c|}
\hline \multirow{2}{*}{ Servicio } & \multicolumn{7}{|c|}{ Año } \\
\cline { 2 - 7 } & $\mathbf{2 0 1 6}$ & $\mathbf{2 0 1 7}$ & $\mathbf{2 0 1 8}$ & $\mathbf{2 0 1 9}$ & $\mathbf{2 0 2 0}$ & \multicolumn{2}{c|}{2021} \\
\hline Vigilancia & 90.228 & 90.228 & 90.228 & 90.228 & 90.228 & 90.228 \\
\hline
\end{tabular}

Elaboración propia

\subsection{Disposición de planta}

\subsubsection{Características físicas del proyecto}

\section{Factor edificio}

El suelo se construirá con cemento y concreto armado, sus materiales no deben desprender sustancias que contaminen el ambiente de la planta, debe ser resistente, antideslizante, no poroso, no absorbente.

Las paredes deben ser lisas, no porosas, no absorbentes, y no deben desprender sustancias que contaminen el ambiente de trabajo.

El techo se construirá de PVC endurecido con una superficie metálica en forma curva. Los bordes en donde se unen techo, paredes y pisos deben ser curvos para facilitar la limpieza. Además debe mantenerse el ambiente de trabajo dentro de la planta.

Por último se distribuirá un alumbrado que asegure el rendimiento de las actividades de trabajo. Ninguno de los equipos de iluminación debe de estar sobre una máquina o proceso para evitar que cuando se caiga por accidente dañe la producción.

\section{Factor servicio}

\section{Área en oficinas:}


El tamaño de las oficinas dependerá del cargo administrativo y serán las siguientes:

Gerente General: 18m2

Sub-Gerente de Administración y Finanzas: 10m2

Jefe de Manufactura: 10m2

Ejecutivos de Ventas y Marketing: 4,5m2

Supervisores de Planta: 4,5m2

Técnico de Calidad: $4,5 \mathrm{~m} 2$

Analista de Compras: $4,5 \mathrm{~m} 2$

Analista Financiero: $4,5 \mathrm{~m} 2$

Analista Contable: $4,5 \mathrm{~m} 2$

Analista de Recursos Humanos: 4,5m2

Recepcionista: $4,5 \mathrm{~m} 2$

\section{Área de servicios higiénicos:}

Los trabajadores administrativos y el personal de planta tendrán baños diferentes. Habrá un baño para damas y para varones tanto en el área administrativa como en la planta de producción. Cada baño del área administrativa tendrá 2 inodoros y 2 lavatorios, en el área de producción los baños tendrán 2 inodoros y 2 lavatorios. Tanto los baños para varones del área administrativa como del área de producción tendrán 1 urinario por baño.

\subsubsection{Determinación de las zonas físicas requeridas}

Para la operación plena de la fábrica se requieren:

- Planta de Producción

- Almacenes de materia prima, insumos y productos terminados

\subsubsection{Cálculo de áreas para cada zona}

\section{Determinación del área de producción proyectada por método de Guerchet}

Para el cálculo del método de Guerchet, se considera que todas las parihuelas utilizadas son del mismo tamaño, los almacenes temporales se calculan a base de un día de trabajo. 
Tabla 5.49

Determinación del área de producción

ELEMENTOS ESTATICOS

Unidad medida: metros

\begin{tabular}{|c|c|c|c|c|c|c|c|c|c|c|c|}
\hline Nombre & $\mathbf{n}$ & $\mathbf{N}$ & $\mathbf{L}$ & A & h & Ss & $\mathrm{Sg}$ & Se & St & Ss $\times n$ & Ss $\times \mathrm{n} \times \mathrm{h}$ \\
\hline Bascula de piso portatil & 1 & 1 & 0,61 & 0,61 & 0,63 & 0,37 & 0,37 & 0,46 & 1,20 & 0,37 & 0,23 \\
\hline Lavadora de frutas & 1 & 1 & 5,00 & 0,70 & 1,00 & 3,50 & 3,50 & 4,29 & 11,29 & 3,50 & 3,50 \\
\hline Faja transportadora de banda & 1 & 2 & 3,00 & 1,10 & 1,60 & 3,30 & 6,60 & 6,06 & 15,96 & 3,30 & 5,28 \\
\hline Descarozadora & 1 & 1 & 6,25 & 1,20 & 1,95 & 7,50 & 7,50 & 9,18 & 24,18 & 7,50 & 14,63 \\
\hline Orientadora de mitades & 1 & 1 & 2,00 & 0,95 & 1,00 & 1,90 & 1,90 & 2,33 & 6,13 & 1,90 & 1,90 \\
\hline Peladora quimica & 1 & 1 & 5,00 & 1,50 & 1,70 & 7,50 & 7,50 & 9,18 & 24,18 & 7,50 & 12,75 \\
\hline Escaldadora tipo inmersion & 1 & 1 & 4,98 & 1,35 & 1,42 & 6,72 & 6,72 & 8,23 & 21,68 & 6,72 & 9,51 \\
\hline Despulpadora de frutas & 1 & 1 & 0,87 & 0,60 & 1,51 & 0,52 & 0,52 & 0,64 & 1,68 & 0,52 & 0,79 \\
\hline Mezcladora de paletas & 1 & 1 & 1,75 & 1,10 & 1,00 & 1,93 & 1,93 & 2,36 & 6,21 & 1,93 & 1,93 \\
\hline Marmita a vapor eléctrica & 1 & 1 & 0,93 & 0,69 & 1,02 & 0,64 & 0,64 & 0,78 & 2,05 & 0,64 & 0,65 \\
\hline Llenadora de liquidos y tapado de frascos & 2 & 1 & 3,50 & 1,73 & 1,68 & 6,06 & 6,06 & 7,41 & 39,05 & 12,11 & 20,34 \\
\hline Esterilizadora de envases & 1 & 1 & 3,40 & 1,00 & 2,50 & 3,40 & 3,40 & 4,16 & 10,96 & 3,40 & 8,50 \\
\hline Esterilizadora de tapas & 1 & 1 & 3,40 & 1,00 & 2,50 & 3,40 & 3,40 & 4,16 & 10,96 & 3,40 & 8,50 \\
\hline Etiquetadora automatica & 2 & 1 & 2,50 & 0,10 & 1,50 & 0,25 & 0,25 & 0,31 & 1,61 & 0,50 & 0,75 \\
\hline Maquina formadora de cajas y encajadora & 1 & 1 & 3,43 & 1,00 & 2,33 & 3,43 & 3,43 & 4,20 & 11,07 & 3,43 & 8,00 \\
\hline Tanque de almacenamiento de hidroxido de sodio concentrado & 1 & 2 & $\mathrm{x}$ & $\mathrm{x}$ & 1,12 & 0,95 & 1,90 & 1,75 & 4,60 & 0,95 & 1,06 \\
\hline Tanque de almacenamiento de hidroxido de sodio diluido de 1,5 - $2 \%$ & 1 & 2 & $\mathrm{x}$ & $\mathrm{x}$ & 1,12 & 0,95 & 1,90 & 1,75 & 4,60 & 0,95 & 1,06 \\
\hline Tanque de almacenamiento temporal de mezcla pasteurizada & 1 & 1 & 1,00 & 1,00 & 2,00 & 1,00 & 1,00 & 1,22 & 3,22 & 1,00 & 2,00 \\
\hline Almacen temporal de cajas de durazno antes de pesado & 8 & \begin{tabular}{l|l}
$x$ \\
\end{tabular} & 1,20 & 1,00 & 1,76 & 1,20 & 0,00 & 0,73 & 15,48 & 9,60 & 16,88 \\
\hline Almacen temporal de las harinas antes de pesado & 1 & $\mathrm{x}$ & 1,20 & 1,00 & 1,95 & 1,20 & 0,00 & 0,73 & 1,93 & 1,20 & 2,34 \\
\hline Almacen temporal antes del esterilizado de envases y tapas & 7 & $\mathrm{x}$ & 1,20 & 1,00 & 1,76 & 1,20 & 0,00 & 0,73 & 13,54 & 8,40 & 14,77 \\
\hline Almacen temporal de las harinas antes del mezclado & 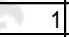 & $\mathrm{x}$ & 1,20 & 1,00 & 1,95 & 1,20 & 0,00 & 0,73 & 1,93 & 1,20 & 2,34 \\
\hline Almacen temporal de producto terminado en el area de encajonado & 6 & $\mathrm{x}$ & 1,20 & 1,00 & 1,76 & 1,20 & 0,00 & 0,73 & 11,61 & 7,20 & 12,66 \\
\hline & & & & & & & & TOTAL & 245 & 87 & 150 \\
\hline
\end{tabular}

\section{ELEMENTOS MOVILES}

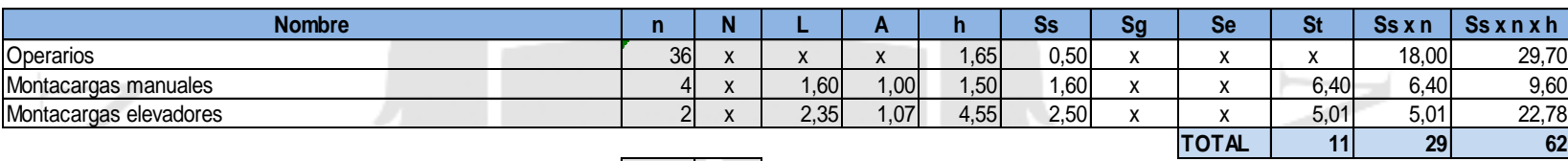

Elaboración propia

Tabla 5.50

Cálculo del almacén temporal de mezcla pasteurizada

\begin{tabular}{|c|c|c|}
\hline & Litros & $\mathrm{Kg}$ \\
\hline Capacidad & 1000 & 933 \\
\hline
\end{tabular}

\begin{tabular}{|l|r|r|}
\hline Cantidad alm.: & 4.077 & $\mathrm{~kg} /$ turno \\
\hline
\end{tabular}

\begin{tabular}{|l|r|l|}
\hline$N^{\circ}$ de tanques: & 5 & \\
\hline
\end{tabular}

Elaboración propia 
Tabla 5.51

Cálculo del almacén temporal de cajas de durazno antes del pesado

\begin{tabular}{|r|l|}
\hline 5143,46 & $\mathrm{~kg}$ durazno \\
\hline 18,24768 & $\mathrm{~kg} /$ caja \\
\hline 282 & cajas \\
\hline
\end{tabular}

\begin{tabular}{|l|r|r|r|}
\hline \multicolumn{4}{|c|}{ Medidas en metros } \\
\hline & \multicolumn{1}{|c|}{ largo } & ancho & \multicolumn{1}{c|}{ altura } \\
\hline Caja & 0,55 & 0,275 & 0,268 \\
\hline Parihuela & 1,2 & 1 & 0,15 \\
\hline \multicolumn{5}{|r|}{ h total } & 1,758 \\
\hline
\end{tabular}

\begin{tabular}{|c|c|}
\hline Cantidad de cajas por nivel & 6 \\
\hline Cantidad de niveles/parihuela & 6 \\
\hline Cantidad de cajas/parihuela & 36 \\
\hline $\mathrm{N}^{\circ}$ de parihuelas & 8,0 \\
\hline
\end{tabular}

Elaboración propia

Tabla 5.52

Cálculo del almacén temporal de cajas de las harinas antes del pesado

Para harinas solo se utilizara una parihuela, la cual puede contener los 4 tipos de harina

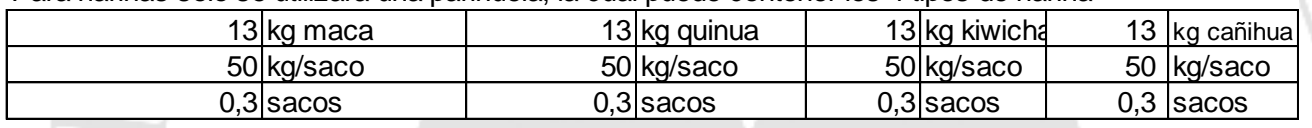

\begin{tabular}{|l|r|r|r|}
\hline \multicolumn{4}{|c|}{ Medidas en metros } \\
\hline & largo & ancho & \multicolumn{1}{c|}{ altura } \\
\hline Saco & 1 & 0,6 & 0,3 \\
\hline Parihuela & 1,2 & 1 & 0,15 \\
\hline \multicolumn{5}{|r|}{} & h total & 1,95 \\
\cline { 3 - 5 }
\end{tabular}

\begin{tabular}{|l|r|}
\hline Cantidad de sacos por nivel & 2 \\
\hline Cantidad de niveles/parihuela & 6 \\
\hline Cantidad de sacos/parihuela & 12 \\
\hline & \\
\hline \multicolumn{1}{|c|}{$\mathbf{N}^{\circ}$ de parihuelas } & $\mathbf{1 , 0}$ \\
\hline
\end{tabular}

Elaboración propia

\section{Tabla 5.53}

Cálculo del almacén temporal antes del esterilizado de envases

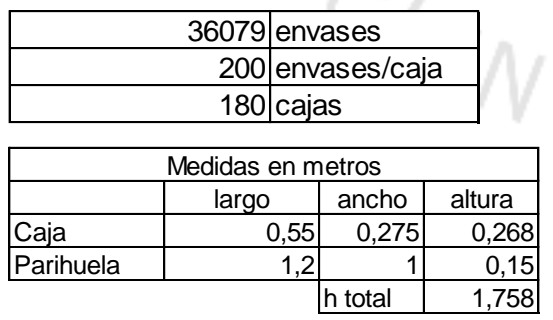

\begin{tabular}{|l|r|}
\hline Cantidad de cajas por nivel & 6 \\
\hline Cantidad de niveles/parihuela & 6 \\
\hline Cantidad de cajas/parihuela & 36 \\
\hline \multicolumn{2}{|c|}{$\mathbf{N}^{\circ}$ de parihuelas } \\
\hline
\end{tabular}

Elaboración propia 
Tabla 5.54

Cálculo del almacén temporal antes del esterilizado de tapas

\begin{tabular}{|r|l|}
\hline 36079 & tapas \\
\hline 2500 & tapas/caja \\
\hline 14 & cajas \\
\hline
\end{tabular}

\begin{tabular}{|l|r|r|r|}
\hline \multicolumn{4}{|c|}{ Medidas en metros } \\
\hline & \multicolumn{1}{|c|}{ largo } & ancho & altura \\
\hline Caja & 0,55 & 0,275 & 0,01 \\
\hline Parihuela & 1,2 & 1 & 0,15 \\
\hline \multicolumn{5}{|r|}{ h total } & 0,65 \\
\cline { 2 - 4 }
\end{tabular}

\begin{tabular}{|l|r|}
\hline Cantidad de cajas por nivel & 6 \\
\hline Cantidad de niveles/parihuela & 50 \\
\hline Cantidad de cajas/parihuela & 300 \\
\hline \multicolumn{2}{|c|}{$\mathbf{N}^{\circ}$ de parihuelas } \\
\hline
\end{tabular}

Elaboración propia

\section{Tabla 5.55}

\section{Cálculo del almacén temporal de las harinas antes del mezclado}

Para harinas solo se utilizara una parihuela, la cual puede contener los 4 tipos de harina

\begin{tabular}{|r|r|r|r|r|r|r|r|}
\hline 13 & $\mathrm{~kg}$ maca & 13 & $\mathrm{~kg}$ quinua & 13 & $\mathrm{~kg}$ kiwich & 13 & $\mathrm{~kg}$ cañihua \\
\hline 50 & $\mathrm{~kg} / \mathrm{saco}$ & 50 & $\mathrm{~kg} / \mathrm{saco}$ & 50 & $\mathrm{~kg} / \mathrm{saco}$ & 50 & $\mathrm{~kg} / \mathrm{saco}$ \\
\hline 0,3 & sacos & 0,3 & sacos & 0,3 & sacos & 0,3 & $\mathrm{sacos}$ \\
\hline
\end{tabular}

\begin{tabular}{|c|c|c|c|}
\hline \multicolumn{4}{|c|}{ Medidas en metros } \\
\hline & largo & ancho & altura \\
\hline Saco & 1 & 0,6 & $\begin{array}{r}0,3 \\
\end{array}$ \\
\hline Parihuela & 1,2 & 1 & 0,15 \\
\hline & & $h$ total & 1,95 \\
\hline
\end{tabular}

\begin{tabular}{|c|c|}
\hline Cantidad de sacos por nivel & 2 \\
\hline Cantidad de niveles/parihuela & 6 \\
\hline Cantidad de sacos/parihuela & 12 \\
\hline $\mathrm{N}^{\circ}$ de parihuelas & 1,0 \\
\hline
\end{tabular}

Elaboración propia

\section{Tabla 5.56}

Cálculo del almacén temporal de producto terminado en el área de encajonado

\begin{tabular}{|r|l|}
\hline 36.079 & envases \\
\hline 200 & envases/caja \\
\hline 180 & cajas \\
\hline
\end{tabular}

\begin{tabular}{|c|c|c|c|}
\hline \multicolumn{4}{|c|}{ Medidas en metros } \\
\hline & largo & ancho & altura \\
\hline Caja & 0,55 & 0,275 & 0,268 \\
\hline Parihuela & 1,2 & 1 & 0,15 \\
\hline & & $\mathrm{h}$ total & 1,758 \\
\hline
\end{tabular}

\begin{tabular}{|l|r|}
\hline Cantidad de cajas por nivel & 6 \\
\hline Cantidad de niveles/parihuela & 6 \\
\hline Cantidad de cajas/parihuela & 36 \\
\hline & \\
\hline $\mathbf{N}^{\circ}$ de parihuelas & $\mathbf{6 , 0}$ \\
\hline
\end{tabular}

Elaboración propia 
Tabla 5.57

Análisis del 30\% de los almacenes temporales

\begin{tabular}{|c|c|}
\hline \multicolumn{2}{|c|}{ Analisis del $30 \%$ para tanque de almacenamiento temporal de mezcla ya pasteurizada } \\
\hline Maquina de llenado y tapado & $83 \%>30 \%$ \\
\hline \multicolumn{2}{|c|}{ Analisis del $30 \%$ para el Almacen temporal de cajas de durazno antes de pesado } \\
\hline Balanzal & $2580 \%>30 \%$ \\
\hline \multicolumn{2}{|c|}{ Analisis del $30 \%$ para el Almacen temporal de las harinas antes de pesado } \\
\hline Balanzal & $322 \%>30 \%$ \\
\hline \multicolumn{2}{|c|}{ Analisis del $30 \%$ para el Almacen temporal antes del esterilizado de envases y tapas } \\
\hline Esterilizadores & $124 \% \mid>30 \%$ \\
\hline \multicolumn{2}{|c|}{ Analisis del $30 \%$ para el Almacen temporal de las harinas antes del mezclado } \\
\hline Mezcladora & $62 \% \mid>30 \%$ \\
\hline Analisis del $30 \%$ para el Almacen temporal de producto terminado en & area de encajor \\
\hline Encajadoral & $210 \% \mid>30 \%$ \\
\hline
\end{tabular}

Tabla 5.58

Cálculo del área de producción

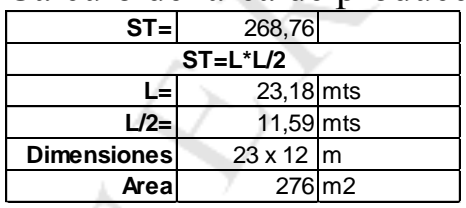

Elaboración propia

\section{Calculo del área de los almacenes}

Los almacenes guardaran la cantidad necesaria para un mes de producción del año 2021, de acuerdo a la producción estimada. Se tendrá un almacén para las materias primas, un almacén de insumos, un almacén para el producto terminado en cajas con 200 envases cada una y un almacén para barriles de gasolina para los montacargas.

Tabla 5.59

Cálculo del área del almacén de materias primas

\begin{tabular}{|l|r|l|}
\hline \multicolumn{3}{|c|}{ Cantidad a almacenar (kg/mes) } \\
\hline Durazno & 192.571 & \\
\hline Cajas de durazno & 18 & $\mathrm{~kg} / \mathrm{caja}$ \\
\hline Total de cajas de durazno & 10.553 & cajas $/ \mathrm{mes}$ \\
\hline
\end{tabular}

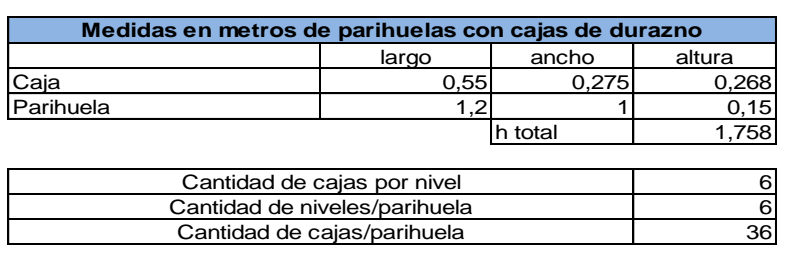

$\mathrm{N}^{\circ}$ de parihuelas

\begin{tabular}{|l|c|}
\hline$N^{\circ}$ de parihuelas requerido & 293,14 \\
\hline
\end{tabular}

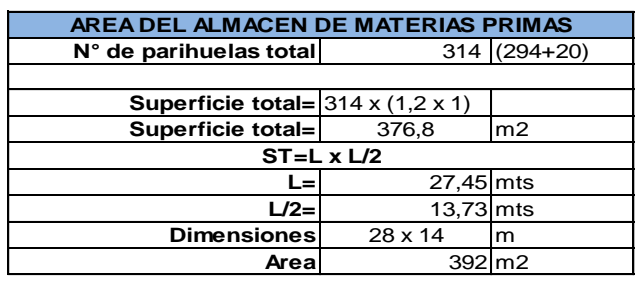

Elaboración propia
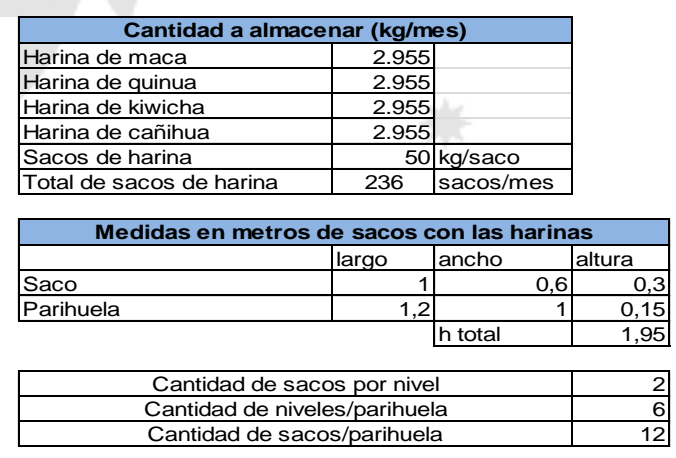

\begin{tabular}{|l|c|}
\hline$N^{\circ}$ de parihuelas & 19,70 \\
\hline
\end{tabular}

\begin{tabular}{|l|c|}
\hline $\mathrm{N}^{\circ}$ de parihuelas requerido & 20 \\
\hline
\end{tabular} 
Tabla 5.60

Cálculo del área del almacén de insumos parte 1

\begin{tabular}{|l|r|l|}
\hline \multicolumn{2}{|c|}{ Cantidad a almacenar (envases/mes) } \\
\hline Envases vacios & 1.477 .438 & envases \\
\hline Cajas con envases & 200 & envases/caja \\
\hline Total de cajas & 7.387 & cajas/mes \\
\hline \multicolumn{2}{|c|}{ Tego } \\
\hline \multicolumn{2}{|c|}{ Cantidad a almacenar (Tego/mes) } \\
\hline \multicolumn{2}{|c|}{14,44} & envases \\
\hline Cantidad a almacenar (cajas desarmadas/mes) \\
\hline \multicolumn{2}{|c|}{7.387} & cajas \\
\hline Cantidad a almacenar (etiquetas/mes) \\
\hline Etiquetas & 1.477 .438 & etiquetas \\
\hline Bobinas de etiquetas & 70.000 & etiquetas/bobina \\
\hline Total de bobinas & 21,11 & bobinas/mes \\
\hline
\end{tabular}

\begin{tabular}{|c|c|c|c|}
\hline \multicolumn{4}{|c|}{ Medidas en metros de parihuelas con envases vacios en cajas } \\
\hline & largo & ancho & altura \\
\hline Caja & 0,55 & 0,275 & 0,268 \\
\hline Parihuela & 1,2 & 1 & 0,15 \\
\hline \multicolumn{3}{|c|}{ h total } & 1,758 \\
\hline \multicolumn{3}{|c|}{ Cantidad de cajas por nivel } & 6 \\
\hline \multicolumn{3}{|c|}{ Cantidad de niveles/parihuela } & 6 \\
\hline \multicolumn{3}{|c|}{ Cantidad de cajas/parihuela } & 36 \\
\hline
\end{tabular}

\begin{tabular}{|l|r|}
\hline$N^{\circ}$ de parihuelas & 205,20 \\
\hline$N^{\circ}$ de parihuelas requerido & 206 \\
\hline
\end{tabular}

\begin{tabular}{|c|c|c|c|}
\hline \multicolumn{4}{|c|}{ Medidas en metros de parihuelas con envases de tego } \\
\hline & largo & ancho & altura \\
\hline Tego & 0,25 & 0,25 & 0,35 \\
\hline Parihuela & 1,2 & 1 & 0,15 \\
\hline & & & 2,25 \\
\hline
\end{tabular}

\begin{tabular}{|c|r|}
\hline Cantidad de envases por nivel & 16 \\
\hline Cantidad de niveles/parihuela & 6 \\
\hline Cantidad de envases Tego/parihuela & 96 \\
\hline
\end{tabular}

$\mathrm{N}^{\circ}$ de parihuelas

\begin{tabular}{|l|r|}
\hline$N^{\circ}$ de parihuelas requerido & 0,15 \\
\hline
\end{tabular}

\section{EQUIPOS DE PROTECCION ALIMENTARIA}

\begin{tabular}{|r|r|l|}
\hline \multicolumn{2}{|c|}{ Cantidad a almacenar (guantes/mes) } \\
\hline Guantes (Par) & 1.040 & guantes \\
\hline Cajas con guantes & 200 & guantes/caja \\
\hline Total de cajas & 5 & cajas/mes \\
\hline \multicolumn{2}{|r|}{} \\
\hline Cantidad a almacenar (trajes/mes) \\
\hline Trajes & 1.040 & trajes \\
\hline Cajas con trajes & 50 & trajes/caja \\
\hline Total de cajas & 21 & cajas/mes \\
\hline
\end{tabular}

\begin{tabular}{|l|r|r|r|}
\hline Medidas en metros de parihuelas con Equipos de protección alimentaria \\
\hline \multicolumn{2}{|c|}{ largo } & ancho & \multicolumn{1}{c|}{ altura } \\
\hline Equipos de Proteccion & 0,25 & 0,25 & 0,35 \\
\hline Parihuela & 1,2 & 1 & 0,15 \\
\hline \\
\begin{tabular}{|l|r|r|}
\hline \\
\hline
\end{tabular} \\
\hline \\
Cantidad de cajas por nivel & 6 \\
\hline Cantidad de cajas con E.P.A. /parihuela & 96 \\
\hline
\end{tabular}

$\mathrm{N}^{\circ}$ de parihuelas antidad de niveles/parihuela

$\mathrm{N}^{\circ}$ de parihuelas requerido 0,36

Elaboración propia

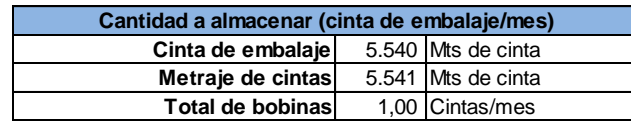

Medidas en metros de parihuelas con cintas de embalaje

\begin{tabular}{|l|r|rr|r|}
\hline & \multicolumn{1}{|c|}{ largo } & ancho & \multicolumn{1}{|c|}{ altura } \\
\hline Cinta de embalaje & 0,150 & 0,150 & 14,4 \\
\hline Parihuela & 1,2 & 1 & 0,15 \\
\hline \multicolumn{3}{|c|}{ h total } & 14,550 \\
\cline { 2 - 4 }
\end{tabular}

\begin{tabular}{|c|r|}
\hline Cantidad de cintas por nivel & 1 \\
\hline Cantidad de niveles/parihuela & 1 \\
\hline Cantidad de cintas de embalaje/parihuela & 1 \\
\hline
\end{tabular}

\begin{tabular}{|l|r|}
\hline$N^{\circ}$ de parihuelas & 1 \\
\hline$N^{\circ}$ de parihuelas requerido & 1 \\
\hline
\end{tabular}

\begin{tabular}{|c|c|c|c|}
\hline \multicolumn{4}{|c|}{ Medidas en metros de parihuelas con cajas desarmadas } \\
\hline & largo & ancho & altura \\
\hline Caja desarmada & 0,543 & 0,275 & 0,008 \\
\hline Parihuela & 1,2 & 1 & 0,15 \\
\hline \multicolumn{3}{|c|}{ h total } & 1,75 \\
\hline \multicolumn{3}{|c|}{ Cantidad de cajas por nivel } & 6 \\
\hline \multicolumn{3}{|c|}{ Cantidad de niveles/parihuela } & 200 \\
\hline \multicolumn{3}{|c|}{ Cantidad de cajas desarmadas/parihuela } & 1.200 \\
\hline
\end{tabular}

\begin{tabular}{|l|r|}
\hline$N^{\circ}$ de parihuelas & 6,16 \\
\hline$N^{\circ}$ de parihuelas requerido & 7 \\
\hline
\end{tabular}

\begin{tabular}{|c|c|c|c|}
\hline \multicolumn{4}{|c|}{ Medidas en metros de parihuelas bobinas de etiquetas } \\
\hline & largo & ancho & altura \\
\hline Bobina & 1 & 0,55 & 0,55 \\
\hline Parihuela & 1,2 & 1 & 0,15 \\
\hline & & & 2,35 \\
\hline \multicolumn{3}{|c|}{ Cantidad de bobinas por nivel } & 2 \\
\hline \multicolumn{3}{|c|}{ Cantidad de niveles/parihuela } & 4 \\
\hline \multicolumn{3}{|c|}{ Cantidad de bobinas/parihuela } & 8 \\
\hline
\end{tabular}

\begin{tabular}{|l|r|}
\hline$N^{\circ}$ de parihuelas & 2,64 \\
\hline
\end{tabular}

\begin{tabular}{|l|r|}
\hline$N^{\circ}$ de parihuelas requerido & 3 \\
\hline
\end{tabular}

\begin{tabular}{|r|r|l|}
\hline \multicolumn{2}{|c|}{ Cantidad a almacenar (mascarillas/mes) } \\
\hline Mascarillas & 1.040 & mascarillas \\
\hline Cajas con mascarillas & 300 & mascarillas/caja \\
\hline Total de cajas & 3 & cajas/mes \\
\hline
\end{tabular}

\section{Cantidad a almacenar (cubiertas de zapato/mes)}

\begin{tabular}{l|l|l|} 
Cubiertas de zapatos & 1.040 & cubiertas de zapatos \\
\hline
\end{tabular} Cajas con cubiertas de zapatos 200 cubiertas/caja \begin{tabular}{lrl} 
Total de cajas & 5 & cajas $/ \mathrm{mes}$ \\
\hline
\end{tabular} 
Tabla 5.61

Cálculo del área del almacén de insumos parte 2

\begin{tabular}{|r|c|l|}
\hline \multicolumn{4}{|c|}{ AREA DEL ALMACEN DE INSUMOS } \\
\hline $\mathbf{N}^{\circ}$ de parihuelas total & 219 & \\
\hline \multicolumn{3}{|c|}{} \\
\hline Superficie total $=$ & $218 \times(1,2 \times 1)$ & \\
\hline Superficie total $=$ & 263 & $\mathrm{~m} 2$ \\
\hline $\mathbf{S T}=\mathrm{L} \times \mathbf{L} / \mathbf{2}$ \\
\hline $\mathrm{L}=$ & 22,93 & $\mathrm{mts}$ \\
\hline $\mathrm{L} / \mathbf{2}=$ & 11,46 & $\mathrm{mts}$ \\
\hline Dimensiones & $23 \times 12$ & $\mathrm{~m}$ \\
\hline Area & 276 & $\mathrm{~m} 2$ \\
\hline
\end{tabular}

Elaboración propia

Tabla 5.62

Cálculo del área del almacén de productos terminados

\begin{tabular}{|l|r|l|}
\hline \multicolumn{3}{|c|}{ Cantidad a almacenar (envases/mes) } \\
\hline Compota & 1.477 .438 & envases \\
\hline Cajas de compota & 200 & envases/caja \\
\hline Total de cajas & 7.387 & cajas/mes \\
\hline
\end{tabular}

\begin{tabular}{|l|r|r|r|}
\hline \multicolumn{5}{|c|}{ Medidas en metros de parihuelas con producto terminado } \\
\hline & \multicolumn{1}{|c|}{ largo } & ancho & \multicolumn{1}{c|}{ altura } \\
\hline Caja & 0,55 & 0,275 & 0,268 \\
\hline Parihuela & 1,2 & 1 & 0,15 \\
\hline \multicolumn{3}{r|}{ h total } & 1,758 \\
\hline
\end{tabular}

\begin{tabular}{|c|r|}
\hline Cantidad de cajas por nivel & 6 \\
\hline Cantidad de niveles/parihuela & 6 \\
\hline Cantidad de cajas/parihuela & 36 \\
\hline
\end{tabular}

\begin{tabular}{|l|r|}
\hline $\mathrm{N}^{\circ}$ de parihuelas & 205,20 \\
\hline $\mathrm{N}^{\circ}$ de parihuelas requerido & 206 \\
\hline
\end{tabular}

\begin{tabular}{|r|c|l|}
\hline AREA DEL ALMACEN DE PRODUCTO TERMINADO \\
\hline $\mathbf{N}^{\circ}$ de parihuelas & \multicolumn{2}{|c|}{206} \\
\hline Superficie total $=$ & \multicolumn{2}{|c|}{$206 \times(1,2 \times 1)$} \\
\hline Superficie total $=$ & 247,2 & $\mathrm{~m} 2$ \\
\hline $\mathbf{S T}=\mathrm{L} \times \mathbf{~ L} / \mathbf{2}$ \\
\hline $\mathbf{L}=$ & 22,24 & $\mathrm{mts}$ \\
\hline $\mathbf{L} / \mathbf{2}=$ & 11,12 & $\mathrm{mts}$ \\
\hline Area & 276 & $\mathrm{~m} 2$ \\
\hline Dimensiones & $23 \times 12$ & $\mathrm{~m}$ \\
\hline
\end{tabular}

Elaboración propia

\section{Tabla 5.63}

Cálculo del área del almacén de los barriles de gasolina

\begin{tabular}{|l|r|l|}
\hline \multicolumn{2}{|c|}{ Cantidad a almacenar (barriles/mes) } \\
\hline Gasolina & 2756 & litros/mes \\
\hline Barriles de gasolina & 150 & litros/barril \\
\hline Total de barriles & 19 & barriles/mes \\
\hline
\end{tabular}

AREA PARA ALMACENAMIENTO DE BARRILES

\begin{tabular}{|l|r|l|}
\hline Diámetro & 0,60 & metros \\
\hline Altura & 1,35 & metros \\
\hline Área & $\mathbf{5 , 3 7}$ & $\mathbf{m 2}$ \\
\hline
\end{tabular}

Elaboración propia 


\subsubsection{Dispositivos de seguridad industrial y señalización}

La planta cuenta con los siguientes dispositivos de seguridad industrial y señalización:

- Sensor de humo fotoeléctrico: Detecta la presencia de humo en el aire y emite una señal acústica para avisar el peligro de incendio.

- Sensor de calor de temperatura fija: Cuando el sensor de calor alcanza la temperatura máxima fijada este se activa y emite una señal acústica para avisar el peligro de incendio. Este tipo de sensor se utiliza en los espacios donde se tienen máquinas que emiten vapor ya que los sensores de humo fallarían.

- Alarma manual: Le permite al personal dar aviso sobre el peligro de incendio

- Sirena con luz estroboscópica: Al accionarse los sensores de humo o de calor o las alarmas manuales este dispositivo emite una señal audible y destellos de luz para que el personal salga de las estaciones de trabajo.

- Extintor: Consiste en un recipiente metálico que contiene un agente extintor a presión que debe dispararse a la base del fuego respectivo.

- Tablero de control contra incendios: Los sensores de humo fotoeléctricos, de calor de temperatura fija, alarmas manuales y sirenas con luces estroboscópicas están conectados a un tablero de control contra incendios que se ubica en el centro de vigilancia.

La ubicación de los dispositivos de seguridad industrial y señalización es la siguiente: 
Figura 5.11

Ubicación de dispositivos de seguridad industrial y señalización

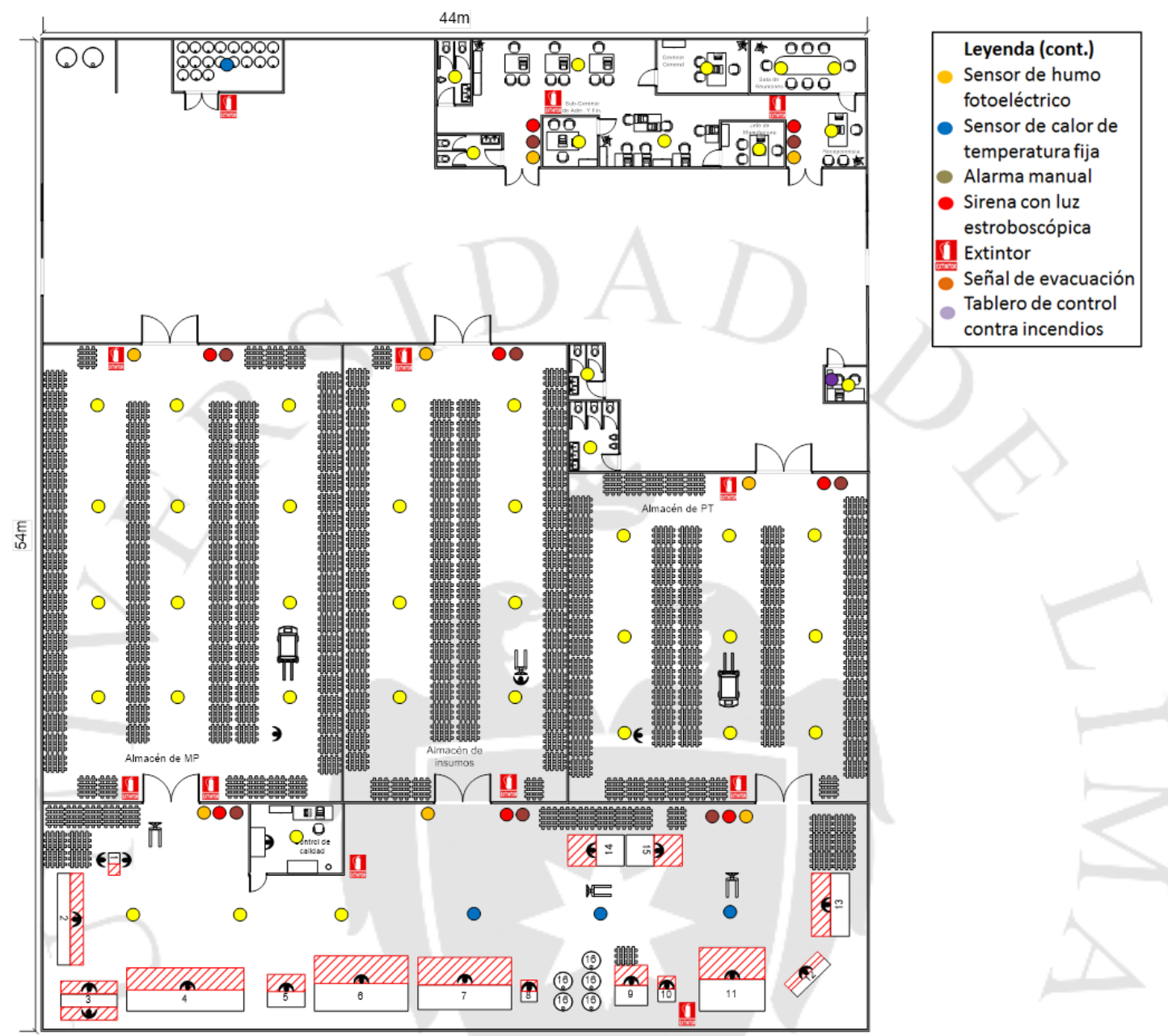

Elaboración propia

De acuerdo a lo analizado se establecerá el presupuesto de seguridad industrial y señalización:

Tabla 5.64

Presupuesto de dispositivos de seguridad industrial

\begin{tabular}{|l|r|r|r|r|r|r|}
\hline \multicolumn{1}{|c|}{ Presupuesto de seguridad industrial y señalización } & $\mathbf{2 0 1 6}$ & $\mathbf{2 0 1 7}$ & $\mathbf{2 0 1 8}$ & $\mathbf{2 0 1 9}$ & $\mathbf{2 0 2 0}$ & $\mathbf{2 0 2 1}$ \\
\hline $\begin{array}{l}\text { Mantenimiento de sensores de humo fotoeléctrico, de } \\
\text { calor de temperatura fija, alarmas manuales, sirenas con } \\
\text { luz estroboscópica y tablero de control contra incendios }\end{array}$ & 118 & 118 & 118 & 118 & 118 & 118 \\
\hline Señales de evacuación & 27 & 27 & 27 & 27 & 27 & 27 \\
\hline Mantenimiento de extintores & - & 78 & 78 & 78 & 78 & 78 \\
\hline Señales de extintores & 39 & 39 & 39 & 39 & 39 & 39 \\
\hline \multicolumn{1}{r|}{ Total (S/.) } & 183 & 261 & 261 & 261 & 261 & 261 \\
\hline
\end{tabular}

Elaboración propia 


\subsubsection{Disposición general}

\section{Análisis relacional de las áreas de la empresa}

Como se podrá observar en la siguiente figura, cada casilla representa la intersección de dos actividades, a su vez están divididas horizontalmente en dos; la parte superior representa el valor de aproximación y la parte inferior indica las razones que han inducido a elegir ese valor.

\section{Tabla 5.65}

Lista de motivos

\begin{tabular}{|r|l|}
\hline \multicolumn{1}{|l}{ CODIGO } & LISTA DE MOTIVOS \\
\hline 1 & Secuencia de proceso \\
\hline 2 & Por flujo de materiales y equipos \\
\hline 3 & Para facilitar control \\
\hline 4 & Por utilizacion de equipos similares \\
\hline 5 & Por el servicio \\
\hline 6 & Por seguimiento de las actividades \\
\hline 7 & Por no ser necesario \\
\hline 8 & Por mucho ruido \\
\hline 9 & Por no contaminar el producto \\
\hline 10 & Por ser peligroso \\
\hline
\end{tabular}

Elaboración propia

Figura 5.12

Diagrama relacional

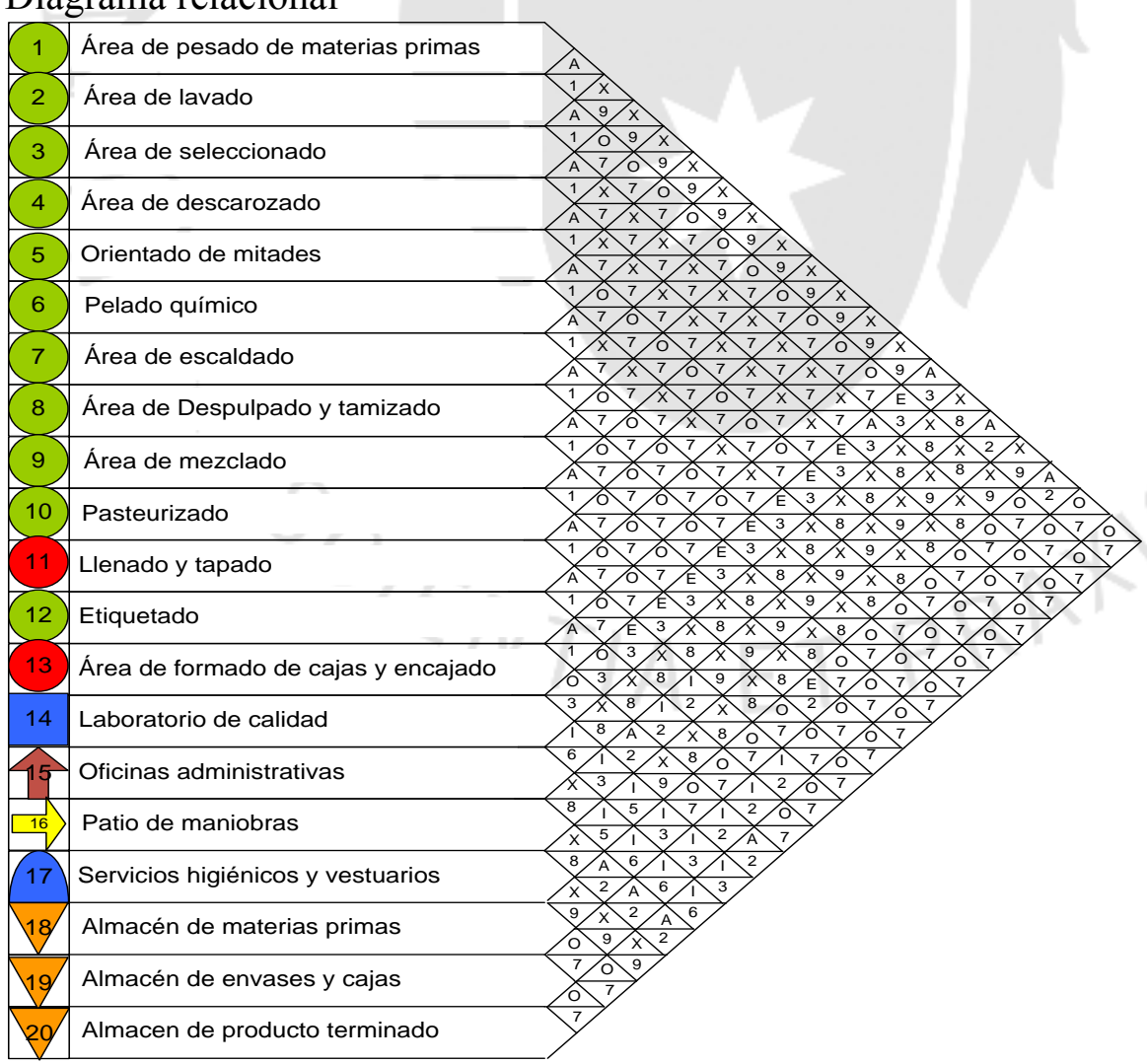

Elaboración propia 
Tabla 5.66

Tabla relacional

\begin{tabular}{|c|c|c|cccc|cccc|}
\hline \multicolumn{10}{|c|}{ TABLA DE RELACIONES } \\
\hline $\mathrm{A}$ & $\mathrm{E}$ & $\mathrm{I}$ & \multicolumn{7}{c|}{$\mathrm{O}$} & \multicolumn{3}{c|}{ X } & \\
\hline $1-2$ & $2-14$ & $11-16$ & $13-14$ & $10-13$ & $3-18$ & $7-13$ & $1-3$ & $3-7$ & $4-16$ & $8-16$ \\
$2-3$ & $4-14$ & $12-16$ & $18-19$ & $2-6$ & $3-19$ & $7-18$ & $1-4$ & $3-8$ & $4-17$ & $8-17$ \\
$3-4$ & $5-14$ & $14-16$ & $19-20$ & $5-9$ & $3-20$ & $7-19$ & $1-5$ & $3-9$ & $5-15$ & $9-15$ \\
$4-5$ & $6-14$ & $14-15$ & $2-4$ & $7-11$ & $4-18$ & $7-20$ & $1-6$ & $3-10$ & $5-16$ & $9-16$ \\
$5-6$ & $7-14$ & $14-17$ & $5-7$ & $8-12$ & $4-19$ & $8-13$ & $1-7$ & $3-11$ & $5-17$ & $9-17$ \\
$6-7$ & $8-14$ & $15-17$ & $7-9$ & $9-13$ & $4-20$ & $8-18$ & $1-8$ & $3-12$ & $6-8$ & $10-15$ \\
$7-8$ & $9-14$ & $15-18$ & $8-10$ & $2-7$ & $5-10$ & $8-19$ & $1-9$ & $3-13$ & $6-9$ & $10-16$ \\
$8-9$ & $10-14$ & $14-18$ & $9-11$ & $2-8$ & $5-11$ & $8-20$ & $1-10$ & $3-15$ & $6-10$ & $10-17$ \\
$9-10$ & $11-14$ & $15-19$ & $10-12$ & $2-9$ & $5-12$ & $9-19$ & $1-11$ & $3-16$ & $6-11$ & $11-15$ \\
$10-11$ & $9-18$ & $14-19$ & $11-13$ & $2-10$ & $5-13$ & $9-20$ & $1-12$ & $3-17$ & $6-12$ & $11-17$ \\
$11-12$ & & $13-19$ & $12-14$ & $2-11$ & $5-18$ & $10-18$ & $1-13$ & $4-6$ & $6-13$ & $12-15$ \\
$12-13$ & & $12-19$ & $18-20$ & $2-12$ & $5-19$ & $10-19$ & $1-15$ & $4-7$ & $6-15$ & $12-17$ \\
$16-18$ & & $11-19$ & $2-5$ & $2-13$ & $5-20$ & $10-20$ & $1-17$ & $4-8$ & $6-16$ & $13-15$ \\
$13-16$ & & $14-20$ & $5-8$ & $1-19$ & $6-18$ & $11-18$ & $1-15$ & $4-9$ & $6-17$ & $13-17$ \\
$16-19$ & & $15-20$ & $7-10$ & $1-20$ & $6-19$ & $11-20$ & $1-16$ & $4-10$ & $7-15$ & $15-16$ \\
$16-20$ & & & $8-11$ & $2-18$ & $6-20$ & $12-18$ & $1-17$ & $4-11$ & $7-16$ & $16-17$ \\
$13-20$ & & & $9-12$ & $2-19$ & $7-12$ & $12-20$ & $3-5$ & $4-12$ & $7-17$ & $17-18$ \\
$1-14$ & & & & $2-20$ & & $13-18$ & $3-6$ & $4-13$ & $8-15$ & $17-19$ \\
$3-14$ & & & & & & & & $4-15$ & & $17-20$ \\
$1-18$ & & & & & & & & & & \\
\hline
\end{tabular}

Elaboración propia

Figura 5.13

Análisis de relaciones

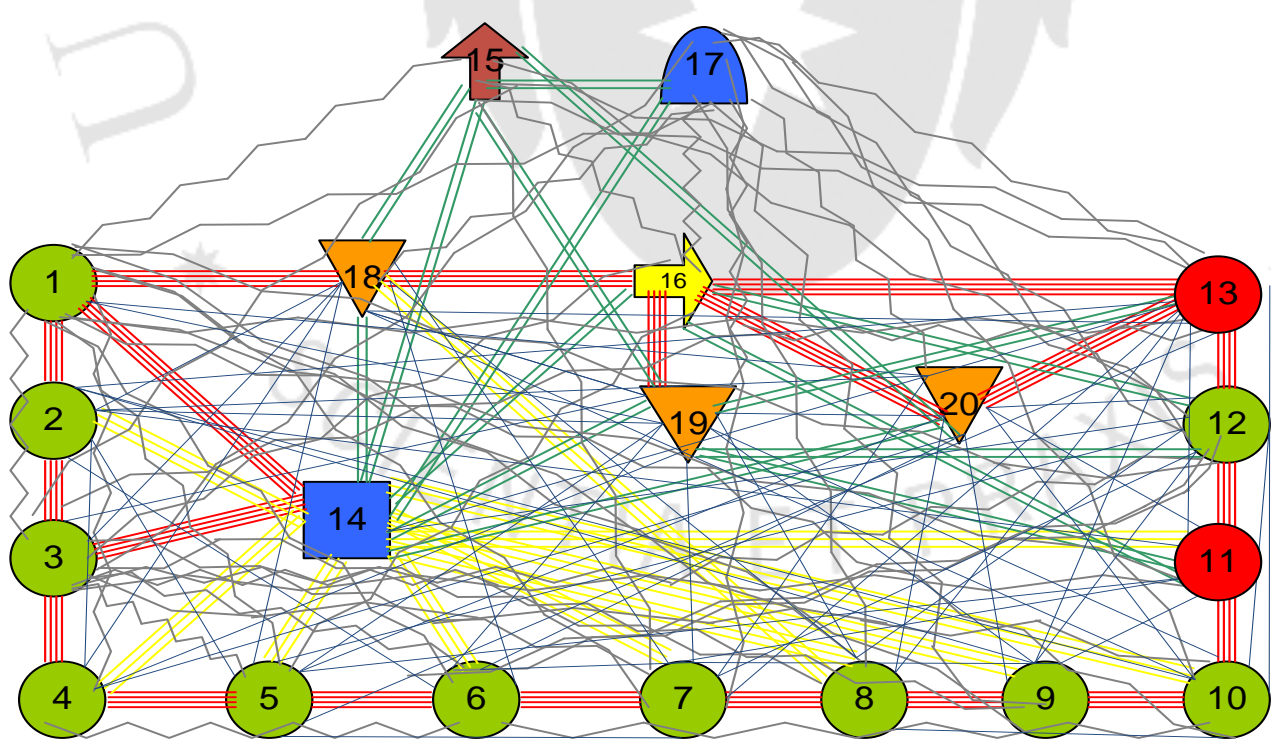

Elaboración propia

\subsubsection{Disposición de detalle}


Figura 5.14

Disposición de la planta de producción de compotas para bebés

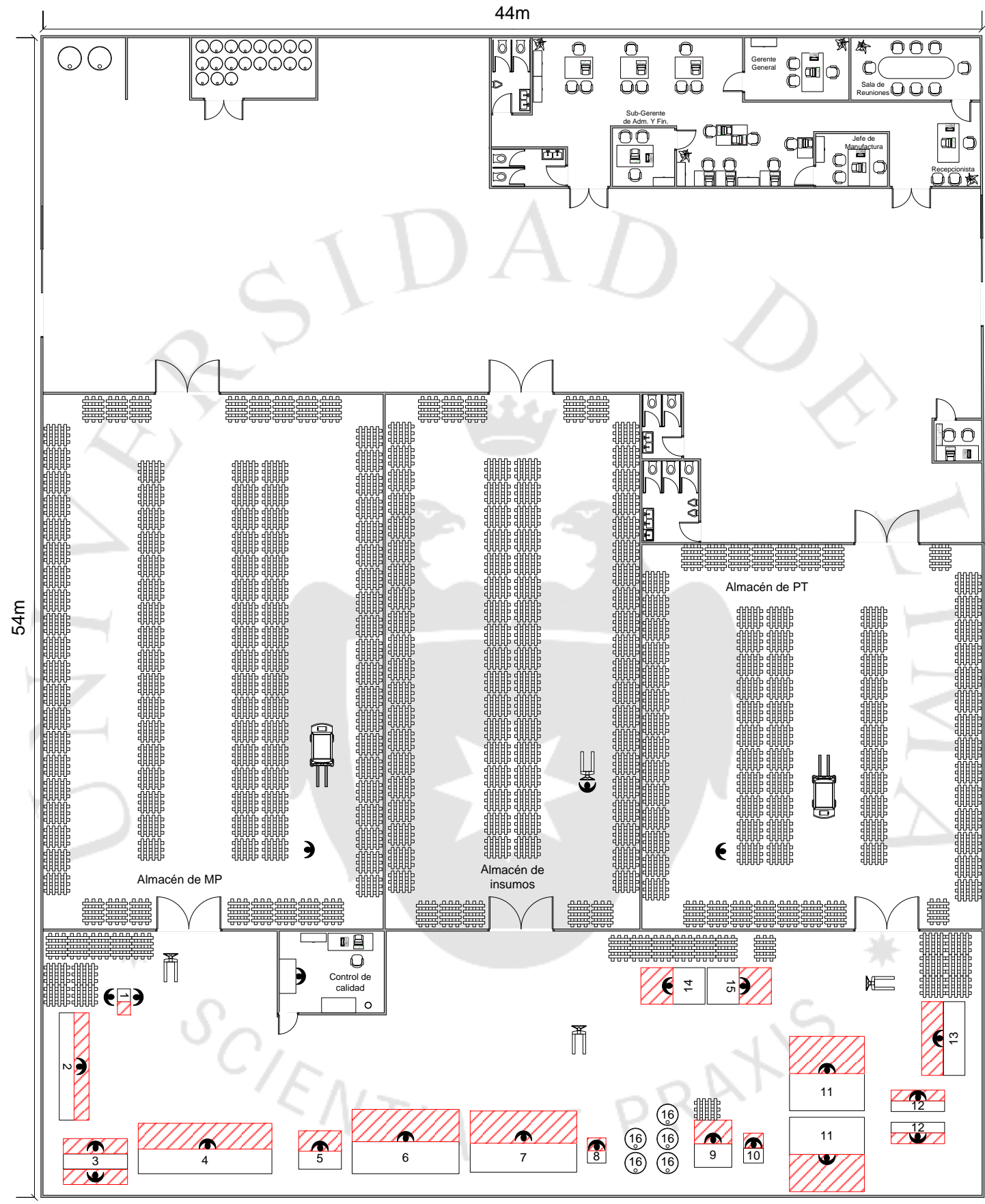

Elaboración propia

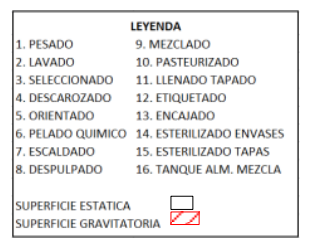

\begin{tabular}{|c|c|c|c|}
\hline \multicolumn{4}{|c|}{ PLANO DE DISTRIBUCIÓN DE PLANTA DE } \\
PRODUCCIÓN DE COMPOTA PARA BEBÉS \\
\hline ESCALA: & FECHA: & DIBUJANTE: & ÁREA: \\
\hline $1: 200$ & $29 / 02 / 2016$ & $\begin{array}{c}\text { Ricardo Rivas } \\
\text { Horacio Aldana }\end{array}$ & $2376 \mathrm{~m} 2$ \\
\hline
\end{tabular}




\subsection{Cronograma de implementación del proyecto}

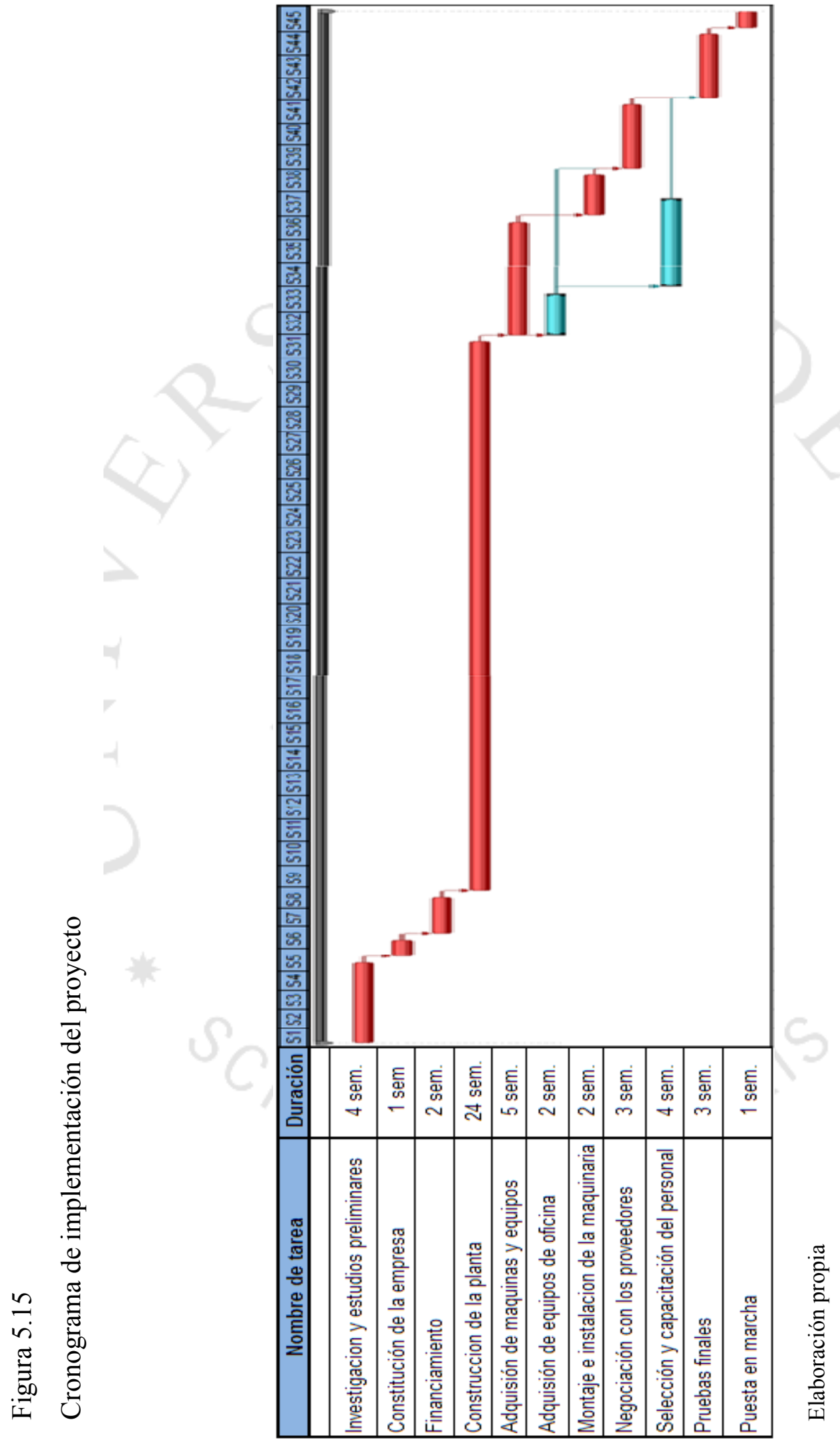




\section{CAPÍTULO VI: ORGANIZACIÓN ADMINISTRATIVA}

\subsection{Organización empresarial}

\section{Gerente general}

Es el líder del proyecto y responsable de la dirección, debe definir lo objetivos organizacionales y establecer las políticas generales que regirán a la empresa. Planifica el crecimiento de la empresa a corto y largo plazo. Es el representante legal y judicial de la empresa. También será el encargado de guiar al grupo de vendedores y hacer frente a los cambios en el mercado meta por lo que, debe diseñar las estrategias para hacerle frente y permitir el logro de los objetivos empresariales.

\section{Ejecutivos de ventas}

Se tienen 2 ejecutivos de venta: Un ejecutivo para atender 2 canales de distribución que son "Health and beauty retailers" (Farmacias) y "other grocery retailers" (Tiendas de alimentos, quioscos y mercados) y el otro ejecutivo para atender 3 canales de distribución que son "hypermarkets" (Hipermercados), "supermarkets" (Supermercados) y "independent smalls grocers" (Bodegas). Los ejecutivos de ventas son los encargados de realizar las cotizaciones, coordinar los servicios de venta, trato directo con los clientes y realizar las proyecciones de ventas.

$>$ Ejecutivo de marketing

Debe planificar y dirigir las políticas de mercadeo del producto así como, proponer y coordinar las campañas promocionales que incrementen la participación de la empresa en el mercado objetivo.

\section{Sub-Gerente de administración y finanzas}

Es el encargado de elaborar y ejecutar el plan financiero estratégico de la empresa, mediante la supervisión y seguimiento del registro de las operaciones financieras y contables. Es el responsable de optimizar las acciones económicas y manejo de presupuestos para satisfacer las necesidades de fondos para los programas de trabajo.

\section{Jefe de manufactura}


Es el responsable de gestionar el proceso de producción de las compotas y buscar la máxima eficiencia en el uso de los recursos asignados para lograr productos de calidad. Supervisa el correcto funcionamiento de las maquinarias y equipos. Presenta cuando requiera la sub-gerencia de administración y finanzas, la capacidad de producción real de la planta así como, los objetivos para mejorar la eficiencia y calidad del proceso productivo.

\section{$>$ Supervisor de producción}

Encargado de ejecutar el programa de producción usando los recursos asignados, vela por el correcto funcionamiento de las máquinas buscando la máxima eficiencia, dirige y asigna las funciones del personal de planta.

\section{- Operarios de planta}

Son los encargados del manejo de las máquinas y equipos para la fabricación del producto. Son los responsables del uso eficiente de la materia prima y la ejecución de las mejoras a los procesos.

\section{- Técnico de calidad}

Es el encargado de realizar las pruebas de calidad a la materia prima entrante y a los productos terminados para su almacenamiento.

\section{Supervisor de almacén de materia prima, insumos y producto terminado}

Es el encargado del manejo de stocks de la empresa. Debe asegurar el correcto almacenamiento de los ítems de los almacenes, supervisar el traslado de ellos a la planta y cuidar que los ítems no sean dañados o robados.

- Operarios de almacén

Son los encargados del manejo de la materia prima, insumos y producto terminado en los almacenes. Velan por la seguridad de los ítems, su correcto almacenamiento, el despacho de ellos a la planta, así como la carga o descarga.

\section{Analista de compras}

Gestionar y controlar el proceso de compras nacionales e internacionales, con el propósito de garantizar el stock de materia prima, insumos y equipos necesarios.

\section{Analista financiero}


Busca el uso eficiente de los recursos financieros mediante el seguimiento y evaluación del presupuesto de la empresa. Es el responsable de desarrollar estrategias financieras que permitan la autonomía financiera de la empresa.

\section{Analista Contable}

Es el responsable de elaborar los estados de situación financiera de la empresa, así como manejar el flujo mensual de ingresos y egresos.

\section{$>$ Analista de recursos humanos}

Encargado de manejar la planilla de los trabajadores de la empresa, los perfiles de trabajo para las entrevistas, los programas de beneficios y las actividades recreativas.

\section{$>$ Recepcionista}

Encargada de gestionar adecuadamente las relaciones humanas con el personal y los clientes, recibir y distribuir la correspondencia, controlar los espacios para reuniones así como realizar los trámites documentarios requeridos por la gerencia.

\subsection{Requerimientos de personal directivo, administrativo y de servicios}

Puesto: Gerente general

\section{Cantidad: 1}

Competencias y formación: Experiencia en planificación estratégica, liderazgo de equipos de trabajo, negociación, proactividad, comunicación efectiva a todo nivel, visión de negocios, análisis de situación, gestión de calidad, compromiso laboral, ética profesional. Con experiencia mínima de 5 años en el sector de alimentos de consumo masivo y debe contar con una maestría en finanzas o administración de empresas. Conocimiento de 2 idiomas, incluido el inglés. Manejo de Microsoft Office nivel avanzado.

\section{Funciones:}

- Ejercer la representación legal y judicial de la empresa.

- Definir la misión, visión y objetivos de la empresa.

- Administrar las actividades de la empresa, garantizando el cumplimiento de las normas, reglamentos, políticas e instructivos internos y los establecidos por las entidades de regulación y control.

- Coordinar, controlar y hacer un seguimiento de las metas a corto y largo plazo de la empresa. 
- Supervisar la administración financiera de la empresa y cumplir con las regulaciones tributarias y demás obligaciones legales.

- Seguimiento a la cadena de valor de la empresa y estudio de proyectos de mejora.

- Supervisar las capacitaciones y los planes de seguridad de la empresa.

- Representar a la empresa en el aspecto comercial.

- Realizar los estudios de mercado para el producto y definir el mercado objetivo.

- Coordinar y ejecutar las políticas de comercialización orientadas al logro de una mayor y mejor posición en el mercado.

- Supervisar el desarrollo y mejora de las políticas y objetivos de promoción y ventas que ofrece la empresa.

- Realizar seguimiento de la competencia y el mercado a fin de establecer ventajas competitivas para la venta de los productos.

Puesto: Ejecutivo de Venta

Cantidad: 2

Ejecutivo de ventas: Encargados de buscar y coordinar la venta de los productos en Lima.

Competencias y formación: Pensamiento estratégico, adaptabilidad al cambio en la demanda, proactividad, empatía, tolerancia al trabajo bajo presión, compromiso laboral, disponibilidad para viajes de trabajo. Experiencia en estudio de mercado, trato al cliente, cotizaciones, indicadores comerciales. Experiencia mínima de 2 años en el sector, grado de bachiller y estudios orientados a la venta de productos. Conocimiento 2 idiomas, incluido el inglés. Manejo de Microsoft Office nivel avanzado.

\section{Funciones:}

- Preparar las propuestas comerciales para los concursos, licitaciones y otros clientes potenciales.

- Atender las solicitudes de cotización y servicios, realizando las labores administrativas que se deriven de dichos procesos de acuerdo a las normas y políticas comerciales de la empresa.

- Coordinar con las áreas internas de la empresa todos los requerimientos operativos y administrativos para poder participar en los concursos y licitaciones comerciales.

- Administrar los trámites documentarios necesarios y archivar el historial de los clientes. 
- Manejar indicadores relacionados a la satisfacción de los clientes, de acuerdo a los servicios ofrecidos, a fin de optimizar procesos.

Puesto: Ejecutivo de Marketing

\section{Cantidad: 1}

Competencias y formación: Pensamiento estratégico, adaptabilidad al cambio en la demanda, proactividad, tolerancia al trabajo bajo presión. Experiencia en estudio de mercado, trato al cliente, diseño de productos, campañas de promoción. Experiencia mínima de 2 años en el sector, estudios orientados al marketing y grado de bachiller. Conocimiento 2 idiomas, incluido el inglés. Manejo de Microsoft Office nivel avanzado.

\section{Funciones:}

- Desarrollar el plan de marketing integral que contenga los objetivos y estrategias de publicidad y ventas del producto. Así como gestionar su presupuesto.

- Diseñar el plan de publicidad que mejore la presencia de la empresa en el mercado objetivo. Así como diversas actividades promocionales.

- Proponer políticas de mercado y sectorización para optimizar las ventas del producto.

- Coordinar y ejecutar las acciones publicitarias aprobadas por la empresa.

\section{Puesto: Jefe de Manufactura}

\section{Cantidad: 1}

Competencias y formación: Liderazgo de equipos de trabajo, proactividad, comunicación a todo nivel, análisis de situación, pensamiento estratégico, compromiso laboral, ética profesional, tolerancia al trabajo bajo presión, orientación al logro de metas. Experiencia en plantas de producción de alimentos, gestión de calidad, manejo de residuos, sistema de gestión de calidad y gestión ambiental, seguridad y salud en el trabajo, mantenimiento de máquinas y equipos, control de stocks, supervisión de personal, optimización de procesos y recursos, manejo de indicadores productivos. Experiencia mínima de 5 años en el sector, profesional en las carreras de ingeniería mecánica o industrial y debe contar con grado de maestría. Estudios orientados al manejo de procesos de producción. Conocimiento 2 idiomas, incluido el inglés. Manejo de Microsoft Office nivel avanzado.

\section{Funciones:}


- Elaborar el programa de producción.

- Seguimiento al abastecimiento de materia prima e insumos.

- Aprobar los requerimientos de compra.

- Controlar los costos de producción y búsqueda de la mejora en los niveles de productividad.

- Seguimiento al correcto funcionamiento de las máquinas y equipos.

- Supervisa el uso eficiente de la materia prima e insumos que entran y salen del proceso de producción.

- Supervisa la eficiencia de los procesos y la calidad de los productos.

- Vigilar las materias primas, insumos y productos terminados en stock, a fin de evitar pérdidas por: daño de los ítems, robos, fechas de vencimiento, etc.

- Supervisar los planes de seguridad industrial.

- Coordinar las labores de los supervisores de áreas.

- Definir las funciones de los trabajadores a su cargo y realizar las capacitaciones necesarias.

Puesto: Supervisor de producción

\section{Cantidad: 1}

Competencias y formación: Liderazgo de equipos de trabajo, proactividad, comunicación a todo nivel, compromiso laboral, ética profesional, tolerancia al trabajo bajo presión. Experiencia en manejo de personal, en plantas de producción de alimentos, manejo de residuos, sistema de gestión de calidad, mantenimiento de máquinas y equipos, optimización de procesos y recursos. Experiencia mínima de 3 años en puestos similares, profesional con grado de bachiller y estudios orientados a la optimización de procesos. Conocimiento de inglés avanzado y manejo de Microsoft Office nivel avanzado.

\section{Funciones:}

- Ejecutar el programa de producción, usar eficientemente los recursos asignados.

- Supervisar el correcto manejo de los equipos y maquinarias, de acuerdo a los procedimientos establecidos.

- Administrar al personal de planta. Supervisar los planes de seguridad industrial.

- Brindar las facilidades para los programas de capacitación del personal. 
Puesto: Operario de planta

Cantidad: 36

Competencias y formación: Proactividad, facilidad de comunicación, compromiso laboral, ética profesional. Experiencia en plantas de producción de alimentos y en manejo de máquinas similares. Carrera técnica orientada a la industria alimentaria.

\section{Funciones:}

- Manejo de las maquinarias de la planta. Uso eficiente de recursos asignados.

- Solicitar los insumos y equipos necesarios para realizar su trabajo.

- Reportar las fallas en las máquinas o entrega de semielaborados en mal estado.

- Participar en los proyectos de mejora.

Puesto: Técnico de calidad

Cantidad: 2

Competencias y formación: Proactividad, facilidad de comunicación, compromiso laboral, ética profesional. Experiencia en plantas de producción de alimentos, sistemas de gestión de calidad, manejo de equipos e instrumentos para pruebas de calidad. Carrera técnica o profesional orientada a la calidad, mínimo 2 años de experiencia en puestos similares.

\section{Funciones:}

- Realizar pruebas de calidad a la materia prima e insumos.

- Realizar las pruebas de calidad a los productos terminados.

- Reportar los lotes rechazados de materiales al supervisor.

- Manejar un indicador de productos terminados no conforme, a fin registrar los rechazos periódicamente y apoyar en la toma de decisiones.

Puesto: Supervisor de almacén de materia prima, insumos y producto terminado

\section{Cantidad: 1}

Competencias y formación: Liderazgo de equipos de trabajo, proactividad, comunicación a todo nivel, compromiso laboral, ética profesional, tolerancia al trabajo bajo presión. Experiencia en manejo de personal, control de stocks, seguimiento de órdenes de compra, manejo de residuos, recepción y despacho de materiales, sistemas de gestión de calidad. Experiencia mínima de 3 años en puestos similares, profesional con grado de bachiller y 
estudios orientados al manejo de inventarios. Conocimiento de inglés avanzado y manejo de Microsoft Office nivel avanzado.

\section{Funciones:}

- Supervisar la recepción de la materia prima entrante y los insumos para su almacenamiento, así como realizar los trámites documentarios correspondientes.

- Velar por el correcto almacenamiento de todos los materiales y productos, de acuerdo a las especificaciones del proveedor y las normas vigentes.

- Ingresar al sistema todo material que entre, se despache o salga de la planta.

- Reportar la falta de stock para la producción, así como los incumplimientos en los plazos de entrega del proveedor.

- Registrar la ubicación de cada material del almacén en el sistema.

- Supervisar la carga del producto terminado para su distribución, así como los trámites documentarios correspondientes.

- Supervisar que todo lo que este en el almacén no sea dañado o robado.

- Controles de stock continuos y realización de reportes de inventarios.

- Dejar visibles las señales de peligros y riesgos de cada material

- Supervisar el plan de seguridad industrial de los almacenes.

- Dirigir al personal a su cargo y solicitar las capacitaciones necesarias.

Puesto: Operario de almacén

\section{Cantidad: 4}

Competencias y formación: Proactividad, facilidad de comunicación, ética profesional. Experiencia en manejo de stocks, instructivos de almacenamiento, recepción y despacho de materiales, debe contar con brevete para manejo de montacargas. Carrera técnica o experiencia previa en puestos similares, mínimo 2 años de experiencia.

\section{Funciones:}

- Manejo de montacargas para recepción y despacho de materiales o producto terminado. Control de materiales despachados.

- Realizar el correcto almacenamiento de las materias primas, insumos y productos terminados. Informar de anomalías al supervisor.

- Informar los materiales o productos que estén cerca de caducidad al supervisor. 
Puesto: Analista de compras

\section{Cantidad: 1}

Competencias y formación: Proactividad, comunicación a todo nivel, compromiso laboral, trabajo en equipo, ética profesional, experiencia en manejo de proveedores, control de stock, aduanas, órdenes de compra, sistemas de gestión de calidad, manejo de cotizaciones y facturas. Carrera profesional o especialización orientada a la gestión de la cadena de suministros, mínimo 3 años de experiencia en puestos similares. Conocimiento mínimo de 2 idiomas, incluido el inglés. Manejo de Microsoft Office nivel avanzado.

\section{Funciones:}

- Actualizar la base de datos de proveedores nacionales o internacionales por materia prima e insumo, a fin de obtener los mejores precios del mercado y los acuerdos más convenientes para la empresa. Estandarizar los precios de compra de materia prima e insumo, para una mejor gestión de costos.

- Acordar los plazos de entrega con los proveedores y realizar seguimiento a las órdenes de compra. Reportar los incumplimientos en los plazos de entrega al área financiera a fin de aplicar las sanciones establecidas.

- Coordinar con el proveedor la devolución de la materia prima que no aprobó los controles de calidad.

- Coordinar con el transportista el despacho del producto terminado.

Puesto: Sub-Gerente de administración y finanzas

\section{Cantidad: 1}

Competencias y formación: Experiencia en planificación estratégica, liderazgo de equipos de trabajo, negociación, proactividad, comunicación efectiva a todo nivel, transparencia, visión de negocios, análisis de situación, compromiso laboral, ética profesional, manejo de indicadores financieros, gestión administrativa, manejo de fondos, estudios de inversión, análisis de presupuestos. Con experiencia mínima de 5 años en sistemas financieros de empresas de producción y debe contar con una maestría en finanzas o administración de empresas. Conocimiento mínimo de 2 idiomas, incluido el inglés. Manejo de Microsoft Office nivel avanzado.

\section{Funciones:}


- Desarrollar los estados financieros de la empresa. Elaborar los presupuestos mensuales y anuales. Garantizar el capital de trabajo de la empresa.

- Supervisar el flujo de caja de la empresa. Gestionar las cuentas bancarias.

- Manejar y optimizar los indicadores financieros de la empresa.

- Proponer alternativas de inversión que minimicen el riesgo de pérdida financiera y al mismo tiempo ofrezcan buenos rendimientos.

- Aprobar y hacer seguimiento a los acuerdos de préstamos e inversión.

- Procurar hacer los pagos correspondientes al personal en planilla, agentes externos y entidades prestamistas en las fechas acordadas.

- Aprobar las órdenes de compra. Supervisar los tratos con proveedores y acordar las formas de pago. Propiciar la seguridad financiera.

- Aprobar los perfiles de trabajo y los salarios de los colaboradores de la empresa.

Puesto: Analista financiero

\section{Cantidad: 1}

Competencias y formación: Experiencia en planificación estratégica, transparencia, visión de negocios, análisis de situación, manejo de indicadores financieros, manejo de fondos, estudios de inversión, análisis de presupuestos, conocimiento de la normativa bancaria y tramite legales correspondientes. Experiencia mínima de 5 años en cargos similares, carrera profesional orientada a la economía y finanzas. Dominio del inglés. Manejo de Microsoft Office nivel avanzado.

\section{Funciones:}

- Identificar las desviaciones en los presupuestos y otras observaciones pertinentes.

- Registrar y supervisar el avance del ejercicio presupuestado.

- Optimizar el control de las finanzas mediante el manejo de indicadores financieros, como herramientas de previsión para elaborar un diagnóstico.

- Manejo de créditos y cobranzas.

Puesto: Analista contable

\section{Cantidad: 1}

Competencias y formación: Experiencia en planificación estratégica, transparencia, tolerancia al trabajo bajo presión, análisis de situación, manejo de estados financieros, 
análisis de presupuestos, gestión tributaria, conocimiento de la normativa bancaria y trámites legales correspondientes, compromiso laboral, ética profesional. Experiencia mínima de 5 años en cargos similares, carrera profesional de contabilidad u otra orientada a la economía y finanzas. Dominio del inglés. Manejo de Microsoft Office nivel avanzado.

\section{Funciones:}

- Elaborar los estados financieros de la empresa. Gestión tributaria de la empresa.

- Control y seguimiento de facturas. Análisis de las normativas legales vigentes para el cumplimiento de las funciones dentro de la empresa.

- Realizar el pago a proveedores, personal en planilla y prestamistas. Manejo de la caja chica de la empresa. Manejo del flujo mensual de ingresos y egresos.

- Realizar el inventario de activos físicos de la empresa e ingresarlo al sistema.

Puesto: Analista de recursos humanos

\section{Cantidad: 1}

Competencias y formación: Transparencia, confidencialidad, análisis de situación, proactividad, comunicación a todo nivel, compromiso laboral, ética profesional. Experiencia en manejo de planillas, gestión de personas, definición de perfiles de trabajo, entrevistas laborales, programas de capacitación y labores sociales. Carrera profesional de administración, psicología organizacional u otra a fines, con experiencia mínima de 3 años en puestos similares. Dominio del inglés. Manejo de Microsoft Office nivel avanzado.

\section{Funciones:}

- Planificar y coordinar la selección, capacitación y desarrollo del personal de la empresa. Impulsar el desarrollo y retención del talento.

- Proponer y dirigir los programas de bienestar, líneas de carrera, convenios educativos y entretenimiento para los colaboradores de la empresa.

- Gestionar las planillas de los trabajadores: contratos y remuneración. Brindar las facilidades para el pago del seguro social o seguros privados de los trabajadores.

- Registrar y archivar los datos de los colaboradores y ex colaboradores de la empresa. Realizar los trámites legales y documentarios requeridos por el área de recursos humanos.

- Supervisar las horas de entrada y salida de los trabajadores.

- Coordinar los programas de capacitación a los trabajadores. 
- Brindar charlas de capacitación a todos los trabajadores sobre las leyes laborales vigentes, así como las facilidades para ponerlas en práctica.

\section{Puesto: Recepcionista}

\section{Cantidad: 1}

Competencias y formación: Proactividad, comunicación a todo nivel, compromiso laboral, ética profesional, tolerancia al trabajo bajo presión. Experiencia en trato con clientes, en manejo de personal, gestión administrativa, manejo de correspondencia. Carrera profesional de administración u otra a fines, experiencia en puestos similares mínima de 6 meses. Dominio del inglés. Manejo de Microsoft Office nivel avanzado.

\section{Funciones:}

- Recepción y atención al cliente o colaboradores de la empresa. Recepción y despacho de correspondencia. Recepción e ingreso de detalle de las facturas.

- Informar al gerente general las reuniones o asuntos que tenga programados.

- Archivar documentos del gerente general. Realizar reportes requeridos por la gerencia.

\subsection{Estructura organizacional}

Figura 6.1

Organigrama de la empresa

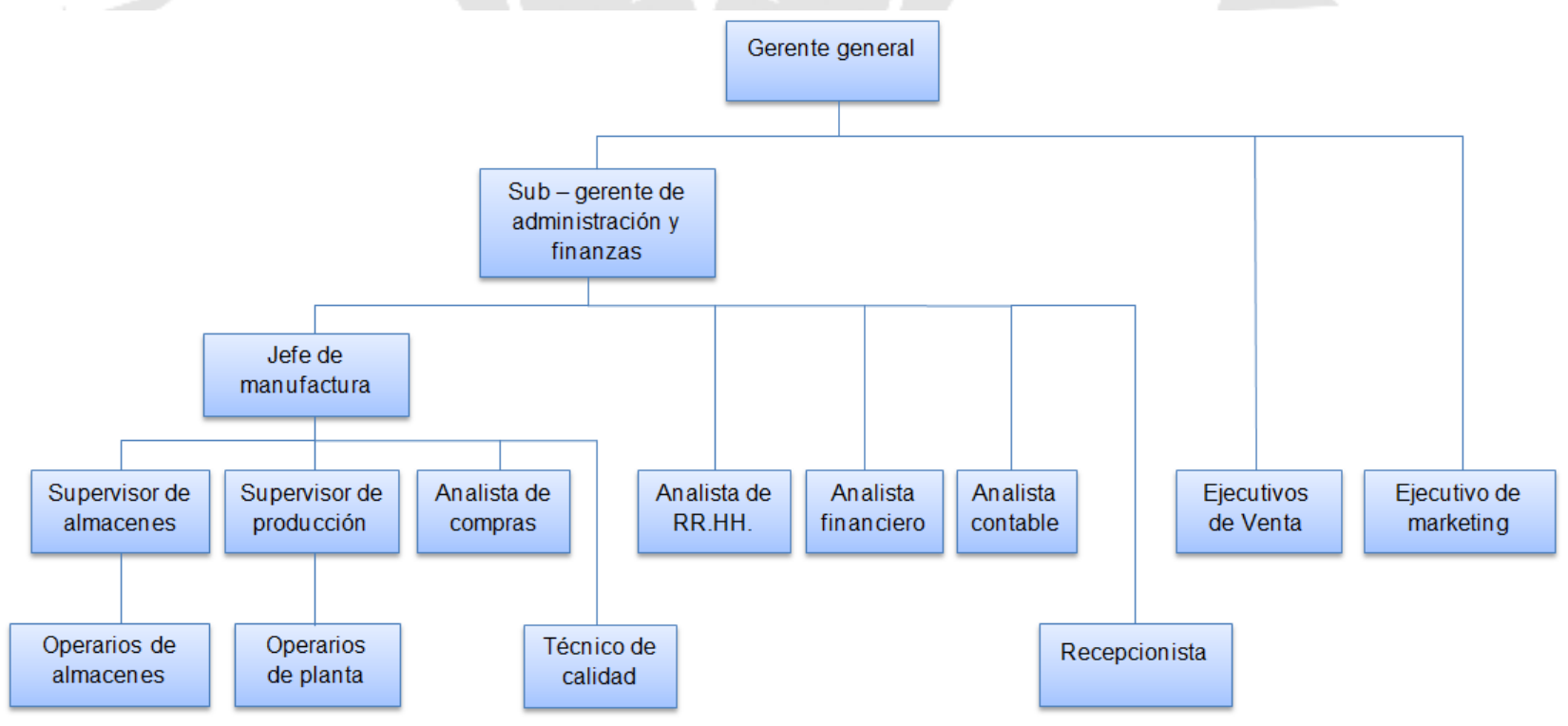

Elaboración propia 


\section{CAPÍTULO VII: ASPECTOS ECONÓMICOS Y FINANCIEROS}

\subsection{Inversiones}

\subsubsection{Estimación de las inversiones de largo plazo (tangibles e intangibles)}

La inversión total del proyecto está conformada por todas las compras y adquisiciones necesarias para constituir la empresa y el inicio de la producción. Se conforma de las inversiones fijas tangibles, las inversiones fijas intangibles y el capital de trabajo para los cuatro primeros meses de operación. La inversión fija tangible está conformada por:

Tabla 7.1

Inversión fija tangible del proyecto

\begin{tabular}{|c|c|c|c|c|c|c|}
\hline Activos Tangibles & $\begin{array}{c}\text { Precio } \\
\text { Unitario (\$) }\end{array}$ & Unidad & Cantidad & Unidad & $\begin{array}{c}\text { Precio total } \\
(\$)\end{array}$ & $\begin{array}{l}\text { Precio total } \\
\text { (S/.) }\end{array}$ \\
\hline Costo del Terreno & 140 & $\mathrm{~m} 2$ & 2.376 & $\mathrm{~m} 2$ & 332.640 & 1.123 .658 \\
\hline Costo de construcción & 180 & $\mathrm{~m} 2$ & 2.376 & $\mathrm{~m} 2$ & 427.680 & 1.444 .703 \\
\hline Báscula de piso portátil & 300 & Unidad & 1 & Unidad & 300 & 1.013 \\
\hline Lavadora de frutas & 20.000 & Unidad & 1 & Unidad & 20.000 & 67.560 \\
\hline Faja transportadora & 500 & Unidad & 1 & Unidad & 500 & 1.689 \\
\hline Máquina descarozadora & 5.000 & Unidad & 1 & Unidad & 5.000 & 16.890 \\
\hline Orientadora de mitades & 3.000 & Unidad & 1 & Unidad & 3.000 & 10.134 \\
\hline Peladora química & 20.000 & Unidad & 1 & Unidad & 20.000 & 67.560 \\
\hline Escaldadora tipo inmersión & 5.000 & Unidad & 1 & Unidad & 5.000 & 16.890 \\
\hline Despulpadora de frutas & 3.000 & Unidad & 1 & Unidad & 3.000 & 10.134 \\
\hline Mezcladora de paletas & 4.000 & Unidad & 1 & Unidad & 4.000 & 13.512 \\
\hline Marmita a vapor eléctrica & 2.000 & Unidad & 1 & Unidad & 2.000 & 6.756 \\
\hline Máquina de llenado y tapado & 15.000 & Unidad & 2 & Unidad & 30.000 & 101.340 \\
\hline Etiquetadora automática & 5.000 & Unidad & 2 & Unidad & 10.000 & 33.780 \\
\hline Máquina formadora de cajas & 10.000 & Unidad & 1 & Unidad & 10.000 & 33.780 \\
\hline Máquina esterilizadora de envases & 15.000 & Unidad & 2 & Unidad & 30.000 & 101.340 \\
\hline Tanque de almacenamiento de acero inoxidable & 1.500 & Unidad & 5 & Unidad & 7.500 & 25.335 \\
\hline Bomba de doble husillo & 1.200 & Unidad & 1 & Unidad & 1.200 & 4.054 \\
\hline Bomba peristáltica SPX32 & 2.500 & Unidad & 1 & Unidad & 2.500 & 8.445 \\
\hline Tanque de almacenamiento de hidróxido de sodio & 1.000 & Unidad & 2 & Unidad & 2.000 & 6.756 \\
\hline Montacargas CAT & 8.500 & Unidad & 2 & Unidad & 17.000 & 57.426 \\
\hline Carretilla hidráulica manual & 100 & Unidad & 4 & Unidad & 400 & 1.351 \\
\hline Puerta corta fuegos & 100 & Unidad & 6 & Unidad & 600 & 2.027 \\
\hline Extractor manual de gasolina & 14 & Unidad & 1 & Unidad & 14 & 48 \\
\hline Barril acero inoxidable para gasolina & 100 & Unidad & 19 & Unidad & 1.900 & 6.418 \\
\hline Extintores & 30 & Unidad & 13 & Unidad & 384 & 1.299 \\
\hline Sensor de humo fotoeléctrico & 12 & Unidad & 46 & Unidad & 552 & 1.865 \\
\hline Sensor de calor de temperatura fija & 14 & Unidad & 4 & Unidad & 56 & 189 \\
\hline \begin{tabular}{|l|l|} 
Alarma manual \\
\end{tabular} & 14 & Unidad & 8 & Unidad & 112 & 378 \\
\hline Sirena con luz estrobos cópica & 10 & Unidad & 8 & Unidad & 80 & 270 \\
\hline Tablero de control contra incendios & 360 & Unidad & 1 & Unidad & 360 & 1.216 \\
\hline Camaras de seguridad & 150 & Unidad & 4 & Unidad & 600 & 2.027 \\
\hline Parihuela & 38 & Unidad & 761 & Unidad & 28.918 & 97.685 \\
\hline Escritorio & 245 & Unidad & 16 & Unidad & 3.920 & 13.242 \\
\hline Silla de oficina & 56 & Unidad & 40 & Unidad & 2.250 & 7.600 \\
\hline Laptop Dell & 473 & Unidad & 16 & Unidad & 7.574 & 25.584 \\
\hline Celular Samsung Galaxy S4 & 150 & Unidad & 7 & Unidad & 1.050 & 3.547 \\
\hline TOTAL & & & & & 982.090 & 3.317 .501 \\
\hline
\end{tabular}

Elaboración propia 
La inversión fija intangible está compuesta por los siguientes activos:

Tabla 7.2

Inversión fija intangible del proyecto

\begin{tabular}{|l|r|}
\hline \multicolumn{1}{|c|}{ Activo Fijo Intangible } & Precio Total (S/.) \\
\hline Estudio de pre factibilidad & 5.500 \\
\hline Constitución de la empresa & 500 \\
\hline Registro Sanitario & 600 \\
\hline Registro de la Marca & 2.000 \\
\hline Capacitación de personal & 5.000 \\
\hline Software Microsoft Dynamics ERP Professional & 63.236 \\
\hline Software Microsoft Office 2013 & 4.500 \\
\hline TOTAL & 81.336 \\
\hline
\end{tabular}

Elaboración propia

La pérdida de valor contable de los activos fijos tangibles se denomina depreciación (Ver anexo 2) (Ver anexo 3) y la de los activos fijos intangibles se denomina amortización (Ver anexo 4).

\subsubsection{Estimación de inversiones de corto plazo - Capital de trabajo}

El capital de trabajo de la empresa permitirá cubrir los costos y gastos de los 4 primeros meses de operación, a continuación se muestra su cálculo:

Tabla 7.3

Capital de trabajo para los 4 primeros meses de operación

\begin{tabular}{|l|r|}
\hline \multicolumn{1}{|c|}{ Costos y Gastos } & Costo (S/.) \\
\hline Mano de Obra & 525.778 \\
\hline Materia Prima & 358.778 \\
\hline Insumos & 276.411 \\
\hline Energía Eléctrica & 29.206 \\
\hline Agua y Alcantarillado & 3.612 \\
\hline Combustible & 25.650 \\
\hline Implementos de seguridad & 14.686 \\
\hline Telefonía e Internet & 8.388 \\
\hline Publicidad y promoción & 44.762 \\
\hline Dispositivos de seg. y señl. & 183 \\
\hline Mantenimiento & 5.942 \\
\hline Distribución & 2.101 \\
\hline Vigilancia & 30.076 \\
\hline Limpieza & 24.288 \\
\hline TOTAL & 1.349 .861 \\
\hline
\end{tabular}

Elaboración propia

\section{Resumen de inversión:}

Luego de obtener las inversiones tangibles, intangibles y el capital de trabajo, se procede a determinar la inversión total del proyecto en soles. 
Tabla 7.4

Inversión total del proyecto

\begin{tabular}{|l|r|r|}
\hline INVERSIONES & COSTO (S/.) & PORCENTAJE \\
\hline Inversión Tangible & 3.317 .501 & $70 \%$ \\
\hline Inversión Intangible & 81.336 & $2 \%$ \\
\hline Capital de Trabajo & 1.349 .861 & $28 \%$ \\
\hline Inversión Total & $\mathbf{4 . 7 4 8 . 6 9 8}$ & $100 \%$ \\
\hline
\end{tabular}

Elaboración propia

Esta inversión total, se obtendrá mediante capital propio y financiamiento. La deuda tendrá una tasa de interés anual de $21,21 \%$, mientras que el costo de capital será de $23 \%$.

Tabla 7.5

Relación deuda/capital propio

\begin{tabular}{|l|r|r|}
\hline & Porcentaje & Monto (S/.) \\
\hline Financiamiento & $40 \%$ & 1.899 .479 \\
\hline Capital propio & $60 \%$ & 2.849 .219 \\
\hline Inversión Total & & 4.748 .698 \\
\hline
\end{tabular}

Elaboración propia

\subsection{Costo de producción}

\subsubsection{Costo de materia prima, insumos y otros materiales}

Tabla 7.6

Costo de materias primas para el periodo del proyecto

\begin{tabular}{|l|r|r|r|r|r|r|r|}
\hline \multirow{2}{*}{ Materia Prima } & Precio & \multicolumn{6}{|c|}{ Costo de MP para el periodo del proyecto (soles/año) } \\
\cline { 3 - 8 } & Unitario & \multicolumn{1}{|c|}{$\mathbf{2 0 1 6}$} & $\mathbf{2 0 1 7}$ & \multicolumn{1}{c|}{$\mathbf{2 0 1 8}$} & $\mathbf{2 0 1 9}$ & \multicolumn{1}{|c|}{$\mathbf{2 0 2 0}$} & \multicolumn{1}{c|}{$\mathbf{2 0 2 1}$} \\
\hline Durazno & 1,40 & 563.614 & 799.498 & 1.134 .034 & 1.608 .454 & 2.281 .217 & 3.235 .195 \\
\hline Harina de maca & 35,00 & 216.207 & 306.694 & 435.025 & 617.017 & 875.094 & 1.241 .048 \\
\hline Harina de quinua & 18,00 & 111.192 & 157.728 & 223.727 & 317.323 & 450.048 & 638.253 \\
\hline Harina de kiwicha & 10,00 & 61.773 & 87.627 & 124.293 & 176.290 & 250.027 & 354.585 \\
\hline Harina de cañihua & 20,00 & 123.547 & 175.254 & 248.586 & 352.581 & 500.054 & 709.170 \\
\hline Total & & 1.076 .334 & 1.526 .801 & 2.165 .664 & 3.071 .665 & 4.356 .440 & 6.178 .251 \\
\hline
\end{tabular}

Elaboración propia

Tabla 7.7

Costo de los insumos para el periodo del proyecto

\begin{tabular}{|l|r|r|r|r|r|r|r|}
\hline \multirow{2}{*}{\multicolumn{1}{c|}{ Insumos }} & Precio & \multicolumn{3}{c|}{ Costo de insumos para el periodo del proyecto (soles/año) } \\
\cline { 3 - 8 } & Unitario & \multicolumn{1}{c|}{$\mathbf{2 0 1 6}$} & \multicolumn{1}{c|}{$\mathbf{2 0 1 7}$} & \multicolumn{1}{c|}{$\mathbf{2 0 1 8}$} & \multicolumn{1}{c|}{$\mathbf{2 0 1 9}$} & \multicolumn{1}{c|}{$\mathbf{2 0 2 0}$} & \multicolumn{1}{c|}{$\mathbf{2 0 2 1}$} \\
\hline Envases y tapas & 0,22 & 691.863 & 981.421 & 1.392 .079 & 1.974 .453 & 2.800 .301 & 3.971 .353 \\
\hline Etiquetas & 0,03 & 86.483 & 122.678 & 174.010 & 246.807 & 350.038 & 496.419 \\
\hline Cajas & 0,8 & 12.355 & 17.525 & 24.859 & 35.258 & 50.005 & 70.917 \\
\hline Tego al 0,1\% & 4,05 & 2.446 & 3.469 & 4.921 & 6.980 & 9.899 & 14.038 \\
\hline Hidroxido de sodio 2\% & 4,05 & 36.031 & 51.111 & 72.498 & 102.827 & 145.837 & 206.824 \\
\hline Cintas de embalaje & 7,11 & 56 & 79 & 112 & 159 & 225 & 320 \\
\hline Total & & 829.233 & 1.176 .284 & 1.668 .479 & 2.366 .483 & 3.356 .304 & 4.759 .871 \\
\hline
\end{tabular}

Elaboración propia 


\subsubsection{Costo de la mano de obra directa}

Tabla 7.8

Costo de mano de obra directa

\begin{tabular}{|l|r|r|r|r|r|r|}
\hline \multicolumn{1}{|c|}{ Áreas } & Cantidad & $\begin{array}{c}\text { Sueldo } \\
\text { Mensual }\end{array}$ & \multicolumn{1}{c|}{$\begin{array}{c}\text { Sueldo } \\
\text { Anual }\end{array}$} & $\begin{array}{c}\text { Gratificaci } \\
\text { ón Anual }\end{array}$ & $\begin{array}{c}\text { CTS } \\
\text { Anual }\end{array}$ & $\begin{array}{c}\text { Costo } \\
\text { Total (S/.) }\end{array}$ \\
\hline Pesado & 2 & 900 & 21.600 & 3.600 & 2.100 & 27.300 \\
\hline Lavado & 2 & 900 & 21.600 & 3.600 & 2.100 & 27.300 \\
\hline Seleccionado & 4 & 900 & 43.200 & 7.200 & 4.200 & 54.600 \\
\hline Descarozado & 2 & 900 & 21.600 & 3.600 & 2.100 & 27.300 \\
\hline Orientado & 2 & 900 & 21.600 & 3.600 & 2.100 & 27.300 \\
\hline Pelado quimico & 2 & 900 & 21.600 & 3.600 & 2.100 & 27.300 \\
\hline Escaldado & 2 & 900 & 21.600 & 3.600 & 2.100 & 27.300 \\
\hline Despulpado ytamizado & 2 & 900 & 21.600 & 3.600 & 2.100 & 27.300 \\
\hline Mezclado & 2 & 900 & 21.600 & 3.600 & 2.100 & 27.300 \\
\hline Pasteurizado & 2 & 900 & 21.600 & 3.600 & 2.100 & 27.300 \\
\hline Llenado ytapado & 4 & 900 & 43.200 & 7.200 & 4.200 & 54.600 \\
\hline Etiquetado & 4 & 900 & 43.200 & 7.200 & 4.200 & 54.600 \\
\hline Encajado & 2 & 900 & 21.600 & 3.600 & 2.100 & 27.300 \\
\hline Esterilizado de tapas & 2 & 900 & 21.600 & 3.600 & 2.100 & 27.300 \\
\hline Esterilizado de envases & 2 & 900 & 21.600 & 3.600 & 2.100 & 27.300 \\
\hline Calidad & 2 & 2.000 & 48.000 & 8.000 & 4.667 & 60.667 \\
\hline Almacen MP e Insumos & 2 & 900 & 21.600 & 3.600 & 2.100 & 27.300 \\
\hline Almacen de PT & 2 & 900 & 21.600 & 3.600 & 2.100 & 27.300 \\
\hline TOTAL & 42 & & & & & 606.667 \\
\hline
\end{tabular}

Elaboración propia

\subsubsection{Costo indirecto de fabricación (materiales indirectos, mano de obra indirecta y}

\section{costos generales de planta)}

Tabla 7.9

Costos Implementos de seguridad

\begin{tabular}{|c|c|c|c|c|c|c|}
\hline \multirow{2}{*}{ Equipos } & \multicolumn{6}{|c|}{ Costo Implementos de seguridad para periodo del proyecto (soles/año) } \\
\hline & 2016 & 2017 & 2018 & 2019 & 2020 & 2021 \\
\hline Guantes de Protección(Par) & 82 & 82 & 82 & 82 & 82 & 82 \\
\hline Mascarillas & 491 & 491 & 491 & 491 & 491 & 491 \\
\hline Trajes de cuerpo & 42.083 & 42.083 & 42.083 & 42.083 & 42.083 & 42.083 \\
\hline Cubiertas de zapatos & 1.403 & 1.403 & 1.403 & 1.403 & 1.403 & 1.403 \\
\hline $\begin{array}{ll}\text { TOTAL } \\
\end{array}$ & 44.059 & 44.059 & 44.059 & 44.059 & 44.059 & 44.059 \\
\hline
\end{tabular}

Elaboración propia 
Tabla 7.10

Costo de mano de obra indirecta

\begin{tabular}{|l|r|r|r|r|r|r|}
\hline \multicolumn{1}{|c|}{ Areas } & Cantidad & \multicolumn{1}{c|}{$\begin{array}{c}\text { Sueldo } \\
\text { Mensual }\end{array}$} & \multicolumn{1}{c|}{$\begin{array}{c}\text { Sueldo } \\
\text { Anual }\end{array}$} & $\begin{array}{c}\text { Gratificación } \\
\text { Anual }\end{array}$ & CTS Anual & $\begin{array}{c}\text { Costo Total } \\
(\mathbf{S} / .)\end{array}$ \\
\hline Gerente General & 1 & 20.000 & 240.000 & 40.000 & 23.333 & 303.333 \\
\hline Sub-Gerente de Administración y Finanzas & 1 & 12.000 & 144.000 & 24.000 & 14.000 & 182.000 \\
\hline Jefe de Manufactura & 1 & 7.000 & 84.000 & 14.000 & 8.167 & 106.167 \\
\hline Ejecutivos de Ventas & 2 & 3.000 & 72.000 & 12.000 & 7.000 & 91.000 \\
\hline Ejecutivo de Marketing & 1 & 3.000 & 36.000 & 6.000 & 3.500 & 45.500 \\
\hline Supervisor de Producción & 1 & 2.500 & 30.000 & 5.000 & 2.917 & 37.917 \\
\hline Supervisor de Almacenes & 1 & 2.500 & 30.000 & 5.000 & 2.917 & 37.917 \\
\hline Analista de Compras & 1 & 2.500 & 30.000 & 5.000 & 2.917 & 37.917 \\
\hline Analista Financiero & 1 & 2.500 & 30.000 & 5.000 & 2.917 & 37.917 \\
\hline Analista Contable & 1 & 2.500 & 30.000 & 5.000 & 2.917 & 37.917 \\
\hline Analista de RR. HH. & 1 & 2.500 & 30.000 & 5.000 & 2.917 & 37.917 \\
\hline Recepcionista & 1 & 1.000 & 12.000 & 2.000 & 1.167 & 15.167 \\
\hline TOTAL & 13 & & & & & 970.667 \\
\hline
\end{tabular}

Elaboración propia

Tabla 7.11

Costo de energía eléctrica

\begin{tabular}{|l|r|c|r|}
\hline Proceso o máquina & $\begin{array}{r}\text { Kw/ } \\
\text { año }\end{array}$ & Tarifa (soles/kw) & $\begin{array}{r}\text { Costo total } \\
\text { (soles/año) }\end{array}$ \\
\hline Lavado & 25.072 & 0,3943 & 9.886 \\
\hline Seleccionado & 786 & 0,3943 & 310 \\
\hline Descarozado & 9.610 & 0,3943 & 3.789 \\
\hline Orientado & 3.276 & 0,3943 & 1.292 \\
\hline Pelado químico & 13.104 & 0,3943 & 5.167 \\
\hline Escaldado & 4.914 & 0,3943 & 1.938 \\
\hline Despulpado y tamizado & 13.104 & 0,3943 & 5.167 \\
\hline Mezcladora & 4.368 & 0,3943 & 1.722 \\
\hline Pasteurizado & 91.728 & 0,3943 & 36.168 \\
\hline Llenado y tapado & 13.104 & 0,3943 & 5.167 \\
\hline Etiquetado & 4.193 & 0,3943 & 1.653 \\
\hline Encajado & 10.920 & 0,3943 & 4.306 \\
\hline Esterilizado de tapas & 5.242 & 0,3943 & 2.067 \\
\hline Esterilizado de envases & 5.242 & 0,3943 & 2.067 \\
\hline Bomba de doble husillo & 6.552 & 0,3943 & 2.583 \\
\hline Bomba SPX32 & 10.920 & 0,3943 & 4.306 \\
\hline & & Total & 87.588 \\
\hline & & Cargo fijo anual & 29 \\
\hline & & COSTO TOTAL & $\mathbf{8 7 . 6 1 7}$ \\
\hline
\end{tabular}

Elaboración propia

Tabla 7.12

Costo de agua potable

\begin{tabular}{|c|c|c|c|c|c|c|}
\hline Año & \multicolumn{1}{|c|}{2016} & 2017 & 2018 & 2019 & 2020 & 2021 \\
\hline $\begin{array}{c}\text { Costo de agua Total } \\
\text { (soles/año) }\end{array}$ & 10.210 & 13.352 & 17.809 & 24.130 & 33.093 & 45.803 \\
\hline
\end{tabular}

Elaboración propia 
Tabla 7.13

Costo de telefonía e internet

\begin{tabular}{|l|c|c|c|r|}
\hline \multicolumn{1}{|c|}{ Telefonia e internet } & Cantidad & Equipo & $\begin{array}{c}\text { Costo } \\
\text { mensual }\end{array}$ & $\begin{array}{c}\text { Costo Total } \\
\text { (soles/año) }\end{array}$ \\
\hline Gerente General & 1 & Celular & 100 & 1.200 \\
\hline $\begin{array}{l}\text { Sub-Gerente de Administración } \\
\text { y Finanzas }\end{array}$ & 1 & Celular & 100 & 1.200 \\
\hline Jefe de Manufactura & 1 & Celular & 100 & 1.200 \\
\hline Ejecutivos de Ventas & 2 & Celular & 100 & 2.400 \\
\hline Ejecutivo de Marketing & 1 & Celular & 100 & 1.200 \\
\hline Supervisor de Producción & & Celular & 100 & - \\
\hline Supervisor de Almacenes & & Celular & 100 & - \\
\hline Analista de Compras & 1 & Celular & 100 & 1.200 \\
\hline Analista Financiero & 1 & Celular & 100 & 1.200 \\
\hline Analista Contable & 1 & Celular & 100 & 1.200 \\
\hline Analista de Recursos Humanos & & Celular & 100 & - \\
\hline Recepcionista & & Celular & 100 & - \\
\hline TOTAL & & & & 10.800 \\
\hline
\end{tabular}

Elaboración propia

Tabla 7.14

Costos de Anexos - Teléfonos fijos

\begin{tabular}{|c|c|c|c|c|c|c|c|c|}
\hline Areas & Cantidad & Equipo & 2016 & 2017 & 2018 & 2019 & 2020 & 2021 \\
\hline Gerente General & 1 & Telefono fijo & 957,6 & 898 & 898 & 898 & 898 & 898 \\
\hline $\begin{array}{l}\text { Sub-Gerente de } \\
\text { Administración y Finanzas }\end{array}$ & 1 & Telefono fijo & 957,6 & 898 & 898 & 898 & 898 & 898 \\
\hline Jefe de Manufactura & 1 & Telefono fijo & 957,6 & 898 & 898 & 898 & 898 & 898 \\
\hline Ejecutivos de Ventas & 2 & Telefono fijo & 1915,2 & 1.795 & 1.795 & 1.795 & 1.795 & 1.795 \\
\hline Ejecutivo de Marketing & 1 & Telefono fijo & 957,6 & 898 & 898 & 898 & 898 & 898 \\
\hline Supervisor de Producción & 1 & Telefono fijo & 957,6 & 898 & 898 & 898 & 898 & 898 \\
\hline Supervisor de Almacenes & 1 & Telefono fijo & 957,6 & 898 & 898 & 898 & 898 & 898 \\
\hline \begin{tabular}{|l|} 
Analista de Compras \\
\end{tabular} & 1 & Telefono fijo & 957,6 & 898 & 898 & 898 & 898 & 898 \\
\hline Analista Financiero & 1 & Telefono fijo & 957,6 & 898 & 898 & 898 & 898 & 898 \\
\hline Analista Contable & 1 & Telefono fijo & 957,6 & 898 & 898 & 898 & 898 & 898 \\
\hline Analista de Recursos Humanos & 1 & Telefono fijo & 957,6 & 898 & 898 & 898 & 898 & 898 \\
\hline Recepcionista & 1 & Telefono fijo & 957,6 & 898 & 898 & 898 & 898 & 898 \\
\hline Técnico de calidad & 1 & Telefono fijo & 957,6 & 898 & 898 & 898 & 898 & 898 \\
\hline Área de vigilancia & 1 & Telefono fijo & 957,6 & 898 & 898 & 898 & 898 & 898 \\
\hline TOTAL & & & 14364 & 13464 & 13464 & 13464 & 13464 & 13464 \\
\hline
\end{tabular}

Elaboración propia

Tabla 7.15

Costo de combustible para el período del proyecto (soles/año)

\begin{tabular}{|l|c|c|c|c|c|c|}
\hline \multirow{2}{*}{ Combustible } & \multicolumn{5}{|c|}{ Costo del combustible para el periodo del proyecto (soles/año) } \\
\cline { 2 - 7 } & $\mathbf{2 0 1 6}$ & $\mathbf{2 0 1 7}$ & $\mathbf{2 0 1 8}$ & $\mathbf{2 0 1 9}$ & $\mathbf{2 0 2 0}$ & $\mathbf{2 0 2 1}$ \\
\hline Gasolina 98 BA & 76.951 & 76.951 & 76.951 & 76.951 & 76.951 & 76.951 \\
\hline
\end{tabular}

Elaboración propia

Tabla 7.16

Costo de Mantenimiento

\begin{tabular}{|l|r|r|r|r|r|r|}
\hline \multicolumn{1}{|c|}{ Año } & \multicolumn{1}{c|}{$\mathbf{1}$ 2016 } & \multicolumn{1}{c|}{$\mathbf{2 0 1 7}$} & \multicolumn{1}{c|}{$\mathbf{2 0 1 8}$} & \multicolumn{1}{c|}{$\mathbf{2 0 1 9}$} & \multicolumn{1}{c|}{$\mathbf{2 0 2 0}$} & \multicolumn{1}{c|}{$\mathbf{2 0 2 1}$} \\
\hline Costo de Máquinas & 594.238 & 594.238 & 594.238 & 594.238 & 594.238 & 594.238 \\
\hline Mantenimiento (3\%) & $\mathbf{1 7 . 8 2 7}$ & $\mathbf{1 7 . 8 2 7}$ & $\mathbf{1 7 . 8 2 7}$ & $\mathbf{1 7 . 8 2 7}$ & $\mathbf{1 7 . 8 2 7}$ & $\mathbf{1 7 . 8 2 7}$ \\
\hline
\end{tabular}

Elaboración propia 


\subsection{Presupuestos Operativos}

\subsubsection{Presupuesto de ingreso por ventas}

Tabla 7.17

Presupuesto de ingreso por ventas

\begin{tabular}{|l|r|r|r|r|r|r|}
\hline \multicolumn{1}{|c|}{ Año } & \multicolumn{1}{c|}{$\mathbf{2 0 1 6}$} & \multicolumn{1}{c|}{$\mathbf{2 0 1 7}$} & \multicolumn{1}{c|}{$\mathbf{2 0 1 8}$} & \multicolumn{1}{c|}{$\mathbf{2 0 1 9}$} & \multicolumn{1}{c|}{$\mathbf{2 0 2 0}$} & $\mathbf{2 0 2 1}$ \\
\hline Demanda en compotas & 2.851 .082 & 4.044 .317 & 5.736 .591 & 8.136 .482 & 11.539 .700 & 16.365 .465 \\
\hline Precio unitario en soles & 1,57 & 1,57 & 1,57 & 1,57 & 1,57 & 1,57 \\
\hline Ingreso por ventas (S/.) & 4.476 .199 & 6.349 .578 & 9.006 .447 & 12.774 .276 & 18.117 .330 & 25.693 .779 \\
\hline
\end{tabular}

Elaboración propia

\subsubsection{Presupuesto operativo de costos}

Tabla 7.18

Presupuesto de costo de producción

\begin{tabular}{|l|r|r|r|r|r|r|}
\hline \multicolumn{1}{|c|}{ Año } & \multicolumn{1}{c|}{$\mathbf{2 0 1 6}$} & \multicolumn{1}{c|}{$\mathbf{2 0 1 7}$} & \multicolumn{1}{c|}{$\mathbf{2 0 1 8}$} & \multicolumn{1}{c|}{$\mathbf{2 0 1 9}$} & \multicolumn{1}{c|}{$\mathbf{2 0 2 0}$} & \multicolumn{1}{c|}{$\mathbf{2 0 2 1}$} \\
\hline Costo Fijo & $\mathbf{6 9 6 . 9 8 4}$ & $\mathbf{6 9 6 . 9 8 4}$ & $\mathbf{6 9 6 . 9 8 4}$ & $\mathbf{6 9 6 . 9 8 4}$ & $\mathbf{6 9 6 . 9 8 4}$ & $\mathbf{6 9 6 . 9 8 4}$ \\
\hline Mano de obra directa & 606.667 & 606.667 & 606.667 & 606.667 & 606.667 & 606.667 \\
\hline Energía eléctrica & 87.617 & 87.617 & 87.617 & 87.617 & 87.617 & 87.617 \\
\hline Agua (Fijo) & 2.701 & 2.701 & 2.701 & 2.701 & 2.701 & 2.701 \\
\hline Costo Variable & $\mathbf{1 . 9 1 3 . 7 0 1}$ & $\mathbf{2 . 7 1 4 . 6 2 4}$ & $\mathbf{3 . 8 5 0 . 5 1 0}$ & $\mathbf{5 . 4 6 1 . 3 6 3}$ & $\mathbf{7 . 7 4 5 . 6 6 9}$ & $\mathbf{1 0 . 9 8 4 . 8 1 5}$ \\
\hline Materia prima & 1.076 .334 & 1.526 .801 & 2.165 .664 & 3.071 .665 & 4.356 .440 & 6.178 .251 \\
\hline Insumos & 829.233 & 1.176 .284 & 1.668 .479 & 2.366 .483 & 3.356 .304 & 4.759 .871 \\
\hline Agua (Variable) & 8.135 & 11.539 & 16.368 & 23.215 & 32.925 & 46.694 \\
\hline CIF & $\mathbf{1 3 9 . 0 2 0}$ & $\mathbf{1 3 9 . 0 9 8}$ & $\mathbf{1 3 9 . 0 9 8}$ & $\mathbf{1 3 9 . 0 9 8}$ & $\mathbf{1 3 9 . 0 9 8}$ & $\mathbf{1 3 9 . 0 9 8}$ \\
\hline Mantenimiento tercerizado & 17.827 & 17.827 & 17.827 & 17.827 & 17.827 & 17.827 \\
\hline Combustible & 76.951 & 76.951 & 76.951 & 76.951 & 76.951 & 76.951 \\
\hline Seguridad Alimentaria & 44.059 & 44.059 & 44.059 & 44.059 & 44.059 & 44.059 \\
\hline Dispositivos y Señalización & 183 & 261 & 261 & 261 & 261 & 261 \\
\hline Depreciación Fabril & $\mathbf{1 4 2 . 1 5 2}$ & $\mathbf{1 4 2 . 1 5 2}$ & $\mathbf{1 4 2 . 1 5 2}$ & $\mathbf{1 4 2 . 1 5 2}$ & $\mathbf{1 4 2 . 1 5 2}$ & $\mathbf{1 4 2 . 1 5 2}$ \\
\hline \multicolumn{1}{|c|}{ Costo de producción (S/.) } & 2.891 .857 & 3.692 .857 & 4.828 .744 & 6.439 .597 & 8.723 .903 & 11.963 .049 \\
\hline
\end{tabular}

Elaboración propia

\subsubsection{Presupuesto operativo de gastos}

Tabla 7.19

Presupuesto operativo de gastos administrativos

\begin{tabular}{|l|r|r|r|r|r|r|}
\hline \multicolumn{1}{|c|}{ Año } & \multicolumn{1}{c|}{$\mathbf{1}$ 2016 } & \multicolumn{1}{c|}{$\mathbf{2 0 1 7}$} & \multicolumn{1}{c|}{$\mathbf{2 0 1 8}$} & \multicolumn{1}{c|}{$\mathbf{2 0 1 9}$} & \multicolumn{1}{c|}{$\mathbf{2 0 2 0}$} & \multicolumn{1}{c|}{$\mathbf{2 0 2 1}$} \\
\hline Gastos administrativos & $\mathbf{1 . 2 9 9 . 5 1 0}$ & $\mathbf{1 . 3 5 4 . 8 1 1}$ & $\mathbf{1 . 4 4 0 . 8 1 9}$ & $\mathbf{1 . 5 5 3 . 8 5 4}$ & $\mathbf{1 . 7 2 0 . 4 4 8}$ & $\mathbf{1 . 9 4 7 . 7 4 1}$ \\
\hline Mano de obra indirecta & 970.667 & 970.667 & 970.667 & 970.667 & 970.667 & 970.667 \\
\hline Telefonía e internet & 25.164 & 24.264 & 24.264 & 24.264 & 24.264 & 24.264 \\
\hline Distribución & 6.302 & 6.302 & 12.604 & 12.604 & 18.906 & 18.906 \\
\hline Vigilancia & 90.228 & 90.228 & 90.228 & 90.228 & 90.228 & 90.228 \\
\hline Limpieza & 72.863 & 72.863 & 72.863 & 72.863 & 72.863 & 72.863 \\
\hline Publicidad y promoción & 134.286 & 190.487 & 270.193 & 383.228 & 543.520 & 770.813 \\
\hline Depreciación No Fabril & $\mathbf{9 . 3 6 7}$ & $\mathbf{9 . 3 6 7}$ & $\mathbf{9 . 3 6 7}$ & $\mathbf{9 . 3 6 7}$ & $\mathbf{2 . 0 8 4}$ & $\mathbf{2 . 0 8 4}$ \\
\hline Amortización de intangibles & $\mathbf{8 . 1 3 4}$ & $\mathbf{8 . 1 3 4}$ & $\mathbf{8 . 1 3 4}$ & $\mathbf{8 . 1 3 4}$ & $\mathbf{8 . 1 3 4}$ & $\mathbf{8 . 1 3 4}$ \\
\hline Gastos generales (S/.) & 1.317 .010 & 1.372 .312 & 1.458 .320 & 1.571 .355 & 1.730 .666 & 1.957 .959 \\
\hline
\end{tabular}

Elaboración propia 


\subsection{Presupuestos Financieros}

\subsubsection{Presupuesto de Servicio de Deuda}

\section{Costo de capital:}

Con base en el comportamiento de los inversionistas con aversión al riesgo, existe una relación de equilibrio implícita entre el riesgo y el rendimiento esperado para cada valor. Cuanto mayor sea el riesgo sistemático de una acción, mayor será el rendimiento que los inversionistas esperarán de esa acción. Se utilizará el método CAPM para su estimación, aplicando la siguiente fórmula:

Rf: Tasa libre de riesgo. Es un concepto teórico que supone que en la economía existe una alternativa de inversión que no tiene riesgo para el inversionista.

$\mathrm{Rf}=5,9 \%$

Rm: Rendimiento esperado para el portafolio de mercado. Es un promedio ponderado de los rendimientos esperados de los valores o acciones que constituyen ese portafolio, las ponderaciones son iguales a la proporción de los fondos totales invertidos en cada valor.

$\mathrm{Rm}=35 \%$

Beta: Es el coeficiente para la acción. Un índice de riesgo sistemático, que mide la sensibilidad de rendimiento de una acción a los cambios en los rendimientos del portafolio del mercado. La beta de un portafolio es simplemente el promedio ponderado de las betas de las acciones individuales en este.

$\operatorname{Beta}(\beta)=58 \%$

$$
\operatorname{Cok}=\mathrm{Rf}+(\mathrm{Rm}-\mathrm{Rf}) * \beta
$$

Cok $=23 \%$

Servicio de la deuda: Se usará una tasa de interés anual del 21,21\% ofrecida para pequeñas empresas por Asbanc (Asociación de bancos del Perú), un año de gracia parcial, cuotas crecientes y se pagará durante 6 años que es la duración del proyecto. 
Tabla 7.20

Servicio de la deuda

\begin{tabular}{|c|c|r|r|r|l|}
\hline Año & Principal & $\begin{array}{c}\text { Factor de } \\
\text { amortización }\end{array}$ & Amortización & Interés & Cuota \\
\hline 0 & 1.899 .479 & & & & \\
\hline 1 & 1.899 .479 & & - & 402.879 & 402.879 \\
\hline 2 & 1.772 .847 & 0,07 & 126.632 & 402.879 & 529.511 \\
\hline 3 & 1.519 .583 & 0,13 & 253.264 & 376.021 & 629.285 \\
\hline 4 & 1.139 .687 & 0,20 & 379.896 & 322.304 & 702.199 \\
\hline 5 & 633.160 & 0,27 & 506.528 & 241.728 & 748.255 \\
\hline 6 & - & 0,33 & 633.160 & 134.293 & 767.453 \\
\hline
\end{tabular}

Elaboración propia

\subsubsection{Presupuesto de Estado de Resultados:}

Tabla 7.21

Estado de resultados

\begin{tabular}{|l|r|r|r|r|r|r|}
\hline \multicolumn{1}{|c|}{ Año } & \multicolumn{1}{c|}{$\mathbf{1}$ 2016 } & \multicolumn{1}{c|}{$\mathbf{2 0 1 7}$} & \multicolumn{1}{c|}{$\mathbf{2 0 1 8}$} & \multicolumn{1}{c|}{$\mathbf{2 0 1 9}$} & \multicolumn{1}{c|}{$\mathbf{2 0 2 0}$} & \multicolumn{1}{c|}{$\mathbf{2 0 2 1}$} \\
\hline Ventas & 4.476 .199 & 6.349 .578 & 9.006 .447 & 12.774 .276 & 18.117 .330 & 25.693 .779 \\
\hline Costo fijo & 696.984 & 696.984 & 696.984 & 696.984 & 696.984 & 696.984 \\
\hline Costo variable & 1.766 .494 & 2.505 .806 & 3.554 .317 & 5.041 .258 & 7.149 .848 & 10.139 .829 \\
\hline CIF & 139.020 & 139.098 & 139.098 & 139.098 & 139.098 & 139.098 \\
\hline Depreciacion fabril & 142.152 & 142.152 & 142.152 & 142.152 & 142.152 & 142.152 \\
\hline Utilidad bruta & 1.731 .550 & 2.865 .538 & 4.473 .896 & 6.754 .784 & 9.989 .247 & 14.575 .716 \\
\hline Gastos administrativos & 1.299 .510 & 1.354 .811 & 1.440 .819 & 1.553 .854 & 1.720 .448 & 1.947 .741 \\
\hline Depreciacion no fabril & 9.367 & 9.367 & 9.367 & 9.367 & 2.084 & 2.084 \\
\hline Amortizacion de intangibles & 8.134 & 8.134 & 8.134 & 8.134 & 8.134 & 8.134 \\
\hline Utilidad operativa & 414.540 & 1.493 .226 & 3.015 .577 & 5.183 .430 & 8.258 .582 & 12.617 .757 \\
\hline Gastos financieros (Interés) & 402.879 & 402.879 & 376.021 & 322.304 & 241.728 & 134.293 \\
\hline $\begin{array}{l}\text { Utilidad antes de Participaciones } \\
\text { y Impuesto a la Renta }\end{array}$ & 11.660 & 1.090 .347 & 2.639 .556 & 4.861 .126 & 8.016 .854 & 12.483 .464 \\
\hline Participación (10\%) & 1.166 & 109.035 & 263.956 & 486.113 & 801.685 & 1.248 .346 \\
\hline Impuesto a la renta (28\%) & 3.265 & 305.297 & 739.076 & 1.361 .115 & 2.244 .719 & 3.495 .370 \\
\hline Utilidad neta & $\mathbf{7 . 2 2 9}$ & $\mathbf{6 7 6 . 0 1 5}$ & $\mathbf{1 . 6 3 6 . 5 2 5}$ & $\mathbf{3 . 0 1 3 . 8 9 8}$ & $\mathbf{4 . 9 7 0 . 4 5 0}$ & $\mathbf{7 . 7 3 9 . 7 4 8}$ \\
\hline Reserva legal (10\%) & 723 & 67.601 & 163.652 & 301.390 & 36.477 & \\
\hline Utilidad disponible & $\mathbf{6 . 5 0 6}$ & $\mathbf{6 0 8 . 4 1 3}$ & $\mathbf{1 . 4 7 2 . 8 7 2}$ & $\mathbf{2 . 7 1 2 . 5 0 8}$ & $\mathbf{4 . 9 3 3 . 9 7 3}$ & $\mathbf{7 . 7 3 9 . 7 4 8}$ \\
\hline
\end{tabular}

Elaboración propia

Se establece que un $10 \%$ del beneficio del ejercicio debe destinarse a la reserva legal, que debe ser un $20 \%$ del capital propio.

\subsubsection{Presupuesto de Estado de Situación Financiera}

El estado de situación financiera resume los bienes, pasivos y el capital de los dueños de un negocio en un momento, generalmente al final del año o trimestre. Muestra los activos totales, pasivos totales y el patrimonio o capital de los accionistas. 
Tabla 7.22

Estado de Situación Financiera Año 1

\begin{tabular}{|l|r|l|l|r|}
\hline \multicolumn{5}{|c|}{ Estado de Situación Financiera Año 2016 } \\
\hline \multicolumn{1}{|c|}{ ACTIVO: } & Valor (S/.) & & \multicolumn{1}{c|}{ PASIVO Y PATRIMONIO: } & Valor (S/.) \\
\hline & & & & \\
\hline ACTIVO CORRIENTE & $\mathbf{1 . 5 1 6 . 7 4 2}$ & & PASIVO CORRIENTE & $\mathbf{1 . 8 9 9 . 4 7 9}$ \\
\hline Caja & 1.369 .534 & & Deuda a corto plazo & 1.899 .479 \\
\hline Materia Prima & - & & & \\
\hline Insumos & - & & & \\
\hline Inventario de Producto Terminado & 147.208 & & PASIVO NO CORRIENTE & - \\
\hline & & & Deuda a largo plazo & \\
\hline ACTIVO NO CORRIENTE & $\mathbf{3 . 2 3 9 . 1 8 5}$ & & & $\mathbf{2 . 8 5 6 . 4 4 8}$ \\
\hline Terreno & 1.123 .658 & & & 2.849 .219 \\
\hline Edificación, máquinas y equipos & 2.193 .843 & & PATRIMONIO & - \\
\hline Depreciación Acumulada & -151.519 & & Capital social & 6.506 \\
\hline Activos fijos intangibles & 81.336 & & Resultados acumulados & 723 \\
\hline Amortización Acumulada & -8.134 & & Resultado de ejercicio al 31/12/2016 & \\
\hline & & & Reserva Legal & $\mathbf{4 . 7 5 5 . 9 2 7}$ \\
\hline
\end{tabular}

Elaboración propia

\subsubsection{Flujo de caja a corto plazo}

Es el flujo de entradas y salidas de efectivo en un periodo dado. Determinado el saldo disponible para el próximo periodo de análisis.

\section{Tabla 7.23}

Cálculo de Flujo de caja

\begin{tabular}{|c|c|c|}
\hline Año & 0 & 1 \\
\hline Ingresos (S/.) & 1.349 .861 & 4.476.199 \\
\hline Capital de Trabajo & 1.349 .861 & \\
\hline Ingreso por ventas & - & 4.476 .199 \\
\hline Egresos (S/.) & 0 & 4.456 .525 \\
\hline Mano de obra directa & & 606.667 \\
\hline Energía eléctrica & & 87.617 \\
\hline Materia prima & & 1.076 .334 \\
\hline Insumos & & 829.233 \\
\hline Agua & & 10.835 \\
\hline Mantenimiento tercerizado & & 17.827 \\
\hline Combustible & & 76.951 \\
\hline Implementos de seguridad & & 44.059 \\
\hline Dispositivos y Señalización & $\mathrm{x}$ & 183 \\
\hline Mano de obra indirecta & 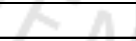 & 970.667 \\
\hline Telefonía e internet & +2 & 25.164 \\
\hline Distribución & +2 & 6.302 \\
\hline Vigilancia & & 90.228 \\
\hline Limpieza & & 72.863 \\
\hline Publicidad y promoción & & 134.286 \\
\hline Gastos financieros (Interés) & & 402.879 \\
\hline Participación (10\%) & & 1.166 \\
\hline Impuesto a la renta (28\%) & & 3.265 \\
\hline \multicolumn{3}{|l|}{ Balance de Caja } \\
\hline Saldo inicial de caja & - & 1.349 .861 \\
\hline Flujo neto anual & 1.349 .861 & 19.674 \\
\hline Financiamiento & - & - \\
\hline Saldo final de caja & 1.349 .861 & 1.369 .534 \\
\hline
\end{tabular}

Elaboración propia 


\subsection{Flujo de fondos netos}

\subsubsection{Flujo de fondos económicos}

Se utiliza para determinar la rentabilidad del proyecto sin considerar su financiamiento.

Tabla 7.24

Flujo de fondos económicos

\begin{tabular}{|l|r|r|r|r|r|r|r|}
\hline \multicolumn{1}{|c|}{ RUBRO } & \multicolumn{1}{c|}{$\mathbf{0}$} & \multicolumn{1}{c|}{$\mathbf{1}$} & \multicolumn{1}{c|}{$\mathbf{2}$} & \multicolumn{1}{c|}{$\mathbf{3}$} & $\mathbf{4}$ & $\mathbf{5}$ & $\mathbf{6}$ \\
\hline Inversion total & -4.748 .698 & & & & & & \\
\hline Utilidad antes de reserva legal & & 7.229 & 676.015 & 1.636 .525 & 3.013 .898 & 4.970 .450 & 7.739 .748 \\
\hline (+) Depreciacion fabril & & 142.152 & 142.152 & 142.152 & 142.152 & 142.152 & 142.152 \\
\hline (+) Depreciacion no fabril & & 9.367 & 9.367 & 9.367 & 9.367 & 2.084 & 2.084 \\
\hline (+) Amortizacion intangibles & & 8.134 & 8.134 & 8.134 & 8.134 & 8.134 & 8.134 \\
\hline (+) Gastos financieros x(1-t) & & 290.073 & 290.073 & 270.735 & 232.059 & 174.044 & 96.691 \\
\hline (+) Valor en libros & & & & & & & 3.805 .349 \\
\hline Fujo neto de fondos economicos & -4.748 .698 & 456.955 & 1.125 .741 & 2.066 .912 & 3.405 .609 & 5.296 .863 & 11.794 .157 \\
\hline
\end{tabular}

Elaboración propia

\subsubsection{Flujo de fondos financieros}

Se utiliza para determinar la rentabilidad del proyecto considerando gastos financieros e impuestos.

Tabla 7.25

Flujo de fondos financieros

\begin{tabular}{|l|r|r|r|r|r|r|r|}
\hline \multicolumn{1}{|c|}{ RUBRO } & \multicolumn{1}{c|}{$\mathbf{0}$} & \multicolumn{1}{c|}{$\mathbf{1}$} & \multicolumn{1}{c|}{$\mathbf{2}$} & \multicolumn{1}{c|}{$\mathbf{3}$} & \multicolumn{1}{c|}{$\mathbf{4}$} & \multicolumn{1}{c|}{$\mathbf{5}$} & \multicolumn{1}{c|}{$\mathbf{6}$} \\
\hline Inversion total & -4.748 .698 & & & & & & \\
\hline Deuda & 1.899 .479 & & & & & & \\
\hline Utilidad antes de reserva legal & & 7.229 & 676.015 & 1.636 .525 & 3.013 .898 & 4.970 .450 & 7.739 .748 \\
\hline$(+)$ Depreciacion fabril & & 142.152 & 142.152 & 142.152 & 142.152 & 142.152 & 142.152 \\
\hline$(+)$ Depreciacion no fabril & & 9.367 & 9.367 & 9.367 & 9.367 & 2.084 & 2.084 \\
\hline$(+)$ Amortizacion intangibles & & 8.134 & 8.134 & 8.134 & 8.134 & 8.134 & 8.134 \\
\hline$(-)$ Amortizacion/Principal & & - & -126.632 & -253.264 & -379.896 & -506.528 & -633.160 \\
\hline$(+)$ Valor en libros & & & & & & & 3.805 .349 \\
\hline Fujo neto de fondos financieros & -2.849 .219 & 166.882 & 709.035 & 1.542 .913 & 2.793 .655 & 4.616 .291 & 11.064 .306 \\
\hline
\end{tabular}

Elaboración propia 


\section{CAPÍTULO VIII: EVALUACIÓN ECONÓMICA Y FINANCIERA DEL PROYECTO}

\subsection{Evaluación económica: VAN, TIR, B/C, PR.}

Tabla 8.1

Evaluación económica

\begin{tabular}{|l|r|l|}
\hline VAN Economico & 4.252 .919 & \\
\hline TIR Economico & $42 \%$ & \\
\hline Relacion B/C & 1,90 & \\
\hline Periodo de Recuperación (Años) & 4,55 & 4 años 6 meses \\
\hline Tasa Costo de Capital & $23 \%$ & \\
\hline
\end{tabular}

Elaboración propia

Tabla 8.2

Cálculo del VAN económico por años y determinación del periodo de recupero

\begin{tabular}{|l|r|r|r|r|r|r|}
\hline Actual & 371.508 & 744.094 & 1.110 .725 & 1.487 .902 & 1.881 .452 & 3.405 .934 \\
\hline Acumulado & 371.508 & 1.115 .603 & 2.226 .328 & 3.714 .230 & 5.595 .682 & 9.001 .616 \\
\hline Presente & -4.377 .189 & -3.633 .095 & -2.522 .370 & -1.034 .468 & 846.985 & 4.252 .919 \\
\hline
\end{tabular}

Elaboración propia

\subsection{Evaluación financiera: VAN, TIR, B/C, PR.}

Tabla 8.3

Evaluación financiera

\begin{tabular}{|l|r|r|}
\hline VAN Financiero & 4.639 .674 & \\
\hline TIR Financiero & $52 \%$ & \\
\hline Relacion B/C & 2,63 & \\
\hline Periodo de Recuperación (Años) & 4,12 & 4 años 1 mes \\
\hline Tasa Costo de Capital & $23 \%$ & \\
\hline
\end{tabular}

Elaboración propia

Tabla 8.4

Cálculo del VAN financiero por años y determinación del periodo de recupero

\begin{tabular}{|l|r|r|r|r|r|r|}
\hline Actual & 135.676 & 468.660 & 829.137 & 1.220 .541 & 1.639 .712 & 3.195 .167 \\
\hline Acumulado & 135.676 & 604.336 & 1.433 .473 & 2.654 .013 & 4.293 .726 & 7.488 .892 \\
\hline Presente & -2.713 .542 & -2.244 .883 & -1.415 .746 & -195.205 & 1.444 .507 & 4.639 .674 \\
\hline
\end{tabular}

Elaboración propia 


\subsection{Análisis de ratios (liquidez, solvencia, rentabilidad) e indicadores económicos y financieros del proyecto}

Análisis de ratios:

\section{- Razón de liquidez}

Este indicador mide la capacidad de pago en el corto plazo. Cuantos nuevos soles de activos se tienen para hacer frente a las deudas, por cada nuevo sol de pasivo que se tiene. Entre mayor sea el resultado, existe mayor posibilidad de que los pasivos de corto plazo sean pagados ya que hay activos suficientes para convertirse en efectivo cuando se requieran. Para calcularlo se utilizará la siguiente formula.

$$
\text { Razón de liquidez }=\frac{\text { Activo Corriente }}{\text { Pasivo Corriente }}=\frac{1.503 .322}{1.887 .575}=0,80
$$

Es decir, por cada sol de deuda hay 0,80 soles en activos corrientes que pueden transformarse en dinero rápidamente. Por lo que se podría atender casi toda la deuda a corto plazo, si fuese necesario.

\section{- Razón de solvencia}

Este indicador muestra la proporción en que los recursos existentes en la empresa son financiados por personas ajenas a la entidad. Indica el grado de propiedad que terceros tienen sobre la empresa. Mientras más bajo sea, podría facilitarse las gestiones para obtener un crédito, ya que la empresa tendría mayor autonomía financiera. Sin embargo hay que tener una cierta proporción de deudas para evitar un exceso de capitales propios. Para calcularlo se utilizará la siguiente formula.

$$
\text { Razón de solvencia }=\frac{\text { Pasivo Total }}{\text { Activo Total }}=\frac{1.887 .575}{4.742 .506}=0,40
$$

Es decir, que el $40 \%$ de la empresa pertenece a terceros. Por lo que se cuenta con autonomía financiera suficiente para hacer otro préstamo, si fuese requerido.

\section{- Razón de rentabilidad neta}

Determina el margen obtenido luego de deducir de las ventas o ingresos, todos los costos y gastos así como pago de deudas, impuestos y participaciones. Por lo que mientras más alto sea es mejor. Para calcularlo se utilizará la siguiente formula.

$$
\text { Razón de rentabilidad neta }=\frac{\text { Utilidad Neta despues de Imp.y Partic. }}{\text { Ventas netas }}=\frac{23.569}{4.419 .178}=0,01
$$


Es decir, por cada sol de ventas se obtiene 0,01 soles de utilidad neta.

\section{Análisis de indicadores económicos y financieros:}

Tanto el VAN económico que es 4.252.919 soles y el VAN financiero que es 4.639.674 soles son mayores a 0 , por lo tanto la inversión del proyecto es aceptable pues genera más ganancias después de recuperar lo invertido. Esta afirmación se ve fortalecida debido a que la TIR económica la cual es $42 \%$ y la TIR financiera la cual es $52 \%$ son mayores que el costo de capital (Cok) el cual es $23 \%$. Además la evaluación económica muestra que el periodo de recupero sería de 4 años y 6 meses mientras la evaluación financiera muestra que sería en 4 años y 1 mes, siendo esta última la más importante para los inversionistas, pues se concentra más en los ingresos y egresos que tendría el proyecto. Luego la relación beneficio/costo financiera es 2,63 es decir por cada sol invertido se genera 2,63 soles de ingreso. En conclusión el proyecto es viable debido a que genera más dinero de lo invertido en él y presenta unos flujos tentadores para la inversión.

\subsection{Análisis de sensibilidad del proyecto}

El análisis de sensibilidad financiera se realizará en función al precio venta y se considera 2 situaciones: La situación actual (Optimista) donde el VAN financiero es de 4.639.673,91 soles y su precio de venta es de 1,57 soles/unidad y la situación pesimista donde el VAN financiero es de 0 soles y su precio de venta es de 1,21 soles/unidad.

Figura 8.1

Análisis de sensibilidad financiera

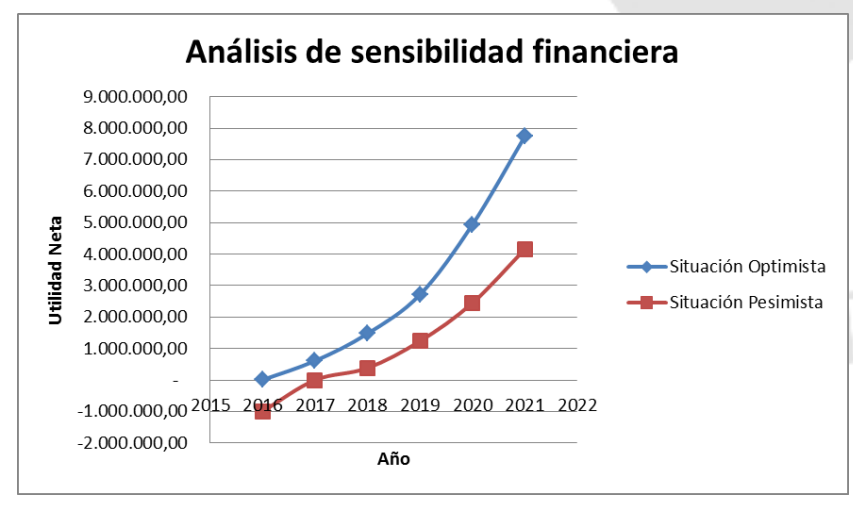

Elaboración propia

De la gráfica se deduce que por debajo del precio de venta de 1,21 soles/unidad el proyecto deja de ser viable pues no logra el rendimiento exigido por los accionistas. 


\section{CAPÍTULO IX: EVALUACIÓN SOCIAL DEL PROYECTO}

\subsection{Identificación de las zonas y comunidades de influencia del proyecto}

De acuerdo al análisis de macro localización y micro localización la planta estará ubicada en Lima, específicamente en el distrito de Ventanilla al costado de la planta térmica de ciclo combinado de Ventanilla. Este terreno cuenta con la zonificación I2 la cual es zona industrial liviana y es para los establecimientos industriales que cumplen las siguientes características:

- Orientación al área de mercado local y a la infraestructura vial urbana

- Posee contacto con el área central

- Venta al por mayor

- Dimensión económica media

- No son molestos, ni peligrosos

Adicionalmente la planta estará a $2.6 \mathrm{~km}$ (6 minutos) de la carretera Nestor Gambetta lo cual facilitará la llegada de materia prima, insumos, materiales y la distribución de las compotas. Ver fotos del terreno (Ver Anexo 5).

Figura 9.1

Ubicación de la Planta

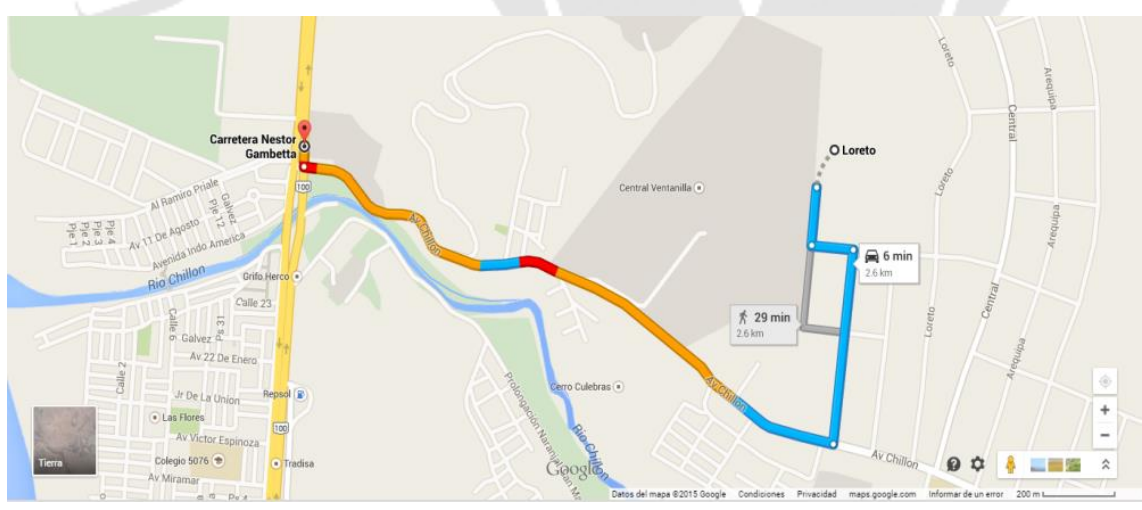

Fuente: Google Maps, (2016)

Se procederá a analizar el impacto que genera la empresa en la comunidad donde está ubicada:

\section{a. Aumento de la congestión vehicular}


La población de Ventanilla específicamente la que está ubicada en la avenida Chillón puede verse afectada por un aumento de camiones los cuales traen suministros y a su vez se encargan de la distribución de las compotas, esto se puede mitigar mediante un adecuado plan de compras con fechas y horarios establecidos y un correcto plan de distribución para evitar la congestión vehicular e incomodidad de la comunidad.

Figura 9.2

Población avenida Chillón

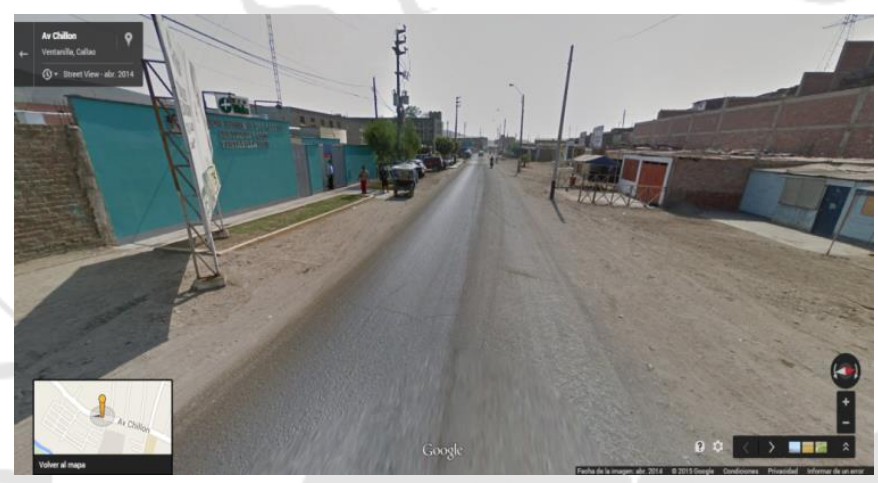

Fuente: Google Maps, (2016)

\section{b. Disminución de la tasa de desempleo}

Debido a que se generan nuevos puestos de trabajo por la operación de la planta esto beneficiará a la comunidad de ventanilla y tendrá un impacto positivo en los proveedores pues con el aumento de su demanda estos necesitarán mayor cantidad de personal para cumplir con los requerimientos y a su vez se genera un beneficio a otras comunidades.

\section{c. Revalorización de los terrenos}

El terreno donde está ubicada la planta presenta un incremento de su valor por la construcción que se realiza y a su vez los terrenos adyacentes se revalorizan por la urbanización de la zona.

\section{d. Aumento de la contaminación por generación de residuos sólidos}

La población de Ventanilla específicamente la que se ubica en Loreto puede verse afectada por el incremento de generación de residuos sólidos debido a los envases de desinfectante, cajas de durazno, sacos de harinas, cajas de envases y tapas, bolsas que contenían bobinas de etiquetas y bobinas de cinta de embalaje, rafia que 
se utiliza para amarrar las planchas de cajas de cartón desarmadas, cajas de guantes de protección, cajas de mascarillas, cajas de cubiertas de zapato, cajas de trajes de cuerpo y los equipos de seguridad alimentaria desechables como guantes de protección, mascarillas, cubiertas de zapato y trajes de cuerpo. Esto se puede mitigar mediante un plan de disposición de residuos sólidos.

\section{e. Aumento de la contaminación por la emisión de gases contaminantes}

La población de Ventanilla específicamente la que se ubica en la avenida Chillón puede verse afectada por el incremento de gases contaminantes como $\mathrm{CO}, \mathrm{CO} 2 \mathrm{y}$ SOX producto de la combustión que se realiza en los motores de los camiones. Esto se puede disminuir mediante un plan de mantenimiento que debe realizar la empresa distribuidora y los proveedores a su flota de camiones.

\section{f. Aumento de la contaminación por generación de efluentes}

La población de Ventanilla puede verse afectada por el aumento de efluentes en su sistema de alcantarillado los cuales son resultado del proceso de producción y están conformados por agua, tierra, tego, residuos de durazno e hidróxido de sodio en baja concentración. Estos efluentes son tratados en la planta de tratamiento de aguas residuales de Ventanilla.

\section{Impacto en la zona de influencia del proyecto}

Se procederá a cuantificar el impacto que genera la empresa en la comunidad donde está ubicada:

\section{a) Disminución de la tasa de desempleo}

Tabla 9.1

Disminución de la tasa de desempleo en Lima y Ventanilla

\begin{tabular}{|l|l|}
\hline Disminución de la tasa de desempleo en Lima & $0,0228 \%$ \\
\hline
\end{tabular}

\begin{tabular}{|l|c|}
\hline \multicolumn{2}{|c|}{ Datos } \\
\hline Nuevos Empleos & 55 \\
\hline PEA Total & 5.106 .983 \\
\hline PEA Ocupada & 4.866 .262 \\
\hline PEA Desocupada & 240.721 \\
\hline
\end{tabular}

\begin{tabular}{|l|l|}
\hline Disminución de la tasa de desempleo en Ventanilla & $1,1174 \%$ \\
\hline
\end{tabular}

\begin{tabular}{|l|c|}
\hline \multicolumn{2}{|c|}{ Datos } \\
\hline Nuevos Empleos & 55 \\
\hline PEA Total & 112.390 \\
\hline PEA Ocupada & 107.468 \\
\hline PEA Desocupada & 4.922 \\
\hline
\end{tabular}

Elaboración propia 


\section{b) Revalorización del terreno de la planta}

Tabla 9.2

Revalorización del terreno de la planta

\begin{tabular}{|l|r|}
\hline Valor Inicial (Costo del terreno) en dólares & $332.640,00$ \\
\hline $\begin{array}{l}\text { Valor Final ( Costo del terreno + Costo de } \\
\text { construcción ) en dólares }\end{array}$ & $760.320,00$ \\
\hline
\end{tabular}

\begin{tabular}{|l|r|}
\hline Incremento de su valor en dólares & $427.680,00$ \\
\hline Incremento de su valor en soles & $1.444 .703,04$ \\
\hline
\end{tabular}

\begin{tabular}{|l|r|}
\hline \multicolumn{2}{|c|}{ Datos } \\
\hline Metros cuadrados & $2.376,00$ \\
\hline $\begin{array}{l}\text { Costo del terreno (dólares/metro } \\
\text { cuadrado) }\end{array}$ & 140,00 \\
\hline $\begin{array}{l}\text { Costo de construcción (dólares/metro } \\
\text { cuadrado) }\end{array}$ & 180,00 \\
\hline Tipo de cambio (Soles/dólar) & 3,378 \\
\hline
\end{tabular}

Elaboración propia

\section{c) Generación de residuos sólidos para el periodo del proyecto}

Tabla 9.3

Generación de residuos sólidos para el periodo del proyecto

\begin{tabular}{|c|c|c|c|c|c|c|c|c|}
\hline \multirow{2}{*}{ Materia Prima } & \multirow{2}{*}{ Residuo } & \multirow{2}{*}{ Unidad } & \multicolumn{6}{|c|}{ Generación de residuos sólidos para el periodo del proyecto } \\
\hline & & & 2016 & 2017 & 2018 & 2019 & 2020 & 2021 \\
\hline Durazno & Cajas de durazno & Cajas/año & 22.062 & 31.295 & 44.391 & 62.961 & 89.296 & 126.638 \\
\hline Harina de maca & Saco de Harina & Sacos/año & 124 & 175 & 249 & 353 & 500 & 709 \\
\hline Harina de quinua & Saco de Harina & Sacos/año & 124 & 175 & 249 & 353 & 500 & 709 \\
\hline Harina de kiwicha & Saco de Harina & Sacos/año & 124 & 175 & 249 & 353 & 500 & 709 \\
\hline Harina de cañihua & Saco de Harina & Sacos/año & 124 & 175 & 249 & 353 & 500 & 709 \\
\hline
\end{tabular}

\begin{tabular}{|c|c|c|c|c|c|c|c|c|}
\hline \multirow{2}{*}{ Insumo } & \multirow{2}{*}{ Residuo } & \multirow{2}{*}{ Unidad } & \multicolumn{6}{|c|}{ Generación de residuos sólidos para el periodo del proyecto } \\
\hline & & & 2016 & 2017 & 2018 & 2019 & 2020 & 2021 \\
\hline Envases & Cajas & Cajas/año & 15.443 & 21.907 & 31.073 & 44.073 & 62.507 & 88.646 \\
\hline Tapas & Cajas & Cajas/año & 1.235 & 1.753 & 2.486 & 3.526 & 5.001 & 7.092 \\
\hline Etiquetas & Bolsas de plástico & Bolsas/año & 44 & 63 & 89 & 126 & 179 & 253 \\
\hline Etiquetas & Cilindro de cartón & Cilindros de cartón/año & 44 & 63 & 89 & 126 & 179 & 253 \\
\hline Plancha de caja desarmada & Rafia & Metros de rafia /año & 640 & 908 & 1.287 & 1.826 & 2.590 & 3.673 \\
\hline Cintas de embalaje & Bolsas de plástico & Bolsas/año & 8 & 11 & 16 & 22 & 32 & 45 \\
\hline Cintas de embalaje & Cilindro de cartón & Cilindro de cartón/año & 8 & 11 & 16 & 22 & 32 & 45 \\
\hline Tego al $0,1 \%$ & Envase de plástico & Envases/año & 30 & 43 & 61 & 86 & 122 & 173 \\
\hline
\end{tabular}

\begin{tabular}{|c|c|c|c|c|c|c|c|c|}
\hline \multirow{2}{*}{ Equipos de seguridad alimentaria } & \multirow{2}{*}{ Residuo } & \multirow{2}{*}{ Unidad } & \multicolumn{6}{|c|}{ Generación de residuos sólidos para el periodo del proyecto } \\
\hline & & & 2016 & 2017 & 2018 & 2019 & 2020 & 2021 \\
\hline Guantes de Protección(Par) & Cajas & Cajas/año & 125 & 125 & 125 & 125 & 125 & 125 \\
\hline Guantes de Protección(Par) & Par de guantes & Par de guantes/año & 12.480 & 12.480 & 12.480 & 12.480 & 12.480 & 12.480 \\
\hline Mascarillas & Cajas & Cajas/año & 125 & 125 & 125 & 125 & 125 & 125 \\
\hline Mascarillas & Mascarilla & Mascarillas/año & 12.480 & 12.480 & 12.480 & 12.480 & 12.480 & 12.480 \\
\hline Trajes de cuerpo & Cajas & Cajas/año & 250 & 250 & 250 & 250 & 250 & 250 \\
\hline Trajes de cuerpo & Traje & Trajes/año & 12.480 & 12.480 & 12.480 & 12.480 & 12.480 & 12.480 \\
\hline Cubiertas de zapatos & Cajas & Cajas/año & 125 & 125 & 125 & 125 & 125 & 125 \\
\hline Cubiertas de zapatos & Par de cubiertas zapatos & $\begin{array}{c}\text { Cubiertas de } \\
\text { zapato/año }\end{array}$ & 12.480 & 12.480 & 12.480 & 12.480 & 12.480 & 12.480 \\
\hline
\end{tabular}

\begin{tabular}{|c|c|c|c|c|c|c|c|}
\hline \multirow{2}{*}{ Residuo } & \multirow{2}{*}{ Unidad } & \multicolumn{5}{|c|}{ Generación de residuos sólidos para el periodo del proyecto } \\
\cline { 3 - 8 } & & $\mathbf{2 0 1 6}$ & $\mathbf{2 0 1 7}$ & $\mathbf{2 0 1 8}$ & $\mathbf{2 0 1 9}$ & $\mathbf{2 0 2 0}$ & $\mathbf{2 0 2 1}$ \\
\hline Merma & $\mathrm{Kg} / \mathrm{año}$ & 78.271 & 111.029 & 157.487 & 223.371 & 316.800 & 449.282 \\
\hline
\end{tabular}

Elaboración propia 


\subsection{Análisis de indicadores sociales}

Se procederá a medir el impacto social del proyecto mediante indicadores macroeconómicos:

a) Valor agregado:

Tabla 9.4

Cálculo del valor agregado

\begin{tabular}{|l|r|r|r|r|r|r|}
\hline \multicolumn{1}{|c|}{ Tasa social de descuento } & \multicolumn{1}{|c|}{$10 \%$} \\
\hline \multirow{2}{*}{ Items } & \multicolumn{1}{|c|}{ Año } \\
\cline { 2 - 7 } & \multicolumn{1}{|c|}{$\mathbf{2 0 1 6}$} & \multicolumn{1}{c|}{$\mathbf{2 0 1 7}$} & \multicolumn{1}{c|}{$\mathbf{2 0 1 8}$} & \multicolumn{1}{c|}{$\mathbf{2 0 1 9}$} & \multicolumn{1}{c|}{$\mathbf{2 0 2 0}$} & $\mathbf{2 0 2 1}$ \\
\hline Sueldos y salarios & 1.577 .333 & 1.577 .333 & 1.577 .333 & 1.577 .333 & 1.577 .333 & 1.577 .333 \\
\hline Depreciación activos tangibles & 151.519 & 151.519 & 151.519 & 151.519 & 144.236 & 144.236 \\
\hline Amortización activos intangibles & 8.134 & 8.134 & 8.134 & 8.134 & 8.134 & 8.134 \\
\hline Gastos financieros (Intereses) & 402.879 & 402.879 & 376.021 & 322.304 & 241.728 & 134.293 \\
\hline Utilidad Antes de impuestos & 11.660 & 1.090 .347 & 2.639 .556 & 4.861 .126 & 8.016 .854 & 12.483 .464 \\
\hline Valor Agregado & 2.151 .525 & 3.230 .212 & 4.752 .562 & 6.920 .415 & 9.988 .285 & 14.347 .460 \\
\hline Valor Agregado actualizado & 1.955 .932 & 2.669 .597 & 3.570 .670 & 4.726 .737 & 6.201 .939 & 8.098 .767 \\
\hline Valor Agregado acumulado & 1.955 .932 & 4.625 .529 & 8.196 .199 & 12.922 .936 & 19.124 .875 & 27.223 .642 \\
\hline
\end{tabular}

\section{\begin{tabular}{|l|l|}
\hline Valor Agregado (S/.) & 27.223 .642 \\
\hline
\end{tabular}}

Elaboración propia

El aporte que se realiza a los insumos y materia prima para su transformación es de

27.223.642 soles.

\section{b) Densidad de capital:}

Tabla 9.5

Cálculo de la densidad de capital

\begin{tabular}{|l|r|l|}
\hline \multicolumn{2}{|c|}{ Densidad de capital } \\
\hline Inversión total & 4.748 .698 & soles \\
\hline Número de empleos & 55 & personas \\
\hline Densidad de capital & $\mathbf{8 6 . 3 4 0}$ & soles/persona \\
\hline
\end{tabular}

Elaboración propia

El monto de la inversión por empleo generado es de 86.340 soles/persona.

\section{c) Intensidad de capital:}


Tabla 9.6

Cálculo de intensidad de capital

\begin{tabular}{|l|r|l|}
\hline \multicolumn{3}{|c|}{ Intensidad de capital } \\
\hline Inversión total & 4.748 .698 & soles \\
\hline Valor Agregado & 27.223 .642 & soles \\
\hline Intensidad de capital & $\mathbf{0 , 1 7}$ & \\
\hline
\end{tabular}

Elaboración propia

Se necesita 0,17 soles de inversión para generar 1 sol de valor agregado.

d) Productividad de la mano de obra:

Tabla 9.7

Cálculo de productividad de la mano de obra

\begin{tabular}{|l|r|l|}
\hline \multicolumn{3}{|c|}{ Productividad de mano de obra } \\
\hline Cantidad promedio producida & 8.788 .296 & envases de compota \\
\hline Precio de la compota & 1,57 & soles/envase de compota \\
\hline Valor promedio de la producción anual & 13.797 .624 & soles \\
\hline Número de puestos generados & 55 & personas \\
\hline Productividad de mano de obra & $250.865,89$ & soles/persona \\
\hline
\end{tabular}

Elaboración propia

Se produce $250.865,89$ soles por persona.

e) Relación producto - capital

Tabla 9.8

Cálculo de relación producto - capital

\begin{tabular}{|l|r|l|}
\hline \multicolumn{3}{|c|}{ Relación producto - capital } \\
\hline Valor Agregado & 27.223 .642 & soles \\
\hline Inversión total & 4.748 .698 & soles \\
\hline Relación producto - capital & $\mathbf{5 , 7 3}$ & \\
\hline
\end{tabular}

Elaboración propia

Se genera 5,73 soles de valor agregado por 1 sol de inversión. 


\section{CONCLUSIONES}

- El proyecto es viable técnicamente debido a que es posible producir la compota y la fórmula a utilizar tiene la aprobación de un nutricionista, es viable económicamente pues produce un ingreso atractivo para los accionistas y es viable socialmente pues permite dinamizar la economía de los agricultores y crea puestos de trabajo.

- La compota a ofrecer tiene aceptación por los padres de nivel socioeconómico A, B y $\mathrm{C}$ de un estilo de vida catalogado como los sofisticados y las modernas pues es un producto natural libre de preservantes donde se utiliza cereales andinos los cuales son ricos en proteínas, vitaminas y minerales siendo estos su principal atractivo.

- El proyecto muestra un gran potencial debido a que no hay producción nacional, ya que todo es atendido mediante importaciones, y el precio a ofrecer está por debajo del de la competencia con una calidad superior lo cual permite obtener una tasa de retorno atractiva. 


\section{RECOMENDACIONES}

- Es necesario mantener un alto estándar de calidad durante el proceso de producción pues sirve como una característica de diferenciación con respecto a la competencia.

- Se puede adecuar la línea de producción para diferentes combinaciones de sabores pero estas deben ser validadas mediante un nutricionista pues hay que tener un cuidado especial con respecto a la alimentación de los bebés. 


\section{REFERENCIAS}

Acodex. (2016). Extractor manual de gasolina. Recuperado de http://www.acodexpump.com/productline-1.php?id=3\&kid=1\&cid $=0$

Alibaba. (2016). Barril de acero inoxidable para combustible. Recuperado de http://spanish.alibaba.com/product-gs/new-big-oil-barrel-15011679810820.html?s=p

Alpina (2016). Línea de compotas Alpina Baby. Recuperado de http://www.alpina.com.co/productos/compotas-alpina-baby/

Asociación peruana de empresas de investigación de mercados(Apeim). (2015). Niveles socioeconómicos 2015. Recuperado de http://www.apeim.com.pe/wpcontent/themes/apeim/docs/nse/APEIM-NSE-2015

Bornemann. (2016). Bomba. Recuperado de http://www.bornemann.com/productos/ soluciones-de-bombeo-probadas-en-muchos-mbitos-para-casi-todo-tipo-de-fluidos/ bomba-de-doble-husillo-tipo-slh

Cabinplant. (2016). Mezcladora de paletas. Recuperado de http://cabinplant.es/productos_y_soluciones/seleccione_procesomaquina/mezcla_y_ recubrimiento/mezclador_de_paletas/

Calorcol. (2016). Puerta cortafuegos. Recuperado de http://www.calorcol.com/

Camprodon. (2016). Faja transportadora. Recuperado de http://www.camprodon.biz/

CITALSA. (2016). Máquina pulpeadora. Recuperado de http://www.citalsa.com/ciproducts/5/353\#firstproduct

Daga Avalos, W. (2016). Producción integrada del cultivo de durazno. Recuperado de http://www.inia.gob.pe/capacitacion-a-distancia/cap-cursos-virtuales/79capacitacion/cursos/428-produccion-integrada-del-cultivo-de-durazno

Dosimur. (2016). Máquina encajonadora. Recuperado de http://www.dosimur.com/?menu=productos\&opcion=encajadoras\&seccion=formad ora-de-cajas 
Euromonitor. (2015). Consumo de compotas para bebés en Perú. Recuperado de http://www.euromonitor.com/baby-food

Fastline. (2016). Máquina etiquetadora. Recuperado de http://www.fastline.com.mx/ productos/etiquetadoras/1.html\#

Instituto nacional de agricultura y riego. (2016). Cultivo de quinua en costa rendirá más de 4 mil kilos por hectárea. Recuperado de http:/www.inia.gob.pe/sala-deprensa/notas-de-prensa/618-inia-cultivo-de-quinua-en-costa-rendira-mas-de-4-milkilos-por-hectárea

Instituto nacional de estadística e informática. (2015). Series nacionales. Recuperado de https://www.inei.gob.pe/sistemas-consulta/

JERSA. (2016). Escaldadora tipo inmersión. Recuperado de http://www.jersa.com.mx/index.php/equipos/procesos-termicos/itemlist/category/ 106-escaldadoras

JERSA. (2016). Tanque de acero inoxidable. Recuperado de http://www.jersa.com.mx/index.php/equipos/manejo-de-materiales/itemlist/ category/25-tanques

Manitowocfoodservice. (2016). Marmita de vapor electrica fija KEL. Recuperado de http://www.manitowocfoodservice.com/es/general/pcleveland

Ministerio de transportes y comunicaciones. (2015). Anuario estadistico 2015. Recuperado de https://www.mtc.gob.pe/estadisticas/publicaciones/anuarios/ANUARIO_ ESTADISTICO_2015

Omip. (2016). Máquina descarozadora. Recuperado de http://www.omip.net/es/node/43

Omip. (2016). Peladora Química. Recuperado de http://www.omip.net/es/node/47

Organismo supervisor de la inversión en energía y minería. (2016). Pliegos tarifarios de electricidad. Recuperado de http://www.osinergmin.gob.pe/seccion/institucional/ regulacion-tarifaria/pliegos-tarifarios/electricidad

Pharmachine. (2016). Máquina de llenado y tapado al vacío. Recuperado de http://pharmachine.es/2-vial-machine.html

PLASTINAK. (2016). Tanque de almacenamiento de hidroxido de sodio. Recuperado de http://www.plastinak.com/ 
PROMEC. (2016). Esterilizador electronico de frascos y tapas. Recuperado de http://www.promec-srl.com/esp_sterilizzatrici_rotoax_ecs.htm

SEDAPAL. (2016). Estrutura tarifaria de agua y alcantarillado. Recuperado de http://www.sedapal.com.pe/pt_PT/estructura-tarifaria

Sormac. (2016). Máquina lavadora de duraznos. Recuperado de http://www.sormac.es/es/producto/Lavadora-de-frutas-FW-100-44

Toledo, M. (2016). Bascula de Piso. Recuperado de http://pe.mt.com/lac/es/ home/products/Industrial_Weighing_Solutions/floor-scales-heavyduty/floor_pit_palette_scales/deckmate.html

Unimaq. (2016). Montacargas CAT. Recuperado de http://www.unimaq.com.pe/ modelos.php? $\bmod =241 \&$ marca $=70 \&$ serv $=3$

Watson-Marlow. (2016). Bomba de hidroxido de sodio. Recuperado de http://www.watsonmarlow.com/

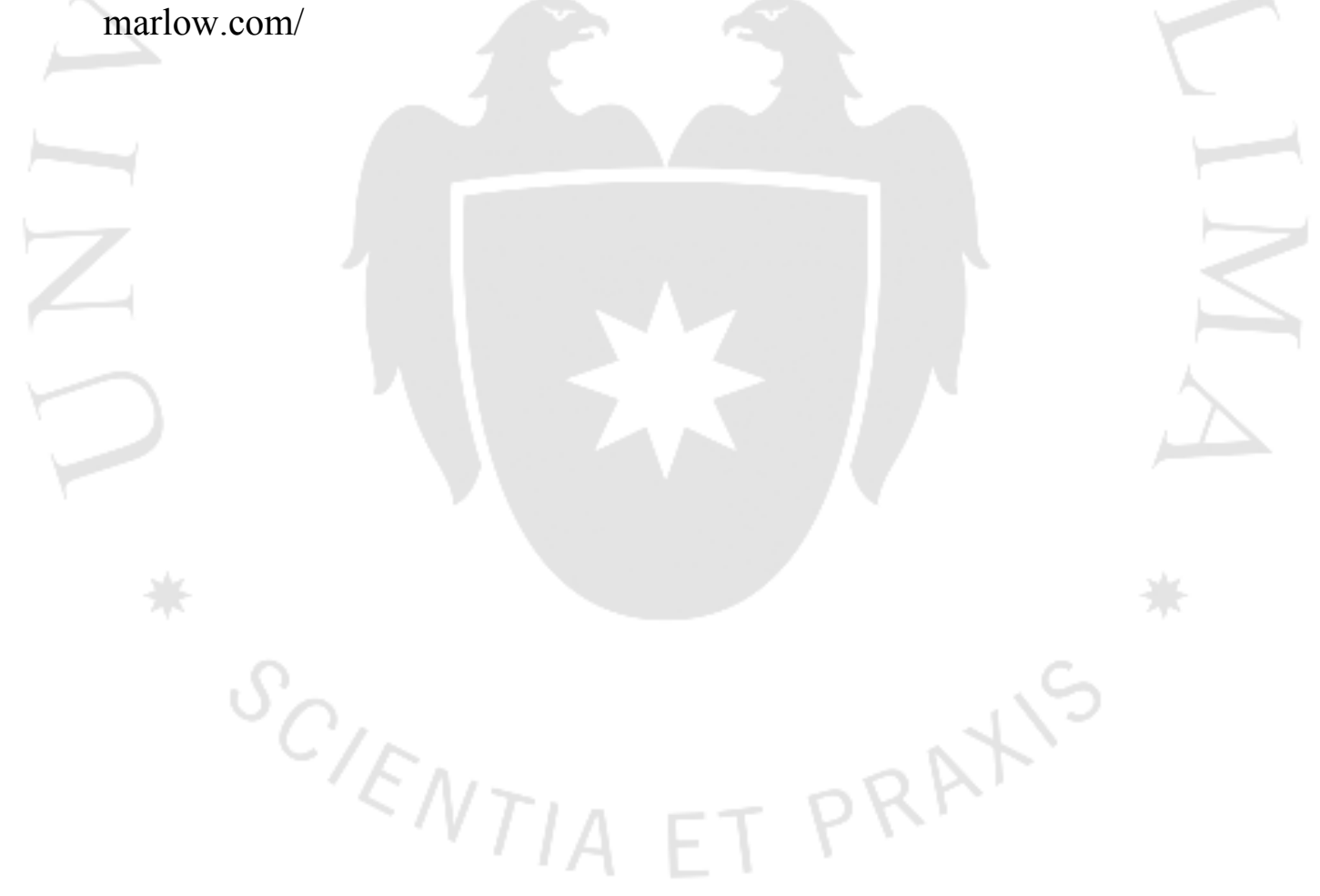




\section{BIBLIOGRAFÍA}

Arroyo Trujillano, N. C. (2002). Estudio de prefactibilidad para la instalación de una planta procesadora de alimentos para bebés a base de quinua, kiwicha, cañihua, manzana, plátano y leche. (Tesis para optar el título de ingeniero industrial) Lima: Universidad de Lima, Fondo editorial.

Carrillo Tan, S. R. (1992). Estudio de factibilidad para instalar una planta de extracción de pulpa de durazno (prunus persica) en la provincia de Huaral. (Tesis para optar el título de ingeniero industrial) Lima: Universidad de Lima, Fondo Editorial.

Castro, J. (2007). Con su reputación de vigorizante mágico la maca se pasea por el mundo. Perú empresarial - $N^{\circ} 012,10$.

Concha Pacheco, F. M. (1989). La desnutrición y sus efectos en el desarrollo del niño. Lima: San Marcos.

Chavez Alvarez, J. (2006). Plantas medicinales. Caser: Riesgos de mercados, (pag. 75 92).

Dobkin, L. (2008). Renace la Quinua, (pag. 28 - 37). Washington D.C.: Américas.

Díaz, B., Jarufe, B., \& Noriega, M. T. (2007). Disposición de Planta. Lima: Universidad de Lima, Fondo Editorial.

Escobedo, A. P. (2011). Estudio preliminar para la instalación de una planta productora de compotas para bebés de lúcuma enriquecida con kiwicha. (Seminario de investigación de ingeniería industrial) Lima: Universidad de Lima, Fondo Editorial.

Konz, S. (1991). Diseño de instalaciones industriales. México, D.F.: Noriega Limusa.

Mendoza Flores, A. (1994). La niñez en el Perú: Desnutrición y déficit intelectual y físico: Como evitar el deterioro a las futuras generaciones. Lima: DESA.

Meyhuay M. (1999). El alto valor de la quinua. Multimodal, 34.

Mujica, A. E. (1999). Resúmenes de investigaciones en quinua (chenopodiu, quinoa will) de la Universidad Nacional del Altiplano. Puno: Universidad Nacional del Altiplano.

Pollitt Burga, E. (2002). Consecuencias de la desnutrición en el escolar peruano. Lima: PUCP. 
Pollitt Burga, E. (2007). Desnutrición, pobreza e inteligencia. Lima: Universidad Ricardo Palma.

Reaño M., V. (2011). Sano deleite: Las grandes marcas apuestan por más granos andinos. Semana economica - Año 26, $N^{\circ} 1279,30$.

Sapag Chain, N. (2014). Preparación y evaluación de proyectos. (Sexta Edición). México D.F.: McGraw-Hill.

Scott, G. (1987). La kiwicha: Un enfoque socio económico. Proceso económico - $N^{\circ} 64$, 25.

Sommelier, V. (2008). La quinua: Lágrimas del sol. Sommelier, vinos \& más $N^{\circ} 34$, (46 48).

Sumar Kalinowsi, L. (1986). Nuevas alternativas alimentarias para el Perú. Agro Enfoque $N^{\circ} 4,12$.

Van Horne, J. (2010). Fundamentos de administración financiera. ( $13 \mathrm{ra}$ ed). México: Pearson Educación. 


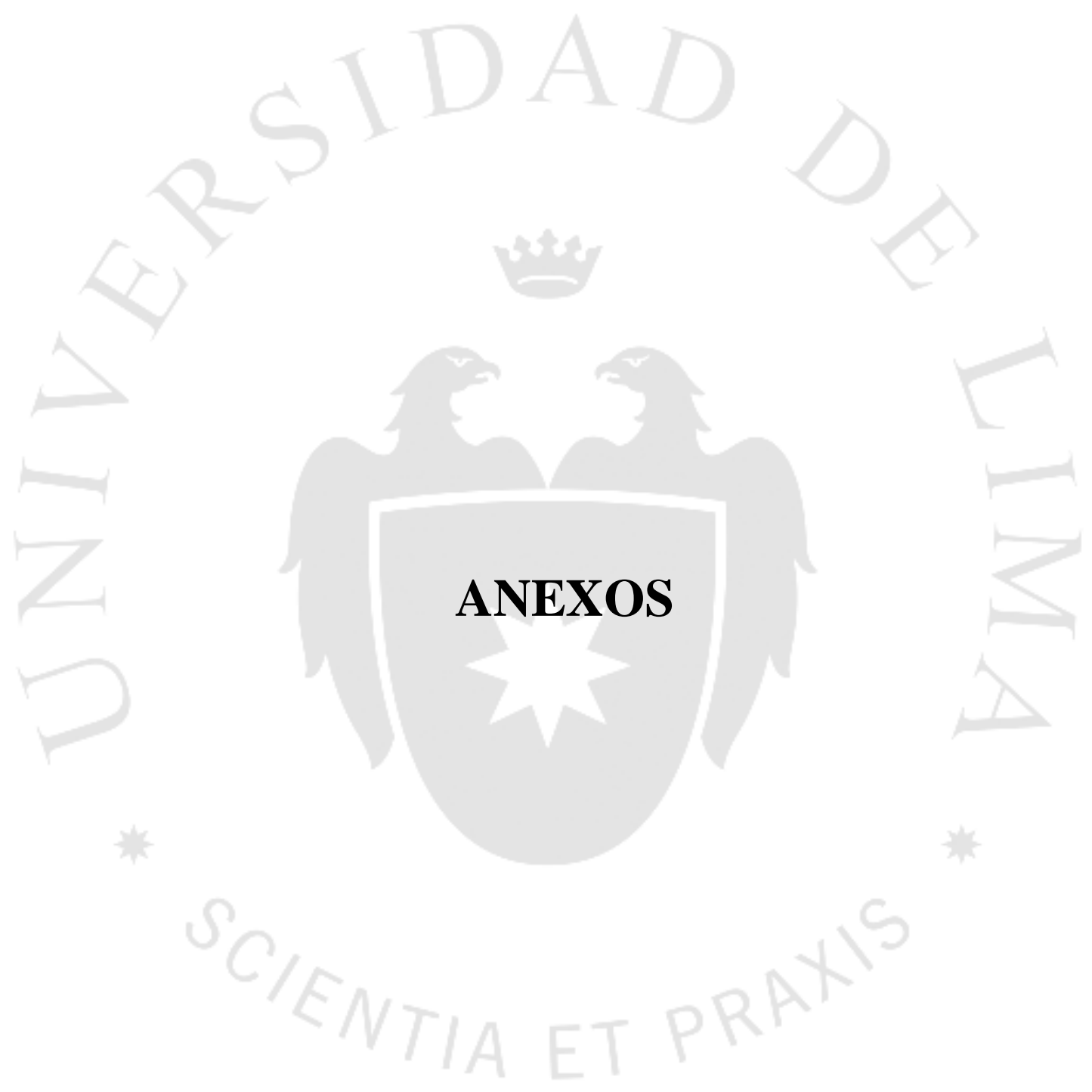




\section{Anexo 1 Encuesta sobre alimentos para bebé}

\begin{tabular}{|l|l|l|}
\hline Sexo (encuestado) & $\mathrm{M}$ & $\mathrm{F}$ \\
\hline
\end{tabular}

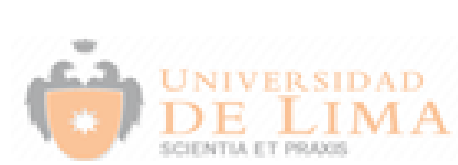

(Anexo 1) Encuesta sobre alimentos para bebé

Buenas tardes somos alumnos de la Universidad de Lma y la presente encuesta tene como enalidad conocer su opinion acerca de las compotas para bebss. Agradeceremos su particlpacion.

1. ¿Usted tene babss?

a) SI

b) No

\$l la respuesta anterior $\theta 8 \mathrm{NO}$, dar por finallzada

la encuesta.

2. ¿Cuantos bebss tene?
a) 1
b) 2
C) $30 \mathrm{mss}$

3. ¿Cual es la edad de su bebe?
a) Menos de 6 meses
b) Entre 6 y 9 meses
C) Entre 9 a 12 meses
d) Mas de un aho

4. ¿Usted compra o prepara compotas para allmentar a su bebe?
a) Compro compot3s
b) Preparo las compotas en casa
C) Ambas a) y b)
d) Ninguna

51 la respuesta $\theta \theta$ a) O C) eeguilr con la encuesta.

\$l $\theta 8$ b), responder eclo las preguntas 5, 9, 10 y

11. \$l $\theta$ d), dar por finallzada la encuesta.

5. ¿Que sabor de compota preftere? Puede marcar mas de una opcion.
a) De durazno
b) De marzana
C) De mango
d) De pera
e) Otros:

6. ¿Cual es su trecuencla de compra de trascos de compota y cuantas compra?
a) Diarla
b) Semanal
c) Cuincenal
d) Mensual

7. ¿En donde compra las compotas para su bebs(8)? Puede marcar mas de una opclion.
a) Supermercad os
b) Mayoristas
C) Farmaclas
d) Bodeg 35
e) Otros:

8. ¿Que marca de compota para bebe compra hablualmente? Puede marcar mas de una opcion.
a) Heinz
b) Gerber
c) Alpina
d) Ago
e) Otros:

9. ¿Que caracterlsticas considdera mas importantes en las compot35 para bebas? Puede marcar mas de una opclon:
a) Preclo
b) Valor nutriclonal
c) Sabor
d) Otros:

10. ¿Comprarla una compota para bebe a base de durazeno enriquecldo con maca, quinua, klwicha y cah̆hua?
a) $\mathrm{St}$
b) No

SI la respuesta anterlor e日 NO, dar por finallzada la encuesta.

11. En la escala del 1 al 10 diga usted, tenlendo en cuenta: 1-"Muy poco probable que 10 compre" y 10-"De todas maneras lo compro". con que seguridad comprarla las compotas para bebs a base de durazno enriquecldas con maca, quinua, klwicha y caȟnua. Marque con una $\mathrm{X}$

\begin{tabular}{|l|l|l|l|l|l|l|l|l|l|}
\hline 1 & 2 & 3 & 4 & 5 & 6 & 7 & 8 & 9 & 10 \\
\hline
\end{tabular}

¡Gracias por su participación!

Elaboración propia 


\section{Anexo 2 Depreciación de activos tangibles}

\begin{tabular}{|c|c|c|c|c|c|c|c|c|c|c|}
\hline Activos tangibles & $\begin{array}{c}\text { Precio total } \\
\text { (S/.) }\end{array}$ & $\begin{array}{l}\text { Deprec. } \\
\text { anual \% }\end{array}$ & 2016 & 2017 & 2018 & 2019 & 2020 & 2021 & $\begin{array}{c}\text { Deprec. } \\
\text { total }\end{array}$ & $\begin{array}{l}\text { Valor en } \\
\text { libros }\end{array}$ \\
\hline Costo del Terreno & 1.123 .658 & 0 & & & & & & & - & 1.123 .658 \\
\hline Costo de construcción & 1.444 .703 & $5 \%$ & 72.235 & 72.235 & 72.235 & 72.235 & 72.235 & 72.235 & 433.411 & 1.011 .292 \\
\hline Báscula de piso portátil & 1.013 & $10 \%$ & 101 & 101 & 101 & 101 & 101 & 101 & 608 & 405 \\
\hline Lavadora de frutas & 67.560 & $10 \%$ & 6.756 & 6.756 & 6.756 & 6.756 & 6.756 & 6.756 & 40.536 & 27.024 \\
\hline Faja transportadora & 1.689 & $10 \%$ & 169 & 169 & 169 & 169 & 169 & 169 & 1.013 & 676 \\
\hline Máquina descarozadora & 16.890 & $10 \%$ & 1.689 & 1.689 & 1.689 & 1.689 & 1.689 & 1.689 & 10.134 & 6.756 \\
\hline Orientadora de mitades & 10.134 & $10 \%$ & 1.013 & 1.013 & 1.013 & 1.013 & 1.013 & 1.013 & 6.080 & 4.054 \\
\hline Peladora química & 67.560 & $10 \%$ & 6.756 & 6.756 & 6.756 & 6.756 & 6.756 & 6.756 & 40.536 & 27.024 \\
\hline Escaldadora tipo inmersión & 16.890 & $10 \%$ & 1.689 & 1.689 & 1.689 & 1.689 & 1.689 & 1.689 & 10.134 & 6.756 \\
\hline Despulpadora de frutas & 10.134 & $10 \%$ & 1.013 & 1.013 & 1.013 & 1.013 & 1.013 & 1.013 & 6.080 & 4.054 \\
\hline Mezcladora de paletas & 13.512 & $10 \%$ & 1.351 & 1.351 & 1.351 & 1.351 & 1.351 & 1.351 & 8.107 & 5.405 \\
\hline Marmita a vapor eléctrica & 6.756 & $10 \%$ & 676 & 676 & 676 & 676 & 676 & 676 & 4.054 & 2.702 \\
\hline Máquina de llenado y tapado & 101.340 & $10 \%$ & 10.134 & 10.134 & 10.134 & 10.134 & 10.134 & 10.134 & 60.804 & 40.536 \\
\hline Etiquetadora automática & 33.780 & $10 \%$ & 3.378 & 3.378 & 3.378 & 3.378 & 3.378 & 3.378 & 20.268 & 13.512 \\
\hline Máquina formadora de cajas & 33.780 & $10 \%$ & 3.378 & 3.378 & 3.378 & 3.378 & 3.378 & 3.378 & 20.268 & 13.512 \\
\hline Máquina esterilizadora de envases & 101.340 & $10 \%$ & 10.134 & 10.134 & 10.134 & 10.134 & 10.134 & 10.134 & 60.804 & 40.536 \\
\hline $\begin{array}{l}\text { Tanque de almacenamiento de } \\
\text { acero inoxidable }\end{array}$ & 25.335 & $10 \%$ & 2.534 & 2.534 & 2.534 & 2.534 & 2.534 & 2.534 & 15.201 & 10.134 \\
\hline Bomba de doble husillo & 4.054 & $10 \%$ & 405 & 405 & 405 & 405 & 405 & 405 & 2.432 & 1.621 \\
\hline Bomba peristáltica SPX32 & 8.445 & $10 \%$ & 845 & 845 & 845 & 845 & 845 & 845 & 5.067 & 3.378 \\
\hline $\begin{array}{l}\text { Tanque de almacenamiento de } \\
\text { hidróxido de sodio }\end{array}$ & 6.756 & $10 \%$ & 676 & 676 & 676 & 676 & 676 & 676 & 4.054 & 2.702 \\
\hline Montacargas CAT & 57.426 & $10 \%$ & 5.743 & 5.743 & 5.743 & 5.743 & 5.743 & 5.743 & 34.456 & 22.970 \\
\hline Carretilla hidráulica manual & 1.351 & $10 \%$ & 135 & 135 & 135 & 135 & 135 & 135 & 811 & 540 \\
\hline Puerta corta fuegos & 2.027 & $10 \%$ & 203 & 203 & 203 & 203 & 203 & 203 & 1.216 & 811 \\
\hline Extractor manual de gasolina & 48 & $10 \%$ & 5 & 5 & 5 & 5 & 5 & 5 & 29 & 19 \\
\hline Barril acero inoxidable para gasolina & 6.418 & $10 \%$ & 642 & 642 & 642 & 642 & 642 & 642 & 3.851 & 2.567 \\
\hline Extintores & 1.299 & $10 \%$ & 130 & 130 & 130 & 130 & 130 & 130 & 779 & 519 \\
\hline Sensor de humo fotoeléctrico & 1.865 & $10 \%$ & 186 & 186 & 186 & 186 & 186 & 186 & 1.119 & 746 \\
\hline Sensor de calor de temperatura fija & 189 & $10 \%$ & 19 & 19 & 19 & 19 & 19 & 19 & 114 & 76 \\
\hline Alarma manual & 378 & $10 \%$ & 38 & 38 & 38 & 38 & 38 & 38 & 227 & 151 \\
\hline Sirena con luz estroboscópica & 270 & $10 \%$ & 27 & 27 & 27 & 27 & 27 & 27 & 162 & 108 \\
\hline Tablero de control contra incendios & 1.216 & $10 \%$ & 122 & 122 & 122 & 122 & 122 & 122 & 730 & 486 \\
\hline Camaras de seguridad & 2.027 & $10 \%$ & 203 & 203 & 203 & 203 & 203 & 203 & 1.216 & 811 \\
\hline Parihuela & 97.685 & $10 \%$ & 9.769 & 9.769 & 9.769 & 9.769 & 9.769 & 9.769 & 58.611 & 39.074 \\
\hline Escritorio & 13.242 & $10 \%$ & 1.324 & 1.324 & 1.324 & 1.324 & 1.324 & 1.324 & 7.945 & 5.297 \\
\hline Silla de oficina & 7.600 & $10 \%$ & 760 & 760 & 760 & 760 & 760 & 760 & 4.560 & 3.040 \\
\hline Laptop Dell & 25.584 & $25 \%$ & 6.396 & 6.396 & 6.396 & 6.396 & 0 & 0 & 25.584 & 0 \\
\hline Celular Samsung Galaxy S4 & 3.547 & $25 \%$ & 887 & 887 & 887 & 887 & 0 & 0 & 3.547 & 0 \\
\hline TOTAL & 3.317 .501 & & 151.519 & 151.519 & 151.519 & 151.519 & 144.236 & 144.236 & 894.547 & 2.422 .954 \\
\hline
\end{tabular}

Elaboración propia

\section{Anexo 3 Depreciación fabril y no fabril}

\begin{tabular}{|l|r|r|r|r|r|r|r|}
\hline & \multicolumn{1}{|c|}{$\mathbf{2 0 1 6}$} & \multicolumn{1}{c|}{$\mathbf{2 0 1 7}$} & \multicolumn{1}{c|}{$\mathbf{2 0 1 8}$} & \multicolumn{1}{c|}{$\mathbf{2 0 1 9}$} & \multicolumn{1}{c|}{$\mathbf{2 0 2 0}$} & \multicolumn{1}{c|}{$\mathbf{2 0 2 1}$} & \multicolumn{1}{|c|}{ TOTAL } \\
\hline Depreciación fabril & \multicolumn{1}{|c|}{142.152} & 142.152 & 142.152 & 142.152 & 142.152 & 142.152 & 852.911 \\
\hline Depreciación no fabril & 9.367 & 9.367 & 9.367 & 9.367 & 2.084 & 2.084 & 41.636 \\
\hline TOTAL & 151.519 & 151.519 & 151.519 & 151.519 & 144.236 & 144.236 & 894.547 \\
\hline
\end{tabular}

Elaboración propia

\section{Anexo 4 Amortización de intangibles}

\begin{tabular}{|c|c|c|c|c|c|c|c|c|c|c|}
\hline Activos intangibles & $\begin{array}{c}\text { Precio total } \\
(\mathrm{S} / .)\end{array}$ & $\begin{array}{l}\text { Amortiz. } \\
\text { anual \% }\end{array}$ & 2016 & 2017 & 2018 & 2019 & 2020 & 2021 & $\begin{array}{c}\text { Amortización } \\
\text { total }\end{array}$ & $\begin{array}{c}\text { Valor en } \\
\text { libros }\end{array}$ \\
\hline Estudio de prefactibilidad & 5.500 & $10 \%$ & 550 & 550 & 550 & 550 & 550 & 550 & \begin{tabular}{r|}
3.300 \\
\end{tabular} & 2.200 \\
\hline Constitución de la empresa & 500 & $10 \%$ & 50 & 50 & 50 & 50 & 50 & 50 & 300 & 200 \\
\hline Registro Sanitario & 600 & $10 \%$ & 60 & 60 & 60 & 60 & 60 & 60 & 360 & 240 \\
\hline Registro de la Marca & 2.000 & $10 \%$ & 200 & 200 & 200 & 200 & 200 & 200 & 1.200 & 800 \\
\hline Capacitación de personal & 5.000 & $10 \%$ & 500 & 500 & 500 & 500 & 500 & 500 & 3.000 & 2.000 \\
\hline Software Microsoft Dynamics ERP Professional & 63.236 & $10 \%$ & 6.324 & 6.324 & 6.324 & 6.324 & 6.324 & 6.324 & 37.942 & 25.294 \\
\hline Software Microsoft Office 2013 & 4.500 & $10 \%$ & 450 & 450 & 450 & 450 & 450 & 450 & 2.700 & 1.800 \\
\hline TOTAL & 81.336 & & 8.134 & 8.134 & 8.134 & 8.134 & 8.134 & 8.134 & 48.802 & 32.534 \\
\hline
\end{tabular}

Elaboración propia 


\section{Anexo 5 Imágenes del terreno}

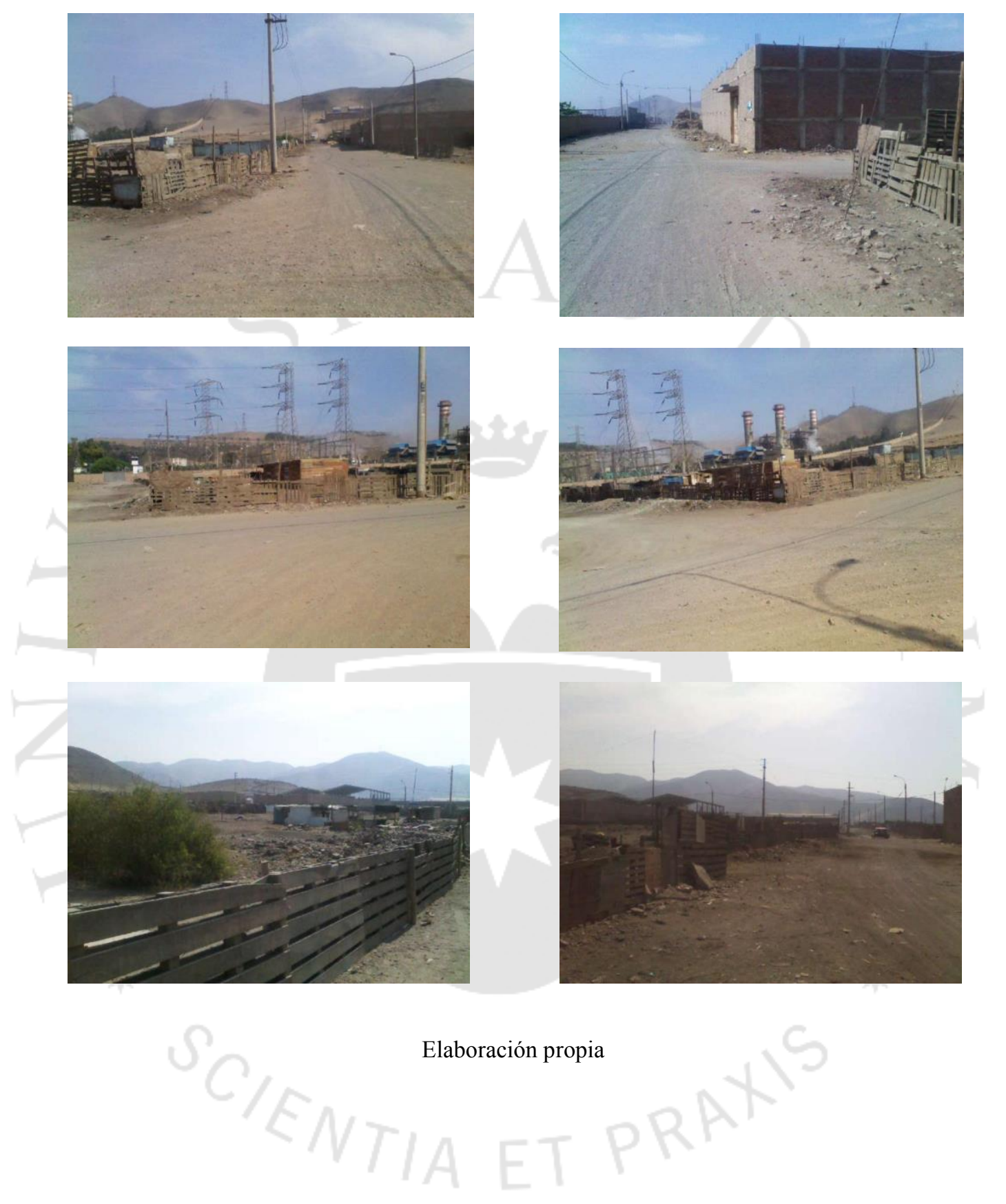

